UNIVERSIDADE DE SÃO PAULO

FACULDADE DE FILOSOFIA, LETRAS E CIÊNCIAS HUMANAS

DEPARTAMENTO DE LINGUÍSTICA

PROGRAMA DE PÓS-GRADUAÇÃO EM SEMIÓTICA E LINGUÍSTICA

ANA CAROLINA FERREIRA ALVES

Morfofonologia, morfossintaxe e o sistema de tempo, aspecto e modo em Arara (Karib) 


\title{
Morfofonologia, morfossintaxe e o sistema de tempo, aspecto e modo em Arara (Karib)
}

\author{
Versão Corrigida
}

Tese apresentada ao Programa de Pós-Graduação em Semiótica e Linguística Geral da Faculdade de Filosofia, Letras e Ciências Humanas da Universidade de São Paulo para obtenção de título de Doutora em Letras, programa de Linguística.

Orientadora: Prof. ${ }^{a}$ Dr. ${ }^{a}$ Luciana Raccanello Storto

Coorientadora: Prof. $^{\text {a }}$ Dr. $^{\text {a }}$ Ana Vilacy Moreira Galucio

De acordo: 
FERREIRA ALVES, A. C. Morfofonologia, morfossintaxe e o sistema de tempo, aspecto e modo em Arara (Karib). 2017. 222 f. Tese (Doutorado em Letras) - Faculdade de Filosofia, Letras e Ciências Humanas, Universidade de São Paulo, São Paulo, 2017.

Aprovado em:

Banca Examinadora

Presidente: Prof ${ }^{\mathrm{a}}$. Dra ${ }^{\mathrm{a}}$. Luciana Raccanello Storto

Instituição: Universidade de São Paulo (USP)

Titular: Prof. Dr. Sérgio Meira de Santa Cruz Oliveira

Instituição: Museu Paraense Emílio Goeldi (MPEG)

Titular: Prof ${ }^{\mathrm{a}}$. Dr ${ }^{\mathrm{a}}$. Gesalma Mara Ferreira dos Santos

Instituição: Universidade Federal do Amapá (UNIFAP)

Titular: Prof. Dr. Spike Gildea

Instituição: University of Oregon (UO)

Titular: Prof ${ }^{a}$. Dr ${ }^{\mathrm{a}}$. Esmeralda Vailati Negrão

Instituição: Universidade de São Paulo (USP) 


\section{AGRADECIMENTOS}

Este trabalho contou com o apoio de muitas pessoas, em contextos diversos, sem as quais o mesmo jamais poderia ter sido realizado. Gostaria de registrar meus sinceros agradecimentos, primeiramente (como não poderia deixar de ser), ao povo Arara pela generosidade de compartilhar sua língua e seu modo de vida, pela estadia em suas aldeias e pelo tempo despendido para me ensinar. Sou grata, em especial, à Iogo Arara - matriarca guerreira que eu sempre vou admirar - Iaut Arara, Pilik Arara, Kuit Arara, Tybrybi Arara, Ilo Arara, Lipo Arara, Onat Jodo Arara, Pyi Arara, Tatjing Arara, Tjigarywy (Typtjiwa) Arara, Ydomedyk Arara, Awaly Arara, Tymbektodem Arara, Adoum Arara, Iadat Arara, Karato Arara, Mobu Odo Arara, Wiwik Arara, Ororigo Arara, Joru Arara, Tjili Arara, Typu Arara, Motjibi Arara, Engoi Arara (in memoriam), Mumgade Arara, Akui Arara, Mute Arara, Akito Arara, Wyduduk Arara, Tada Arara, Mouko Arara, Tjilau Arara, Uangot Arara, Tjipi Arara, Toitji Arara, Toliktu Arara, Wapyry Arara e Lalau Arara.

Sou imensamente grata às minhas orientadoras, Luciana Storto, pela confiança, respeito e leveza nos momentos de trabalho e discontração, e, Vilacy Galucio, pelo apoio em minha primeira viagem de campo com os Arara e constante incentivo à pesquisa. Agradeço muito ao Spike Gildea, supervisor no exterior durante o estágio de doutorado sanduíche. O mundo acadêmico é melhor com teu entusiasmo pelas línguas Karib! Sérgio Meira também contribuiu extensamente, de modo que o considero um orientador, obrigada pelos direcionamentos e ideias. Agradeço à todo o grupo do Departamento de Linguística da Universidade de São Paulo, principalmente, meus professores. Este trabalho também foi beneficiado pelo ótimo ambiente acadêmico do Departamento de Linguística da Universdade de Oregon. Meus agradecimentos vão, principalmente, à Natalia Caceres, Geny Gonzales, Esteban Montenegro e Simone Mattiola. Também agradeço aos amigos que leram partes de versões anteriores deste trabalho, Antônia Nogueira, Ivan Rocha e Joshua Birchall. Todos, à sua maneira, têm contribuído para o meu amadurecimento acadêmico.

Pelo apoio logístico e amizade em São Paulo, meus agradecimentos à Lorena Orjuela, Fernanda Nogueira e Ivan Rocha. Em Altamira, super obrigada à Eliane Faria, Alessandra Simoni (companheira de campo!), Larissa Lança; Ennyo Max, Wivianny Thayse e família. Pelo apoio técnico e amizade em Belém/Museu Goeldi, obrigada Ellison Cleyton e Heliton Augusto. Também sou grata pelo apoio dos colegas da FUNAI regional de Altamira/FPEMX/CGIRC: Luciano Pohl, Pablo Rodrigues (Tamyum Jodo!), Tatiana Botelho, Leila Sotto-Maior e Maria 
Elisa Guedes. Não posso deixar de expressar minha gratidão à minha família no exterior que me deu inspiração e todo o suporte para que a minha estadia nos EUA fosse a melhor possível, gratidão à Barbara Marbury e ao Kevin Marbury.

Meus agradecimentos também se dirigem a algumas instituições/agências de formento: à CAPES pelo apoio financeiro, ao CNPq pela bolsa sanduíche (processo 201911/2015-9), à FLRC pelo apoio financeiro para o trabalho de campo em 2016, à FUNAI pela concessão da autorização de entrada em terra indígena (processo 08620.00079-2015-78) e ao departamento de linguística do MPEG pelo apoio logístico relacionado ao trabalho de campo.

Devo muitos agradecimentos ao meus familiares, em especial, à minha mãe, Marileia Alves, por estar sempre ao meu lado, apoiando em tudo, e ao Leonard Grala, sempre companheiro, obrigada pela paciência e incentivo nessa jornada.

Também sou grata a todos os que direta ou indiretamente contribuíram com este trabalho, mas não estão presentes nesta lista. Certamente, "a verdade é uma questão de perspectiva". Assim, este estudo não pretende mostrar algo definitivo, mas que seja um passo dentre os demais que serão feitos por futuros estudiosos desta língua. 


\section{RESUMO}

FERREIRA ALVES, A. C. Morfofonologia, morfossintaxe e o sistema de tempo, aspecto e modo em Arara (Karib). 2017. 222 f. Tese (Doutorado em Letras) - Faculdade de Filosofia, Letras e Ciências Humanas, Universidade de São Paulo, São Paulo, 2017.

Esta tese consiste em um estudo descritivo da morfofonologia e da morfossintaxe da língua Arara, pertencente à família linguística Karib. O objetivo principal consiste em compreender como as categorias gramaticais de Tempo, Aspecto e Modo (TAM) interagem com as categorias de pessoa e número no predicado verbal. Certos morfemas de pessoa, assim como de número são selecionados por determinadas propriedades de TAM da sentença. Para dar conta do entendimento completo da interação entre essas categorias, as análises da presente tese incluíram propriedades gerais das interfaces morfofonológica e morfossintática que atuam nas formas e distribuição dos morfemas. Além disso, foram descritas algumas propriedades semântico-pragmáticas. Os morfemas estão sujeitos aos processos alomórficos comuns à língua como assimilação da sonoridade e da nasalidade, além de ablaut. Alomorfes supletivos também foram identificados, bem como morfemas portmanteau. Foram apresentados morfemas de tempo (passados - imediato, médio, distante - e futuro), aspecto (imperfectivo, iterativo, imperfectivo passado e resuntivo) e modo (imperativo, hortativo, vetativo, permissivo, admonitivo, interrogativo, intencional, frustrativo). As flexões de pessoa nos tempos e aspectos mencionados interagem com hierarquia de pessoa em verbos transitivos e com duas classes de verbos intransitivos. Verbos transitivos são afixados por duas séries de prefixos pessoais, A e $\mathrm{O}$, enquanto cada classe de verbo intransitivo é afixada por apenas uma das séries de morfemas morfologicamente semelhantes aos morfemas encontrados em verbos transitivos, $\mathrm{S}_{\mathrm{A}}$ ou $\mathrm{S}_{\mathrm{O}}$. Já os prefixos pessoais que ocorrem com as flexões de modo apresentam paradigmas menores, dos quais fazem parte um restrito conjunto de pessoas. As flexões de número, por sua vez, consistem em morfemas distintos que ocorrem com determinadas flexões de TAM. Apenas na terceira pessoa do passado distante e na terceira do passado médio são selecionados morfemas específicos. Deste modo, o plural é marcado por diferentes morfemas no mesmo paradigma. Também foram abordadas as construções não verbais, nas quais a categoria de TAM é expressa por partículas e morfemas de tempo nominal quando a cópula está ausente e por meio dos morfemas anteriormente investigados quando a cópula verbal itxi está presente. A metodologia 
empregada consistiu em realizar análises coerentes com a estrutura interna da língua, a partir do embasamento de conceitos analíticos provenientes da literatura de viés tipológico funcionalista e histórico-comparativo. Foram utilizados dados atuais, provenientes de trabalho de campo, que consistem em textos e sentenças.

Palavras-chave: Língua Arara (Karib). Morfofonologia. Morfossintaxe verbal. Tempo, Aspecto, Modo. Pessoa. Número. 


\section{ABSTRACT}

FERREIRA ALVES, A. C. Morphophonology, Morphosyntax and the tense, aspect and mood system in Arara (Carib). 2017. 222 pp. Dissertation (PhD in Linguistics) - Faculdade de Filosofia, Letras e Ciências Humanas, Universidade de São Paulo, São Paulo, 2017.

This dissertation is a descriptive study on the morphophonology and morphosyntax of the Arara language, a member of the Karib linguistic family. The main goal of the study is to understand how the grammatical categories of Tense, Aspect and Mood (TAM) interact with the marking of person and number on the predicate. Some person morphemes as well as number morphemes are selected by certain TAM properties of the sentence. To account for the full understanding of the interactions, the analyses include general morphophological processes and morphosyntactic aspects to which these morphemes are subject. In addition, some semanticpragmatic properties are described. Morphemes are subject to processes of assimilation of sonority and nasality, as well as ablaut. There are also some suppletive allomorphs and portamanteau morphemes. TAM suffixes mark tense: three degrees of past (immediate, medial, distant) and future; aspects - imperative, iterative, imperfect used only in the distant past, resumptive; and mood - imperative, hortative, vetitive (prohibitive), permissive, admonitive, interrogative, intentional and frustrative. When inflected for these tense and aspect categories, the person prefixes of the verbs interact with a person hierarchy in transitive verbs and with two classes of intransitive verbs. Transitive verbs can be inflected with two sets of different personal prefixes, $\mathrm{A}$ and $\mathrm{O}$, while each class of intransitive verbs can be inflected by one of the personal prefixes that are similar to the ones found with the transitive verbs, either the $S_{A}$ or $S_{O}$ series of prefixes. Personal prefixes of verbs inflected for all the mentioned moods form smaller paradigms, which are composed by a restricted number of person markers. Regarding the number category, there are distinct morphemes that occur with certain TAM inflections. Specific number morphemes occur only with the third person of the distant past and the third person of the medial past. In this way, the plural is marked by different suffixes in the same paradigm. Non-verbal constructions are also addressed. In these constructions, the TAM category is expressed by particles and morphemes of nominal tense when the copula is absent or by TAM morphemes if the verbal copula itxi is in the predication. The methodology employed is to perform analyses consistent with the internal structures of the language. These 
analyses are based on analytical concepts from typological funcionalist and historicalcomparative literature. We used data from fieldwork, which consists of texts and sentences.

Key words: Arara language (Karib). Morphophonology. Verbal morphosyntax. Tense, Aspect, Modality. Person. Number. 


\section{LISTA DE FIGURAS}

Figura 1.1 - Relação genética da família linguística Karib................................................. 22

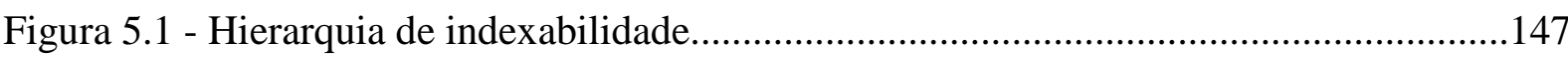

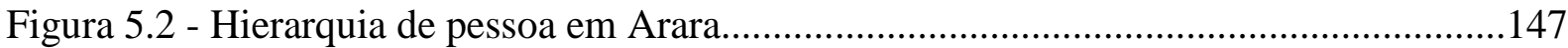




\section{LISTA DE TABELAS}

Tabela 1.1 - A categoria aspectual em Kuikuro

Tabela 2.1 - Inventário fonêmico vocálico

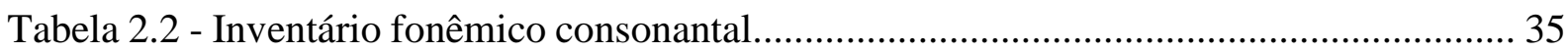

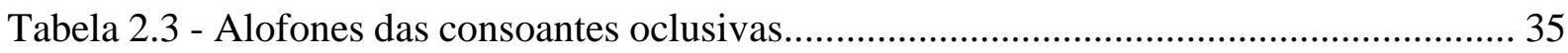

Tabela 2.4 - Lista de grafemas e suas correspondências fonêmicas......................................... 36

Tabela 2.5 - Encontros consonantais internos ao morfema................................................... 39

Tabela 2.6 - Encontros consonantais internos ao morfema................................................... 40

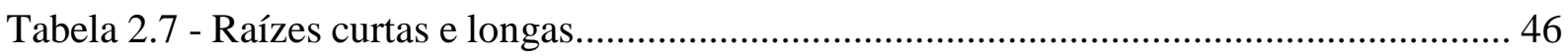

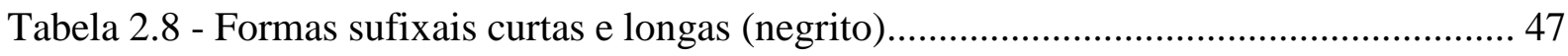

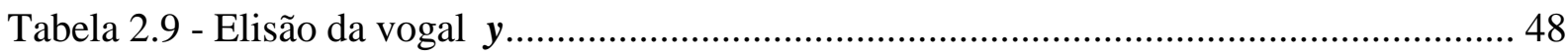

Tabela 2.10 - Manutenção das vogais $\boldsymbol{i}, \boldsymbol{u}$ diante do morfema permissivo $\{-a\}$...................... 49

Tabela 3.1 - Generalização da estrutura da palavra verbal canônica...................................... 73

Tabela 3.2 - Morfemas que ajudam a identificar a classe de verbos....................................... 75

Tabela 3.3 - Comparação de prefixos de verbos transitivos e intransitivos............................. 79

Tabela 4.1 - Notação na linha do tempo, baseada em (SMITH, 1997).................................. 102

Tabela 4.2 - Distinções de tempo gramatical, baseada em (MUELLER 2014, p.25)............. 102

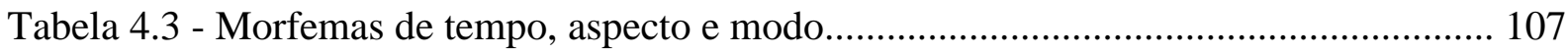

Tabela 4.4 - Resumindo os morfemas de TAM................................................................. 135

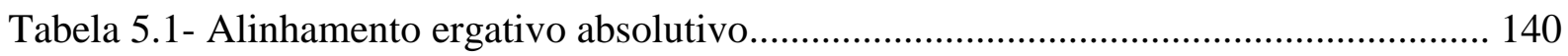

Tabela 5.2 - Termos utilizados para as relações de participantes............................................ 142

Tabela 5.3 - Prefixos argumentais de verbos bivalentes....................................................... 143

Tabela 5.4 - Prefixos empregados na configuração local.................................................... 144

Tabela 5.5 - Prefixos empregados na relação não local.......................................................... 145

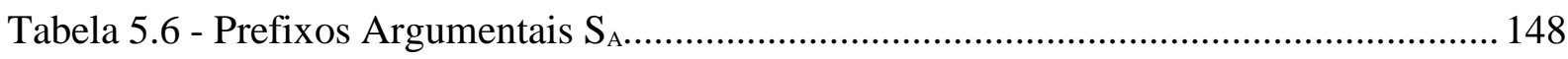

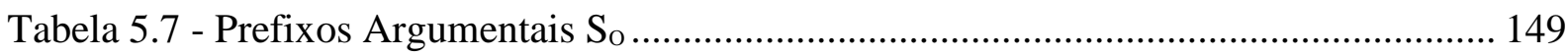

Tabela 5.8 - Padrão completo de morfemas argumentais..................................................... 151

Tabela 5.9 - Verbos intransitivos da classe Sa................................................................. 159

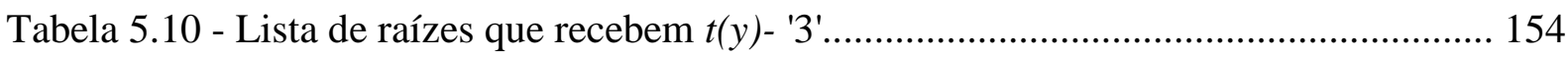

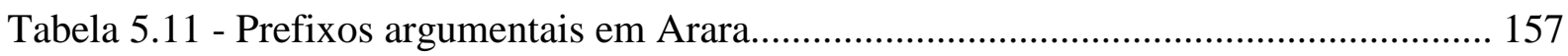

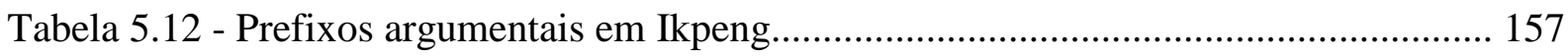

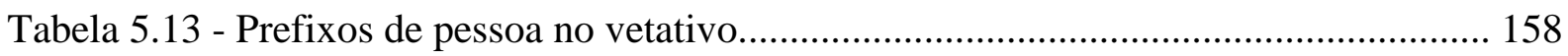

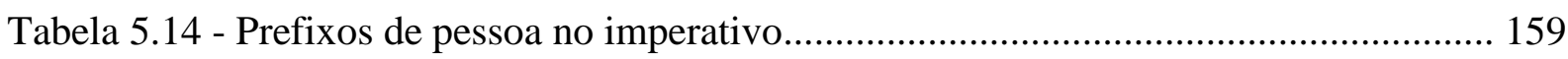

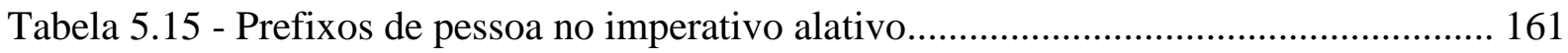

Tabela 5.16 - Prefixos de pessoa no hortativo....................................................................... 162

Tabela 5.17 - Prefixos de pessoa no admonitivo................................................................ 163

Tabela 5.18 - Prefixos de pessoa no permissivo................................................................ 164 
Tabela 5.19 - Prefixos de pessoa no modo intencional 166

Tabela 5.20 - Resumo dos prefixos de pessoa das modalidades orientadas pelo falante e pelo agente. 167

Tabela 5.21 - Morfemas de número I. 168

Tabela 5.22 - Morfemas de número II. 169

Tabela 5.23 - Sufixos do ADM, PERM, 3PSD.DST e 3PSD.MED 175

Tabela 5.24 - sufixos do IMP, HORT, FUT, PSD.MED e PSD.DST. 177

Tabela 5.25 - Sufixos do passado distante nas versões singular e plural. 178

Tabela 5.26 - Síntese dos morfemas de plural 179

Tabela 6.1 - Conjugações da cópula itxi no singular e no plural. 194

Tabela 6.2 - Singular e plural da forma aptam. 199

Tabela 6.3 - Estruturas das construções e suas funções predicativas 201 


\section{Sumário}

AGRADECIMENTOS IV

RESUMO VI

ABSTRACT

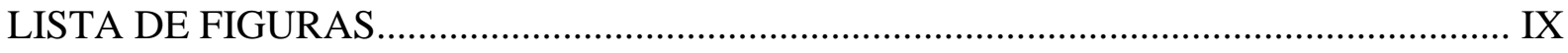

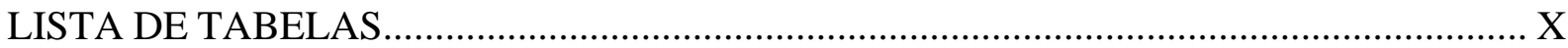

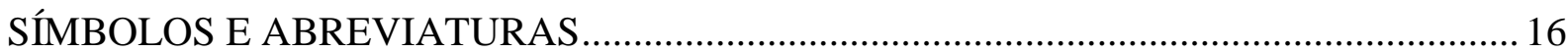

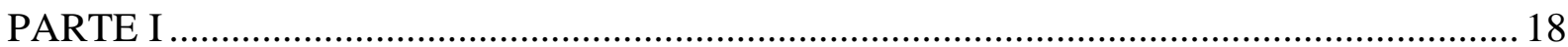

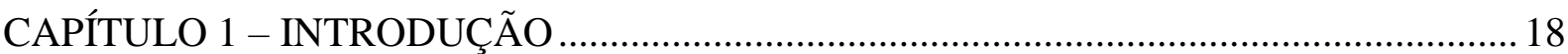

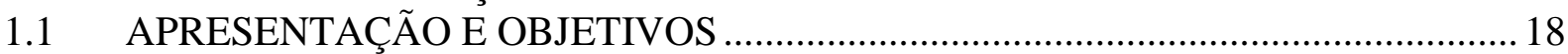

1.2 O POVO ARARA: PANORAMA DO CONTEXTO ATUAL .................................. 19

1.3 A LÍNGUA ARARA E A CLASSIFICAÇÃO INTERNA DA FAMÍLIA

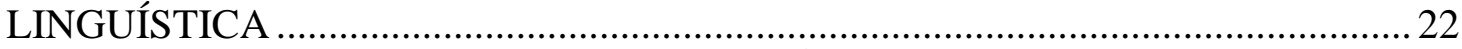

1.4 NOTA SOBRE A SITUAÇÃO SOCIOLINGUÍSTICA ............................................ 23

1.5 TRABALHO DE CAMPO E A CONSTITUIÇÃO DO CORPUS ............................ 24

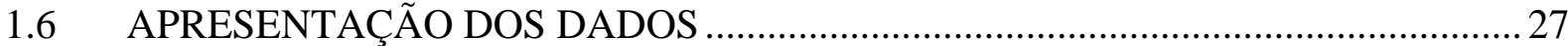

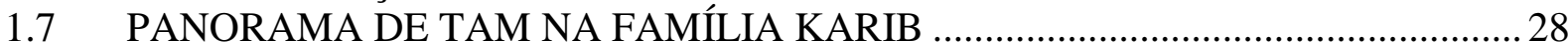

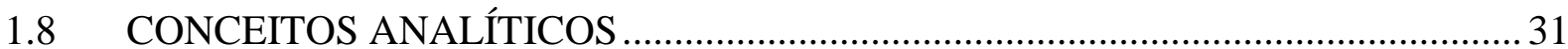

1.9 PANORAMA DA LITERATURA PRÉVIA SOBRE ARARA …............................ 32

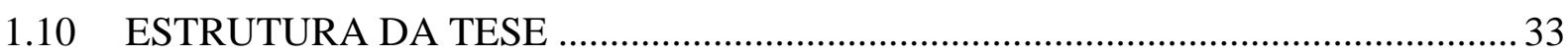

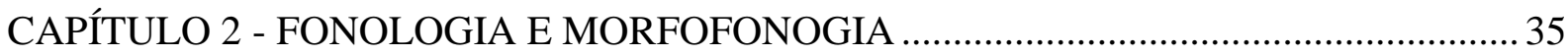

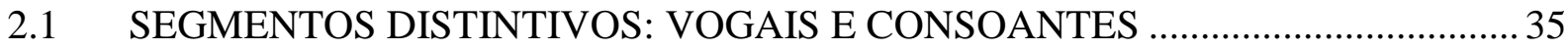

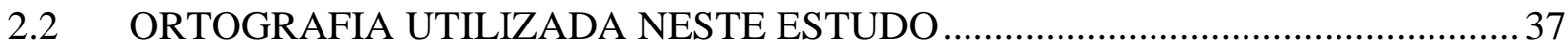

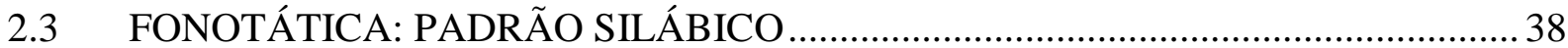

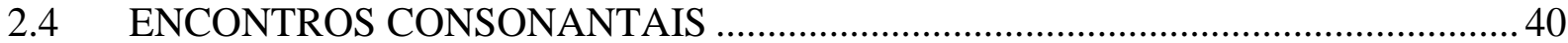

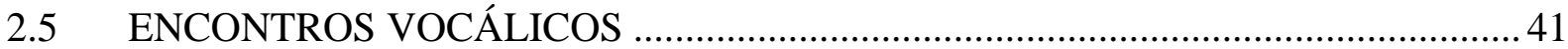

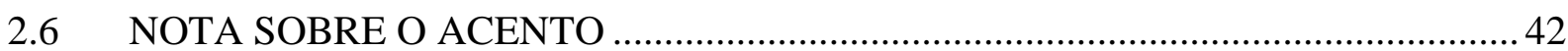

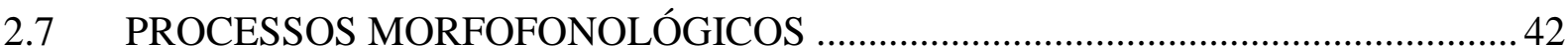

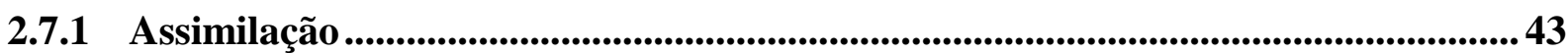

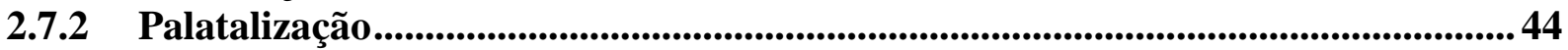

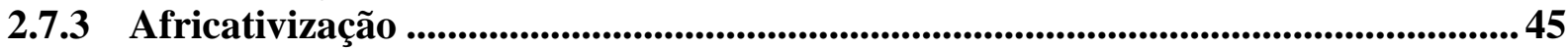

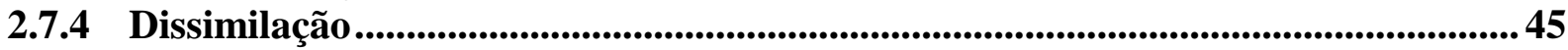

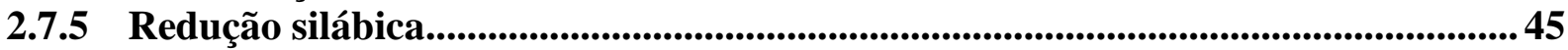

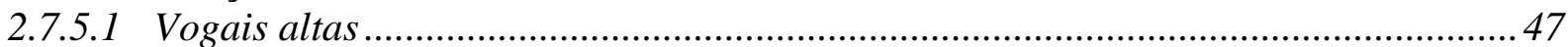

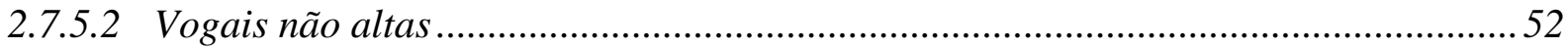

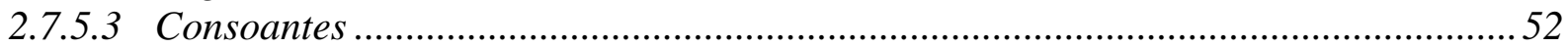

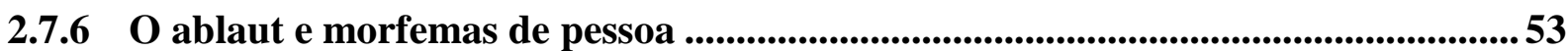

2.8 O DETRAZITIVISADOR \{OTXI- \} E SUAS VARIANTES .....................................56

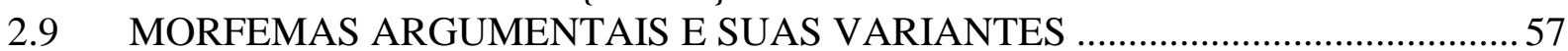

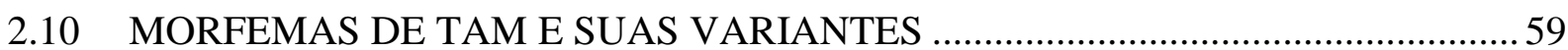

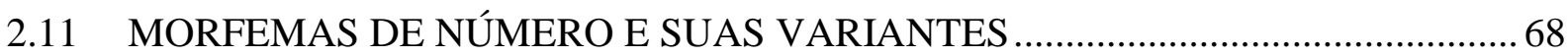

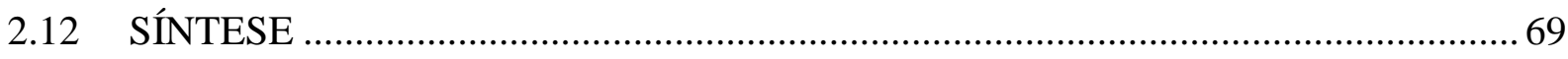


CAPÍTULO 3 - CLASSES DE PALAVRAS

3.1 INTRODUÇÃO À MORFOLOGIA ARARA E ESCLARECIMENTOS

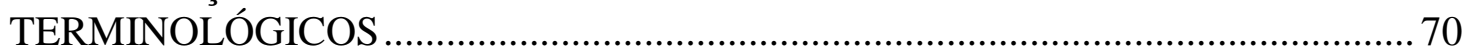

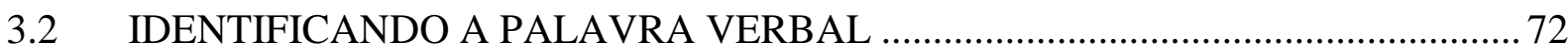

3.2.1 Caracterizações semânticas, morfológicas e sintáticas............................................... 73

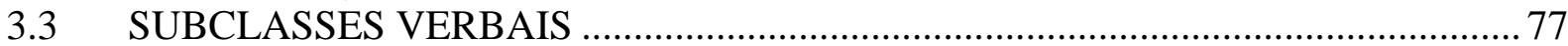

3.3.1 Diferenças entre raízes transitivas e raízes intransitivas .......................................... 77

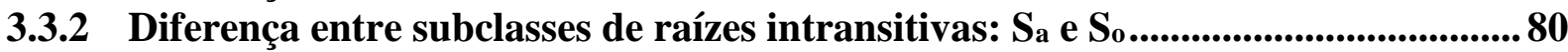

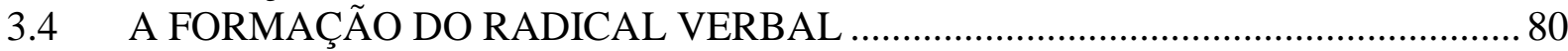

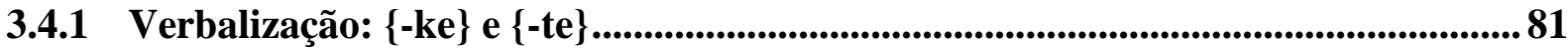

3.4.2 Mudança de valência ............................................................................................................ 83

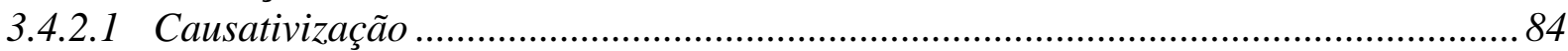

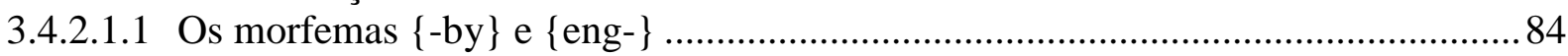

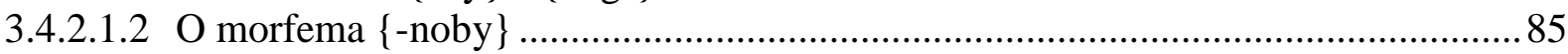

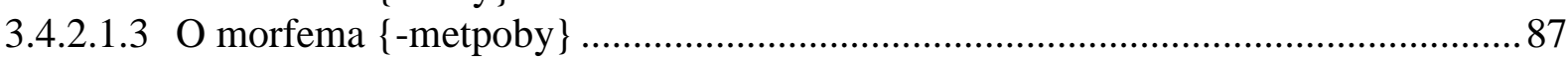

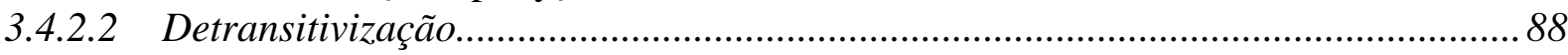

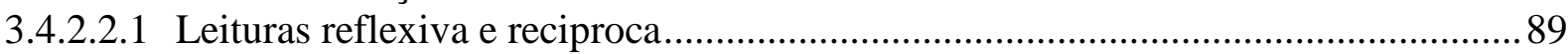

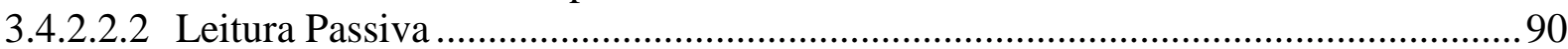

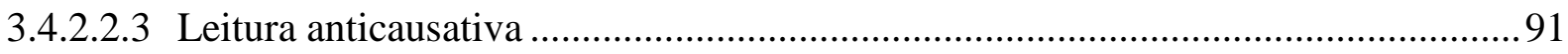

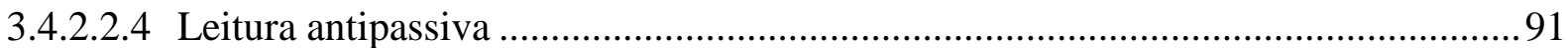

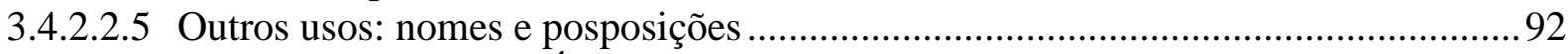

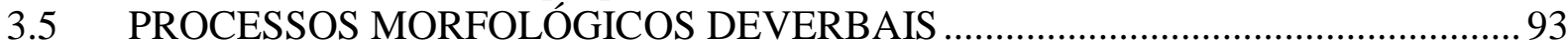

3.5.1 O morfema $\{$-tubo -tpo -tpyn npyn -tubry $\}$ psd.nom ............................... 94

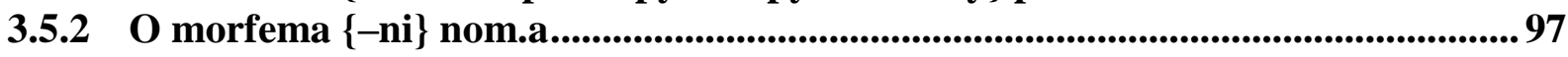

3.5.3 O morfema $\{$-tobot $\sim$-tpot $\}$ nom ........................................................................... 98

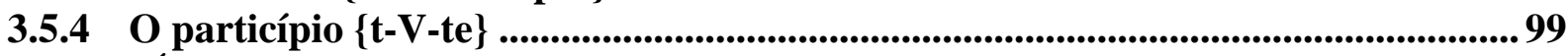

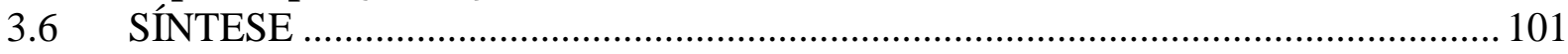

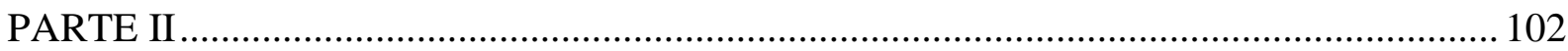

CAPÍTULO 4 - MORFEMAS DE TAM E SUAS FUNÇÕES GRAMATICAIS: ALGUMAS

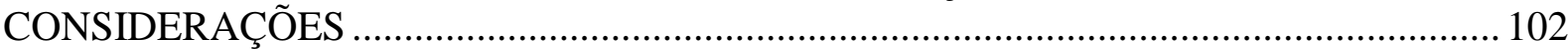

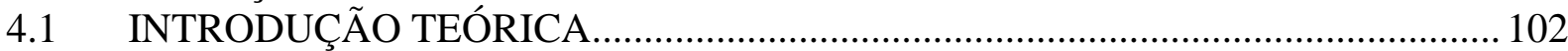

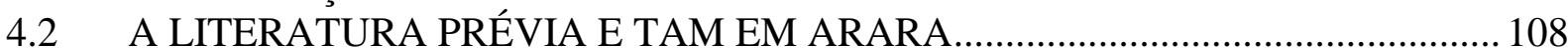

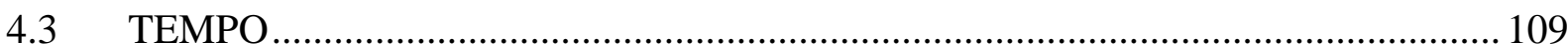

4.3.1 Os passados: $\{-l y \sim-$ ry $\}$ psd.imd, $\{-$ ne $\sim-n\}$ psd.dst, $\{$-te $\sim-t\}$ psd.med ............... 110

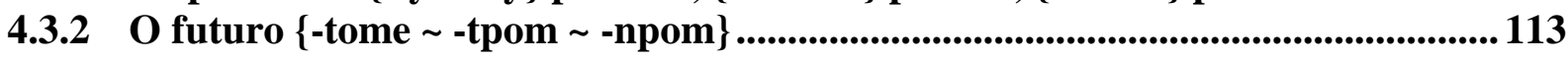

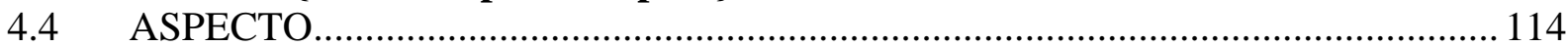

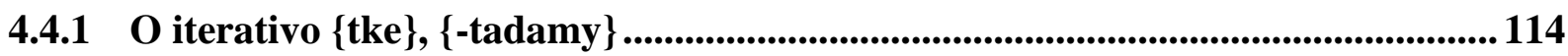

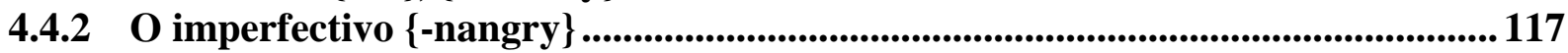

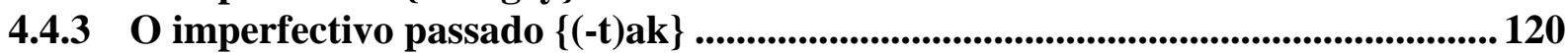

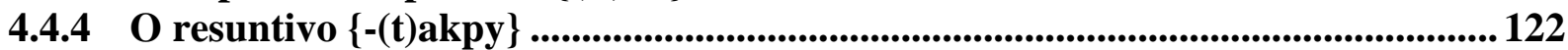

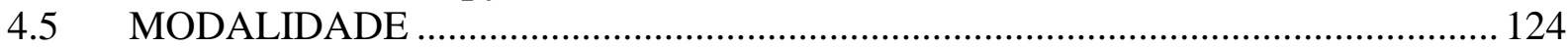

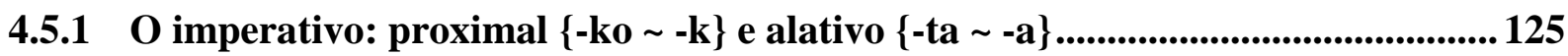

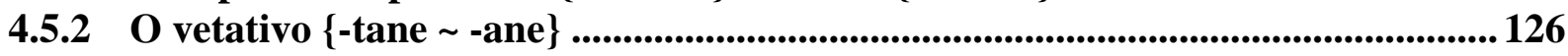

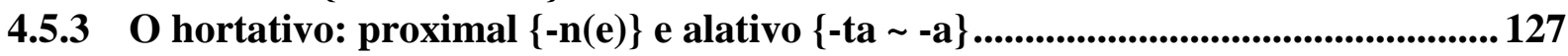

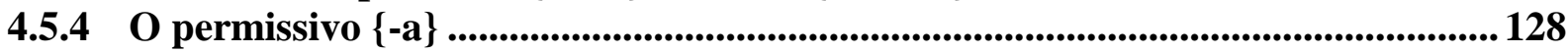

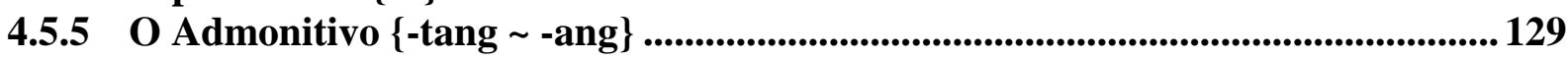

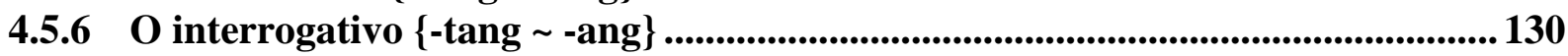

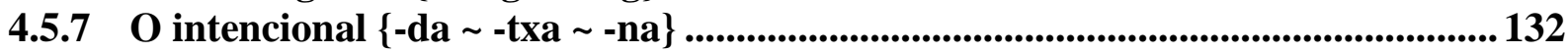


4.5.8 O frustrativo $\{$-menpo $\}$.................................................................................................. 134

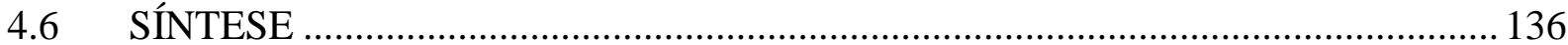

CAPÍTULO 5 - INTERAÇÃO ENTRE AS CONSTRUÇÕES VERBAIS: ÍNDICES DE

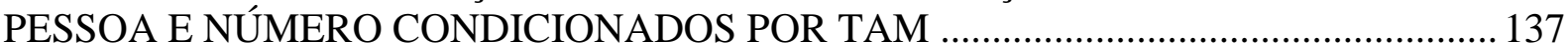

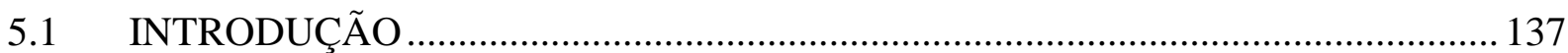

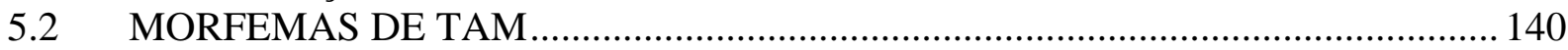

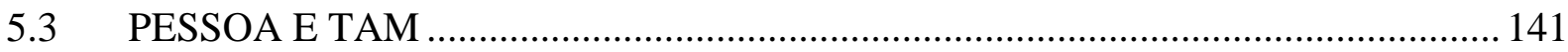

5.3.1 A pessoa nos passados (imediato, distante e médio), no futuro e no imperfectivo

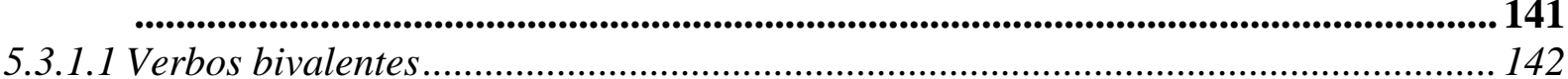

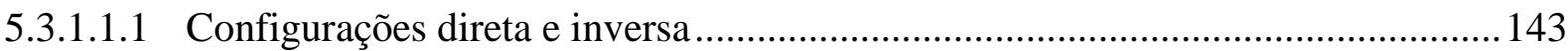

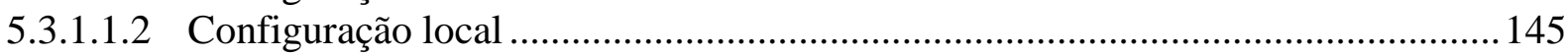

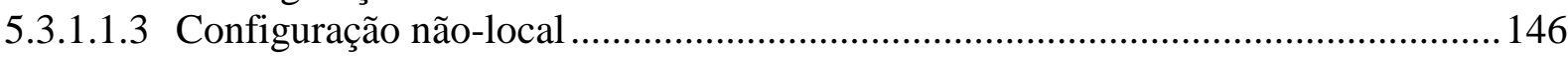

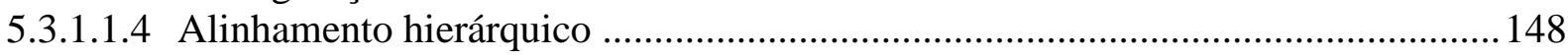

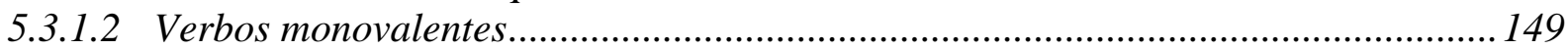

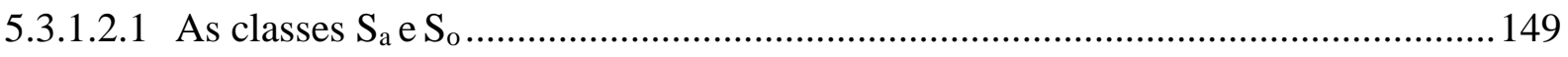

5.3.1.2.2 Sobre a natureza semâtico-morfológica dos predicados monoargumentais ...........152

5.3.1.3 Terceiras pessoas condicionadas pelos passados médio e distante........................... 154

5.3.1.4 Idiossincrasias: $\{t(y)\}\}$ e $\{w-\}$ consoante de ligação ............................................ 156

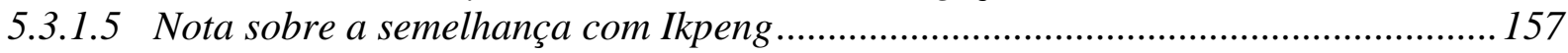

5.3.2 A pessoa no modo vetativo ........................................................................................... 158

5.3.3 A pessoa no imperativo (proximal e alativo) .................................................................. 160

5.3.4 A pessoa no horativo (proximal e alativo) ...................................................................... 163

5.3.5 A pessoa no admonitivo............................................................................................... 164

5.3.6 A pessoa no permissivo.................................................................................................... 165

5.3.7 A pessoa no modo intencional.............................................................................................. 166

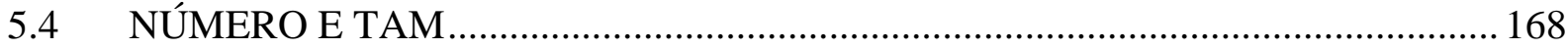

5.4.1 O sufixo \{-ngmo\}, o psd.imd e o ipfv ....................................................................... 173

5.4.2 O sufixo \{-tom\} e o perm, o adm, a 3psd.dst e a 3psd.med ...................................... 175

5.4.3 O sufixo $\{$-ty\}, o imp, o hort, o fut, o psd.dst e o psd.med .......................................... 176

5.4.4 O sufixo $\{$-(t)adyk $\}$ e o psd.dst ....................................................................................... 178

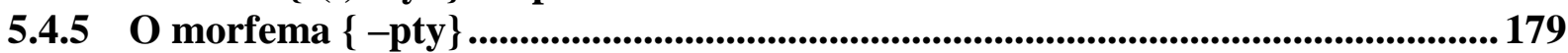

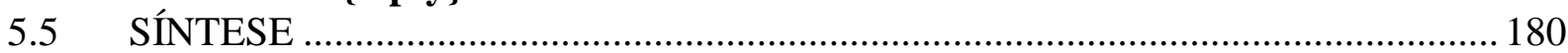

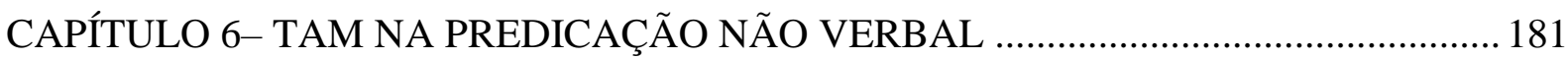

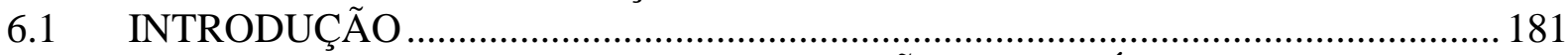

6.2 O PASSADO E O PRESENTE: CONSTRUÇÕES SEM CÓPULA .............................182

6.2.1 Predicados Nominais .............................................................................................................. 182

6.2.2 Predicados Posposicionais.................................................................................................... 184

6.2.3 Predicados Adverbiais......................................................................................................... 184

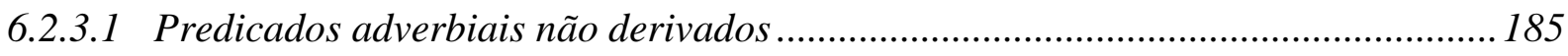

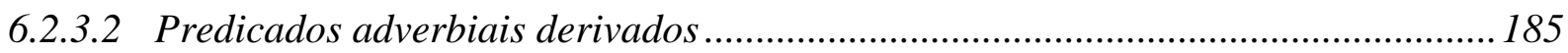

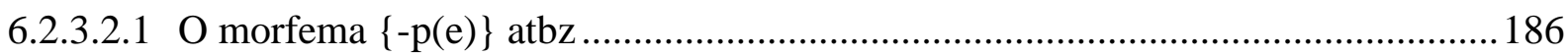

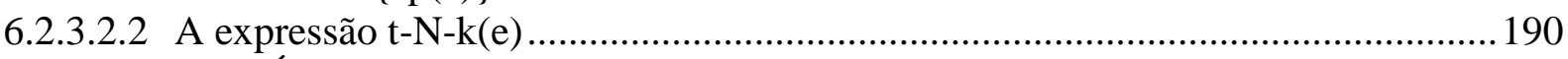

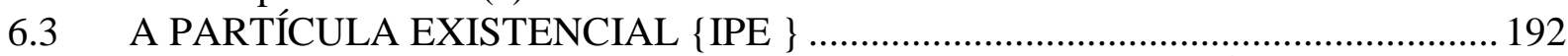

6.4 DEMAIS EXPRESSÕES DE TAM: CONSTRUÇÕES COM A CÓPULA \{ITXI $\}$ /ITI/

6.4.1 Morfofonologia

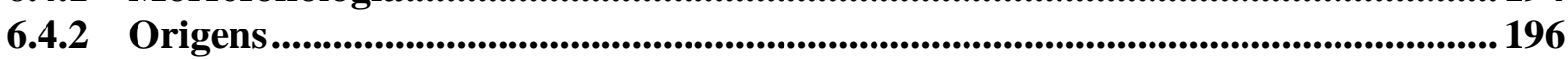


6.4.3 A posição da cópula .............................................................................................................. 197

6.4.4 Outro uso de itxi: verbo auxiliar ............................................................................. 198

6.4.5 O passado imediato e a cópula itxi ....................................................................................... 198

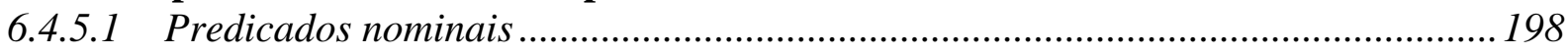

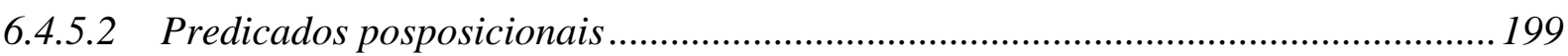

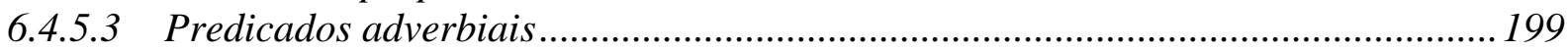

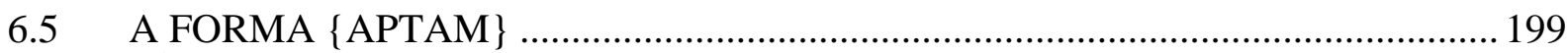

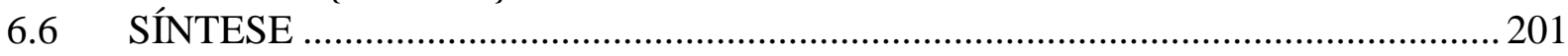

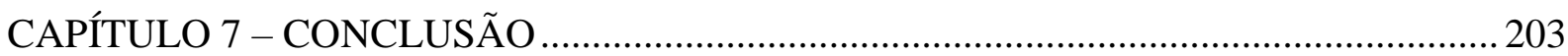

7.1 TAM COMO CATEGORIA FORMAL/GRAMATICAL: SÍNTESE ........................203

7.2 TAM COMO CATEGORIA FUNCIONAL/NOCIONAL: FUTURAS

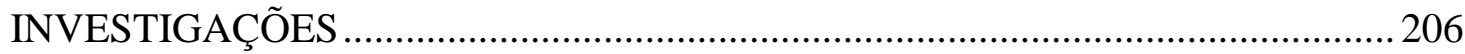

7.2.1 A estrutura t-V-t(e) ..............................................................................................................206

7.2.2 O passado nominal $\{$-tpyn $\sim$-npyn -tubry $\}$.............................................................. 208

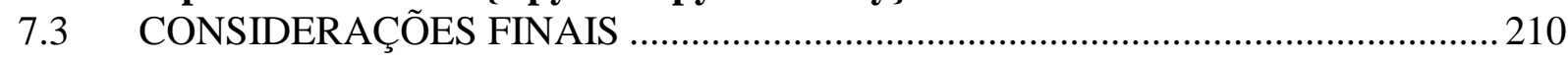

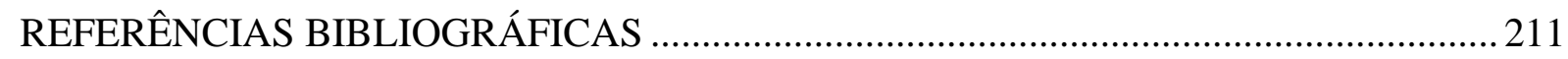

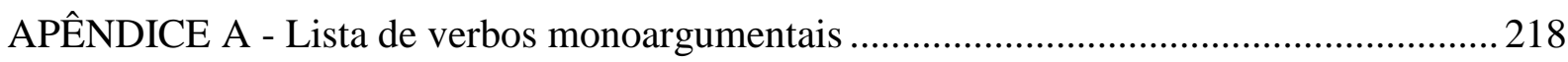

APÊNDICE B - Lista de verbos biargumentais ....................................................................220

ANEXO - Mapa das Terras Indígenas Arara e Cachoeira Seca …………………………....222 


\section{SÍMBOLOS E ABREVIATURAS}

Símbolos

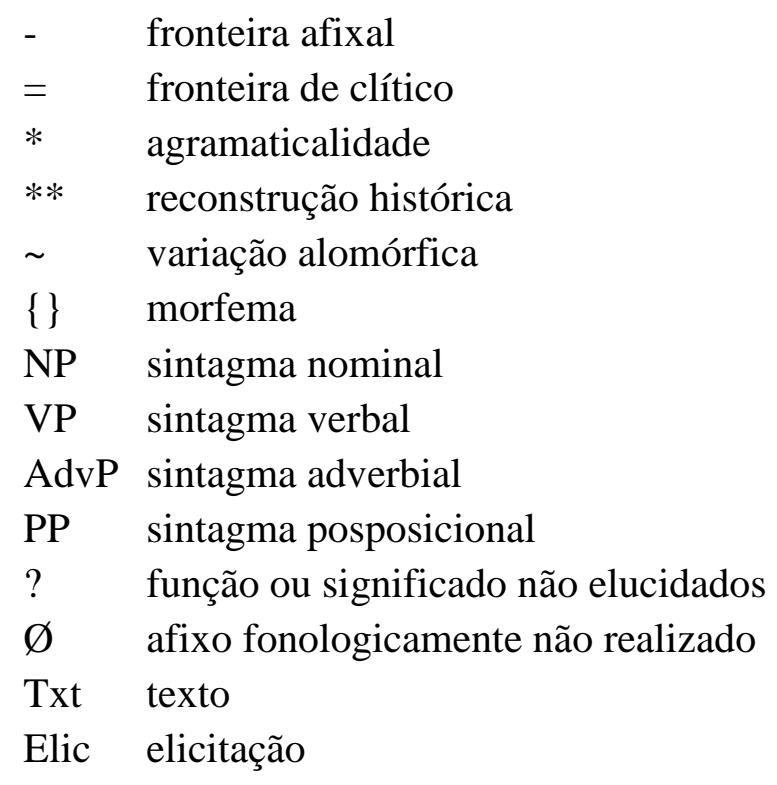

Abreviaturas (Foram padronizadas com a finalidade de se manter a consistência)

$\begin{array}{llll}1 & \text { primeira pessoa singular } & \text { COL } & \text { coletivo } \\ 2 & \text { segunda pessoa singular } & \text { COMT } & \text { comitativo } \\ 3 & \text { terceira pessoa singular } & \text { COM } & \text { pronome conector de sentença } \\ 1+2 & \text { primeira pessoa inclusiva } & \text { COMPL } & \text { completivo } \\ 1+3 & \text { primeira pessoa exclusiva } & \text { CONT } & \text { continuativo } \\ \text { A } & \text { sujeito do verbo transitivo } & \text { COP } & \text { cópula } \\ \text { ABS } & \text { absolutivo } & \text { DAT } & \text { dativo } \\ \text { ADDR } & \text { addressee } & \text { DECL } & \text { declarativo } \\ \text { ADJT } & \text { adjunto } & \text { DEIT } & \text { deitico } \\ \text { ADM } & \text { modo admonitivo } & \text { DER } & \text { morfema derivacional } \\ \text { ADV } & \text { adverbial(izador) } & \text { DESL } & \text { deslocamento } \\ \text { AFIR } & \text { afirmativo } & \text { DIM } & \text { diminutivo } \\ \text { ALA } & \text { alativo } & \text { DIR } & \text { direcional } \\ \text { ANIM } & \text { animado } & \text { DST } & \text { distante (como em PSD.DST) } \\ \text { ASP, A } & \text { aspecto } & \text { DTRZ } & \text { detransitivizador } \\ \text { ATBZ } & \text { atributivizador (adverbializador) } & \text { ERG } & \text { ergativo } \\ \text { AUM } & \text { aumentativo } & \text { EUF } & \text { eufêmico } \\ \text { BEN } & \text { benefativo } & \text { FIN } & \text { finalidade } \\ \text { CAUS } & \text { causativizador } & & \end{array}$




\begin{tabular}{|c|c|c|c|}
\hline FOC & foco & POSSD & possuído \\
\hline FRUST & modo frustrativo & PRD & predicador \\
\hline FUT & futuro & PRES & presente \\
\hline GCM & classificador geral & PRIV & privativo \\
\hline GNOMIC & gnômico & PRO & pronome \\
\hline HAB & habitual & PROP & próprio \\
\hline HORT & hortativo & PROPS & propósito de movimento \\
\hline IDEO & ideofone & PRTC & particípio \\
\hline IPFV & imperfectivo & PSD & passado \\
\hline INC & incorporação & PSSR & possuidor \\
\hline INS & instrumento & QU & pergunta polar \\
\hline INTC & modo intencional & REC & passado recente \\
\hline INTENS & intensificador & RECP & recíproco \\
\hline ITR & iterativo & REFL & reflexivo \\
\hline LOC & caso locativo & REL & relacional \\
\hline M & modo & REM & passado remoto \\
\hline MASC & masculino & RESUN & aspecto resuntivo \\
\hline MED & médio & RPT & modo reportativo \\
\hline $\mathrm{N}$ & não (como em NPSD = não passado ) & $\mathrm{S}$ & sujeito do verbo intransitivo \\
\hline NEG & negação & $S_{1}$ & sujeito do verbo intransitivo \\
\hline NOM & nominal(izador) & $\mathrm{N}_{\mathrm{A}}$ & semelhante a A \\
\hline NUM & número & $\mathrm{SCM}$ & classificador específico \\
\hline $\mathrm{O}$ & objeto & SG & singular \\
\hline ONOM & onomatopeia & $\mathrm{S}_{\mathrm{O}}$ & sujeito do verbo intransitivo \\
\hline PAF & participantes do ato de fala & No & semelhante a $\mathrm{O}$ \\
\hline PART & partícula & SUB & subordinador \\
\hline PFV & perfectivo & $\mathrm{T}$ & Tempo \\
\hline PERG & pergunta & TAM & Tempo, Aspecto, Modo \\
\hline PERM & modo permissivo & $\mathrm{V}$ & verbo \\
\hline PL & plural & VBZ & verbalizador \\
\hline PN & pronome de terceira pessoa & VET & vetativo \\
\hline POSP & posposição & VLC & valência \\
\hline
\end{tabular}




\section{PARTE I}

\section{CAPÍTULO 1 - INTRODUÇÃO}

\subsection{APRESENTAÇÃO E OBJETIVOS}

A partir da década de 1990, o mundo passou a prestar atenção para o fato de que as línguas estavam desaparecendo ( $C f$. KRAUSS, 1992). O choque de realidade levou à consolidação da área da linguística descritiva que, basicamente, consiste na coleta e análise de dados. Esta passou a ser a principal fonte de gramaticas de línguas pouco conhecidas. A partir de 1998 se consolida também a subdisciplina da documentação linguística ( $C f$. HIMMELMAN, 1998). Este é o contexto ${ }^{1}$ em que se enquadra o presente trabalho. À medida em que consiste em um estudo descritivo ${ }^{2}$, a língua é apresentada de acordo com generalizações justificadas por fatos internos à própria língua. Este tipo de estudo se enquadra na tradição boasiana ${ }^{3}$ que remete ao momento em que as disciplinas da antropologia, arqueologia e linguística eram vistas de forma intimamente relacionadas. Aliás, atualmente, tal relação volta a ser buscada por meio de estudos multidisciplinares que pretendem entender aspectos como o movimento dos povos e a interação entre estes e o meio ambiente, por exemplo (Cf. MOORE; STORTO, 2002; FAUSTO; FRANCHETTO; HECKENBERGER, 2008; SHEPARD; RAMIREZ, 2011). Especialmente no caso de línguas Karib cujo trabalho mais completo é de ordem histórica, não é possível ignorar como as mudanças morfológicas ocorrem através dos tempos. Desta forma, além dos padrões gramaticais sincrônicos são mencionados estudos tipológico-funcionalistas e históricos-comparativos da família.

O objetivo principal deste trabalho consiste em realizar um estudo morfofonológico e morfossintático das formas de expressão de Tempo, Aspecto e Modo (TAM) em Arara, Karib. Derbyshire (1999) e Meira (2005) ressaltam a complexidade morfológica peculiar às línguas

\footnotetext{
${ }^{1}$ Cenário apresentado por Hein Van der Voort em palesta proferida na III Biota Amazônica - Museu Goeldi 150 Anos Descobrindo a Amazônia (2016).

${ }^{2}$ A opção de realizar um trabalho de base descritiva ocorreu no contexto de trabalhos anteriores, haja vista que a autora vem realizando estudos desta natureza desde a iniciação científica (com línguas Tupi). Os estudos sobre a língua Arara (Karib) foram iniciados antes deste projeto, com o mestrado e dois pequenos projetos de estudo e documentação da língua e da cultura do povo Arara. Desta forma, a presente tese consiste na continuação e no aprofundamento de conhecimentos construídos ao longo deste percurso.

${ }^{3}$ Uma visão geral dos resultados da tradição Boas-Sapir-Bloomfield é apresentada em Mithun (1996).
} 
Karíb. Segundo este último autor, tal complexidade é comparável à encontrada em línguas românicas. Arara não foge à regra, tornando imperativo o entendimento de sua morfologia e interfaces com a fonologia e a sintaxe para melhor compreender como as categorias gramaticais de TAM são codificadas. Intimamente relacionada a tais categorias está a categoria de número $(\mathrm{N})$, o que levou os autores caribólogos/caribistas a se referirem a esta integração com as siglas TAN ou TAMN, apesar de TAM e $\mathrm{N}$ serem tipologicamente descritas entre as categorias verbal e nominal, respectivamente. Além disso, é esperado que diferentes marcas de pessoa ocorram com as categorias de TAM. Diante destes dois fatos, para o entendimento completo das formas verbais flexionadas por TAM é investigada ainda a integração entre as categorias de pessoa e número e o sistema de marcação de Tempo, Aspecto, Modo.

Mais especificamente, a fim de alcançar o objetivo principal, este estudo busca (I) descrever o significado gramatical das marcas de TAM selecionadas; (II) analisar as alomorfias dos morfemas de raiz e afixos, considerando os processos morfofonológicos envolvidos na afixação; (III) analisar os sistemas de marcação de pessoa determinados pelas formas de TAM selecionadas; e, finalmente, (IV) analisar as diferentes marcas de número que coocorrem com determinadas marcas de TAM, bem como sua relação com os sistemas de pessoa.

Como resultado, esperamos contribuir para aumento da documentação linguística bem como para o avanço do entendimento das principais categorias da gramática desta língua amazônica ainda pouco conhecida. Em maior escala, almejamos colaborar para a inserção de dados das línguas indígenas brasileiras nas discussões teóricas da ciência linguística. No âmbito mais prático, desejamos que este estudo possa se tornar parte das referências necessárias para subsidiar a elaboração de materiais educacionais para o povo Arara.

\subsection{O POVO ARARA: PANORAMA DO CONTEXTO ATUAL}

O povo denominado Arara ${ }^{4}$ é também conhecido como Arara do Pará ou Arara do Xingu. Eles, por sua vez, se autodenominam Ugrongmo $^{5}$. Desde pelo menos a década de 1860 ,

\footnotetext{
${ }^{4}$ No Brasil, há algumas línguas/povos denominados Arara como Arara Karo ou Arara de Rondônia (Tupi), Arara Shawãdawa ou Arara do Acre (Pano), Arara do Beiradão, povo aldeiado no Mato Grosso e os recém contatados Xatanawa ou povo Arara (Pano). Há ainda o povo Arara da Volta grande do Xingu o qual têm o português como língua materna. Sobre o possível parentesco com os Arara (Karib), Marlinda (2012) aponta que "segundo os relatos dos velhos, os Arara da Volta grande do Xingu são descendentes dos Arara do Rio Bacajá. A relação de parentesco com os Arara do rio Iriri (conhecidos como apenas Arara ou Arara do Pará), se existiu, ficou num passado distante." Texto extraído da página do ISA, disponível em: https://pib.socioambiental.org/pt/povo/arara-da-volta-grande-doxingu. Acessado em 16 Dez 2016.

${ }^{5}$ Outras formas encontradas na literatura são: Ukarãngmã, Wokarayma, Ugoroymo.
} 
indígenas identificados como Arara (Karib) vem sendo documentados como habitando ou transitando as áreas entre os rios Xingu, Tapajós, Iriri e Pacajá (COUDREU 1897; NIMUENDAJÚ, 1932). As compilações dos fluxos e presenças destes grupos indígenas feitas por Nimuendajú, apresentadas no Mapa Etnohistórico (IBGE, 1980) demonstram uma abrangência territorial grande, bem como sua persistência temporal (entre, pelo menos, 1861 a $\left.1963^{6}\right)$.

A partir da construção da rodovia Transamazônica (BR 320) na década de 1970 e o maior fluxo de pessoas na região, o processo de atração dos Arara se torna mais um dos trágicos capítulos dos povos indígenas no Brasil com perseguições e massacres, conforme relatos presentes em documentação da época (notícias de jornais, revistas, documentos técnicos ${ }^{7}$ ). $\mathrm{O}$ contato foi feito em várias etapas, durante alguns anos. Duas parcelas do povo aceitaram o contato definitivo em 1981 e 1984. O último grupo foi contatado em 1987 e foi neste que a presente pesquisa realizou-se. Naquela época, eles somavam cerca de 30 indivíduos (TEIXEIRA-PINTO, 1997) os quais são conhecidos como Arara da Cachoeira Seca, em referência ao local onde vivem.

Atualmente, o povo Arara como um todo conta com aproximadamente 550 indívíduos, os quais estão divididos em quatro aldeias: Iriri, Laranjal, Manggarapi e Arumbi. As últimas duas foram formadas recentemente a partir da divisão da aldeia Laranjal. A aldeia Iriri, onde a maior parte da pesquisa de campo foi realizada, está localizada à margem esquerda do rio Iriri, um afluente do rio Xingu, na Terra Indígena (TI) Cachoeira Seca. Esta TI que abrange um território entre os municípios de Placas, Uruará e Altamira teve seu processo de demarcação homologado em Abril de 2016, após 30 anos de tramitação. As demais aldeias estão localizadas na TI Arara (ver anexo).

A cidade de referência para o povo é Altamira, que sedia a coordenação técnica regional do órgão responsável pela execução das políticas indigenistas do governo Federal, a Fundação Nacional do Índio - FUNAI. O deslocamento entre esta cidade e a Aldeia leva de um a dois dias, dependendo das condições pluviométricas sazonais, bem como da disponibilidade de embarcações, uma vez que a viagem é realizada por via fluvial no período de cheia do rio Xingu, geralmente entre os meses de Fevereiro e Junho de cada ano. A cidade de Altamira é cortada pela rodovia transamazônica, estando em uma região conhecida por conflitos ligados à terra

\footnotetext{
${ }^{6}$ No mapa constam os fluxos a partir dos seguintes anos e locais entre o rio Tocantins e o Tapajós: 1861 - rio Xingu; 1863 - rio Xingu (cabeceira); 1869 - rio Tocantins; 1910-1932 - rio Pacajá; 1872 - rio Tapajós; 1896 - rio Iriri; 1930 - rio Pacajá; 1963 - rio Curuá do Sul; 1 ??7 (data ilegível) - rio Iriri.

${ }^{7}$ Alguns desses documentos estão disponíveis em http://armazemmemoria.com.br/centros-indigena/.
} 
(grilagem, mineração, extração ilegal de madeira). Desde 2010/11, a cidade passa por graves crises ocasionadas pela implantação da Usina Hidrelétrica (UHE) Belo Monte. Com o entorno em colapso, o povo e também esta pesquisa não tinham como não ser afetados. Além disso, hoje em dia, a TI Cachoeira Seca é impactada pelo asfaltamento da BR-320 que acaba facilitando o escoamento de madeira ilegal retirada do território.

Antes da implantação da UHE, os não indígenas que faziam parte do cotidiano dos Arara da Aldeia Iriri eram basicamente pescadores, ribeinhos, a técnica em enfermagem, o professor e os funcionários da FUNAI, principalmente na figura do chefe de posto que era responsável por intermediar grande parte das relações e por quem os Arara têm grande afeto. Devido à forma com que se dão as relações com a sociedade envolvente, os Arara da TI Cachoeira Seca são considerados um povo de recente contato ${ }^{8}$. Este foi o contexto encontrado em minha primeira visita à Aldeia Iriri, em 2009. Neste mesmo ano houve uma reestruturação da FUNAI e o cargo de chefe de posto foi extinto. A partir da UHE Belo Monte, por volta de 2010/11, foi verificada uma acelerada mudança no modo de vida dos Arara ${ }^{9}$. Cada vez mais houve a necessidade de saída de indígenas da aldeia para participarem de reuniões em Altamira. Além disso, as demandas dentro da aldeia por meio do programa de comunicação da hidrelétrica também se fizeram presentes numa tentativa de informá-los do que estava acontecendo. Isto quer dizer que houve uma forte demanda de estabelecimento de novas relações com não indígenas as quais, de maneira geral, há bem pouco tempo eram feitas por intermédio do chefe de posto ${ }^{10}$.

Como uma consequência deste cenário, as roças, componente essencial do sustento das famílias, deixaram de ser plantadas. Toneladas de alimentos industrializados foram inseridos em seu cotitiado. Além disso, houve entrada de muitos agentes relacionados à hidrelétrica na aldeia, tais como trabalhadores da construção civil e equipes de mitigação, o que acabou gerando momentos de tensão. Apesar do inevitável "rolo compressor da modernidade", vendido sob o rótulo de desenvolvimento, o povo apresenta enorme capacidade de resiliência ${ }^{11}$ e parece estar filtrando, dentro do possível, o que há de melhor na situação para perpertuar um modo de

\footnotetext{
8 "A Funai considera de recente contato aqueles povos ou grupos indígenas que mantêm relações de contato permanente e/ou intermitente com segmentos da sociedade nacional e que, independentemente do tempo de contato, apresentam singularidades em sua relação com a sociedade nacional e seletividade (autonomia) na incorporação de bens e serviços." Trecho extraído do website da FUNAI, disponível em: http://www.funai.gov.br/index.php/nossas-acoes/povos-indigenas-isolados-e-de-recente-contato?start=1. Acessado em 15/12/2016.

${ }^{9}$ Informações sobre o contexto observado na aldeia Laranjal podem ser obtidos em Belezine (2014).

${ }^{10}$ Situação semelhante ocorria em outras aldeias da região.

${ }^{11}$ Resiliência é tratado aqui como conceito que perpassa a interação da sociobiodiversidade das populações ditas tradicionais, entre as quais estão os grupos indígenas. Para uma discussão mais ampliada do conceito tratando de resiliência biológica e cultural ver SOUZA, R. M. Redes de monitoramento socioambiental e tramas da sustentabilidade. São Paulo: Annablume; Geoplan, 2007.
} 
vida saudável e adequadado, (idealmente) segundo seus próprios princípios. Hoje em dia, as roças da Aldeia Iriri começam a ser retomadas. Parece ter havido um estreitamento dos laços entre as lideranças dos demais grupos indígenas da região. O professores indígenas Arara (assim como das demais etnias) puderam trocar experiências com modelos de escolas indígenas de sucesso por meio de oficinas de capacitação. Além disso, jovens Arara estão se especializando em gestão territorial assim como em gravação de áudio e vídeo de elementos culturais. E, finalmente, parcerias para a geração de renda sustentável estão se consolidando.

Quanto aos impactos a este projeto, do ponto de vista prático da pesquisa, houve um aumento geral dos serviços necessários. Por exemplo, o meio mais viável de se chegar a aldeia Iriri consiste na utilização de embarcações (voadeira), pois à época do inverno amazônico as pedras do rio Xingu são encobertas, o que o torna mais navegável. A partir da chegada de empresas estrangeiras (que vieram quase concomintatemente à hidrelétrica, por exemplo, Belo Sun - extração de minério) e equipes de mitigação dos impactos causados pela UHE, o valor do frete de voadeiras foi substancialmente elevado. Além disso, foi constante o ambiente de insegurança causado pelo aumento da violência na região.

\subsection{A LÍNGUA ARARA E A CLASSIFICAÇÃO INTERNA DA FAMÍLIA LINGUÍSTICA}

A língua Arara (nome homônimo à denominação externa do povo) pertence à família linguística Karíb. Atualmente, esta é formada por cerca de 25 línguas, localizadas em seis países: Colômbia, Venezuela, Guiana, Guiana Francesa, Suriname e Brasil. Em território nacional ou em região de fronteira são encontrados cerca de 17 representantes desta família: Bakairi, Arara, Ikpeng, Waimiri-Atroari, Wai-wai, Katxuyana, Tiriyó, Wayana, Apalaí, Kuikuro, Matipu, Nahukuá, Kalapalo, Makuxi, Ye'kwana, Ingarikó e Taurepang. Para uma visão geral da família linguística ver Rodrigues (1986), Derbyshire (1999), Meira (2005) e Gildea (2012). De acordo com a distribuição geográfica dentro do país, foi convencionado informalmente que os representantes Karíb estão distribuídos em dois ramos principais, a partir do rio Amazonas: o ramo norte, constituído pela maioria das línguas Karib no Brasil, está localizado acima do rio, nas fronteiras com as Guianas e o Suriname, e o ramo sul é formado por todas as línguas que estão abaixo do rio, abrangendo a região do Médio e do Alto Xingu. É com este sentido que os termos línguas Karib do Norte e línguas Karib do Sul são empregados neste trabalho. Quanto à localização geográfica do povo Arara, este se encontra na 
região do Médio Xingu, no sudoeste do Estado do Pará, distante de outros povos Karib do ramo sul que se encontram no Parque Indígena do Xingu, no Mato Grosso.

Quanto à classificação genética interna da família Karib, Meira e Franchetto (2005) sugerem que Arara e Ikpeng estão na fronteira do que se considera dois dialetos de uma mesma língua que, por sua vez, tem Bakairi como representante mais próxima. Este subgrupo foi denominado de Ramo Pekodiano (MEIRA, 2006; GILDEA, 2012), tendo sua consistência recentemente corroborada também pelo método bayesiano (MEIRA; BIRCHALL; CHOUSOU-POLYDOURI, 2015). A figura abaixo ilustra essa classificação. Por outro lado, vale ressaltar que ainda não há estudos comparativos com dados sistematizados de Arara, Ikpeng e Bakairi em seus aspectos lexicais, fonológicos e morfossintáticos.

Figura 1.1 - Relação genética da família linguística Karib

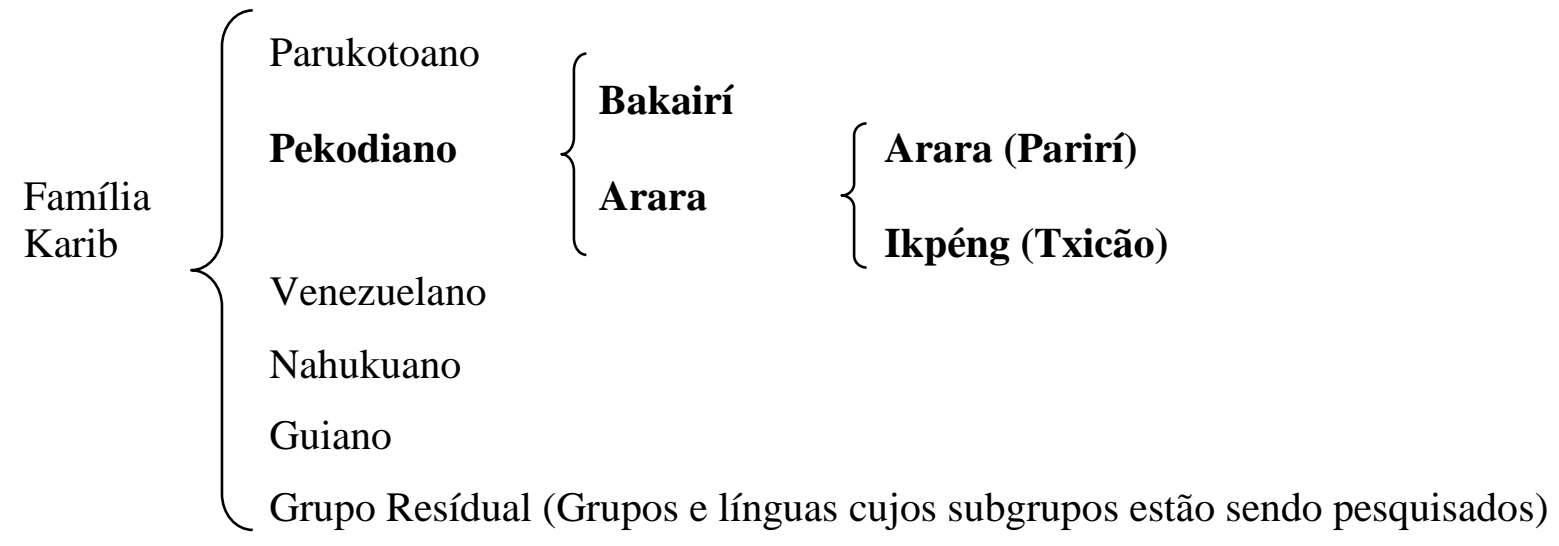

Fonte: Adaptado de Gildea (2012, p. 445, grifo nosso).

\subsection{NOTA SOBRE A SITUAÇÃO SOCIOLINGUÍSTICA}

De maneira genérica, são reconhecidos pelo menos quatro subgrupos do povo, que, possivelmente, representam também quatro dialetos: Korumbengmo, Peleum, Todepkugamo e Arara do rio Iriri. Este trabalho apresenta dados do dialeto dos Arara da aldeia Iriri, dialeto Iriri, e, eventualmente, de um dos demais dialetos. Estes são chamados genericamente de dialeto Arara.

Como a separação das aldeias ocorreu apenas recentemente, ainda é possível verificar dois cenários sociolinguísticos distintos, um referente à aldeia Iriri e outro referente às outras aldeias Arara. O grupo residente na aldeia Iriri, formado por 89 pessoas (Censo pessoal, Março 
de 2014), encontra-se em situação de extrema vulnerabilidade linguística ${ }^{12}$. Há um reduzido número de idosos e adultos plenamente proficientes em Arara. Os jovens, por sua vez, que já demonstram proficiência reduzida, estão formando seus próprios núcleos familiares nos quais as crianças começam a adquirir o português como primeira língua. É comum perceber a troca para o português (code switching) mesmo em conversas apenas entre falantes nativos. Embora as situações comunicativas ainda necessitem ser estudadas detidamente para se chegar a um diagnóstico mais preciso, não se pode negar que a língua portuguesa está cada vez mais ocupando lugar das situações de uso, originalmente, da língua indígena. A situação encontrada na aldeia Laranjal e nas novas aldeias ${ }^{13}$, por outro lado, apesar de vulnerável ${ }^{14}$, aparenta relativa estabilidade. Isto porque há falantes de todas as gerações e a língua continua a ser transmitida entre eles.

\subsection{TRABALHO DE CAMPO E A CONSTITUIÇÃO DO CORPUS}

Esta seção descreve como se deu a obtenção dos dados, chamando a atenção para os acertos e as armadilhas das metodologias adotadas no decorrer do estudo.

Foi realizada pelo menos uma viagem a campo por ano no perído de 2012 a 2016, em diversos contextos. Em média, cada viagem teve a duração de cerca de um mês, com exceção do ano de 2015 quando durou aproximadamente 60 dias. A pesquisa principal foi realizada na aldeia Iriri, TI Cachoeira Seca, mas, algumas vezes, também foi realizada na cidade de Altamira-Pa. Houve apenas duas visitas de cerca de uma semana cada à aldeia Laranjal.

Com relação aos participantes diretos da pesquisa, os termos falantes e colaboradores são usados como sinônimos. Todos eles são falantes nativos. Os mais idosos, com quem foram coletados textos, são fluentes apenas em Arara. Os demais falantes são adultos, proficientes também em Português. Estes auxiliaram nas transcrições, traduções e sessões de elicitação. Há colaboradores de ambos os sexos.

\footnotetext{
12 Para mais informações ver relatório técnico da FUNAI: FERREIRA ALVES, A. C. Levantamento e Sistematização da Documentação Existente sobre o Povo Arara, principalmente no Âmbito da Linguística. Relatório Técnico da FUNAI. 2013, 33p.

${ }^{13}$ De acordo com o ISA (Instituto Sócio Ambiental), o censo em 2012, quando havia apenas a aldeia Laranjal, era de 363 indivíduos (Sesai 2012). Acesso em 17 Jan 2014. http://pib.socioambiental.org/pt/povo/arara.

${ }^{14}$ Consideramos como "vulnerável" a língua que apresenta reduzido número populacional, comparando-se com à população que tem a língua portuguesa como língua materna. Neste ponto, todas as línguas indígenas em território nacional podem ser consideradas vulneráveis.
} 
Metodologias de coleta de dados costumam refletir pressupostos teóricos. Por exemplo, a linguística formal, que busca o estudo de um sistema inato presente na mente dos falantes, usa, principalmente, testes de gramaticalidade realizados por meio de elicitação para saber o que é e o que não é possível ser gerado por esse sistema. Por sua vez, a linguística descritiva, que busca apresentar os fatos linguísticos necessários para a comunicação e não assume possíveis instâncias inatas, em geral advoga mais a favor da coleta de fala natural contextualizada. Este trabalho utiliza uma gama de métodos de obtenção de dados como a observação participante (overhead elicitation), vários tipos de elicitação e gravação, transcrição e tradução de textos. Em concordância com a proposta descritiva buscou-se balancear textos e elicitação, tentando utilizá-los de forma complementar. Como defendido por Bowern (2010):

[...] elicitation of various types is a very useful way of getting data quickly. Even if most of your data comes from recorded narratives (or 'texts') after preliminary work, you will still be working through those texts with a native speaker of the language and asking questions about them. This is also a type of elicitation. Some aspect of a language are only discoverable through elicitation - they will appear in texts so seldom that it will be almost impossible to get enough information about them. (BOWERN, 2010, p. 73)

Neste trabalho, o termo elicitação se refere à coleta de dados baseada: i) em tradução direta de senteças da língua de contato para a língua em estudo, para preencher paradigmas e testar hipóteses. As sentenças foram descontextualizadas ou contextualizadas a partir de alguma situação da vida real da aldeia; ii) em senteças ouvidas no cotidiano que depois eram checadas com o colaborador (overhead elicitation); iii) em estímulos criados pelo Max Planck Institute for Psycholinguistics (MPI) Nijmegen, em especial o vídeo "recíprocos", de 2004; iv) em tradução reversa, isto é, aquela em que uma estrutura da língua em análise (como a combinação de morfemas ou estruturas fundamentadas em textos) é oferecida para que o falante forneça seu significado na língua de contato. Por vezes, este último método criou dados agramaticais, os quais foram utilizados como evidência para argumentar a favor ou contra certas hipóteses.

É importante observar que há inúmeras razões pelas quais um dado pode ser considerado agramatical, como apontam Adger (2002) e Sorace (1996). Neste quesito, durante esta pesquisa, foi observada a importância de se saber isolar, na medida do possível, tais fatores, pois apenas após algum tempo de pesquisa se verificou a produção de dados agramaticais, não pelo elemento em análise, mas outros fatores. Por exemplo, em elicitação do morfema - $d a$ INTC a 
palavra *ini-kody-da [1 A-quebrar-INTC] (Eu vou quebrar) foi considerada agramatical. Segundo esta análise, as razões para isto são de ordem morfofonológica. Primeiro, houve um equívoco quanto à forma da raíz que é passível de sofrer o processo de redução silábica (Capítulo II, seção 2.7.5) e segundo, a forma do morfema intencional que se anexa a raízes terminadas em segmentos consoanatais corresponde à -txa. Assim, o verbo que corresponde ao significado 'quebrar' conjugado no intencional corresponde à ini-kody-txa $\rightarrow$ iniko-txa [1A-quebrar-INTC] 'Eu vou quebrar'.

Ademais, foram considerados agramaticais os dados que provocavam as seguintes reações nos colaboradores. Quando perguntados se um item de tradução reversa era possível, no sentido de que ele (o colaborador) falaria aquilo em alguma situação ou ouvia os seus parentes falarem aquilo, respostas agramaticais eram: "Não, isso não tem na minha língua. Meu povo não fala assim. Ou ainda, Tá inventando? Não, isso não bate com a minha língua. Não dá pra entender". Outra reação comum consistiu no silêncio do falante, seguido de uma forma nova, possível na língua. Além disso, houve casos em que, principalmente, o colaborador mais experiente fazia comentários dizendo que aquele jeito de falar não estava bem correto, que algumas pessoas de sua aldeia falavam assim porque eram muito jovens e ainda não tinham aprendido direito, porque não conversavam com os mais velhos. Esses casos foram considerados tecnicamente gramaticais, mas não correspondentes à preferência do dialeto do colaborador.

São considerados "textos" todos os dados de fala contetualizada, com senteças encadeadas e coerentes entre si. Eles foram total ou parcialmente transcritos e traduzidos com o auxílio dos falantes nativos. A transcrição e a tradução consistem em etapas laboriosas que requerem muito tempo de pesquisa, mas elas se mostraram bastante relevantes ao provir grande parte das informações fonéticas e pragmáticas/semânticas (ex.: plural, significado gramatical das flexões de modo). Foram trabalhados cerca de 21 pequenos textos cujas transcrições e traduções totalizam aproximadamente 2h39"20'. Os conteúdos se referem ao cotidiano pessoal, à confecção de um artefato, de uma festa, a como se cozinha peixe, como se pesca, se faz farinha, entre outros. Há ainda narrações sobre o passado histórico, a cosmologia e um texto baseado no livro de figuras Frog Story (MAYER, 1969).

O corpus é formado tanto por dados obtidos especificamente para esta pesquisa quanto por materiais coletados em dois projetos anteriores: o "Estudo e documentação da língua Arara (Karib): etapas iniciais" (FERREIRA ALVES, 2010a) e o "Estudo e Documentação da Língua Arara (Karib)" (FERREIRA ALVES, 2011), ambos realizados no Museu Paraense Emílio Goeldi (MPEG). Assim como os dados provenientes desses dois projetos, o material do presente 
projeto foi sistematizado para inserção no Acervo de Línguas e Culturas da Amazônia do MPEG $^{15}$. Todas as gravações foram identificadas, e receberam descrições básicas sobre seu conteúdo (criação de meta-dados). É importante ressaltar que o conteúdo do material depositado no acervo pode ser visualizado no portal do Museu Goeldi e pode ser requerido a qualquer momento pelos membros das Aldeias Arara envolvidas. Além disso, os dados linguísticos anotados em campo estão sendo organizados em forma de banco de dados com o auxílio do programa Fieldworks Language Explorer (FLEx). Este programa otimiza o armazenamento de dados lexicais, bem como a criação de base de textos e a interlinearização destes com o banco lexical.

Durante toda a pesquisa, a área de linguística do Museu Goeldi disponibilizou o kit de documentação digital (composto de equipamentos de energia solar, gravador digital, câmera de vídeo e microfones de cabeça), além de ter oferecido seu acervo e apoio técnico.

\subsection{APRESENTAÇÃO DOS DADOS}

A apresentação dos exemplos elencados neste trabalho está baseada nas orientações encontradas nas regras de glossário de Leipzig: convenções para interlinarização morfema por morfema (COMRIE; HASPELMATH; BICKEL, 2008), com alterações onde necessárias (por exemplo, glossas em Português e não em Inglês). O glossário apresenta dez regras de sintaxe e semântica que refletem os usos mais comuns de glossas de textos na área da linguística. Em resumo, a prosposta explicita:

(I) O uso de glossas morfema por morfema, porém sem introduzir uma análise prédefinida;

(II) Valores gramaticais abreviados e grafados em small capitals;

(III) Ponto simples para demonstrar quando dois elementos da glosa correspondem a um elemento na língua em estudo e hífen quando a relação entre a glosa e o exemplo na língua é de um para um.

A seguir, é especificada cada linha dos exemplos encontrados no corpo deste trabalho:

- Linha 1: Forma ortográfica

${ }^{15} \mathrm{O}$ acervo pode ser visualizado em http://arqling.museu-goeldi.br. 
- Linha 2: Forma fonológica

- Linha 3: Glosa morfêmica

- Linha 4: Tradução livre/idiomática em português, entre aspas simples.

Algumas vezes, o dialeto de português do falante é adaptado para o português padrão. No caso de exemplos em outras línguas, uma tradução para o português é fornecida. No capítulo sobre fonética e fonologia são utilizadas as indicações canônicas correspondentes à forma fonética e à fonológica. A maioria dos exemplos em Arara é proveniente de trabalho de campo: aqueles retirados de textos são abreviados (Txt), enquanto os advindos de elicitação recebem a abreviação (Elic.). Exemplos retirados de outros autores têm a referência indicada. A numeração dos exemplos é feita consecutivamente dentro de cada capítulo.

\subsection{PANORAMA DE TAM NA FAMÍLIA KARIB}

Gildea (1998) apresenta um estudo comparativo, referência para estudos em línguas Karib, onde são reconstruídos alguns marcadores de tempo-aspecto-modo. No entanto, as línguas pekodianas não puderam ser incluídas neste estudo, já que os trabalhos existentes sobre elas eram insuficientes na época.

Conforme Meira (1999) (baseado em Gildea (1998)), a codificação de TAM nas línguas Karib pode ser dividida em três sistemas de acordo com sua morfologia: (I) Formas conjugadas, (II) Formas-não conjugadas e (III) Imperativo. Cada sistema apresenta um conjunto de características como apresentadas a seguir:

(I) Formas conjugadas: são caracterizadas, principalmente pela codificação de pessoa, de tempo-aspecto-modo e de diferentes formas e posições de morfemas de número.

(II) Formas-não conjugadas: são menos finitas do que as conjugadas, pois as funções de A ou S não são marcadas por prefixos de pessoa.

(III) Imperativo: está em uma posição intermediária entre estes dois primeiros grupos, já que são afixados apenas por alguns morfemas de pessoa, além a flexão de imperativo. 
$\mathrm{O}$ autor afirma ainda que enquanto todas as línguas apresentam o imperativo, apenas algumas como o Tiriyó (MEIRA, 1999) e Wayana (TAVARES, 2005) possuem ambos os sistemas de formas conjugadas e não conjugadas. A presente descrição trata o imperativo dentre as formas conjugadas. Este último sistema e o de formas não conjugadas são brevemente apresentados a seguir.

Com relação às formas conjugadas, tanto estudos de línguas individuais quanto os tipológicos confirmam a complexidade das flexões de TAM nas línguas Karib. Por exemplo, Meira (1999, p. 279) sugere que o sistema flexional de Tiriyó, e desta família linguística, é comparável ao das línguas européias em nível de complexidade. Mueller (2013, p.78), em seu estudo translinguístico, afirma que as línguas Karib de seu corpus (Hixkaryana, Panare e Tiriyó) são caracterizadas por um elevado grau de fusão entre Tempo, Aspecto, Modo e Número.

Quanto à caracterização semântica, segundo Derbyshire (1999), é comum a existência de mais de um passado. Em Hixkaryana, por exemplo, Derbyshire (1979) descreve uma distinção entre passado e não-passado, na qual o passado possui três distinções (remoteness degree) de tempo absoluto: I) passado imediato, referente a ações que ocorreram no mesmo dia ou na noite anterior, II) passado recente, referente a ações que ocorreram no dia anterior ou em até poucos meses antes, III) passado distante, referente a ações feitas em qualquer momento anterior $^{16}$. A distinção aspectual entre o perfectivo e imperfectivo é aplicada apenas para o passado recente e distante (Ibid, p. 138-139). Alguns exemplos são fornecidos em (1).

(1) Hixkaryana (Karib) (DERBYSHIRE, 1979, p.138-139, tradução nossa)

a) kahatakano

ki-ahataka-no

1SG-Sair-PSD.IMD

'Eu saí.'

b) ronyatxoko

r-onye-yatxoko

3SG.1O-ver-PSD.REC.COMPL.COL

'Eles me viram.'

c) khananihyatxkoni

ki-hananihi-yatxkoni

1SG.2O-ensinar-PSD.DST.CONT.COL

'Eu costumava ensinar vocês todos.'

${ }^{16}$ [...] 'distant past' refers to actions done any time earlier' (DERBYSHIRE, 1979, p. 139) 
Enquanto em Hixkaryana há um sistema de marcas para o passado e para o não passado, em Kuikuro, Santos (2007) apresenta a flexão aspectual como categoria principal e indispensável para a indicação de temporalidade:

Não há, no verbo, uma flexão propriamente de Tempo (Tense), com exceção de -ingo, um sufixo de última posição (só pode ser seguido pela Cópula -i), que glosamos como FUT(uro), que pode ocorrer com verbos e com nomes e que não se submete à lógica das Classes Morfológicas (SANTOS, 2007, p. 96).

Segundo Franchetto (2006 ${ }^{17}$ apud SANTOS, 2007, p.96), no modo descritivo existem apenas três aspectos: aspecto pontual, aspecto continuativo e aspecto perfeito, conforme resumido na tabela 1.1. Santos (2007) demonstra que estes aspectos são expressos por cinco classes morfológicas flexionais.

Tabela 1.1 - A categoria aspectual em Kuikuro

\begin{tabular}{l|l|l}
\hline \multicolumn{2}{c|}{ Pontual } & \multicolumn{1}{c}{ Continuativo } \\
\hline $\begin{array}{l}\text { Descreve um evento } \\
\text { instantâneo, no presente ou no } \\
\text { passado. }\end{array}$ & $\begin{array}{l}\text { Descreve um processo, com } \\
\text { extensão temporal inerente, no } \\
\text { passado ou no presente. }\end{array}$ & $\begin{array}{l}\text { Denota um evento que se } \\
\text { completou e que produziu um } \\
\text { estado definitivo } \\
\text { resultativo. }\end{array}$ \\
\hline
\end{tabular}

Fonte: Tabela baseada em Santos (2007, p. 96)

Por outro lado, Gildea (2012) aponta que no que se refere às flexões até agora apresentadas como tempo e aspecto nas descrições de línguas individuais da família Karib, possivelmente, mostrarão ser de natureza modal. Este breve panorama demonstra que o conhecimento com relação ao significado gramatical das flexões de TAM ainda não é unanime e ainda há muito a ser explorado.

No que se refere as formas não conjugadas, elas são caracterizadas por estruturas derivadas participiais que não apresentam marcas de pessoa ou qualquer flexão de TAM, porém apresentam semântica eventiva e são usadas como verbos plenos. Estas formas correspondem, basicamente, à formas $* * t$-V-ce e ${ }^{* *} t-\mathrm{V}$-ce-mi reconstruídas em Gildea (1998). Exemplos são apresentados em (2) e (3), respectivamente. Observe que devido aos processos morfofonológicos próprios dessas línguas, as expressões modernas não são idênticas às formas reconstruídas. Tampouco as glosas sincrônicas são as mesmas.

\footnotetext{
${ }^{17}$ FRANCHETTO, B. (2006). Are Kuikuro Roots Lexical Categories? In: LOIS, X.; VAPNARSKI, V. (eds).
} Lexical Categories and Root Classes in Amerindian Languages. Bern: Peter Lang, p. 33-68. 
(2) Tiriyó (Karib) (MEIRA, 1995 apud GILDEA, 1998, 14a, p. 24, tradução nossa)

wari nai $\boldsymbol{t}$-ə-e

mulher 3.ser COMPL-ir-COMPL

'A mulher foi.'

(3) Panare (Karib) (GILDEA, 1998, ex 18, p. 25, tradução nossa)

$\begin{array}{llll}\text { uhtawu } & \boldsymbol{t} \text {-ákə-son } & k \partial h & k \partial n \\ \text { ônibus } & \text { GNOMIC-dirigir-GNOMIC } & \text { 3.ANIM.ser } & \text { ele/a }\end{array}$

'Ele pode dirigir o ônibus.'

Em Arara, há sistemas de formas conjugadas e formas não conjugadas cognatas, com características peculiares à língua. Os objetivos apresentados na sessão 1.1 são verificados no sistema de formas conjugadas.

\subsection{CONCEITOS ANALÍTICOS}

Esta subção tem o propósito de esclarecer alguns conceitos analíticos que foram tomados como ferramentas descritivas neste estudo. Demais terminologias são explanadas no interior dos capítulos.

Marcas morfossintáticas ou gramaticais de TAM se referem aos afixos flexionais obrigatoriamente expressos nas formas finitas do radical verbal ou da cópula verbal. Um exemplo pode ser observado no inglês. Nesta língua, a flexão do tempo presente $-s$ ocorre quando o sujeito é a terceira pessoa singular, como em She run-s 'Ela corre'. Isto é, a descrição (ou análise) dessa flexão temporal deve fazer referência tanto à forma morfológica da flexão quanto ao sistema sintático de concordância de pessoa e número.

Estas marcas são entendidas como formas gramaticalizadas. Gramaticalização pode ser definida como um processo que se refere ao desenvolvimento gradual de morfemas gramaticais a partir de morfemas lexicais ou da combinação de morfemas lexicais com gramaticais ou lexicais (BYBEE; PERKINS; PAGLIUCA, 1994). No que tange aos significados expressos pelas categorias de TAM, não raro uma categoria pode expressar mais de um significado, o que é compatível com o processo. Como observa Croft (2015, p. 17): The grammaticalization process is, however, gradual. Many constructions that we observe in languages have progressed at least partly along a grammaticalization path. As a consequence they display "mixed", or at least peculiar, grammatical structure or behavior. Desta forma, 
seguindo a visão de estudos tipológicos e históricos, as categorias de TAM são vistas como categorias específicas a cada língua (exceto na apresentação dos conceitos gerais de TAM), as quais podem ser comparadas translinguísticamente.

As definições das categorias individuais são feitas no decorrer da tese. As de TAM são apresentadas no Capítulo 4 que traz definições gerais e discussões sobre os significados de cada morfema analizado. As categorias de pessoa e número são contempladas no Capítulo 5.

\subsection{PANORAMA DA LITERATURA PRÉVIA SOBRE ARARA}

Os maiores estudos sobre o povo Arara são de cunho antropológico. A principal referência é a etnografia de Teixeira-Pinto (1997). A língua Arara, por sua vez, possui poucos estudos divulgados em mídia aberta. Os trabalhos mais relevantes do ponto de vista linguístico são: Souza, I. (1988, 2010), Ferreira Alves (2010b, 2013) e Souza, S. (1993, 2010). Os princiais tópicos apresentados nos quatro primeiros trabalhos concernem à fonologia enquanto os dois últimos se referem a alguns aspectos de morfologia geral e morfologia nominal, respectivamente. Os trabalhos dos Souza são baseados nos dialetos da aldeia Laranjal, já os trabalhos de Ferreira Alves são, principalmente, do dialeto falado na aldeia Iriri. A seguir é apresentada uma breve descrição destes trabalhos, segundo a ordem cronológica.

Souza, I. (1988): versa sobre a fonologia. Sua análise fonêmica resulta em 11 fonemas consonantais /p, t, k, tf, m, n, y, l, r, w, j/ e 6 fonemas vocálicos /a, e, i, i, o, u/.

Souza, S. (1993): aborda aspectos de morfofonologia e morfologia. Esta autora apresenta um inventário fonológico formado por 14 consoantes /p, t, k, b, d, g, t $\int$, m, n, y, 1, r, w, j/ e 6 vogais /a, e, i, i, o, u/. Na segunda parte deste trabalho, são elencadas as classes de palavras: substantivos, verbos e posposições. Também foi tratada a mudança de valência, incluindo a causativização, a transitivização, a incorporação e a reflexivização. Foram apresentados os pronomes livres, bem como os paradigmas das marcas de pessoa, caracterizados pelo alinhamento ergativo-absolutivo.

Souza, I. (2010): acrescenta a vibrante bilabial ensudercida /B/ e a fricativa glotal /h/ ao quadro de fonemas apresentando em Souza, S. (1993). Apresenta um breve panorama da gramática e descreve a fonologia das línguagens lúdicas (ludlings ou play languages) do povo Arara. 
Souza, S. (2010): descreve a morfologia dos nomes em Arara. São apresentados os morfemas de posse, de pessoa, de caso e de plural. A autora também apresenta nomes compostos e a classe dos adjetivos e predicados adjetivais denominais.

Ferreira Alves (2010b): descreve e discute os sistemas vocálico e consonantal, utilizando dados, principalmente, do dialeto falado na aldeia Iriri. Traços divergentes encontrados no dialeto Arara também são mencionados. Tal autora apresenta 14 fonemas consonantais /p, t, k, b, d, g, t $\int, \mathrm{m}, \mathrm{n}, \mathrm{y}, \mathrm{l}, \mathrm{r}, \mathrm{w}, \mathrm{j} / \mathrm{e} 6$ vocálicos / a, e, i, i, o, u /, mas observa que um segmento fricativo glotal deveria ser melhor investigado. Os processos fonológicos indentificados são a alofonia dos segmentos consonantais e a assimilação da sonoridade em contexto intervocálico de fronteira de morfema e de palavras. Foram analisadas características acústicas de vogais e consoantes. Aspectos acústicos do acento também foram apresentados: VOT, duração e pitch.

Ferreira Alves (2013): apresenta uma versão em português da fonologia da língua adicionando a consoante oclusiva glotal /h/ ao seu quadro de fonemas, como um segmento de ocorrência limitada. Além disso, neste trabalho são descritos o ablaut e também os processos fonológicos de assimilação consonantal (sonorização, nasalização e palatalização), dissimilação vocálica (alçamento), elisão (vocálica e consoanantal) e africativização (do glide $j$ ).

Quanto às categorias de TAM, o tema ainda não havia sido objeto de estudos mais detalhados. Os trabalhos anteriores apresentam vários morfemas de Tempo, Aspecto e Modo em suas glossas, porém, de modo geral, não são apresentadas as motivações que levaram a escolha dos rótulos das flexões ou mesmo que justifiquem a forma dos morfemas. As análises apresentadas no presente estudo diferem dos anteriores em várias instâncias as quais são apontadas e discutidas em seções pertinentes.

\subsection{ESTRUTURA DA TESE}

Este estudo está organizado em duas partes principais. A primeira parte traz os elementos relevantes para o entendimento das formas com as flexões de TAM no nível da fonologia, da morfofonologia e da morfossintaxe. A segunda focaliza nos aspectos interacionais entre as categorias de TAM, Número e Pessoa, assim como na semântica/função gramatical das categorias de TAM. 
O Capítulo 2 oferece um resumo da fonologia da língua e algumas adições sobre os processos morfofonológicos observados. A morfofonologia das flexões de TAM e Pessoa também são apresentadas.

Os estudos realizados sobre a morfossintaxe são apresentados a partir do Capítulo 3, onde é demonstrado como verbos são diferenciados de outras classes de palavras verificadas na língua. Este capítulo inclui ainda os processos de formação da palavra verbal, assim como processos deverbais.

O estudo sobre os significados gramaticais das flexões de TAM é apresentado no Capítulo 4.

O Capítulo 5 apresenta as categorias de pessoa e de número, mostrando como estas se relacionam com as categorias de TAM.

O capítulo 6 mostra a codificação de TAM nas construções não verbais, com e sem a cópula verbal.

O capítulo 7 traz um resumo das principais conclusões do trabalho e apontamentos para futuros estudos. 


\section{CAPÍTULO 2 - FONOLOGIA E MORFOFONOGIA}

Este capítulo oferece um resumo do sistema fonológico e morfofolonológico da língua Arara. São apresentados os fonemas, a estrutura silábica, o acento e os processos morfofonológicos (assimilação, dissimilação, redução silábica, palatalização e africativização). Majoritariamente, são utilizados dados provenientes do dialeto Iriri, sendo que apenas algumas breves observações sobre o dialeto Arara são fornecidas. A correspondência entre fonemas e grafemas empregados neste trabalho também é apresentada. Os conteúdos referentes à fonologia e aos processos morfonológicos deste capítulo consistem basicamente em uma revisão de Ferreira Alves (2010b, 2013). Os avanços correspondem, principalmente, a algumas questões sobre a redução silábica, o ablaut e as alomorfias das flexões de TAM.

\subsection{SEGMENTOS DISTINTIVOS: VOGAIS E CONSOANTES}

Segundo Ferreira Alves (2010b, 2013), a língua Arara apresenta um sistema de sons fonologicamente distintivos formado por 6 fonemas vocálicos e 15 fonemas consonantais, ilustrados nas tabelas 2.1 e 2.2 , respectivamente:

Tabela 2.1 - Inventário fonêmico vocálico ${ }^{18}$

\begin{tabular}{|l|ccc|}
\cline { 2 - 4 } \multicolumn{1}{c|}{} & Anterior & Medial & Posterior \\
\hline Alta & $\mathrm{i}$ & $\dot{\mathrm{i}}$ & $\mathrm{u}$ \\
média & $\mathrm{e}$ & & $\mathrm{o}$ \\
Baixa & \multicolumn{3}{c}{$\mathrm{a}$} \\
\hline
\end{tabular}

\footnotetext{
${ }^{18}$ Ferreira Alves (2010b, p. 28) apresenta as características acústicas de cada fonema vocálico: /i/ apresenta uma ampla área de dispersão, com várias realizações entre uma vogal central alta [i] e uma vogal posterior alta não arredondada [u], /e/ é articulada como uma vogal anterior média baixa [ع], a vogal /o/ é implementada como uma vogal posterior média baixa [o], /a/ é articulada como uma vogal central baixa [a] ou com uma ligeira ascensão da parte posterior da língua, produzindo uma vogal $[a]$.
} 
Tabela 2.2 - Inventário fonêmico consonantal ${ }^{19}$

\begin{tabular}{|c|c|c|c|c|c|}
\hline & Bilabial & Alveolar & Palatal & Velar & glotal \\
\hline Oclusiva & $\mathrm{p} \quad$ (b) & $\mathrm{t} \quad(\mathrm{d})$ & & $\mathrm{k}(\mathrm{g})$ & \\
\hline Nasal & $\mathrm{m}$ & $\mathrm{n}$ & & $\eta$ & \\
\hline Flepe & & r & & & \\
\hline Lateral & & 1 & & & \\
\hline Fricativa & & & & & (h) \\
\hline Africada & & & t & & \\
\hline Aproximante & $w^{20}$ & & $\mathrm{j}$ & & \\
\hline
\end{tabular}

Segundo esta autora, a previsibilidade de ocorrência entre oclusivas surdas e sonoras é elevada, com a existência de poucos pares mínimos, razão pela qual as oclusivas sonoras são descritas entre parênteses. As oclusivas apresentam um conjunto de alofones, conforme elecandos a seguir:

Tabela 2.3 - Alofones das consoantes oclusivas

\begin{tabular}{l|l|l}
\hline$/ \mathrm{p} /[\mathrm{p}, \mathrm{b}, \beta, \mathrm{m}]$ & $/ \mathrm{t} /[\mathrm{t}, \mathrm{d}, \iota, \mathfrak{g}, \mathrm{n}]$ & $/ \mathbf{k} /[\mathrm{k}, \mathrm{g}, \mathrm{u}, \mathrm{p}]$ \\
\hline$/ \mathbf{b} /[\mathrm{b}, \beta]$ & $/ \mathrm{d} /[\mathrm{d}, \curlywedge]$ & $/ \mathrm{g} /[\mathrm{g}, \mathrm{u}]$ \\
\hline
\end{tabular}

A fricativa glotal é descrita entre parênteses devido ao reduzido número de ocorrências. No presente corpus, ela ocorre apenas em palavras onomatopéicas ou alguns nomes próprios como [tahtfa], [Mohtidi]. Desta forma, esta consoante não será representada no quadro de encontros consoantais.

O fonema / / $\mathrm{f} /$ ocorre apenas em posição de ataque silábico e apresenta realizações diante dos mesmos contextos do fonema /t/, como diante de /a/ em /tfarina/ 'galinha' e /taro/ 'lontra', e diante de /o/ em /tfoktfogulo/ 'pássaro sp.' e /toromo/ 'castanha'. Possivelmente, este fonema foi originado a partir da palatalização da oclusiva alveolar diante de sons palatais /i, $\mathrm{j} /$, o que justificaria o fato de que / $/ \mathfrak{g} /$ perde tal palatalização se o segmento palatal for elidido. De fato, a

${ }^{19}$ Souza, I. (2010, p. 8, 9) aponta a existência de consoantes observadas em um restrito conjunto de palavras no dialeto Arara: a vibrante bilabial ensurdecida [ B ] e as implosivas [6], [đ] ]. Estes segmentos não foram encontrados nos dados analisados do dialeto Iriri.

${ }^{20}$ Aproximante labiovelar 
maioria das ocorrências de /ty/ é diante de /i/, como em /tfitfi/ 'sol', com poucas exceções, /Mohtidi/ NOM.PROP, por exemplo. Por outro lado, hoje em dia, nos casos diante de /a, o/ que são sempre palatais não há mais como afirmar sem sombra de dúvidas que se trata de um segmento palatalizado devido ao ambiente em que se encontra, o que nos leva a inserir um fonema africado independente no invetário consonantal. Note que $/ \mathfrak{t} /$ existe enquanto fonema e enquanto alofone de /t/ diante de segmentos palatais. Como uma forma de distinguí-los, sempre que houver variação de $[t]$ para $[t]$, produzida em ambientes nos quais o elemento palatal não está presente, consideramos que a forma subjacente consiste na oclusiva alveolar. Por exemplo, em [itfi-lu] 'deitou' $\rightarrow$ [it-ko] 'deita!', a forma subjacente da raiz é /iti/.

\subsection{ORTOGRAFIA UTILIZADA NESTE ESTUDO}

O sistema de escrita ortográfica foi introduzido por missionários do Summer Institute of Linguistics (SIL)/Associação Linguística Missionária Evangélica (ALEM) e por professores do Conselho Indigenista Missionário (CIMI) nas aldeias Laranjal e Iriri. Atualmente, são identificados alguns problemas de uso, porém o sistema funciona relativamente bem. Para este trabalho, optou-se por leves modificações. Os grafemas diferentes utilizados são <ng > no lugar $\mathrm{de}<\mathrm{g}>$ ou $<\tilde{\mathrm{g}}>$ para o fonema $/ \mathrm{y} / \mathrm{e}<\mathrm{tx}>$ substituindo $<\mathrm{tj}>$ para o fonema $/ \mathrm{tg} /$. Além disso, apesar do fonema /t/ apresentar palatalização previsível diante de /i, j/, optamos por manter a preferência observada na ortografia prática das aldeias de escrever a palatalização, mesmo nestes ambientes. Assim, a forma fonológica /itili/ 'deitou' é representada ortograficamente como <itxily> 'deitou'. A tabela 2.4 apresenta os grafemas e suas representações fonêmicas.

Tabela 2.4 - Lista de grafemas e suas correspondências fonêmicas

\begin{tabular}{|c|c|c|c|c|c|c|c|}
\hline Grafema & fonema & Grafema & fonema & Grafema & fonema & Grafema & fonema \\
\hline$\langle p\rangle$ & $/ \mathrm{p} /$ & $\langle\mathbf{m}\rangle$ & $/ \mathrm{m} /$ & $\langle w\rangle$ & $/ \mathrm{w} /$ & $\langle\mathbf{a}\rangle$ & /a/ \\
\hline$\langle\mathbf{t}\rangle$ & $/ \mathrm{t} /$ & $<\mathrm{n}>$ & $/ \mathrm{n} /$ & $\langle\mathbf{j}\rangle$ & $/ \mathrm{j} /$ & $\langle\mathrm{e}\rangle$ & /e/ \\
\hline$\langle k>$ & / k/ & $\langle\mathbf{n g}\rangle$ & $/ \mathrm{l} /$ & $\langle t \mathbf{t x}\rangle$ & $/ \mathrm{tg} / / \mathrm{t} /$ & $\langle\mathbf{i}\rangle$ & /i/ \\
\hline$\langle\mathbf{b}\rangle$ & $/ \mathrm{b} /$ & $\langle\mathbf{r}\rangle$ & $/ \mathrm{r} /$ & & & $\langle 0\rangle$ & /o/ \\
\hline$\langle d\rangle$ & $/ \mathrm{d} /$ & $\langle\mathrm{l}\rangle$ & $/ 1 /$ & & & $\langle\mathbf{u}\rangle$ & $/ \mathrm{u} /$ \\
\hline$\langle\mathrm{g}\rangle$ & /g/ & $\langle\mathbf{h}\rangle$ & $/ \mathrm{h} /$ & & & $\langle y\rangle$ & $/ \dot{\mathrm{i}} /$ \\
\hline
\end{tabular}


Como observa Seifart (2006), o desenvolvimento de uma ortografia envolve fatores de natureza variada. Dentre eles estão não apenas aspectos fonológicos, gramaticais e semânticos da língua, mas também fatores não-linguísticos como aspectos pedagógicos, sócio-políticos, técnicos, psicolinguísticos além de sociolinguísticos. Assim, considerando a situação sociolinguística do grupo encontrado na aldeia Iriri (conforme o Capítulo I, seção 1.4) e as observações do atual professor indígena da escola desta comunidade com relação à ortografia dos materiais escolares existentes, optou-se por uma ortografia relativamente mais transparente foneticamente. Porém, o processo de unificação das ortografias práticas ainda está por ser realizado.

\subsection{FONOTÁTICA: PADRÃO SILÁBICO}

A estrutura silábica da língua pode ser representada pela fórmula $(C) \mathrm{V}(\mathrm{C})$ em que a sílaba pode ser formada por uma única vogal e o ataque silábico não é obrigatório. A primeira posição da sílaba pode ser ocupada por uma única consoante ou glide enquanto a coda pode conter apenas uma consoante. A distinção entre sequências GV (glide+vogal), como em (1a), e VV (vogal+vogal), em (1b) e (1c), é feita pelo acento, apresentado na transcrição fonética, que recai sempre sobre a última sílaba da palavra. Note que, em (1a), o acento recai sobre uma sequência GV e em (1b) e (1c) sobre V.

a) /wajo/ 'cuia'

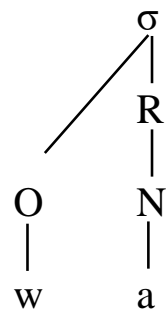

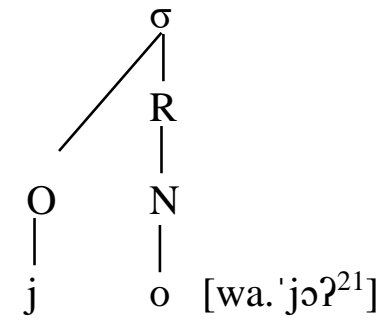

b) /ae/ 'abelha sp.'

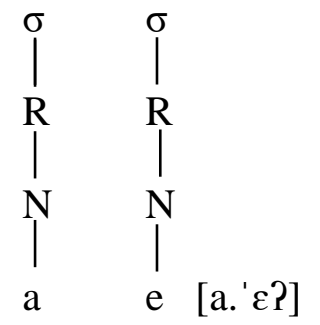

21 Uma oclusiva glotal pode ser inserida, possivelmente, com função demarcativa, sinalizando fronteiras morfológicas. 
c) /kui/ 'pássaro sp.'

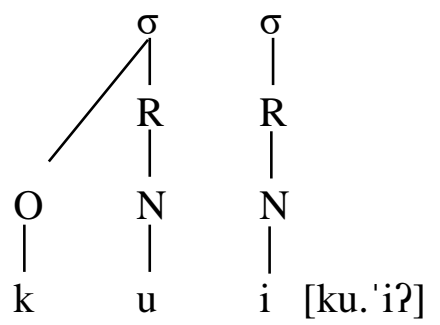

Todos os quatro tipos de sílabas possíveis (V, CV, VC, CVC) ocorrem em posição inicial, medial e final de palavras. Quanto às restrições fonotáticas, a figura a seguir resume a distribuição dos segmentos na estrutura silábica.

Figura 2.1 - Ocorrência dos segmentos em posição de ataque, núcleo e coda.

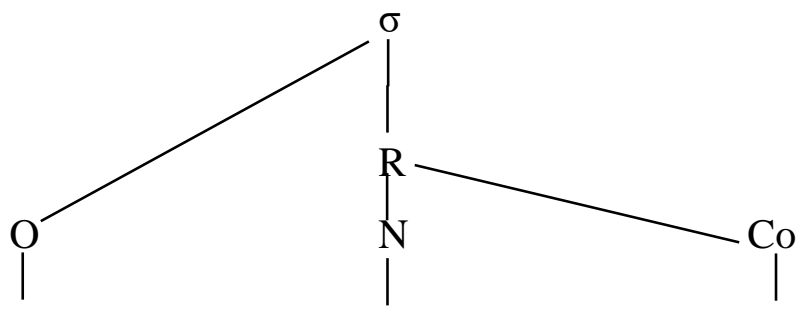

$\mathrm{p}, \mathrm{t}, \mathrm{k}, \mathrm{b}, \mathrm{d}, \mathrm{g}, \mathrm{t}, \mathrm{l}, \mathrm{f}, \mathrm{m}, \mathrm{n}, \mathrm{w}, \mathrm{j} \quad \mathrm{a}, \mathrm{e}, \mathrm{i}, \dot{\mathrm{i}}, \mathrm{o}, \mathrm{u} \quad \mathrm{p}, \mathrm{t}, \mathrm{k}, \mathrm{b}, \mathrm{d}, \mathrm{g}, \mathrm{y}, \mathrm{h}, \mathrm{m}, \mathrm{n}$

Há restrições fonotáticas no início e no final de palavras, onde não ocorrem as oclusivas sonoras /b, d, g/. Além desses segmentos, na posição inicial da palavra, também não ocorrem a nasal velar $/ \mathrm{y} /$ e nem a fricativa glotal $/ \mathrm{h} /$. Os fonemas $/ \mathrm{l}, \mathrm{c}, \mathfrak{f}, \mathrm{w}, \mathrm{j} /$, por sua vez, não ocorrem em posição de coda. O fonema tepe, por conveniência representado como $/ \mathrm{r} /$, apresenta diferentes comportamentos fonotáticos em início de palavra dependendo do dialeto. No dialeto Arara, este segmento não ocorre em posição inicial, enquanto no dialeto Iriri, essa restrição não se aplica. Por exemplo, a palavra para 'terra' é /oroy/ e / roy/ nos dialetos Arara e Iriri, respectivamente.

O glide labiovelar, além de ser um fonema independente, também consiste em um alofone das vogais /u/ e /o/ diante da vogal central baixa /a/. Ou seja, [w] é fone de /w, o, u/. Assim, a palavra /kuary/ 'palha' pode ser pronunciada como [kwa.ry]. Em palavras derivadas, a estrutura morfológica não apresenta isomorfia com o padrão silábico, o que permite, por exemplo, que a expressão /ko-ari-dal [1A20-levar-INTC] 'eu vou te levar' seja pronunciada como $\left[k^{w} a . r i\right.$. ' $\left.d a\right]$. Contudo, como a labialização não é distintiva na língua, não há razão para se criar uma sílaba complexa no início da palavra. 


\subsection{ENCONTROS CONSONANTAIS}

Sequências de consoantes heterossilábicas são encontradas no interior dos morfemas. Exemplos dos encontros consonantais identificados no corpus são oferecidos em (2). A tabela 2.5 apresenta um resumo dessas sequências. As áreas escuras indicam sequências não encontradas.

(2)

a) pi.lep.te 'faca', top.ka.lo 'outro', ip.txi.ma.um 'tipo de flauta'

b) ot.pi.do 'tatu sp.', ot.ko.i.mo 'tatu sp.'

c) ik.pun 'seco', ek.tan 'galho'

d) my.dab.ri 'comida'

e) kog.lon 'amanhã', ug.ro 'nós (incl.)'

f) tom.pan 'todos', am.tet 'corda', tom.txin 'filha (fala do homem)', ka.ra.jam.ke.ni 'falecido Karaja', txim.na 'Nós (excl.)', um.nget.pot 'defumado', wam.ro 'esses'

g) en.pan 'fruta sp.', mon.to 'lá', on.kuk 'Sobe!', on.ma 'caminho', on.ngon 'cacau', yn.txa 'para onde?'

h) eng.py 'idosa', ang.te.ly 'caiu', ko.rong.ko.ro 'sapo sp.', e.reng.my.ly 'bateu', jeng.ne 'apenas a mãe', i.dang.ron 'antes, há tempos', kong.txi.pe 'frio', wung.wung 'rodar fogo'

Tabela 2.5 - Encontros consonantais internos ao morfema

\begin{tabular}{|c|c|c|c|c|c|c|c|c|c|c|c|c|c|c|}
\hline & $\mathrm{p}$ & $\mathrm{t}$ & $\mathrm{k}$ & $\mathrm{b}$ & $\mathrm{d}$ & $\mathrm{g}$ & $\mathrm{m}$ & $\mathrm{n}$ & ng & 1 & $\mathrm{r}$ & $\mathrm{tx}$ & W & $\mathrm{j}$ \\
\hline $\mathrm{p}$ & & $\mathrm{pt}$ & $\mathrm{pk}$ & & & & & & & & & $\mathrm{ptx}$ & & \\
\hline $\mathrm{t}$ & tp & & tk & & & & & & & & & & & \\
\hline $\mathrm{k}$ & $\mathrm{kp}$ & $\mathrm{kt}$ & & & & & & & & & & & & \\
\hline$b$ & & & & & & & & & & & br & & & \\
\hline d & & & & & & & & & & & & & & \\
\hline $\mathrm{g}$ & & & & & & & & & & $\mathrm{gl}$ & gr & & & \\
\hline $\mathrm{m}$ & $\mathrm{mp}$ & $\mathrm{mt}$ & $\mathrm{mk}$ & & & & & $\mathrm{mn}$ & mng & & $\mathrm{mr}$ & & & \\
\hline $\mathrm{n}$ & $\mathrm{np}$ & $\mathrm{nt}$ & nk & & & & $\mathrm{nm}$ & & nng & & & $n t x$ & & \\
\hline $\mathrm{ng}$ & ngp & ngt & ngk & & & & ngm & ngn & & & ngr & ngtx & ngw & \\
\hline 1 & & & & & & & & & & & & & & \\
\hline $\mathrm{r}$ & & & & & & & & & & & & & & \\
\hline
\end{tabular}




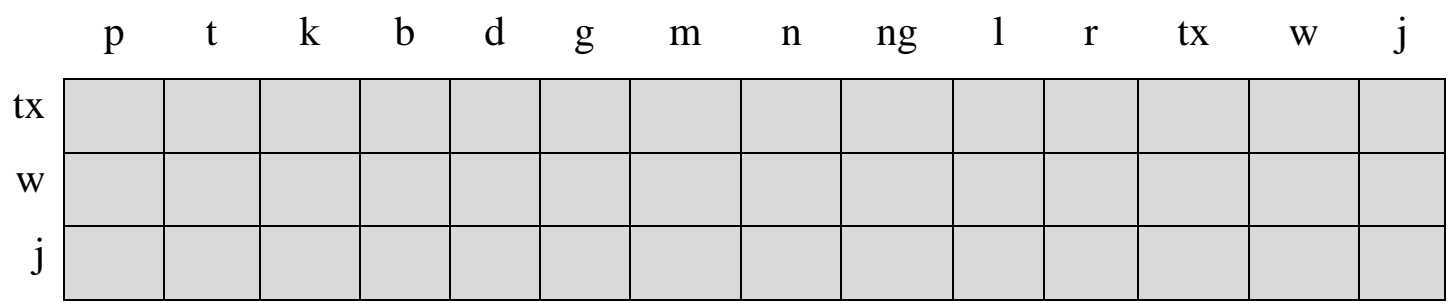

\subsection{ENCONTROS VOCÁLICOS}

As sequências de vogais verificadas no interior de morfemas não derivados são apresentadas na tabela 2.6. Exemplos são fornecidos em (3). Não foram encontradas sequências de vogais homorgânicas, exceto a palavra mok que apresenta a variante longa mook 'terceira pessoa anafórica'.

Tabela 2.6 - Encontros consonantais internos ao morfema

\begin{tabular}{l|l|l|l|l|l|l|}
\multicolumn{1}{c}{ a } & \multicolumn{1}{c}{ e } & i & o & y & \multicolumn{1}{c}{ u } \\
\cline { 3 - 7 } a & & ae & ai & & & au \\
\cline { 2 - 7 } e & & & ei & eo & & eu \\
\cline { 2 - 7 } i & ia & ie & & io & & iu \\
\cline { 2 - 7 } y & & oe & oi & & & ou \\
\cline { 2 - 7 } y & ya & ye & yi & & & \\
\cline { 2 - 7 } u & ua & ue & ui & uo & & \\
\cline { 2 - 7 } & & & &
\end{tabular}

(3)

a) a.e 'abelha sp.', pa.i.me 'casado', a.ut 'costela'

b) ka.re.i ${ }^{22}$ 'não.indígena', Peo NOM.PROP, ty.me.u.re 'paca'

c) a.bi.a.na 'quaixada', pu.mi.e 'mulher', na.bi.ot 'batata', e.bi.u 'ponte'

d) o.no.e 'árvore.sp', ot.ko.i.mo 'tatu sp.', po.u 'caititu'

e) im.py.a.txi 'braço', my.e 'bolsa, sacola', ta.ky.i 'farinha'

f) i.du.a 'mata', e.du.et 'rede dele', i.mu.in 'casco', ku.o 'sapo sp.'

${ }^{22}$ A pronúncia varia entre [karei $\sim$ karej] 


\subsection{NOTA SOBRE O ACENTO}

O acento ocorre sempre na última sílaba da palavra, tanto em palavras dissilábicas, quanto trissilábicas e polissilábicas em geral, inclusive, em palavras derivadas, conforme apresentado nos exemplos em (4), (5), (6) e (7), respectivamente.

(4)

a) [pa.'ma] 'Pama'

b) [ta.'mu] 'Cigarro, tabaco'

c) [ka.'na] 'Cana de açúcar' (empréstimo)

a) [pu.ru. 'wa] 'Pupunha do mato'

b) [ta.ku. 'i] 'Farinha'

c) [o.go.'i] 'Cobra (genérico)'

d) [ka.ja.'tu] 'Maracanã'

(6)

a) [ta.gan.ta.' ga] 'Borboleta'

b) [tw.run.du. 'run] 'Nambu sp.'

c) [i.røу.mu.' $\eta$ 'Areia'

g) [i.wa.ka.'til] 'Nádega(s)'

h) [i.wa.ka.ti.' ’o] 'Nádega(s)'

i) $[u . ' d J] \quad$ 'Vá!'

j) [u.ds.' 'lm] 'Ele foi embora'

k) [u.ds.luy.'mo] 'Eles foram embora'

\subsection{PROCESSOS MORFOFONOLÓGICOS}

Os processos morfofonológicos apresentados a seguir são: assimilação, palatalização, africativização, dissimilação, redução silábica e ablaut. 


\subsubsection{Assimilação}

A assimilação consiste no principal processo morfofonológico identificado. Há assimilação da nasalidade e da sonoridades nos contextos descritos a seguir.

Ocorre assimilação da sonoridade em dois ambientes: em fronteira de palavra e entre afixos e raiz. Oclusivas em fronteira de palavras, contexto intervocálico ou entre vogal e glide, são realizadas, obrigatoriamente, sonoras. Nestes ambientes, /p, t, k/ são realizados de forma lenis $^{23}$ ('fraca'), a qual é caracterizada foneticamente pela diminuição da duração e perda da explosão espontânea (burst). Exemplos, retirados de Ferreira Alves (2013, p. 217), são apresentados a seguir:

\begin{tabular}{|c|c|c|c|}
\hline /kuгер отго/ & $\rightarrow$ & kure [ $\boldsymbol{\beta}]$ omø & 'você é bonito/a \\
\hline /paebra piget/ & $\rightarrow$ & pacbra [ $\boldsymbol{\beta}]$ iget & 'um pouco verde' \\
\hline /pone tarik/ & - & pone [ d ] arik & 'piranha grande' \\
\hline /wampiat wanpel & $\rightarrow$ & wãpia [ $\mathbf{d}]$ wanpe & ‘açaí está grosso’ \\
\hline /pilik jamit/ & 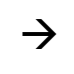 & pili [ $\boldsymbol{\Psi}$ ] jamut & ‘criação da Pilik' \\
\hline /wauri kurep/ & $\rightarrow$ & wauri [ м ] urep & 'bacaba está gostosa \\
\hline
\end{tabular}

Entre morfema afixal e raiz, o processo de assimilação da sonoridade também é obrigatório. Este processo é verificado, por exemplo, quando ocorre prefixação de morfema de pessoa, criando um contexto intervocálico, como demonstrado nos exemplos em (9). Algumas exceções foram observadas no corpus ${ }^{24}$.
a) pilepte
b) $\quad$-bilepten
c) arun tempulu
d) ty-dempulu
'Garganta de guariba'
'Garganta dele mesmo'

\footnotetext{
${ }^{23}$ Odden (2005) define assimilação como um processo pelo qual dois segmentos se tornam mais parecidos porque um segmento toma uma ou mais características de um segmento vizinho. Dentro da seção sobre assimilação, o autor apresenta a lenição (ou enfraquecimento) como a interação segmental mais comum entre consoantes e vogais ou, às vezes, outras sonorantes, sendo que o processo está fora do domínio das assimilações de lugar/ponto de articulação. Exemplos típicos de lenição envolvem o vozeamento de oclusivas surdas, ou o vozeamento e a africativização (spirantization) de oclusivas.

${ }^{24}$ Para maiores detalhes ver Ferreira Alves (2013).
} 
e) Pilik kokunangry
'Está chamando a Pilik'

f) i-gokuk

'Chama!'

A assimilação da sonoridade em contexto pós-nasal ocorre apenas no dialeto Arara. Neste caso, uma consoante nasal causa a sonorização de oclusivas e da africada que as seguem, como ilustrado nos exemplos (10). Esta assimilação ocorre i) dentro de morfema não derivado (sem morfologia de flexão ou derivação), como em (10a), ii) em fronteira de morfema, (10b), e iii) em fronteira de palavra, (10c). Os exemplos a seguir ilustram a diferença verificada entre os dialetos Arara e Iriri. As consoantes nasais sobrescritas indicam a elisão opcional da consoante nasal ( ver subceção 2.7.5.3).

Variante Arara Variante Iriri

a) /poreyko $/ \quad \rightarrow \quad\left[p \supset r \varepsilon^{\eta}\right.$ 'go] $\quad\left[p o r \varepsilon^{\eta}\right.$ 'ks] 'Tamanduá sp.'

b) $/ k o$-an-tfal $\rightarrow \quad\left[k^{w} a^{n}\right.$ 'dza] $\rightarrow \quad\left[k^{w} a^{n}\right.$ 'tfa] 'Eu vou te levar'

c)/imren pitfin/ $\rightarrow$ [umren butfin] [umrenputfin] 'Ele/a morreu'

A assimilação da nasalidade, por seu turno, é realizada por oclusivas que precedem uma consoante nasal em ambos os dialetos. Isto ocorre tanto em fronteira de palavra, como em (11a), quanto em fronteira de mofemas presos, (11b) e (11c).
a) Jjeduet\#moro/ $\rightarrow$ jeduc[n] moro 'Aquela é minha rede'
b) lip-nayritl $\rightarrow$ i[m]nayru (Ele/a) vai banhar'
c) luk-mayartl $\rightarrow$ u[y]mayarm 'Nosso (incl.) peito'

\subsubsection{Palatalização}

Ocorre palatalização dos fonemas /t/ e /n/ diante de glide palatal /j/ ou vogal alta anterior /i/. A palatalização de /t/ é obrigatória, enquanto a de /n/ é opcional. Os exemplos são de Ferreira Alves (2013, p. 271).
a) lonat\#jodo/ $\rightarrow$ ona[t]] Jds 'Dono do milho'
b) /kut-iptal $\rightarrow$ ku[t]]ipta 'nós vamos tomar banho'
c) lenibeyril $\rightarrow$ e[n]ibeyri '(ele/a) carregou' 
d) linikodinil $\rightarrow$ i[n]iksrini 'eu cortei (ela/a)

\subsubsection{Africativização}

O fonema $/ \mathrm{j} /$ diante de $/ \varepsilon /$ ou $/ \mathrm{u} /$ pode ser, opcionalmente, africativizado em fronteira de palavra apenas quando a palavra anterior terminar em consoante, conforme exemplos em (13), extraídos de Ferreira Alves (2013, p. 271).
a) /womium\#jepil
$\rightarrow$ womium $[t \boldsymbol{t}]$ epi
'Casca de banana'
b) /Wiwik\#jedegumril
$\rightarrow \quad$ Wiwik[t]]cdegumru
'Joelho da Wiwik'
c) /idem\#jumi/
$\rightarrow \quad$ idem[t]]umi
'comida do teu marido'

\subsubsection{Dissimilação}

As vogais médias /e, o/ se tornam altas ([i, u], respectivamente) diante da vogal central baixa /a/, em fronteira de morfema, como nos exemplos (15). Souza, S. (2010, p. 116-117) também descreve o fenômeno de alçamento para o dialeto Arara.
a) /jetpe-aytel
$\rightarrow$ [jetpiangte]
'Eu pisei'
b) lobage-aytom\#kal $\rightarrow$ [obagiaytomka]
'Vocês acordaram?'
c) /tukto-aktfi/
$\rightarrow \quad$ [tuktuakti]
'Para a roça'
d) /ini-no-anal
$\rightarrow \quad$ [iniuana]
'Eu vou deixar O'

\subsubsection{Redução silábica}

Na família Karib, os estudiosos de várias línguas apontaram o fato de que vogais ou sílabas ora aparecem ora desaparecem. Inicialmente, este fenômeno foi tratado como epêntese (Cf. KOEHN; KOEHN (1986) para Apalaí, DERBYSHIRE (1985) para Hixkaryana, entre outros). Por outro lado, Gildea (1995) demonstrou detalhadamente a pertinência de uma análise unificada de redução silábica, possivelmente, para toda a família linguística, o que é reiterado 
em Gildea (2012). Este autor utiliza dados de cinco línguas do ramo norte (cujo ambiente prosódico/morfológico condicionante da redução silábica é o mesmo) para fundamentar sua generalização. De acordo com a análise de Gildea, a elisão consiste apenas em um dos estágios da redução silábica. Ele enfatiza ainda que a generalização só foi possível a partir de um estudo diacrônico, pois apenas o estudo sincrônico de uma dada língua pode deixar o analista sem informações suficientes para identificar que os processos observados fazem parte de um fenômeno maior.

A expressão redução silábica foi cunhada pela primeira vez por Mattéi Muller (1980) e adotada por Gildea (1995) para descrever um processo com vários estágios que envolvem a elisão de segmentos. Posteriormente, Álvares (2000), independentemente, também chega à conclusão de que uma análise a favor do processo de elisão é superior à de epêntese, que antes do reconhecimento da conexão dos processos entre as línguas, fora dada como possível explicação para as alomorfias. Conforme explicado em Meira (1999) para a língua Tiriyó, o processo de redução silábica se refere a um padrão em que alomorfes diferem por um segmento ou uma sílaba, os quais são apagados. De acordo com o autor, tal apagamento é, geralmente (mas nem sempre), condicionado pela forma da sílaba adjacente e pode ser no início da raiz, quando ela recebe um prefixo, ou no final, quando ela recebe um sufixo, sendo este último o caso mais frequente.

A seguir são elencados os pontos gerais do processo em final de raiz, segundo Gildea (1995):

(I) Todos os sufixos que apresentam a forma -CV causam redução, exceto as formas modernas do morfema reconstruído **-ri 'nominalizador de ação' que é postulado como o morfema que possibilita identificar a forma longa da raiz;

(II) A forma longa está sujeita a uma sequência de processos em contextos que causam a redução. Suscintamente, o processo inicia-se com a vogal final da raiz sendo elidida e formando um encontro consonantal com a primeira consoante do sufixo -CV. Este encontro consonantal, dependendo da língua, pode sofrer outros processos como dissimilação, debucalização ${ }^{25}$ ou a simples elisão de uma das consoantes, deixando como resquício uma consoante longa ou uma ${ }^{25}$ 'Loss of supralaryngeal features, with the consonant dropping back and down in the oral cavity (GILDEA 1995,
p. 84)' 
consoante intervocálica fortis (oposta a consoantes lenis, que são sonorizadas em contexto intervocálico de acordo com esta hipótese).

\subsubsection{Vogais altas}

Para línguas do ramo Pekodiano, ainda não há descrições detalhadas sobre a redução silábica. Em Arara, vários processos de elisão são identificados, incluindo os estágios descritos em Gildea (1995). Conforme demonstrado a seguir, a redução silábica é responsável por uma parte significativa das alomorfias que afeta tanto morfemas de raiz quanto morfemas sufixais. Segundo a hipótese de redução silábica em final de raiz, apenas raízes/radicais cujo último segmento consiste em uma vogal alta são passíveis de elisão. Em Arara, estas vogais correspondem a /i, u, y/ as quais são elididas quando a raiz (ou o radical) é anexada por morfemas -CV ou iniciados por essa sequência.

A redução não ocorre diante do morfema de passado $\left\{-l y \sim-n y^{26} \sim r y\right\}$ que seria um reflexo moderno de $*_{-}^{*} r i$ 'nominalizador de ação'. O processo também é vetado se sua ocorrência causar a formação de um tipo silábico não permitido na língua. Assim, vogais precedidas de encontros consoantais, por exemplo, não sofrem a redução, já que a elisão do segmento vocálico poderia criar o encontro de três consoantes ou uma palavra com dois encontros consonantais. O corpus analisado apresenta um conjunto de alomorfes resultantes do processo de redução o qual é apresentado na tabela 2.7. A primeira coluna mostra a forma longa, obtida pelo acréscimo dos morfema de passado (quando não há redução) e as demais colunas ilustram a forma curta dessas raízes (quando há redução), além da glosa da raiz.

Tabela 2.7 - Raízes curtas e longas

\begin{tabular}{|c|c|c|c|}
\hline $\begin{array}{c}\text { Raiz afixada } \\
\text { por } \\
\{-l y\} \text { PSD.IMD }\end{array}$ & \multicolumn{2}{|c|}{$\begin{array}{c}\text { Raiz afixada por morfemas } \\
\text { (iniciados por) }-\mathrm{CV} \text { : } \\
\{\text {-ty }\} \text { COL, }\{\text {-nangry }\} \text { IPFV, } \\
\{\text {-tak }\} \text { IPFV.PSD }\end{array}$} & Glosa da raiz \\
\hline agu-ly & $a \boldsymbol{k}-t y-k$ & ang-nangry & 'comer O' \\
\hline origu-ly & orik-ty-k & oring-nangry & 'dançar' \\
\hline$i$-mongogu-ly & $i$-mongok-ty- $k$ & i-mongong-nangry & 'esperar O' \\
\hline$i-\operatorname{det} x i-n y$ & $i$-de-tyk & kuni-de-tak & 'responder O' \\
\hline
\end{tabular}

\footnotetext{
${ }^{26}$ Há variação livre entre $\{-l y \sim-n y\}$ verificada apenas no dialeto Iriri. No dialeto Arara, a única forma existente é $\{-l y\}$.
} 


\begin{tabular}{|c|c|c|c|}
\hline $\begin{array}{c}\text { Raiz afixada } \\
\text { por } \\
\{-l y\} \text { PSD.IMD }\end{array}$ & \multicolumn{2}{|c|}{$\begin{array}{c}\text { Raiz afixada por morfemas } \\
\text { (iniciados por) }-\mathrm{CV} \text { : } \\
\{\text {-ty }\} \text { COL, }\{\text {-nangry }\} \text { IPFV, } \\
\{\text {-tak }\} \text { IPFV.PSD }\end{array}$} & Glosa da raiz \\
\hline abotxi-ny & $a b o-t y-k$ & abo-nangry & 'segurar O' \\
\hline odetxi-ny & ode-ty-k & kun-te-tak & 'casar', 'embarcar' \\
\hline itxi-ny & $i-t y-k$ & kun-i-tak & 'deitar' \\
\hline etxi-ny & $\boldsymbol{e}-t y-k$ & kun-e-tak & 'buscar O' \\
\hline alumy-ny & alum-ty- $k$ & alum-nangry & 'pular' \\
\hline omomy-ny & omom-ty-k & kun-omom-tak & 'entrar' \\
\hline angkody-ny & angko-ty- $k$ & angko-nangry & 'cortar O' \\
\hline eneby-ny & enep-ty- $k$ & enem-nangry & 'trazer O' \\
\hline
\end{tabular}

Como podemos perceber na tabela 2.7, outros processos causam modificação das raízes, contribuindo para a existência de mais de uma forma da mesma raiz diante de diferentes sufixos. Um desses processos consite na assimilação da nasalidade, como no caso das raízes para 'dançar', origu+nangry $\rightarrow$ orig +nangry $\rightarrow$ oring-nangry, e para 'esperar' i-mongogu-nangry $\rightarrow i$-mongog-nangry $\rightarrow$ i-mongong-nangry. Com relação à criação de oclusivas fortis (opostas às oclusivas lenis), de acordo com nossa hipótese, o encontro de duas consoantes oclusivas homorgânicas, mesmo após a queda de uma delas, deixa a fonotática de encontro consoantal, impedindo a lenição. Assim, temos as oclusivas surdas da segunda coluna e o caminho de processos morfofonológicos que se inicia com a elisão da vogal final da raiz, quando esta é anexada por afixo - CV, seguida da perda da palatalização (possivelmente originada pela vogal i) e, subsequente, queda da consoante homorgânica, como na raiz para 'segurar': abotxi-ty- $k \rightarrow$ abot-ty-k $\rightarrow$ abotyk.

Além das alomorfias das raízes, veja que alguns morfemas sufixais também apresentam formas curtas e longas, conforme demonstrado na tabela 2.8 .

Tabela 2.8 - Formas sufixais curtas e longas (negrito)

\begin{tabular}{|c|c|c|c|}
\hline $\begin{array}{l}\text { Morf. sufixal } \\
\text { seguido por } \\
\{- \text {-ly }\} \text { PSD.IMD }\end{array}$ & \multicolumn{2}{|c|}{$\begin{array}{l}\text { Morfema sufixal seguido por } \\
\text { morfemas (iniciados por) -CV: } \\
\{\text {-ty }\} \text { COL e }\{\text {-tak }\} \text { IPFV.PSD }\end{array}$} & Glosa da raiz \\
\hline erang-noby-ny & erang-nop-ko & erang-nop-ty-k & 'assustar O' \\
\hline i-dagi-numy-ny & $i$-dagi-num-ko & kuni-dagi-num-tak & 'assobiar' \\
\hline igak-tumy-ny & igak-tum-ko & igak-tum-ty-k & 'sair, correr' \\
\hline
\end{tabular}


Note que o entendimento da redução silábica é essencial para a análise das alomorfias tanto das raízes quanto das flexões de TAM em Arara, possibilitando a verificação das formas básicas desses morfemas.

Ainda como consequência do processo de redução silábica, verificamos a formação dos alomorfes $^{27}$ sufixais -kom e -ngmo PL/COL. Ambos os alomorfes são derivados da forma **-komo após dois tipos de redução silábica em contextos previsíveis. A adição deste sufixo a raízes terminadas em consoante causou a elisão da última vogal para evitar o encontro de três consoantes, dando origem à forma -kom $(* *-k o m o \rightarrow-k o m / C C)$, enquanto após raízes terminadas em vogal provocou a queda da antepenúltima vogal e a consequente nasalização da oclusiva velar, originando o alomorfe -ngmo $\left(* *_{-}\right.$komo $\rightarrow-k m o \rightarrow-n g m o /$ V). Exemplos dos alomorfes são apresentados em (16a) e (16b), após consoantes, e em (16c) e (16d), após vogais.
a) owem-kom
'Bagagem de vocês'
b) ugon-kom
'Homens'
c) otxingo-ngmo
'Casas'
d) pumie-ngmo
'Mulheres, mulherada'

Diante do morfema permissivo, um sufixo diferente de $-\mathrm{CV}$, o processo de redução, possivelmente, está se generalizado. Isto porque a afixação do sufixo permissivo $\{-a\}$ causa elisão, embora apenas da vogal alta posterior não arredondada $\boldsymbol{y}^{28}$. Exemplos são oferecidos na tabela 2.9. Este fato difere do que ocorreu com as línguas Karib do Norte que mantiveram a forma longa diante deste sufixo.

Tabela 2.9 - Elisão da vogal $\boldsymbol{y}$

\begin{tabular}{|l|l|l|}
\hline $\begin{array}{c}\text { Raiz afixada por } \\
\{-l y \sim-n y\}\end{array}$ PSD.IMD & $\begin{array}{c}\text { Raiz afixada por } \\
-\mathrm{V}:\{-a\} \text { PERM }\end{array}$ & Glosa da raiz \\
\hline alumy-ny & $n$-alum- $a$ & 'pular' \\
\hline omomy- $n y$ & $n$-omom- $a$ & 'entrar' \\
\hline
\end{tabular}

\footnotetext{
${ }^{27}$ Souza, S. (2010, p.65) considera esta alomorfia um caso de supleção em Arara. Em Ikpeng, o morfema cognato é tratado como um caso de metátese ( $C f$. PACHECO 2001, p. 48). Veja que adotar para o Arara o mesmo tratamento dado ao Ikpeng não seria suficiente para explicar a forma do alomorfe -ngmo. Seria necessário acrescentar a posterior ocorrência de nasalização da oclusiva velar (-kom > -kmo > -ngmo) após a metátese. Porém, a metátese em si seria um processo válido apenas para o sufixo -kom, enquanto a redução silábica consiste em um fenômeno muito mais geral.

${ }^{28}$ Duas exceções são encontradas no corpus. Uma é a raiz para 'amarrar' que, em geral, mantém a vogal $\boldsymbol{y}, i$-momyny [3O-amarrar-PSD.IMD]'amarrou O', i-momy- $k$ [3O-amarrar-IMP] 'amarra-o!', ni-momy-a [3-amarrar-PERM] 'Deixa-o amarrar'; e a outra exeção é a raiz para 'falar', Ø-edady-ly [30-falar-PSD.IMD] 'falou', Ø-edady- $k$ [3-falarIMP] 'fala!', j-edady-ang-ne [1A-falar-IPFV.PSD-PSD.DST] 'eu falava'.
} 


\begin{tabular}{|l|l|l|}
\hline $\begin{array}{c}\text { Raiz afixada por } \\
\text {-ly } \sim-n y\} \text { PSD.IMD }\end{array}$ & $\begin{array}{c}\text { Raiz afixada por } \\
-\mathrm{V}:\{-\boldsymbol{a}\} \text { PERM }\end{array}$ & Glosa da raiz \\
\hline $\begin{array}{l}\text { angkody- } n y \\
\text { eneby- } n y\end{array}$ & $n$-angkod- $a$ & 'cortar O' \\
\hline
\end{tabular}

Por outro lado, as vogais altas $\boldsymbol{i}, \boldsymbol{u}^{29}$ não são elididas diante do mesmo sufixo $\{-a\}$, como demonstrado na tabela 2.10. Veja que, se a vogal $i$ houvesse sido deletada neste contexto, verificaríamos a perda da palatalização da consoante que a antecede, visto que, historicamente as africadas surgiram a partir da palatalização das consoantes oclusivas alvelares diante de segmentos palatais. Note também que a redução não ocorre diante do permissivo, mas ocorre diante de sufixos $-\mathrm{CV}$, conforme esperado. Isto pode ser obervado nas colunas 3 e 4 (copiadas da tabela 2.7, por conveniência). Sincronicamente, como já mencionado, consideramos que a perda da palatalização indica uma consoante cuja forma subjacente é alveolar, enquanto os casos em que não ocorre esta variação entre africada e alveolar indicam a ocorrência de uma consoante subjacentemente africada. Porém, há casos em que não é possível afirmar sem dúvidas qual seria a forma subjacente ${ }^{30}$.

Tabela 2.10 - Manutenção das vogais $\boldsymbol{i}, \boldsymbol{u}$ diante do morfema permissivo $\{-a\}$

\begin{tabular}{|c|c|c|c|c|}
\hline $\begin{array}{l}\text { Raiz afixada por } \\
\{-l y \sim-n y\} \text { PSD.IMD }\end{array}$ & $\begin{array}{l}\text { Raiz afixada por } \\
-\mathrm{V}:\{-a\} \text { PERM }\end{array}$ & \multicolumn{2}{|c|}{$\begin{array}{c}\text { Raiz afixada por }-\mathrm{CV}: \\
\{- \text { ty }\} \text { COL, }\{\text {-nangry }\} \text { IPFV, }\{- \\
\text { tak }\} \text { IPFV.PSD }\end{array}$} & $\begin{array}{l}\text { Glosa da } \\
\text { raiz }\end{array}$ \\
\hline$i$-detxi-ny & $n i-\operatorname{det} x i-a$ & $i-d e-t y k$ & kuni-de-tak & 'responder O' \\
\hline abotxi-ny & n-abotxi-a & $a b o-t y-k$ & abo-nangry & 'segurar O' \\
\hline odetxi-ny & n-odetxi-a & ode-ty-k & kun-te-tak & $\begin{array}{l}\text { 'casar', } \\
\text { 'embarcar' }\end{array}$ \\
\hline itxi-ny & $n$-itxi-a & $i-t y-k$ & kun-i-tak & 'deitar' \\
\hline agu-ny & n-agu-a & $a-k o$ & kun-ak-tak & 'comer O' \\
\hline$i$-mongogu-ny & $n i-m o n g o g u-a$ & $i$-mongo-ko & kun-mongok-tak & 'esperar O' \\
\hline
\end{tabular}

A seguir são apresentados os casos de ocorrência de redução silábica na posição inicial da raiz.

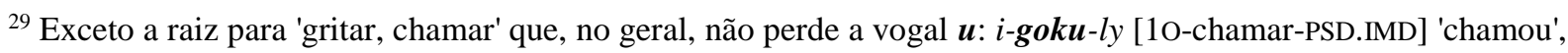
$i$-gogku-a [3-chamar-IMP.ALA] 'chama lá', $i$-goku- $k$ [3-chamar-IMP] 'chama-o!'

${ }^{30}$ Por outro lado, a forma da raiz etxi 'buscar O' apresenta a versão longa apenas com o passado distante. Com o permissivo ocorre uma forma diferente das que ocorrem com outros morfemas, pois ocorre não apenas a perda da palatalização, mas também a assimilação da sonoridade an-ed-a [3-buscar-PERM]. Este caso necessita mais de investigações.
} 
Vogais altas em posição inicial da raiz também sofrem redução. Há elisão das vogais altas $\boldsymbol{u}, \boldsymbol{y}, \boldsymbol{i}$ na primeira sílaba $\mathrm{CV}(\mathrm{C}=$ oclusiva com dissolução oral ou nasal $)$ da palavra quando a raiz recebe prefixo vocálico $\mathrm{V}$-. Os exemplos em (17) mostram, na primeira coluna, formas antes da elisão (quando são possuídas por um sintagma nominal) e, na segunda coluna, as formas de citação que são as anexadas pela terceira pessoa $i$-. Os exemplos são de Ferreira Alves (2013, p. 275).
a) $/ N P$ munu/
$\rightarrow$ i-mnu 'Carne'
b) INP pirintal
$\rightarrow$ i-brunta 'Outro, parceiro'
c) INP midabriyo/
$\rightarrow \quad i$-mtabri 'Comida'
d) INP pitfin/
$\rightarrow$ i-ptin 'Canela'

No mesmo contexto, não há elisão de outras vogais, conforme demonstrado nos exemplos oferecidos a seguir:
a) INP panan/
$\rightarrow$ i-banan 'Orelha'
b) INP poril
$\rightarrow$ i-borm 'Boca'
c) INP pet/
$\rightarrow \quad$ i-bet
'Coxa'

Também não há elisão quando a palavra já possui um encontro consonantal. Esta restrição fonotática impede a formação de um encontro entre mais de duas consoantes, como ilustrado em (19)
a) INP tukton/
$\rightarrow \quad i$-dukton
'Roça'
b) INP pilepten/
$\rightarrow$ i-bulepten 'Faca'

A adoção da hipótese de elisão ajuda a compreender o processo de fonogênese de consoantes oclusivas surdas e sonoras da língua. Se as conjecturas estiverem corretas, a regra de sonorização intervocálica explica o surgimento de oclusivas sonoras enquanto o encontro de oclusivas surdas, ocasionado por elisão, poderia ser a origem de oclusivas surdas no mesmo ambiente. Argumentos para esta análise são apresentados em Ferreira Alves (2010b, 2013). A hipótese de fonogênese é baseada em Meira (2005) para Bakairi. Ademais, Ferreira Alves e 
Gildea (2016) ${ }^{31}$ incluem Arara na discussão apresentada em Gildea (2012) sobre o processo de vozeamento intervocálico combinado à redução silábica para criar a distinção fortis-lenis de obstruentes.

\subsubsection{Vogais não altas}

Ocorre elisão das vogais /o, a/ em contextos específicos. Pode ocorrer elisão não obrigatória da vogal /o/ quando seguida pelo sufixo /-ang/. Observe que tal elisão, possivelmente, consiste no último estágio de um processo que se inicia com o alçamento. Como demonstrado anteriormente, /o/ passa a /u/ diante da vogal /a/ quando em fronteira de morfema. Em seguida, pode haver supressão da vogal alçada. Os exemplos em (20a) e (20b) demonstram que a elisão ocorre nos níveis da palavra gramatical e da palavra fonológica, respectivamente.

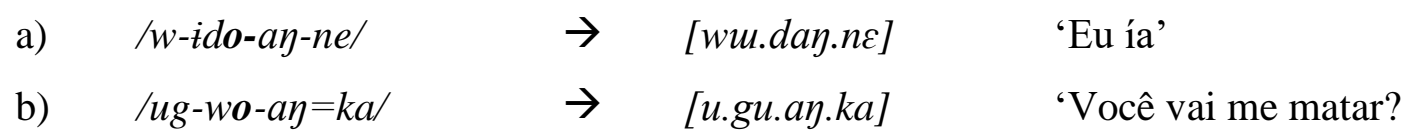

Além disso, ocorre elisão em final de palavra e fronteira de palavras, independente da vogal que segue, a qual permanece na ressilabificação.

\begin{tabular}{|c|c|c|c|c|}
\hline a) & Itfimna\#eneytaynel & $\rightarrow$ & 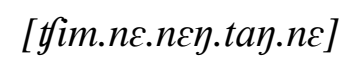 & 'Nós víamos' \\
\hline b) & lak\#pira\#urol & $\Rightarrow$ & [ak.pu.ru.ro] & 'Eu não comi’ \\
\hline c) & /monto\#ikpun/ & $\rightarrow$ & [mõt.ik.pun] & 'Lá onde não havia rio' \\
\hline d) & /woyo\#odol & 2 & [wo.yว.do] & \\
\hline
\end{tabular}

\subsubsection{Consoantes}

Ocorre elisão de consoantes homorgânicas ou que apresentam o mesmo ponto de articulação da oclusiva que segue. A elisão de segmentos consonantais homorgânicos ocorre,

\footnotetext{
${ }^{31}$ FERREIRA ALVES; GILDEA (2016). The creation of a fortis-lenis alternation in Akawaio and Arara (Cariban). Apresentação oral no colóquio internacional AMAZÔNICAS VI, ocorrido de 24 a 28 de Maio de 2016, na Universidade Nacional da Colômbia.
} 
em fronteira de morfema preso e clítico, como em (22a) e (22b) ou em fronteira de palavras. Souza, S. (1993, p.8) já havia apresentado esta elisão no dialeto Arara.
a) $\quad$ i-bi-t=lon/ $\rightarrow \quad[i b u=l o n]$
3 -esposa-POSS $=\mathrm{FOC}$
'Esposa mesmo'
b) Imogin=lon/ $\rightarrow \quad$ [mogu=lon]
DEIT.ANIM=FOC

'Esse mesmo'

c) linga moy tan pudek kak. Kun-te-aduk/

sim DEIT aqui parecido QU 3PSD.DST-dizer-ASP.IPFV.PL

'É assim, né? Eles respondiam.'

[unga moy tan pude kak. $\left.k u^{n} t \int a d u k\right]$

O apagamento não obrigatório de consoante nasal de mesmo ponto de articulação da oclusiva que a segue é exemplificado em (23). Observe nos exemplos que, embora o segmento nasal seja elidido, a nasalidade é retida pela vogal que o precede. A representação fonética utilizada será uma consoante nasal sobrescrita à vogal. Os exemplos são provenientes de Ferreira Alves (2013, p. 276).
a) linkep/ $\rightarrow$ [i' $\left.{ }^{n} k p\right] \quad$ 'Mentira'
b) lintok/ $\rightarrow \quad\left[\boldsymbol{u}^{n}\right.$ tok] 'Onde'
c) lentol $\rightarrow \quad\left[e^{n} t o\right] \quad$ 'Aqui'
d) limpiatil $\rightarrow \quad\left[i^{m}\right.$ puatil $]$ 'Braço'

\subsubsection{O ablaut e morfemas de pessoa}

Conforme demonstram Meira, Gildea e Hoff (2010), o fenômeno conhecido como ablaut é pervasivo na família Karib. Segundo os autores, este processo morfológico/morfofonológico, que corresponde a um padrão de alternância vocálica, ocorre apenas na posição inicial de radicais de nomes possuídos, verbos e posposições flexionados. Ele seria condicionado, historicamente, por elementos palatais que, subsequentemente, foram perdidos. De acordo com o maior número de formas no paradigma de cerca de 21 línguas, foram 
identificados dois padrões: I) o 'padrão posterior', caracterizado pela predominância de $\partial$ ou $o$ em posição inicial da raiz e II) o 'padrão anterior' ${ }^{32}$, caracterizado pela predominância de $e$ na mesma posição. Os mesmos autores classificaram Arara entre as línguas de padrão anterior. Esta seção demonstra que a classificação proposta se confirma.

Dentre os dados analisados (66 itens), as raízes de nomes possuíveis, que tem segmentos vocálicos na posição inical da palavra, apresentam, majoritariamente, as vogais $a$ (10 itens) ou $e$ (18 itens) nesta posição ${ }^{33}$. Além disso, tais itens mostram um padrão de alternância vocálica que dificulta saber qual a forma básica da raiz. A raízes iniciadas por $e$, possivelmente, passaram pela alternância $o \rightarrow e$ e, dentre as raízes iniciadas por $a$, estão aquelas que sofreram a alternância $o \rightarrow a$. O primeiro tipo de alternância é visível comparando-se:

(I) O paradigma de nomes possuídos com a forma não possuída;

(II) A forma flexionada na terceira pessoa reflexiva e

(III) As formas derivada por $t-\ldots-k e, t-\ldots-t e, t-\ldots-r e e^{34}$.

Exemplos são oferecidos em (24), (25) e (26), respectivamente:

(24) Alternância $o \rightarrow e$ (Forma não possuída e paradigma)

a) ong-ru-ngo

olho-POSS-NPOSS

'Olho'

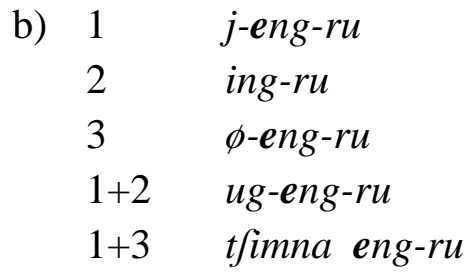

(25) Terceira pessoa reflexiva

t-ong-ru

3REFL-Olho-POSS

'Olho dele mesmo'

\footnotetext{
32 'Front-grade, back-grade'.

${ }^{33}$ Vogal $o$ (1), vogal $i(1)$, consoantes (36).

${ }^{34}$ Morfemas derivacionais que apresentam cognatos em várias línguas, mas com diferentes desdobramentos em cada uma.
} 


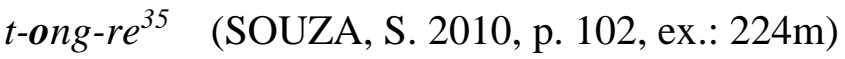

ADV-olho-ADV?

'Tendo olho, com olho ${ }^{36}$,

Perceba que a forma da segunda pessoa no paradigma das formas possuídas apresenta outro tipo de alomorfia (ingru 'Teu olho'), que vai além da alternância $o \rightarrow e$. Este é o padrão observado para todos os paradigmas que sofrem tal alternância. Nestes casos, optamos por descrever a pessoa juntamente com a raiz, isto é, ing-ru [2olho-POSSD]. Souza, I. (2010) se refere ao fenômeno em que o + e $\rightarrow$ i como fusão. Souza, S. (2010, p. 115), por sua vez, aponta a coalescência ${ }^{37}$ como o processo responsável pela vogal $i$. Contudo, esta hipótese é difícil de se sustentar, visto que o segmento resultante de coalescência, geralmente, consiste em um segmento intermediário no espaço vocálico. Por exemplo, na língua Kimatuumbi, /a+u/ $\rightarrow$ [oo]:

Kimatuumbi (ODDEN 2005, p. 245)

(27) pa-ú-kaátité $\rightarrow$ poó-kaátité 'Quando você cortar'

Uma possibilidade de análise plausível consiste na ditongação com perda da vogal inicial $^{38}$. Assim, após o processo histórico de ablaut da vogal da raiz em que o $\rightarrow$ e, a prefixação sincrônica da segunda pessoa nessa raiz causaria uma ditongação: o+engru $\rightarrow$ o-engru [o.eng.ru] $\rightarrow$ o-engru [oeng.ru] $\rightarrow$ o-ingru [oing.ru]. Em seguida, porque a forma da raiz já se tornou diferente das formas com as outras pessoas, a segunda pessoa $o$ - se torna redundante e, assim, passível de queda. Deste modo, temos a forma ingru [ing.ru] por perda do /o/ inicial da palavra.

Ademais, casos deste tipo de alternância vocálica envolvendo a segunda pessoa se repetem no paradigma de morfemas argumentais da série de objeto anexados aos radicais de verbos transitivos e no paradigma dos radicais intransitivos da classe So (Capítulo 5, seções 5.3.1.1.1 e 5.3.1.2). Compare as formas dos radicais transitivo, em (28a) e (28b), e intransitivo, em (29a) e (29b), respectivamente. Consideramos que a semelhança das formas se deve ao

\footnotetext{
${ }^{35}$ Souza, S. (2010) trata este circunfixo como um adjetivizador.

${ }^{36}$ Há dúvidas quanto esta tradução. Alguns exemplos presentes no corpus são typtxigre 'está com diarreia', tymyngre 'está menstruada', tylagagre 'está cuspindo'. Não há tradução na fonte.

37 Este termo é usando tanto na linguística histórica dentre os processos de mudança morfológica ( $C f$. HASPELMATH, 2002, p. 53) quanto na fonética e fonologia ( $C f$. ODDEN, 2005, p. 245). Em ambos os casos, dois elementos dão origem a um que apresenta semelhanças com os segmentos anteriores.

${ }^{38}$ Análise sugerida por Sérgio Meira durante a defesa.
} 
mesmo processo verificado em nominais possuídos, portanto, o mesmo tratamento é dispensado aos radicais verbais flexionados ${ }^{39}$.
a) j-eneng-ry
1A-ver-PSD.IMD
b) ineng-ry
2ver-PSD.IMD
'Eu o vi'
'Ele viu você'

(29)
a) j-eguamy-ny
b) iguamy-ny
1So-sentar-PSD.IMD
2sentar-PSD.IMD
'Eu sentei'
'Você sentou'

\subsection{O DETRAZITIVISADOR \{OTXI- $\}$ E SUAS VARIANTES}

Os alomorfes $\{$ otxi- $\sim$ ot $\}$ ocorrem diante de radicais que iniciam por consoantes, como demonstram os exemplos (30). Note que \{otxi-\} é verificado em raízes licenciadas para o processo de elisão da vogal da primeira sílaba da raiz o que culmina em um encontro consonantal, como em (30a). \{od-\} ocorre diante vogais, conforme apresentado no exemplo (31), e \{on-\}, diante de consoante nasal, como em (32). A distribuição do alomorfe nasal parece ser mais restrita em relação as outras formas, pois foram verificados alguns casos em que o alomorfe otxi- eram usados também diante de nasais, (30d) e (30e). Os contextos de ocorrência são resumidos na estrutura abaixo, seguida dos respectivos exemplos.

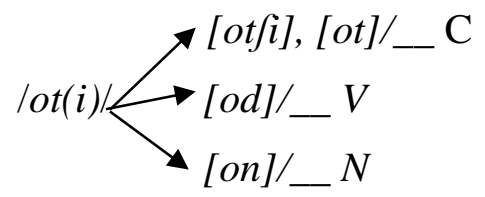

$$
\begin{aligned}
& \text { Ex.: 30a, 30b, 30c, 30d, 30e } \\
& \text { Ex.: 31a, 31b, 31c } \\
& \text { Ex.: 32a, 32b }
\end{aligned}
$$
a) otxi-pkeny
'Se ralou' (no mato)
b) otxi-walatkely 'Virou sozinho'
c) ot-pympotxiny 'Se cobriu'
d) otxi-noly 'Ele/a ficou'
e) otxi-munyny 'Se amarrou'

\footnotetext{
${ }^{39}$ Uma exceção em que a raiz iniciada por /e/ não sofre alteração é o-eriktum-ko [2-sorrir-IMP] 'Sorria!'
} 
(31)

a) od-edentukeny 'Se desatou'

b) 'od-agely 'Se cortou'

c) od-eganobyly 'Se falaram'

a) on-mokuly 'Um cheirou o outro'

b) on-mongoguny 'Um esperou o outro'

\subsection{MORFEMAS ARGUMENTAIS E SUAS VARIANTES}

Esta subseção apresenta de foma unificada os morfemas de pessoa encontrados na conjugação da maioria dos morfemas de TAM. Os processos morfofonológicos anteriormente apresentados são responsáveis pela criação das suas variantes.

Os morfemas $\{o-\}$ ' 20 ', $\{k u t\}$ ' $1+2 \mathrm{~A}$ ', $\{k o-\}$ ' $1 \mathrm{~A} \rightarrow 2 \mathrm{O}$ ' e $\{u g u-\}$ ' $1+2 \mathrm{O}$ ', ' $2 \mathrm{~A} \rightarrow 1 \mathrm{O}^{\prime}$ apresentam alomorfes previsíveis:

\{o-\} 20, 2So: é realizado como uma aproximante labiovelar [w-] diante de vogal central baixa /a/. A realização [o-] ocorre diante de consoantes e da vogal /u/. Diante de raízes iniciadas por /e/ a segunda pessoa é indicada por uma forma supletiva da raiz em que a vogal /e/ passa a /i/. Por exemplo, a raiz eneng 'ver' em j-eneng-ry [1A-ver-PSD.IMD] 'Eu o vi' passa a ineng-ry [2verPSD.IMD] 'Você o viu'. Em raízes iniciadas por /y/ há inserção da consoante temática $\{-w$ - $\}$ entre a raiz e o prefixo; assim a forma [o-], esperada diante de consoante, é verificada, conforme o exemplo (33d). A fórmula abaixo resume os alomorfes de segunda pessoa e seus ambientes de ocorrência ${ }^{40}$. Demais exemplos são oferecidos em (33).

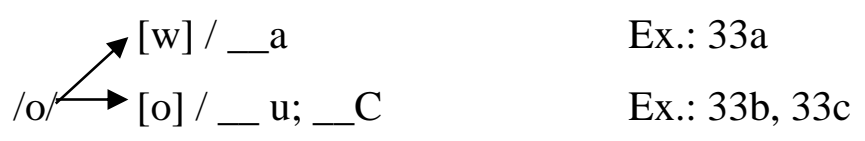

$\begin{array}{llll}\text { a) } & \boldsymbol{w}- & \text { abotxiny } & \text { '(Ele/a) segurou você' } \\ \text { b) } & \boldsymbol{o}- & \text { gokuly } & \text { '(Ele/a) chamou você' } \\ \text { c) } & \boldsymbol{o}- & \text { ubitkely } & \text { '(Ele/a) procurou você' }\end{array}$

${ }^{40}$ Quanto às demais vogais, isto é /o, i/, o corpus apresenta uma única raiz iniciada por /o/ conjugada pela segunda pessoa (ongong 'morder') cuja forma encontrada foi ingong-ry 'Ele me mordeu'. Esta forma é considerada um caso de supleção semelhante às formas de segunda pessoa das raízes iniciadas por /e/. As raízes iniciadas por /i/ são intransitivas $\mathrm{S}_{\mathrm{A}}$ e não recebem o índice $o$ - para a segunda pessoa. 
d) o-w- ybyly (Ele/a) banhou você'

$\{k u t\} 1+2 \mathrm{~A}, 1+2 \mathrm{~S}_{\mathrm{A}}$ : é realizado como [kut -$]$ diante da vogal anterior alta /i/, [kud-] diante das demais vogais, isto é, /a, e, o, u, í/, [kun-] diante de consoantes nasais e [kut-] diante de demais consoantes. Exemplos são apresentados abaixo:

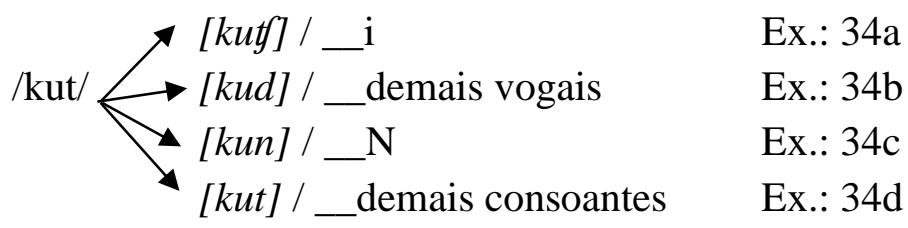
a) $\quad$ kutf- itxiny
'Nós (incl.) deitamos'
b) kud- egrugeny
'Nós (incl.) o lavamos'
c) kun- mongoguny
'Nós (incl.) o esperamos'
d) kut- kokuny
'Nós (incl.) o chamamos'

\{ko-\} 1A20: é realizado como [kw-] diante da vogal central baixa /a/, como [k-] diante de raízes que em outras conjugações iniciam por vogal média baixa anterior /e/, mas quando a segunda pessoa objeto está envolvida apresentam a forma supletiva iniciada pela vogal /i/. Isto é, paralelamente ao apresentado para o morfema de $o$ - 2, a raiz eneng 'ver' em ug-eneng-ry [2A1OVER-PSD.IMD] 'Você me viu' passa à $k$-ineng-ry [1 A2O-2ver-PSD.IMD] 'Eu vi você'. Ademais, o alomorfe [ko-] ocorre diante de consoantes e também de /u/. Diante de palavras cujas raízes iniciam por /it e /o/ foi verificado o acréscimo do segmento temático [-w-], como nos exemplos (35e) e (35f). A estrutura abaixo resume os alomorfes e seus ambientes de ocorrência:

$$
/ \mathrm{ko} / \longleftrightarrow \begin{array}{ll}
{\left[k^{w}\right] / \_\mathrm{a}} & \text { Ex.: } 35 \mathrm{a} \\
{[k] / \_\mathrm{i}(\text { raiz supletiva) })} & \text { Ex.: 35b } \\
{[k o] / \_\mathrm{u}, \text { consoantes }} & \text { Ex.: 35c-f }
\end{array}
$$

\begin{tabular}{|c|c|c|c|}
\hline a) & $k w=$ & abotxiny & 'Eu segurei você' \\
\hline b) & $k-$ & inebyny & 'Eu trouxe você' \\
\hline c) & ko- & ubitkely & 'Eu procurei você' \\
\hline d) & ko- & noly & 'Eu deixei você' \\
\hline e) & ko- $\quad w-$ & okpetkeda & 'Eu vou arrumar você' \\
\hline f) & ko- $\quad w-$ & ybyly & 'Eu banhei você' \\
\hline
\end{tabular}

\{ugu-\} 1+20, 2A10: Este prefixo possui alomorfes previsíveis \{ugu-, ug-, ung-, uk-\} os quais são mesmos apontados para o marcador de posse nominal apresentado em Ferreira Alves 
(2013). A forma [ugu-] foi tomada como básica por ser a que ocorre em um maior número de ambientes (incluindo as ocorrências em raízes nominais) ${ }^{41}$. Em radicais verbais, este alomorfe é anexado diante de encontros consonantais e diante de oclusivas homorgânicas. $\mathrm{O}$ alomorfe [ug-] ocorre diante de radicais iniciados por vogais, $[u k]$, diante de radicais iniciados por oclusivas surdas e [ung-], diante de radicais iniciados por consoantes nasais.

ugu $\begin{cases}{[u g u] / \_ \text {encontro consonantal; } \mathrm{C}_{[+ \text {velar }]}} & \text { Ex.: 36a, 36b } \\ {[u g] / \_\mathrm{V}} & \text { Ex.:36c } \\ {[u k] / \_\mathrm{C}_{[-\mathrm{velar}]}} & \text { Ex.: } 36 \mathrm{~d} \\ {[u n g] / \_\mathrm{N}} & \text { E.: } 36 \mathrm{e}\end{cases}$
a) ugu- kpiny
'Ele molhou nós dois'
b) ugu- gokuny
'Ele chamou nós dois'
c) ug- ubytkeny
'Ele procurou nós dois'
d) uk- pongry
'Você me encontrou'
e) ung- noly
'Ele deixou nós dois'

\subsection{MORFEMAS DE TAM E SUAS VARIANTES}

As flexões de TAM são sufixais e a ocorrência de seus alomorfes é, na maioria das vezes, determinada de acordo com a natureza vocálica ou consonantal do segmento que o antecede. Geralmente, em ambiente intervocálico, os alomorfes apresentam uma versão vozeada e, em ambiente de encontro consonantal, uma versão desvozeada. Por vezes, há um terceiro alomorfe após a consoante nasal velar, caso contrário, ocorre a versão desvozeada (no dialeto Iriri). Além disso, foi verificada a existência de alomorfes supletivos cujas formas não apresentam semelhanças entre si, mas apresentam o mesmo significado flexional. Estes morfemas também exibem ocorrências previsíveis, condicionadas fonologicamente pelo contexto vocálico ou consonantal do segmento ao qual são diretamente anexados. Esta seção apresenta os padrões de alomorfia verificados para cada morfema de TAM, os quais serão abordados nos Capítulos subsequentes. Em geral, para a identificação da forma dos morfemas, o presente estudo leva em consideração a análise de redução silábica apresentada na subseção 2.7.5.

\footnotetext{
${ }^{41}$ A forma histórica recosntruída é *uku (Cf. MEIRA; GILDEA; HOFF, 2010).
} 


\subsection{1 $\{-$ ly $\sim$ ny -ry $\}$ PSD.IMD}

Em estudos anteriores é possível verificar um descompasse sobre qual seria a forma deste morfema. Compare os exemplos (37) e (38) nos quais a vogal $\boldsymbol{y}$ ora é tratada como parte da flexão ora como parte da raiz, respectivamente. Ambos os autores usam a glosa REC para passado recente.

(37) (SOUZA, S. 2010, p. 114, tradução nossa)

$w-i b-y l y$

1-banhar-REC

'Eu banhei'

(38) (SOUZA, I. 2010, p. 24, tradução nossa)

$w$-iby-ly

1ERG-banhar-REC

'Eu tomei banho (hoje)'

De acordo com a presente análise, o morfema de passado imediato apresenta os alomorfes $\{-l y \sim-n y \sim-r y\}$. A vogal $y$ faz parte da raiz da mesma forma que as outras vogais e, conforme a regra de redução silábica, é elidida das raízes quando estas são seguidas de sufixo $-\mathrm{CV}$, exceto diante do próprio morfema de passado imediato. Segundo a mesma regra, apenas vogais altas são elididas ${ }^{42}$. Exemplos do morfema -ly são apresentados em (39).
a) t-ygaby-ly
'Teceu O'
b) i-no-ly 'Deixou $\mathrm{O}^{\prime}$
c) j-abu-ly 'Trouxe O'
a) ekumi-ly 'Balançou $\mathrm{O}^{\prime}$
b) aky-ly 'Peneirou $\mathrm{O}$ '
c) 'Acabou $\mathrm{O}^{\prime}$

Há uma variante que ocorre somente no dialeto Iriri. O alomorfe $\{-l y\}$ varia livremente $\operatorname{com}\{-n y\}$. Assim, neste dialeto, duas possíveis pronúncias para a palavra ekumyly 'balançou', por exemplo, são [ckumili] e [عkumini]].

\footnotetext{
${ }^{42}$ Com a exceção da raiz momy 'amarrar O' e edady 'falar' presentes no corpus.
} 
A variante $\{-r y\}$, por sua vez, ocorre após radicais que terminam em nasal velar, (40). Souza, S. (1993, p. 71-72) apresenta a variante $\{-y r y\}$ para o dialeto Arara ${ }^{43}$. No dialeto Iriri, aparentemente, houve um processo de generalização do apagamento da vogal $\boldsymbol{y}$ que antecede a nasal velar, visto que, mesmo diante do morfema de passado, esta vogal não é verificada na raiz. No dialeto Arara, por sua vez, ainda é possível observar uma alternância neste mesmo contexto em que ora a vogal $y$ é pronunciada ora não.
a) eneng-ry 'Viu O'
b) tongong-ry 'Mordeu O'
c) idang-ry 'Ouviu O'

\subsection{2 $\{-$-ne $\sim$-n $\}$ PSD.DIST}

O alomorfe $\{-n e\}$ ocorre após consoantes e $\{-n\}$ após vogais, conforme ilustrado em (41) e (42), respectivamente.
a) omom-ne 'Ele entrou'
b) jeneng-ne 'Eu o vi'
c) janum-ne 'Eu o levantei'
a) $m y-g e-n \quad$ 'Você falou'
b) $y$-bage-n 'Eu acordei'
c) $\quad y$-no-n 'Me deixou'

\subsection{3 $\{$-te $\sim(-t)\}$ PSD.MED}

O alomorfe $\{$-te $\}$ ocorre após consoantes, como exemplificado em (43). (43)

a) aum-te 'Levantou O'

\footnotetext{
${ }^{43} \mathrm{O}$ ambiente descrito pela autora segue a teoria de traços de acordo com a qual a ocorrência deste alomorfe é
} verificada após [+nasal -anterior] (Cf. SOUZA, S. 1993, p. 71). 
b) anum-te 'Ajuntou O'

c) enep-te 'Trouxe O'

A forma após vogal em ju-bage-t [3-acordar-PSD.MD] 'ele acordou' indica a existência de um alomorfe $\{-t\}$. Este indício necessita ser investigado à luz de mais dados (por isso o parênteses no título da subseção), mas é coerente como padrão alomórfico apresentado pela maioria dos morfemas observados. Além disso, este alomorfe é consiste no plural acompanhado do morfema -tang (ver Capítulo IV, subseção 4.3.1, § 5), como nos pares de exemplos em (44).
a) mip-tang-te
'Você banhou'
c) mip-tang-ty-t
'vocês banharam'
b) miptong-tang-te 'Você desceu'
d) miptong-tang-ty-t 'vocês descaram'
c) inmongok-tang-te 'Eu o esperei'
e) inmongok-tang-ty-t 'Eu os esperei'

\subsection{4 $\{$-ne $\sim-n\}$ HORT}

Os alomorfes do hortativo apresentam a mesma distribuição alomórfica verificada para os alomorfes do passado distante. Isto é, em contexto pós consonantal, ocorre a forma \{-ne\}, e, em contexto pós vocálico, a forma afixada é $\{-n\}$, como ilustrado em (45) e (46).
a) kudamnenom-ne 'Vamos carregar O!'
b) kutxim-ne 'Vamos banhar!'
c) kudeneng-ne 'Vamos ver O!'

(46)
a) kutody-n 'Vamos todos embora!'
b) kudodewy-n 'Vamos dar a volta!'
c) kudekpity-n 'Vamos costurar O!'

\subsection{5 $\{-$ ta $\sim-$ a $\}$ IMP.ALA}

O alomorfe $\{$-ta\} ocorre após consoantes, como em (47), e $\{-a\}$ após vogais, (48). 

a) ip-ta 'Vá lá banhar!'
b) orik-ta 'Vá lá dançar!'
c) enen-ta 'Vá lá olhar O'

(48)
a) i-goku-a 'Vá lá chamar O!'
b) egruge-a 'Vá lá lavar O!'
c) onku-a 'Suba lá'

\subsection{6 $\{-\mathrm{ko} \sim-\mathrm{k} \sim-\emptyset\}$ IMP}

A distribuição dos alomorfes do imperativo também depende da natureza vocal ou consonantal do último segmento do radical. $\{-k o\}$ ocorre após consoantes, $\{-k\}$ após vogais e $\{-\emptyset\}$ após nasal velar, como em (49), (50) e (51), respectivamente.
a) enep-ko 'Traga O!'
b) odep-ko 'Vem!'
c) omom-ko 'Entre!'

(50)
a) edabruke-k 'Abra O!'
b) ikpi-k 'Molhe O!'
c) onku-k 'Suba!'
a) eneng- $\varnothing \quad$ 'Veja O!'
b) iptong- $\emptyset \quad$ 'Desça!'
c) idang- $\varnothing \quad$ 'Escute O!'

Apenas em radicais intransitivos So, os quais recebem a segunda pessoa $\{0-\}^{44}$, o imperativo não é marcado por morfema sufixal se a raiz ou radical terminar em vogal, conforme ilustrado em (52). Se, por outro lado, a/o raiz/radical apresentar uma consoante final, a forma

\footnotetext{
${ }^{44}$ Alomorfes são apresentados na seção 2.9.
} 
verbal recebe o morfema de imperativo corresponte. Isto é, o morfema $\{-k o\}$, conforme ilustrado em (53).
a) oabunte 'Afofe!'
b) otxikte 'Urine!'
c) 'Acorde!'
d) orumpo 'Morre!'
e) omulude 'Tosse!'
f) olagakte 'Cospe!'

(53)
a) $i^{45}$ daginum-ko 'Assobia!'
b) oeriktum-ko 'Sorri!'
c) igaktum-ko 'Corre!'
d) obongnum-ko 'Chora!'
e) iguam-ko 'Senta!'
f) oalum-ko 'Pula!'

\subsection{7 $\{\text {-tane } \sim \text {-ane }\}^{46}$ VET}

O alomorfe $\{$-tane $\}$ ocorre após consoantes e $\{$-ane $\}$ após vogais.

(54)
a) iguam-tane 'Você não pode sentar'
b) myp-tane 'Não banha ele'
c) menipton-tane 'Não desce ele'

$(55)$

a) migoku-ane 'Você não pode chamar O'

\footnotetext{
${ }^{45}$ Ablaut

${ }^{46} \mathrm{Em}$ apenas uma raiz foi verificada a forma -txane: $m$-aby-txane o-brinta [2A-brigar-VET 2-outro] 'não briga com os outros, não'. Observe que com a mesma raiz o alomorfe anexado é diferente em $m$-aby-tke-ane [2A-brigarITR-VET] 'não vai ficar brigando'. Note também que forma básica da raiz aparenta terminar em vogal, como em $\emptyset$ aby-ly [3-mexer-PSD.IMD] 'mexeu, brigou'. Souza, S. (1993, p.74) apresenta o alomorfe -jane em m-abyt-jane 'não vai brigar'.
} 
b) mabu-ane 'Você não pode cavar O'

c) medentuki-ane 'Você não poder desamarrar $\mathrm{O}$ '

\subsection{8 $\{$-tang -ang $\}$ ADM}

O alomorfe -tang ocorre após consoantes e -ang após vogais. Exemplos de -tang são apresentados em (56a) e (56b). Em ambos os casos ocorre redução silábica. Observe que, no caso do encontro de consoantes homorgânicas, há elisão de uma delas, como em (56a). Por outro lado, a fonotática de encontro consonantal permanece, impedindo a assimilação da sonoridade em contexto intervocálico. Exemplos da afixação do alomorfe -ang são oferecidos em (57).

a) oangkody+tang $\rightarrow$ oangkot+tang $\rightarrow$ oangkotang 'Cuidado, pode cortar você!'

b) oautketkenoby-tang $\rightarrow$ oautketke-nop-tang 'Cuidado, você pode ficar inchado em todas as partes do corpo.'

a) modakpi-ang 'Você pode ficar bêbado.'

b) jagi-ang 'Pode me cortar (Cuidado).'

\subsection{9 $\{$-da $\sim$-txa $\sim$-na $\}$ INTC}

As formas $\{-d a \sim-t x a \sim-n a\}$ apresentam o mesmo significado flexional, apresentando uma relação alomórfica resultante de assimilação. O alomorfe -txa ocorre após consoantes, como em (58). - da após vogais, (59), e -na ocorre em radicais cujo último segmento era nasal velar, a qual é, obrigatoriamente, elidida antes da sufixação. Exemplos deste último alomorfe são apresentados em (60).
a) jeganop-txa 'Eu vou falar'
b) jygap-txa 'Eu vou tecer O'
c) jengap-txa 'Eu vou comer $\mathrm{O}$ ' 

a) jekpity-da
'Eu vou costurar O'
b) inipke-da
'Eu vou raspar O'
c) jedentu-da
'Eu vou amarrar O'

(60)
a) jeneng $\rightarrow \quad$ jene-na 'Eu vou olhar O'
b) jerimtong $\rightarrow \quad$ jerimto-na 'Eu vou cozinhar $\mathrm{O}$ '
c) jenibeng $\rightarrow \quad$ jenibe-na 'Eu vou carregar O'

\subsubsection{0 \{-tome $\sim$-tpom $\sim$-npom $\}$ FUT}

Os alomorfes supletivos de futuro são previsíveis de acordo com os seguintes contextos: -tome ocorre em radicais cujo último segmento é uma consoante (o que inclui radicais passíveis de redução silábica), como em (61), -tpom ocorre após vogais, conforme exemplificado em (62), e -npom após segmentos nasais, (63).
a) ak-tome
'Depois ele come O'
b) orik-tome
'Ele vai dançar depois'
c) odotpot-tome
'Depois ele vai voltar'
a) jadu-tpom
'Eu vou queimar O depois'
b) manme-tpom
'Depois você joga O'
c) maworuntame-tpom 'Depois você vai conversar'

(63)
a) eniptong $\rightarrow$ enipto-npom 'Ele vai descer O depois'
b) emnang $\rightarrow$ emna-npom 'Depois ele puxa $\mathrm{O}^{\prime}$
c) eneng $\rightarrow \quad$ ene-npom $\quad$ 'Ele vai olhar O depois'

Assim, se o radical da mesma palavra sofrer variação quanto ao último segmento, os alomorfes do sufixo serão previsíveis de acordo com a regra supracitada. Compare os exemplos 
(64a) e (64b), nos quais -tome é afixado diretamente à raiz terminada em consoante e -tpom é afixado após o morfema de plural cujo último segmento consiste em uma vogal. Em (65a) e (65b), podemos ver a alternância entre -npom e -tpom.

(64)

a) jeneptome mobu koglon

j-enep-tome mobu koglon

1A-trazer-FUT canoa amanhã

'Eu vou trazer canoa amanhã' (Elic)

b) meneptytpom

m-enep-ty-tpom

2A-trazer-COL-FUT

'Depois vocês trazem' (Elic)

(65)

a) enenpom talem muren

$\varnothing$-eneng-npom talem mure-n

3-ver-FUT pássaro.gen filho-POSSD

'Ele vai olhar depois o filho do passarinho' (Elic)

b) ogomno menentytpom

ogomno m-eneng-ty-tpom

depois 2A-ver-COL-FUT

'Depois vocês vão olhar' (Elic)

\subsubsection{1 \{-tke $\sim$-tadamy $\}$ ITR}

Os sufixos $\{$-tke $\sim$-tadamy\} são exemplos de alomorfes supletivos, uma vez que não é possível descrever processos morfofonológicos que derivem um do outro ou ambos de uma mesma forma subjacente. O contexto de ocorrência de cada um deles é previsível: -tke ocorre após radicais terminados em vogais e -tadamy após radicais terminados em consoantes, como exemplificado em (66) e (67), respectivamente.

(66)
a) imomy-tke-ny
'Amarrou tudo, um bocado'
b) ke-tke-ny
'Avisou tanto'
c) ibumu-tke-ny
'Matou um bocado (o resto ficou)' 
(67)
a) eganop-tadamy-ny 'Ficou falando tudo, fococando'
b) ibon-tadamy-ny 'Encontrou $\mathrm{O}$ várias vezes'
c) tongo ${ }^{n}$-tadamy-ny 'Mordeu tanto'

\subsubsection{2 $\{-\operatorname{ta}(\mathbf{n}) \sim-\mathbf{a}(\mathbf{n})\}$ ALA}

$\mathrm{O}$ alomorfes $-\tan \sim-\operatorname{ta} \sim-a n \sim-a$ indicam alação, isto é, movimento em direção oposta a do falante. Embora o morfema alativo não se trate de um morfema de TAM, ele é relevante para o entendimento das formas de alguns destes sufixos com os quais coocorre e será citado também em outros capítulos. A forma -tan ocorre após consoantes, como em (68). Quando este alomorfe é seguido de sufixo cuja consoante inicial é homorgânica a sua própria consoante final ocorre a elisão deste segmento nasal, o que causa o surgimento do alomorfe -ta como em (68b) e (68c). O alomorfe -an, por sua vez, ocorre após vogais, como em (69), e a versão - $a$ é verificada quando o sufixo seguinte inicia em nasal alveolar, como em (69b) e (69c). Veja que os alomorfes $-t a \sim-a$ são homófonos aos alomorfes do imperativo alativo, mas o imperativo ocorre recebe marcas de pessoa específicas. As motivações para tal análise são explicitadas no capítulo 4.
a) idang-tan-ty- $k \rightarrow \quad i d a^{n}$-tan-ty- $k$
'Vão lá ouvir!'
b) jeneng $\rightarrow$ jene $e^{n}$-tan-na $\rightarrow$ jene $e^{n}$-ta-na 'Eu vou lá olhar'
c) jygaby $\rightarrow$ jygap-tan-na $\rightarrow$ jygap-ta-na
'Eu vou tecer O para lá'
a) kutke-an-ty-n
'Eu vou lá subir'
b) jedentu-an-na $\rightarrow$ jedentu-a-na
'Eu vou lá remendar O'
c) jekpity-an-na $\rightarrow$ jekpity-a-na
'Eu vou lá costurar O'

\subsection{MORFEMAS DE NÚMERO E SUAS VARIANTES}

Os principais morfemas de número que ocorrem em radicais verbais são afetados pelo processo de sonorização. Os sufixos -ty e -tom apresentam os alomorfes - $d y$ e -dom quando são 
anexados após vogais. Os pares de exemplos em (70) e (71) apresentam a forma surda e a sonora, respectivamente.

(70)
a) ikot-ty-k Quebrem!
b) egruge-dy- $k \quad$ 'Lavem!'
c) enep-ty-k Tragam!
d) iptadamy-dy-k 'Tomem banho!'

(71)
a) wabotang-tom 'Cuidado, vai pegar vocês!'
b) kunke-dom 'Disseram'
c) neguam-tom- $a$ 'Deixa eles sentarem'
d) kunwo-dom 'Mataram'

Mais detalhes sobre estes e outros morfemas de plural são apresentados no decorrer dos capítulos seguintes.

\subsection{SÍNTESE}

Neste capítulo foi revisado o sistema de fonemas da língua, a partir dos trabalhos de Ferreira Alves (2010b, 2013). Além disso, de relevância para o tema deste estudo, foram apresentados os alomorfes dos afixos de pessoa, número e TAM. Tais alomorfes são previsíveis de acordo com os principais processos morfofonológicos encontrados na língua, a saber, a sonorização, a redução silábica, a palatalização, a nasalização, e o ablaut. 


\section{CAPÍTULO 3 - CLASSES DE PALAVRAS}

Este capítulo apresenta critérios que distinguem a classe de verbos das demais principais classes de palavras (nomes, advérbios e posposições). São apresentados os principais padrões morfossintáticos e os contrastes internos à língua que evidenciam tal distinção. A seção 3.1 apresenta o principais conceitos utilizados para a identificação da palavra em Arara, incluindo noções básicas como afixos, raiz/radical, etc. A seção 3.2 traz as características morfossintáticas capazes de diferenciar verbos de nomes, advérbios e posposições. Em 3.3 são apresentadas as subclasses verbais, especialmente a distinção de verbos biargumentais (transitivos) e monoargumentais (intransitivos), que possui duas subclasses de verbos intransitivos $\left(S_{\mathrm{A}}\right.$ e $\left.S_{\mathrm{O}}\right)$, morfologicamente marcadas. Na seção 3.4, são descritos os processos de formação da palavra verbal, bem como de formação de outras classes verbais via processos de mudança de valência (detransitivização e causativização). A seção 3.5 apresenta uma introdução ao processo morfológico deverbal mais produtivo na língua, a nominalização, bem como ao processo de formação do particípio passado.

\subsection{INTRODUÇÃO À MORFOLOGIA ARARA E ESCLARECIMENTOS TERMINOLÓGICOS}

Seguindo o padrão das línguas Karib, os processos morfológicos são abundantes em Arara. A partir de um olhar panorâmico, há uma gama de morfemas dentre prefixos e sufixos, com predominância sufixal. Também foi verificada a existência de circunfixos $(t-\ldots-t e,-k e,-r e$, -e, -nge/-je). Prefixos expressam argumentos pessoais, negação e alteração de valência (detransitivização), enquanto sufixos denotam tempo, aspecto, modo, número, negação, alteração de valência (transitivização/causativisação), mudanças de significado (aumentativo, diminutivo) e mudança de classe (nominalização, verbalização, adverbialização). Os morfemas são sensíveis à natureza vocálica ou consonantal do segmento do radical ao qual se ligam, conforme regras morfofonológicas. Mudanças no radical ocorrem devido aos processos de ablaut (nomes e verbos) e redução silábica (em alguns verbos).

Teorias morfológicas dividem-se entre lexicalistas (lexicalista forte, lexicalista fraca) e não lexicalistas (como a Morfologia Distribuída). Este estudo utiliza conceitos lexicalistas para 
a identificação da palavra em Arara tal como as noções morfológicas básicas de morfema, afixo, raiz, radical entre outras encontradas em Nida (1949) e Haspelmath (2002).

Morfemas são os menores constituintes portadores de significado de uma expressão linguística. Alguns morfemas apresentam significados mais concretos, como o verbo pular, o nome camaleão, ou o adjetivo fácil, enquanto outros apresentam significado mais funcional, como o $-s$ do inglês presente em she read-s 'Ela lê' que serve para marcar a terceira pessoa do singular no presente. Sobre este último tipo de morfema é dito na literatura que possui função gramatical. Há dois tipos de morfemas, os livres que podem ocorrer como uma palavra independente e os presos que nunca ocorrem em isolamento. Com relação à correspondência entre forma e significado nem sempre há isomorfia (correspondência de um-para-um). Este é o caso de morfemas portmanteu, também chamados de morfemas cumulativos ou que apresentam fusão. Esse tipo de morfema apresenta uma forma e mais de um significado simultaneamente, como o $-s$ do inglês supracitado.

A presente análise também utiliza o conceito de morfema zero, aquele que não exibe uma forma fonológica, apenas significado, como em Ø-etpe-k [3-pisar-IMP] 'Pisa!'. Geralmente, este tipo de morfema faz parte de um paradigma. Por outro lado, a expressão não marcado é utilizada com o sentido encontrado na literatura tipológica, relacionada ao conceito de markedness (CROFT, 2003), para se referir a uma oposição binária em que há uma forma ou estrutura não marcada, portanto, mais frequente, típica que se contrapõe a uma forma ou estrutura marcada, menos frequente. Por exemplo, a categoria de plural nominal, em geral, apresenta uma forma marcada, diferente de zero, enquanto o singular é considerado uma categoria não marcada. Veja, porém, que a ausência de um marcador fonológico ainda aponta para um significado diferente de plural. Logo, este caso também se configura na presença de em um morfema zero. Há ainda que se notar, neste estudo, o uso esporádico da expressão não marcado para indicar apenas as ausências, tanto da forma fonológica quanto do significado, como é o caso da categoria de pessoa na construção de imperativo da classe de verbos $\mathrm{S}_{\mathrm{A}}$ que não apresenta marcas de pessoa. Nesta situação, a ausência de um marcador fonológico não implica necessariamente em um significado (seção 3.3.1, item b).

Afixos são morfemas presos cujo significado consiste em uma função gramatical. São classificados como prefixos, infixos, sufixos e circunfixos de acordo com sua posição em relação à base ou radical/raiz. Bases são encontradas em palavras flexionadas ou lexemas derivados, isto é, são quaisquer morfemas anexados por afixos. Radicais, por sua vez, são raízes anexadas por morfemas derivacionais. Raízes são morfemas que não podem ser subdivididos e 
apresentam significado lexical. Em geral, uma raiz pode ser um radical, mas nem todo radical pode ser uma raiz.

$\mathrm{Na}$ maioria das línguas, os conceitos acima são suficientes para a segmentação morfológica, porém há casos em que a divisão entre afixos e raízes, por exemplo, não é tão clara, como em Matsés (FLECK, 2003) e em Bella Coola (MITHUN, 1998 apud HASPELMATH, 2002, p. 20) que apresentam afixos com significado lexical. Exemplos como estes demonstram que mais critérios podem ser inseridos à conceituação morfológica básica, dependendo da língua em análise.

$\mathrm{Na}$ maioria das vezes, apenas uma categoria gramatical é expressa por cada morfema, cujas fronteiras são facilmente reconhecíveis o que coloca o Arara entre as línguas com características aglutinantes. Contudo, algumas vezes, as fronteiras apresentam formas que não são de todo regulares, isto é, são verificadas também características de línguas flexionais. Por exemplo, a vogal /i/ presente nos morfemas de pessoa que poderia ser analisada como 3 pessoa objeto diante de raízes iniciadas por consoantes (in-i-1A-3o, kut-i-1+2A), mas essa vogal não está presente todas as vezes em que se esperaria um marcador $3 \mathrm{O}$ (Capítulo V, seção 5.3.1.1.1, $\S 5)$. Outro caso é o do sufixo de aspecto - ak cuja forma do coletivo -ty ocorre entre a vogal e a consoante - $a-d y-k$. Diante deste tipo de complexidade, optamos pela não divisão do morfema, criando morfemas portmanteau, como - adyk ASP.COL (Capítulo V, seção 5.4.4).

Os conceitos de flexão e derivação também são essenciais em uma descrição morfológica. A abordagem utilizada por este trabalho considera que tais processos fazem parte de um contínuo em que os padrões estão dispostos entre os mais claramente derivacionais em um extremo e os mais claramente flexionais no outro. Haspelmath (2002) aponta um conjunto de propriedades que permite a distinção entre os dois processos. O maior número de propriedades caracteriza o exemplar prototípico de flexão ou derivação que se encontra nos extremos do contínuo.

\subsection{IDENTIFICANDO A PALAVRA VERBAL}

Para diferenciar a classe de verbos das demais classes de palavras, além do critério semântico, foram utilizados critérios morfossintáticos, conforme orientam Schachter e Shopen (2007) e Haspelmath (2001, 2007, 2012). Segundo estes autores, um critério isolado não é suficiente para a classificação de raízes, uma vez que morfemas apresentam diferentes comportamentos em diferentes classes e também porque a distribuição sintática é diferenciada 
para as palavras de cada classe. Este conjunto de propriedades internas à cada língua permite agrupar palavras cujas características comuns levam à definição uma classe ou categoria (palavras utilizadas como sinônimos) gramatical.

As principais classes de palavras ${ }^{47}$ abertas encontradas em Arara são verbos, nomes e advérbios. Os advérbios constituem uma classe mista formada por um grupo derivado com o uso de morfologia derivacional altamente produtiva e por um grupo menor composto por itens não derivados. Posposições formam uma classe fechada a qual, porém, apresenta vários subgrupos. Classes de palavras menores são pronomes pessoais, demonstrativos e interrogativos, além de partículas ${ }^{48}$. Palavras que expressam propriedade (termo para uma categoria semântica (DeLANCEY, 2001; CROFT, 2015), geralmente, associadas à categoria sintática denominada 'adjetivos', estão distribuídas morfossintaticamente entre as classes de nomes e advérbios.

\subsubsection{Caracterizações semânticas, morfológicas e sintáticas}

Do ponto de vista do conteúdo semântico, verbos denotam eventos (ações, processos) (Ø-eganoby-ly [3-falar-PSD.IMD] 'falou', Ø-engaby-ny [3-comer-PSD.IMD] 'comeu', i-rumpo-ly [3-morrer-PSD.IMD] 'morreu'). Em línguas como o português, verbos também denotam estados mentais ('pensar', 'entender', 'alegrar-se'). Note-se que certos tipos de estados mentais ocorrem em algumas línguas Karib como posposições. Este é o caso de Tiriyó (MEIRA, 2004) e também de Arara: o-bobra [2-saudades] 'Saudades de você', inguam-ennge [2saber-COL] 'Vocês sabem, ${ }^{49}$.

Quanto aos aspectos morfológicos, verbos são obrigatoriamente flexionados, apresentando uma rica variedade de afixos exclusivos. A estrutura básica é composta por prefixos argumentais, raiz/radical e sufixos de TAM o que possibilita uma única palavra verbal funcionar como uma sentença completa. Além disso, outros morfemas (negação, relacional,

\footnotetext{
47 Também conhecidas como classes/categorias lexicais, partes do discurso, categorias sintáticas, categorias gramaticais.

${ }^{48}$ Estas não serão tratadas neste trabalho.

${ }^{49}$ Meira (2004) indica que, na verdade, o status dessas posposições que indicam estados mentais é ambíguo quando suas propriedades morfossintáticas são comparadas às de outras classes. Assim, o rótulo 'posposição' é mantido por conveniência. No caso de Arara, há semelhança entre esta classe e a classe de advérbios que recebem o mesmo sufixo de plural $\{-(e) n n g e\}$. Por outro lado, assim como certos nomes possuíveis, tais posposições também recebem marcas de pessoa.
} 
incorporação nominal, detransitivisador etc) podem compor esta estrutura, conforme resumido na tabela abaixo.

Tabela 3.1 - Generalização da estrutura da palavra verbal canônica

\begin{tabular}{|c|c|c|c|c|c|}
\hline ARG REL & FLEX & DERIV & BASE/RADICAL & DERIV & FLEXÃO \\
\hline PESS- j- & ( ?NEG-) & (VLC-) & (INC.NOM)-raiz-(VBZ) & $(-\mathrm{VLC})$ & -ASP -T/A (-NUM) -M (-NUM) \\
\hline
\end{tabular}

Exemplos de alguns elementos que compõem a estrutura da palavra verbal são apresentados em (1) e (2):

(1)

$$
\begin{aligned}
& \text { moringnangryngmo } \\
& \text { m-origu-nangry-ngmo } \\
& \text { 2A-dançar-IPFV-COL } \\
& \text { 'Vocês vão dançar'(Txt) }
\end{aligned}
$$

(2)

urangmo angtely dan
urangmo $\emptyset$-angte-ly tan
criança 3 -cair-PSD.IMD aqui
'Menino caiu aqui' (Txt)

Há diferenças morfológicas entre verbos e demais classes de palavras (nomes, posposições e advérbios). Os afixos exclusivos de classe de verbos são os sufixos de tempo (passado imediato, passado médio, passado remoto, futuro, entre outros), aspecto (iterativo, imperfectivo), modo (imperativo, permissivo, hortativo, vetativo, admonitivo, entre outros). Exemplos dos modos imperativo e hortativo são fornecidos em (3) e (4), respectivamente.

\section{(3) iduet-kom egruge-dy-k}

2rede-COL lavar-COL-IMP

'Lavem as redes de vocês!' (Txt)

(4) kuton

kut-ydo-n

1+2-ir-HORT

'Vamo-nos!' (Elic.)

Os morfemas de pessoa kun(i)- 3PSD.DST, mon(i)- 3PSD.MED, $n(i)-3$, ko- 1A2O, ugu102A e $m(i)$ - 2A também ocorrem apenas em raízes verbais, assim como a categoria de número marcada por -ty e - tom $^{50}$ COL. Estes morfemas são examinados em detalhes no Capítulo V. Ademais, somente verbos sofrem alteração de valência por meio dos afixos otxi- DTRZ, -noby, -metpoby, -by CAUS (subseção 3.4.2). Quanto aos processos de mudança de classes, raízes

\footnotetext{
${ }^{50}$ A exceção encontrada corresponde à partícula interrogativa kang que flexiona com -tom, como em kure-p kangtom [bom-ATBZ 2QU-PL] 'Vocês estão bem?'
} 
verbais podem ser nominalizadas pelo sufixo - ni NOM. Este pode ocorrer em raízes transitivas ou intransitivas, conforme ilustrado em (5) e (6), respectivamente. Há ainda o prefixo $n(i)-{ }^{51}$ cujos cognatos, geralmente, ocorrem apenas em verbos transitivos. Entretanto, devido à ausência de dados mais conclusivos no corpus, não é possível discutir se o prefixo pode contribuir para a distinção de classes verbais.

(5)

opty-ngo udu-ni

remédio-NPOSS dar-NOM.A

'Enfermeiro/a (Elic.)’ (Lit.: Aquele que dá remédio.)

(6) oring-ni

origu-ni

dançar-NOM.A

'Dançarino' (Elic.)

Nomes, por sua vez, apresentam menos morfologia, mas podem ser identificados por meio de morfemas de posse (possuidor e sufixos possessivos), embora nem todos os nomes sejam possuíveis e os prefixos de pessoa sejam também encontrados em verbos e posposições. Além disso, esta classe é afixada por duas variantes do morfema de número -kom -ngmo COL, enquanto verbos podem ser afixados apenas por um desses alomorfes, -ngmo. Nomes também podem ser verbalizados com os sufixos -te, -ke, -tumy, -numy, -my, como apresentado na seção 3.4.1, e adverbializados com os afixos $t$-N-ke, -re, $-e$, -nge/-je.

Posposições recebem prefixos de pessoa (idênticos aos encontrados em nomes e em verbos intransitivos da classe So (Capítulo V, seção 5.3.1.2), ao contrário da classe de advérbios, a qual não recebe morfemas pessoais. O morfema coletivo - $(e)$ nnge e o nominalizador -no que ocorrem apenas nestas duas classes também as diferenciam das classes de verbos e de nomes.

A tabela 3.2 apresenta um resumo das propriedades morfológicas acima mencionadas.

\footnotetext{
${ }^{51}$ Gildea (1998, p. 129) analisa este morfema como um nominalisador de objeto, mas apresenta duas análises alternativas encontradas na literatura: (I) $n$ - como um indicador de que o possuidor da nominalisação não é o $\mathrm{O}$ nocional esperado, mas o A nocional. (II) $n$ - como um tipo de marcador de antipassiva que deriva um verbo intransitivo o qual é depois nominalisado e possuído pelo $\mathrm{S}$ nocional (que era o $\mathrm{A}$ nocional anterior à antipassivisação). Segundo o autor, as possibilidades de análise ainda apresentam lacunas.
} 
Tabela 3.2 - Morfemas que ajudam a identificar a classe de verbos

\begin{tabular}{|c|c|c|c|c|}
\hline & Verbos & Nomes & Posp. & Adv. \\
\hline Pessoa & $\begin{array}{l}\text { Argumentos principais } \\
\operatorname{Kun}(i)-, \operatorname{mon}(i)-, n(i)-\text { etc }\end{array}$ & Possuidor & Objeto & -- \\
\hline TAM & -ko, -ly, -nangry etc. & -- & -- & -- \\
\hline Coletivo & -ngmo, -ty, -tom & -kom -ngmo & -(e)nnge & -(e)nnge \\
\hline Nominalização & $-n i,-t o b o t \sim-t p o t, t-\ldots-t(e)$ & -- & $-n o$ & $-n o,-m$ \\
\hline Verbalização & -- & $\begin{array}{l}-t e,-k e,-t u m y,- \\
\text { numy, -my }\end{array}$ & -- & -- \\
\hline Mud. de valência & -metpoby, -noby, -by, otxi- & -- & -- & -- \\
\hline
\end{tabular}

No que se refere a critérios sintáticos, verbos ocupam a posição de núcleo do predicado, enquanto nomes assumem a posição de argumentos principais e objetos de posposições. Além disso, nomes podem formar construções de modificação genitiva, como em (7), enquanto verbos formam um sintagma $\mathrm{OV}$ em construções com participantes de terceira pessoa sintaticamente expressos, estrutura conhecida em outras línguas Karib. Observe que no exemplo (8) a partícula QU de segunda posição ka ocorre após o primeiro constituinte formado pelo sintagma verbal.

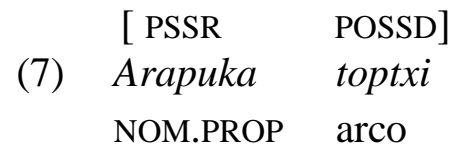

'Arco do Arapuka' (Elic.)

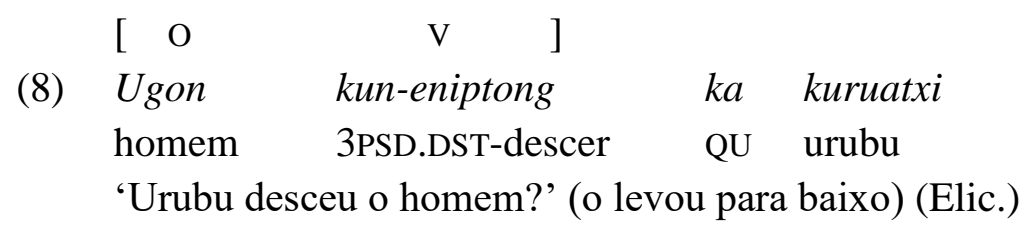

Souza, S. (1993, p. 10) apresenta uma ordem rígida de palavras: OVS, SOV. No dialeto Iriri, o cenário se apresenta de maneira mais flexível, sendo possível encontrar a ordem SVO 
até mesmo em textos ${ }^{52}$. Em seções de elicitação, esta ordem foi aceita por alguns falantes e rejeitada por outros. Segundo nosso colaborador principal, os mais jovens "trocam" as palavras.

A seguir são apresentadas propriedades morfossintáticas que permitem a distinção entre raízes transitivas e intransitivas.

\subsection{SUBCLASSES VERBAIS}

Diferentes classes e subclasses verbais foram identificadas de acordo com características específicas.

\subsubsection{Diferenças entre raízes transitivas e raízes intransitivas}

As propriedades que se mostraram relevantes para a identificação de raízes transitivas e intransitivas são: a) as marcas de pessoa em sentenças declarativas, b) as marcas de pessoa no imperativo e c) a negação.

a) Prefixos de pessoa:

Todos os verbos transitivos recebem tanto os morfemas de pessoa que se referem aos argumentos sintáticos de sujeito, exemplos (9) e (11), quanto de objeto, (10) e (12).

(9) mi-mom-yny

2A-amarrar-PSD.IMD

'Você (o) amarrou'

(11) in-koku-ny

1A-chamar-PSD.IMD

'Eu (o) chamei'
(10) o-mom-yny

2O-amarrar-PSD.IMD

'(Ele) amarrou você'

(12) y-goku-ny

10-chamar-PSD.IMD

'(Ele) me chamou'

\footnotetext{
${ }^{52}$ Ainda há a necessidade de se realizar testes com estes falantes a fim de se verficar onde fica a partícula QU
} nesses casos. 
Por outro lado, verbos intransitivos recebem prefixos do tipo $\mathrm{S}_{\mathrm{A}}{ }^{53}$ (Sujeito de verbo intransitivo morfologicamente semelhante ao sujeito do verbo transitivo), como em (13), ou do tipo $S_{o}$ (Sujeito de verbo intransitivo, morfologicamente semelhante ao objeto do verbo transitivo), como em (15), mas não ambos, como é possível perceber comparando os pares de exemplos (13) e (14), e (15) e (16). Exemplos com* indicam agramaticalidade.

(13) kud-abi-ny

$1+2 \mathrm{~S}_{\mathrm{A}}$-apontar-PSD.IMD

'Nós apontamos'

(15) ug-abad-yly

$1+2 \mathrm{~S}_{\mathrm{o}}$-passar-PSD

'Nós passamos'
(14) *ug-abi-ny

$1+2 \mathrm{~S}_{\mathrm{o}}$-apontar-PSD.IMD

((Ele) nos apontou)

(16) *kud-abad-yly

$1+2 \mathrm{~S}_{\mathrm{A}}$-passar-PSD.IMD

((Ele) nos passou)

b) Marcas de pessoa no imperativo:

Os morfemas de pessoa no imperativo apresentam um padrão de marcação único para cada classe de verbo, possibilitando a distinção entre elas. Verbos transitivos no modo imperativo são flexionados com morfemas de terceira pessoa $\{i-, \varnothing-\} . \emptyset$ - '3' ocorre diante de raízes iniciadas por vogais, como ilustrado em (17c) e (17d), e $\boldsymbol{i}$ - '3' diante de raízes iniciadas por consoantes, (17a) e (17b) $)^{54}$. Apenas verbos intransitivos $S_{O}$ são flexionados com o prefixo de segunda pessoa $\{o-\}$, como em (18). Já verbos intransitivos da classe $S_{\mathrm{A}}$ não recebem marcas de pessoa, (19). Como discutido no Capítulo 5 (subseções 5.3.1.2.1 e 5.3.1.2.2), a natureza morfológica de formação desta classe possibilita compreender porque o comportamento com relação à marca de pessoa é particular.
a) i-momy-k amarra!
b) i-deke-k escreve!
c) $\emptyset$-abu-k cave!
d) Ø-etpe-k pise!
a) o-txikte urine!
b) o-bage acorde!

\footnotetext{
${ }^{53}$ Verbos intransitivos são morfologicamente marcados por diferentes classes de morfemas de pessoa, como apresentado na seção 3.3.2. Mais detalhes são fornecidos no Capítulo 5, seção 5.3.1.2.1.

54 Algumas raízes apresentam uma terceira pessoa idiossincrática, a qual define uma subclasse de verbos irregulares.
} 
(19)
a) onku-k sobe!
b) ip-ko banhe-se!

c) Negação:

Verbos transitivos são flexionados com o sufixo de negação - pyra -bra, ilustrado em (20), enquanto verbos intransitivos, além de receberem o sufixo de negação, tomam o prefixo on- NEG, como exemplificado em (21) com um verbo da classe $\mathrm{S}_{\mathrm{O}}$, e, em (22), com um verbo da classe $\mathrm{S}_{\mathrm{A}}$. Note em (23) que predicados transitivos com on- são agramaticais. Da mesma forma, predicados intransitivos sem o morfema também são agramaticais, (24).

(20) Cláudia ingpome-bra kampot

NOM.PROP apagar-NEG fogo

‘Cláudia não apagou o fogo' (Elic.)

(21) onangtebra jenguaktxi

on-angte-bra j-engua-aktxi

NEG-cair-NEG 1-rosto-POSP

'Eu não me lembrei' (Lit.: 'Não caiu em frente meu rosto') (Elic.)

(22) on-orik-pyra Piu

NEG-dançar-NEG NOM.PROP

'Piu não dançou' (Elic.)

(23) *Cláudia on-ingpome-bra kampot (Cláudia não apagou o fogo) (Elic.) NOM.PROP NEG-apagar-NEG fogo

(24) *orik-pyra Piu (Piu não dançou) (Elic.)

dançar-NEG NOM.PROP

Um possível cognato do morfema on- havia sido identificado apenas em línguas Karib do Norte (Cf. GILDEA 2003, pg.23; CACERES, 2011, pg. 125), porém nestas línguas ele ocorre apenas em verbos transitivos quando o objeto é de terceira pessoa. Em Arara, além de ocorrer apenas em raízes intransitivas, o morfema não se refere somente à terceira pessoa, conforme demonstrado em (25): 


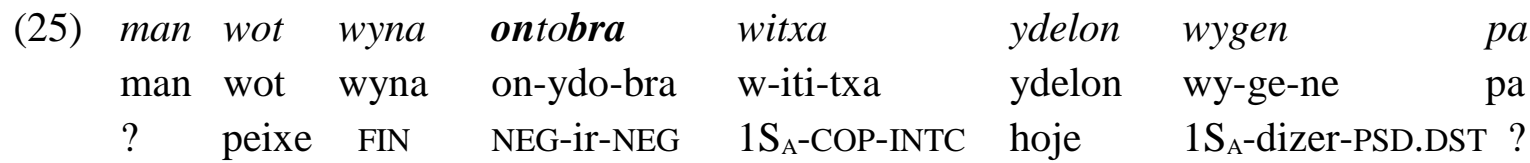

'Eu não vou pescar hoje, eu disse.'

Além da distinção entre verbos transitivos e intransitivos, também é possível identificar duas subclasses de verbos intransitivos, como demonstrado na próxima subseção.

\subsubsection{Diferença entre subclasses de raízes intransitivas: $S_{\mathrm{A}}$ e $S_{o}$}

O padrão de prefixos argumentais permite a categorização de duas classes de verbos intransitivos. Verbos $\mathrm{S}_{\mathrm{A}}$ tomam morfemas semelhantes à série $\mathrm{A}$ de verbos transitivos enquanto verbos da classe $S_{O}$ recebem prefixos de pessoa semelhantes aos prefixos encontrados em nomes, em posposições e na série $\mathrm{O}$ de verbos transitivos. Comparando-se as colunas da tabela 3.3 é possível notar que os morfemas são semelhantes, mas não idênticos. Há diferenças na primeira e segunda pessoas das raízes A e $\mathrm{S}_{\mathrm{A}}$ causadas por duas subclasses de verbos $\mathrm{S}_{\mathrm{A}}$. Estas subclasses apresentam as formas $k$ - ou $w$ - $/ w y$ - para expressar essa pessoa enquanto as formas de sujeito de primeira pessoa de verbos transitivos apresentam a variação entre $j$ - e $i n(i)$-, de acordo com a característica vocal ou consonantal do segmento inicial do radical. As diferenças entre as 2 pessoas são da mesma natureza. Apesar disso, ainda é possível identificar o paralelismo entre as classes A e $S_{A}$, $O$ e $S_{O}$ e a distinção entre $S_{A}$ e $S_{O}$. Os detalhes sobre as configurações destes prefixos são apresentados no Capítulo 5, dedicado às marcas de pessoas, entre outros.

Tabela 3.3 - Comparação de prefixos de verbos transitivos e intransitivos

\begin{tabular}{l|l|l|l|l|}
\hline Pess & \multicolumn{1}{c|}{ SA $_{\mathbf{A}}$} & \multicolumn{1}{c|}{ A } & \multicolumn{1}{c|}{ So } & \multicolumn{1}{c|}{ O/POSP/NOM } \\
\hline $\mathbf{1}$ & $k-, w-, w y-$ & $j-, i n(i)-$ & $j-, y-$ & $j-, y-$ \\
\hline $\mathbf{2}$ & $m-, m y-$ & $m, m i-$ & $o-$ & $o-$ \\
\hline $\mathbf{1 + 2}$ & $k u t-$ & $k u t-$ & $u g u-$ & $u g u-$ \\
\hline $\mathbf{3}$ & $\emptyset-$ & $\emptyset-$ & $i-, \emptyset-$ & $i-, \emptyset-$ \\
\hline
\end{tabular}

\subsection{A FORMAÇÃO DO RADICAL VERBAL}


Esta seção aborda os processos derivacionais capazes de formar verbos a partir de nomes (verbalização) e também os que causam modificação do significado verbal, afetando o número de participantes. Com relação ao último caso, são encontrados os processos de causativização e detransitivização.

\subsubsection{Verbalização: $\{$-ke $\}$ e $\{$-te $\}$}

A existência de verbalizadores que derivam classes específicas de verbos é conhecida em várias línguas Karib como Tiriyó (MEIRA, 1999), Wayana (TAVARES, 2005), Kuikuro (SANTOS, 2007). A partir do exame do comportamento morfossintático dos verbalizadores $\{-k e\}$ e $\{$-te\}, é possível dizer que esta característica também se verifica em Arara, com poucas exceções. A língua em análise se utiliza do sufixo -te 'VZR' para derivar verbos intransitivos (apenas da classe $\mathrm{S}_{\mathrm{o}}$ ) a partir de nomes. Exemplos de nomes e de suas versões verbalizadas são oferecidos em (26) e (27).
a) imulun
$i-m u l u-n$
b) imuludeny
i-mulu-te-ny
3-tosse-POSSD
$3 \mathrm{~S}_{\mathrm{O}}$-tosse-VBR-PSD.IMD
'Tosse'
'Ele/a tossiu'

(27)

a) tamko

tamko

'Idoso, avô' b) idamkodeny

i-damko-te-ny

3So-idoso-VBR-PSD.IMD

'Ele/a envelheceu'

O verbalizador $-k e$, por sua vez, pode ser adicionado a alguns nomes, originando verbos transitivos, conforme os pares de exemplos em (28) e (29), (30) e (31). Possivelmente este morfema se trata de um cognato do sufixo - $k a$ 'verbalizador privativo' verificado em Wayana (Cf. TAVARES, 2005, p. 246) ou o verbalizador -ke em Ikpeng (CHAGAS, 2013, p. 90-95), por exemplo, assim como em outras línguas Karib nas quais deriva verbos cujo significado expressam basicamente "retirar o nome/substantivo". Uma possível exceção encontrada em que o verbo formado pertence à classe de intransitivos-So é iwatkely 'Defecou' 
(28) edabrun

$\emptyset$-edabru-n

3-porta/tampa-POSSD

'Porta ou tampa, o que serve para fechar' (Elic.)

(29) edabrukely

$\varnothing$-edabru-ke-ly

3O-porta/tampa-VBR-PSD.IMD

'Abriu' (Elic) (Lit.: 'tirou o que fechava')

(30) imarabry

i-maraby-ry

3-cerca-POSSD

'cerca, cercado' (Elic.)

(31) imarapkely

i-maraby-ke-ly

3O-cerca- VBR-PSD.IMD

'Abrir o cercado.' (Elic.) (Lit.: 'Tirar a cerca.')

Além disso, vale mencionar que um morfema homófono consiste em um derivacional verbal verificado em verbos transitivos, como exemplificado em (32) e (33) que trazem duas versões do radical verbal, com e sem o morfema $-k e$. Em algumas raízes, o significado deste prefixo se assemelha ao morfema 'des-' em português, presentes em verbos como 'descansar', 'descarregar'. Este sentido pode ser melhor observado no exemplo oferecido em (33b). Para alguns verbos a contraparte sem o referido morfema não é conhecida. Além disso, foi encontrado um exemplo em que o radical formado é intransitivo $\mathrm{S}_{\mathrm{o}}$ : Anpydekely 'Descansou'.

a) edentu-ly

apertar-PSD.IMD

'Ele/a apertou O'

(33)

a) imomy-ny

3O-amarrar-PSD.IMD

'Ele/a amarrou O' b) edentu-ke-ly

apertar-DER-PSD.IMD

'Ele/a afrouxou/desapertou O'

b) imomy-ke-ly

3O-amarrar-DER-PSD.IMD

'Ele/a desamarrou O'

Outro conjunto de morfemas verbalizadores identificado foi: $\{-m y,-n u m y,-$ tumy\}. Os verbos por eles formados são derivados a partir de nomes, conforme exemplificado em (34), (35) e (36) que apresentam os nomes e os resultados das verbalizações. Não foi possível 
verificar o contexto de ocorrência de cada sufixo apenas com o material disponível, porém a forma por eles apresentada sugere algum tipo de relação entre os mesmos, além de que variação alomórfica é um fenômeno comum à língua. Segundo MEIRA (2016, comunicação pessoal), este tipo de variação é comum entre as línguas da família; em alguns casos é cogitada a hipótese de que alguns morfemas verbalizadores incluem a marca de posse, ocasionando alomorfias.
a) i-daginu
3-assobio
b) i-daginu-my-ny
'Assobio'
3-assobiar-VBR-PSD.IMD
'Ele assobiou'

(35)

a) $i-b r i-n$

3-andada-POSSD

'Andada'

(36) b) i-bri-numy-ny

3-andada-VBR-PSD.IMD

'Ele andou'

b) i-gok-tumy-ny

3-gritar-VBR-PSD.IMD

'Ele gritou'

\subsubsection{Mudança de valência}

Valência consiste na inerente relacionabilidade de um item lexical que o permite governar um número particular de argumentos (HASPELMATH; MÜLLER-BARDEY, 2001). No caso da valência verbal aqui apresentada são consideradas as características semânticogramaticais e, sempre que possível, pragmáticas, de acordo com o que o contexto de uso permita depreender. Sintaticamente, o número de argumentos demandado pelo predicado indica a sua valência. De maneira geral, são requeridos um, dois ou três argumentos, sendo os predicados chamados de predicados monoargumentias, biargumentais e triargumentais, respectivamente. Cada argumento, por sua vez se relaciona a um papel semântico (Agente, Paciente, Experiênciador, Estímulo ${ }^{55}$, Causa etc). Contudo, Haspelmath (2014) aponta a reconhecida discrepância entre valência semântica e valência sintática. Em especial, os participantes semânticos não necessariamente são expressos sintaticamente.

${ }^{55}$ Como em "Sarah likes Farid" em que os participantes são caracterizados com os papéis semânticos experienciador e estímulo, respectivamente. Exemplo retirado de Haspelmath, Müller-Bardey (2001, pg.1) 
Em Arara, há verbos monovalentes e bivalentes que podem ter sua valência aumentada ou diminuída, respectivamente. Esta seção apresenta os morfemas eng-, -noby, -metpoby, -by e otxi- como os principais responsáveis pelas operações de causativização e detransitivização.

Em estudo anterior, Souza, S. (1993) identifica os morfemas: nop-, metpop- e $-p$ 'causativisadores'; eng-e $b$ - 'transitivisadores'; e od- ad- 'reflexivos', ond- and- 'reflexivos negativos'. Os dados aqui investigados não incluem os morfemas ond- and- e $b$-. Este último morfema não foi encontrado no corpus analisado. Quanto aos alomorfes ond- and-, no dialeto Iriri foi verificada a existência apenas do alomorfe ont-. $\mathrm{O}$ assunto demanda mais pesquisa.

\subsubsection{Causativização}

Os causativizadores possibilitam a inserção de um segundo agente (causer) a um predicado, forçando o agente da versão original (sujeito baixo ou caussee) a ocupar uma posição gramatical diferente. De acordo com Haspelmath e Müller-Bardey (2001), as possíveis posições gramaticais observadas translinguisticamente são: se o verbo for intransitivo, o causee passa a assumir o papel de objeto direto da causativisação, ou seja, o verbo simplesmente se torna transitivo. Se, por sua vez, o verbo for transitivo o causee pode ser tratado de três maneiras: ele pode ser tornar um objeto indireto, pode ser expresso como uma frase instrumental, ou se tornar um "segundo objeto" direto. Neste último caso, os autores apontam que análises detalhadas devem mostrar que o paciente do evento causado não consiste em um objeto direto verdadeiro no sentido de que não apresenta todas as propriedades de objetos diretos na língua.

Em Arara, verbos transitivos e intransitivos podem ser causativizados. Os novos padrões de valência são estabelecidos pelos causativizadores -noby, -metpoby, -by e eng-. Como demonstrado nas próximas subseções, quando verbos intransitivos são causativizados por -noby o causee assume o papel de objeto direto. Por sua vez, na causativização de verbos transitivos por -metpoby, o causee assume o papel de um argumento oblíquo. Quanto aos afixos -by e eng, mais informações são necessárias sobre o papel desempenhados pelos argumentos.

\subsection{Os morfemas $\{$-by $\}$ e $\{$ eng- $\}$}


Estes dois morfemas são pouco frequentes. Souza, S. (1993, p. 52) observa que o causativisador $-p$ ocorre apenas com certos verbos transitivos e intransitivos. Dentre os dados do dialeto analisado, este sufixo foi encontrado apenas em raízes transitivas. Exemplos são apresentados em (37) e (38).

(37) abybyly

$\emptyset$-aby-by-ly

3-mexer-CAUS-PSD.IMD

'Ele mandou mexer' (Elic.)

(38) janmebyly

j-anme-by-ly

1A-jogar-CAUS-PSD.IMD

'Ele mandou derrubar ela' (Elic.)

O prefixo eng-, por seu turno, foi verificado apenas em coorrência com o causativisador -by em uma única raiz, page 'acordar'. Testes com outros verbos geraram formas agramaticais. A mudança do padrão de valência do predicado intransitivo page pode ser observada comparando-se os exemplos em (39) e (40).

\begin{tabular}{|c|c|c|}
\hline (39) & jubagely & urangmo \\
\hline & ju-bage-ly & uran \\
\hline & $\begin{array}{l}\text { 3S } \mathrm{S}_{\mathrm{o}} \text {-acordar-PSD.IMD } \\
\text { 'A criança acordou' (E}\end{array}$ & \\
\hline
\end{tabular}

(40) urangmo jengpageptangte

urangmo j-eng-page-by-tang-te

criança 1A-CAUS-acordar-CAUS-ASP-PSD.MED

'Eu fiz a criança acordar' (Elic.)

A seguir é apresentado o comportamento do causativizador -noby.

\subsection{O morfema $\{$-noby $\}$}

O sufixo -noby CAUS simplesmente aumenta a valência de verbos intransitivos So. A adição de um segundo argumento nuclear (objeto) pode ser verificada comparando-se os exemplos (41), (42) e (43). Veja que uma das estratégias de identificação um verbo intransitivo 
consiste em examinar a forma do imperativo já que apenas verbos intransitivos $S_{o}$ apresentam morfologia de segunda pessoa. Este é o caso da raiz para 'afofar', também traduzido como 'desmurchar', apresentado em (41). Assim, observe em (42) que o argumento rong 'terra' só pode ser incluído na sentença quando o causativisador -noby está presente. Caso contrário, a sentença se torna agramatical, como em (43). O mesmo processo é ilustrado no par (44) e (45), que mostram a versão monoargumental e biargumental, respectivamente. O exemplo (46), por sua vez, demonstra que a versão intransitiva da raiz erang aceita um argumento oblíquo introduzido por uma posposição instrumental, enquanto na versão transitivizada, em (47), é possível acrescentar um argumento principal (sem posposição). Este último exemplo demonstra ainda que como os prefixos de pessoa que indicam as relações entre $1 \mathrm{~A} \rightarrow 3 \mathrm{O}$ e $3 \mathrm{~A} \rightarrow 1 \mathrm{O}$ são homófonos, são possíveis duas interpretações da sentença, se considerada fora de contexto.

(41) o-abunte

2-afofar 'afofa!'

(42) Tyaugo abunte-noby-ny rong saúva afofar-CAUS-PSD.IMD terra

'(A) saúva afofou (a) terra' (Elic.)

(43) *Tyaugo abunte-ny rong saúva afofar-PSD.IMD terra

(A saúva afofou a terra) (Elic.)

(44) urangmo dyngkyny dan

urangmo t-yngky-ny tan

criança 3-dormir-PSD.IMD aqui

'Menino dormiu aqui' (Txt)

(45) Poty tyngkynobyny urangmo

Poty t-yngky-noby-ny urangmo

NOM.PROP 3-dormir-CAUS-PSD.IMD criança

'Poty fez a criança dormir' (Elic.)

(46) (imro) erangy-ny ogoi=ge

ele assustar.se-PSD.IMD cobra=INS

'(Ele) se assustou com (a) cobra.' (Elic.) 
(47) Ogoi j-erang-noby-ny

cobra 10-assustar-CAUS-PSD.IMD

'(A) cobra me assustou ou eu espantei/assustei (a) cobra.' (Elic.)

Testes com verbos $S_{\mathrm{A}}$ foram rejeitados, como ilustrado em (48) e (49). A tentativa com verbos transitivos também resultou na completa rejeição ou causou incerteza nos falantes o que foi identificado pelo símbolo '?' no exemplo (50).

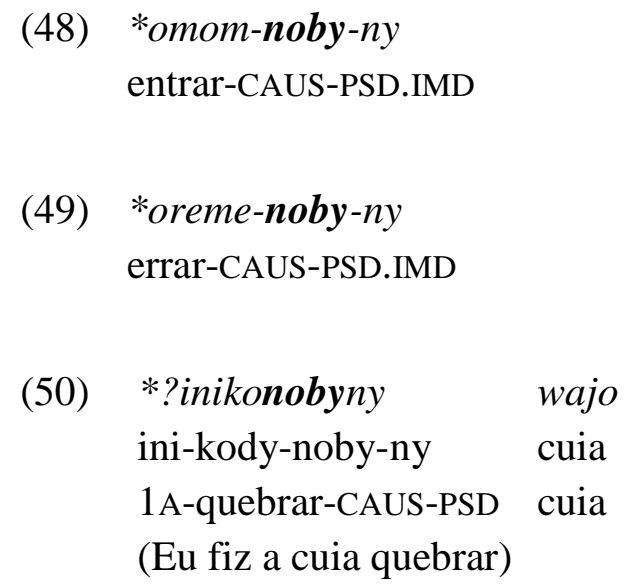

\subsection{O morfema $\{$-metpoby $\}$}

O morfema -metpoby adiciona o significado de causa e possibilita a inserção de um segundo agente a um predicado. Em verbos transitivos, o causee é expresso como um argumento oblíquo, como em (51) e (52). Em textos, geralmente, o causee é omitido, (53). Testes de mudança de valência com verbos intransitivos $S_{A}$ ainda não foram realizados. Alguns falantes aceitaram a inserção do morfema em verbos intransitivos da classe So. Neste caso, o agente da versão intransitiva (causee) assume as mesmas posições apresentadas anteriormente com o morfema -noby, como ilustrado em (54) e (55).

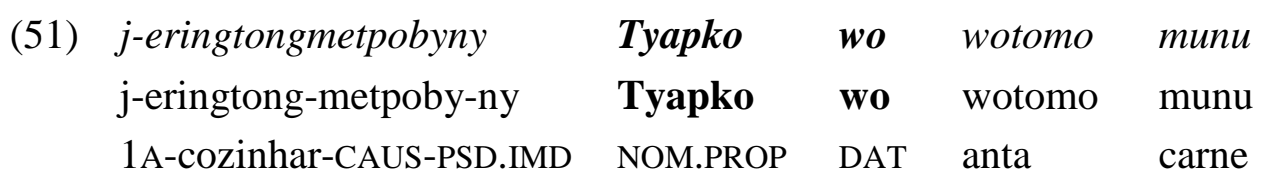

'Eu mandei Tyapko cozinhar carne de anta (Elic.) 
$(52)$

$\begin{array}{llll}\text { Paulo } & \text { wyna } & \text { inwomepoptana } & \text { abiana } \\ \text { Paulo } & \text { wyna } & \text { in-wo-mepoby-tan-na } & \text { abiana' } \\ \text { NOM.PROP } & \text { DAT } & \text { 1A-matar-CAUS-ALA-INTC } & \text { queixada }\end{array}$

‘Eu vou lá mandar Paulo matar porcão’ (Elic.)

(53)

Ynga ba menengmetpoptanpom erongmo

Ynga ba m-eneng-metpoby-tan-npom ero-ngmo

sim ? 2A-ver-CAUS-ALA-FUT isso-COL

'Sim, vocês mostrem essas coisas (para ela)' (Lit.: 'Sim, vocês façam-na ver essas coisas')

(54)

$\begin{array}{lll}\text { Kaiana } & \text { tynkymetpobyny } & \text { Marika } \\ \text { Kaiana } & \text { t-ynky-metpoby-ny } & \text { Marika } \\ \text { NOM.PROP } & \text { 3-dormir-CAUS-PSD.IMD } & \text { NOM.PROP } \\ \text { 'Kaiana fez Marika dormir' (Elic) } & \end{array}$

$\begin{array}{lll}\text { Tyaugo abuntemetpobyny } & \text { rong } \\ \text { Tyaugo abunte-metpoby-ny } & \text { rong } \\ \text { saúva afofar-CAUS-PSD.IMD } & \text { terra } \\ \text { 'A saúva afofou a terra' (Elic) } & \end{array}$

\subsubsection{Detransitivização}

Esta subseção apresenta as discussões iniciais sobre a interação entre aspectos semânticos, pragmáticos e gramaticais envolvidos no decréscimo de valência via morfologia detransitivisadora.

Enquanto é comum que diferentes morfemas sejam empregados para indicar as funções reflexiva, reciproca, voz médio-passiva, antiaplicativa, anticausativa e antipassiva, em línguas Karib este amplo espectro semântico é expresso pelo mesmo morfema detransitivizador (SAPIÉN et. al, trabalho em andamento). A expansão deste marcador para algumas dessas funções semânticas é apontada em Meira (1999), para cognatos em Tiriyó, e em Meira (2000) para cognatos em línguas Karib do Norte (Apalai, Kari'ña,Wayana, Makushi, Katxuyana e Panare). Em Arara, o morfema detransitivizador otxi- deriva verbos intransitivos da classe $\mathrm{S}_{\mathrm{A}} \mathrm{e}$ apresenta as funções reflexiva, reciproca, voz médio-passiva, antipassiva e anticausativa, como apresentado no decorrer desta subseção. 
O morfema é glosado genericamente como um detransitivizador devido ao fato de que os papéis semânticos codificados pelo mesmo sujeito intransitivo (morfologicamente semelhante ao A da versão transitiva) não serem previsíveis a partir da versão transitiva. Isto é, ora o papel semântico do agente é demovido, ora o papel do paciente (os termos 'agente' (A) e 'paciente' (P) são tomados de forma genérica). Analisamos os processos de demoção como partes de um mesmo fenômeno, embora estejam apresentados separadamente nos subitens a seguir.

Metodologicamente, foram analisados apenas os verbos detransitvizados que apresentam uma contraparte transitiva identificada. Embora a maioria dos verbos da classe $S_{A}$ apresente morfologia detransitivisadora reconhecível, ainda é desconhecido se tais raízes apresentam uma versão transitiva ou se se tratam de raízes lexicalizadas, isto é, formas deponentes $^{56}$. Estes casos não foram desconsiderados nesta análise. Assim, tendo em vista as duas versões da raiz, foram comparados os padrões de valência, antes e após a detransitivização, no que se refere:

(i) Aos papéis semânticos da versão transitiva (agente - paciente) e

(ii) Qual papel é assumido pelo sujeito na versão intransitiva.

Verificou-se que, quando o agente é removido, as sentenças detransitizadas podem apresentar leituras como reflexiva, reciproca, anticausativa e passiva, enquanto, quando o objeto é removido, a leitura possível é de antipassiva. As análises das raízes foram realizadas mesmo em construções nominalizadas.

\subsection{Leituras reflexiva e reciproca}

As leituras reflexiva e reciproca consistem nas mais comuns dentre os itens analisados. No caso da leitura reflexiva, o número de papéis semânticos continua o mesmo encontrado da versão transitiva, isto é, um agente e um paciente, mas a referência é ao mesmo participante. Compare os exemplos em (56) e (57). Veja que (56) demonstra A e P com referências diferentes na versão transitiva enquanto que em (57) o argumento $S$ da versão intransitiva, inferido pelo

\footnotetext{
${ }^{56}$ De acordo com a terminologia de Kemmer (1994, p. 183), o termo depondente se refere uma classe de verbos que não possui a contraparte de verbos sem a morfologia de voz média. Meu uso do termo é baseado nesta definição e corresponde à classe de verbos cuja contraparte sem a morfologia detransitivisadora é desconhecida.
} 
contexto, assume ambos os papéis A e P. Ou seja, S (a pessoa que o urubu tirou da árvore) é o 'jogador' e o elemento 'jogado' o qual sofre deslocamento durante a ação.

$\begin{array}{llll}{[\mathrm{O}} & \mathrm{V}] & \mathrm{A} & \\ \text { urangmo } & \text { anme-ny } & \text { koriamy, } & \emptyset \text {-eneng- } \varnothing \\ \text { menino } & \text { jogar-PSD.IMD } & \text { veado } & \text { 3-ver-IMP } \\ \text { 'O veado jogou o menino, olha!' (Txt) } & \end{array}$

(57) [od-anme-ny $]_{V P} \quad[\text { warami-um }=b o k]_{P P}$, kun-ke na

DTRZ-jogar-PSD.IMD babaçu-AUM sobre 3PSD.DST-dizer ?

'(A pessoa que o urubu tirou da árvore) Correu para perto do coqueiro, ele disse.' (Txt)

Na leitura reciproca, por sua vez, o argumento sintático $S$ também expressa dois papéis semânticos (A e P), porém estes não apresentam referentes idênticos, como demonstrado em (58). Os dois referentes são inferidos pelo contexto.

tyy tytong, tytong, tytong otxi-wi-nangry mong

IDEO.parar IDEO.balançar IDEO IDEO DTRZ-namorar-IPFV DEIT

'Parados, balanço, balanço, balanço... estão namorando (aquele que se transformou em tatu e a filha dele)' (Txt)

\subsection{Leitura Passiva}

O cenário da leitura passiva é caracterizado pela omissão do participante agente. Desta forma, S assume o papel semântico de P. Observe em (59) que o papel semântico de kure consiste no participante visto que é codificado como o $\mathrm{S}$ da sentença, enquanto o papel semântico daquele que viu (tximna $1+3$ ) pode ser inferido pelo contexto, mas não é expresso sintaticamente. Assim, seria possível a tradução '[...] quando terra boa era vista'. No exemplo em (60) é possível verificar que o sujeito (ugumi 'nossa comida') assume o papel do 'elemento assado' (isto é, S assume o papel do P), enquanto A da versão transitiva é codificado por um argumento oblíquo instrumental, semelhante a uma by phrase. Note em (61), que apesar de inanimado e não volitivo, o argumento txitxi 'sol' pode ser usado como sujeito nesta língua.

$\begin{array}{llllll}\text { (59) } & \text { [tukto } & \text { tximna } & \text { kunagiang } & \text { mylo] } & \text { [kure } \\ \text { tukto } & \text { tximna } & \text { kun-age-ak } & \text { mylo } & \text { kure } & \text { od-eneng-tup } \\ \text { roça } & 1+3 & \text { 3PSD.DST-cortar-ASP } & \text { lá } & \text { boa } & \text { DTRZ-ver-SUB }\end{array}$

'Nós derrubávamos roça lá no mato quando víamos terra boa' (Txt) 


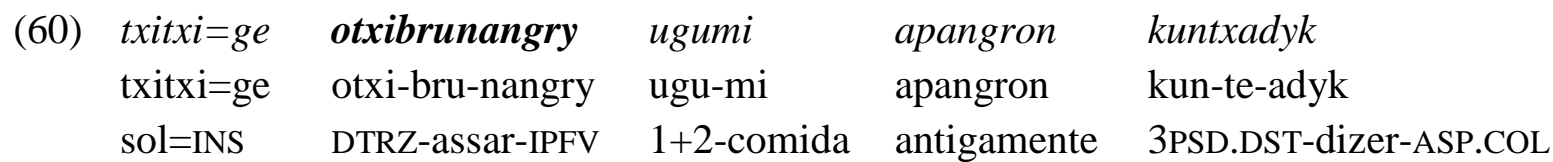

lon ba apangron kuntxadyk

lon ba kangron ku -te-adyk

FOC ? antigamente 3PSD.DST-dizer-ASP.COL

'Antigamente, assava nossa comida no sol, eles contavam lá' (Txt). (Lit.: Antigamente, nossa comida se assava pelo sol, eles contavam mesmo.)

(61) i-bru-bra txitxi

3O-assar-NEG sol

'Sol não assa' (Txt)

\subsection{Leitura anticausativa}

A anticausativisação é verificada quando o agente é removido completamente e $\mathrm{S}$ codifica o paciente de um verbo transitivo. Apenas um exemplo de leitura anticausativa foi encontrado. O exemplo (62) apresenta um exemplo da versão transitiva do verbo para 'começar' e, em (63), é apresentada a verão detransitivizada em que o agente não existe semanticamente.
janpyryda
iwanonpot
j-anpyry-da
i-wanong-npot
1 A-começar-INTC
3-empurrar-NOM

'Eu vou começar a empurrar' (Elic) (Lit.: 'Eu vou começar a empurração')

(63) warite n-i-tang od-anpyry-tpot

como 3-COP-INT DTRZ-começar-NOM

'Como é que vai ficar no começo?'

\subsection{Leitura antipassiva}

$\mathrm{Na}$ leitura antipassiva o sujeito $\mathrm{S}_{\mathrm{A}}$ se refere ao argumento originário $\mathrm{A}$, isto é, $\mathrm{S}_{\mathrm{A}}=\mathrm{A}$. $\mathrm{O}$ argumento O não é expresso, como em (64). Neste exemplo, o sujeito assume o papel de agente 
e como o objeto não faz referência ao mesmo participante, a leitura reflexiva é excluída. Pelo contexto, sabe-se que o agente não segurou a si mesmo, mas o 'genipapeiro' para evitar sua própria queda. O 'elemento segurado', porém, não é expresso sintaticamente. Outra possibilidade verificada é o objeto nocional ser expresso como um argumento oblíquo, conforme ilustrado em (65).

(64) okydokte anane od-abotxi-ny
parar(?) um $\quad$ DTRZ-segurar-PSD.IMD
'Parou (e) um se segurou' (Txt)

(65)

\begin{tabular}{|c|c|c|}
\hline odabotxiny & mobe byem & ektan pok \\
\hline od-abotxi-ny & mobe $=$ byem & ektan=pok \\
\hline DTRZ-segurar-PSD.IMD & cajá=parecido & galho $=$ sobre \\
\hline
\end{tabular}

$\begin{array}{lll}\text { kurompe } & \text { ektan pok } & \text { kuntxak } \\ \text { kurompe } & \text { ektan=pok } & \text { kun-te-ak } \\ \text { jenipapeiro } & \text { galho=sobre } & \text { 3PSD.DST-?dizer-IPFV.PSD } \\ \text { '(Ele) grudou no galho do cajazeiro, do genipapeiro, dizia' (Txt) }\end{array}$

\subsection{Outros usos: nomes e posposições}

O morfema otxi- também foi verificado em poucas raízes nominais, aquelas restritas a termos de parentesco, como em (66). Também foi verificado em raízes posposicionais, em (67) e (68). O limitado número de ocorrências em nomes e posposições sugere que o morfema não consiste em um pronome reflexivo, uma vez que pronomes são observados em um amplo conjunto de raízes. De qualquer modo, note-se o caráter flexional além do derivacional de otxi, o que é comum às línguas que apresentam reflexivizadores morfológicos. Como apontam Haspelmath e Müller-Bardey (2001, p. 16), de forma geral, o mais esperado é que os morfemas de mudança de valência estejam localizados na direção derivacional do contínuo flexionalderivacional devido à sua função. Isto porque, a mudança do número de participantes ou da natureza de seus papéis temáticos acarreta uma modificação substancial na situação descrita e é altamente relevante para o significado verbal. 
(66) ot-pin-kom bo

RECP-irmão.dela-COL deitar

'Casal de irmãos deitaram' (Lit.: Deitou com o próprio irmão dela)

(67)
mun agia
kelyngmo
odwo

mon age-a

ke-ly-ngmo

otxi-wo

DEIT cortar-IMP.ALA

dizer-PSD.IMD-COL

RECP-DAT

'"Corta lá", eles falaram entre os dois'

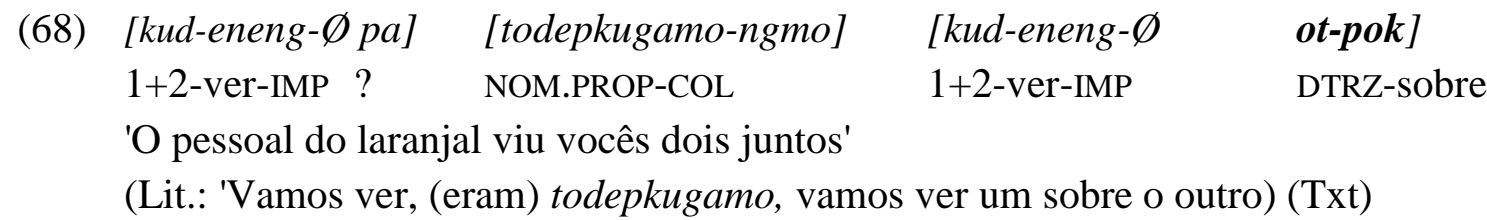

\subsection{PROCESSOS MORFOLÓGICOS DEVERBAIS}

Raízes verbais podem ser nominalizadas. Este processo é amplamente produtivo, sendo também possível a nominalização de advérbios e posposições. Foram identificados vários morfemas deverbais, alguns dos quais são reconhecidamente antigos, apresentando cognatos em outras línguas como $\{-n i\},\{-$ tobot $\sim-t p o t\},\{t-\ldots-t(e)\}$, e outros que podem estar em pleno processo de gramaticalização em que seu status derivacional, possivelmente, está se tornando mais flexional ${ }^{57}$. Este é o caso, por exemplo, de $\{$-tubo $\sim$-tpo -tubry -tpyn $\sim$ npyn $\}$ que são anexados a nomes ou nominalizações acrescentando uma semântica de passado, mas que estão sendo usados diretamente em raízes verbais, nominalizando-as. Embora estes alomorfes ainda demandem estudos mais completos, já é possível verificar alguns padrões.

Souza, S. (2010, p.91-95) apresenta estes últimos alomorfes apenas como sufixos de modificação nominal. A presente análise, por sua vez, introduz uma nova função moninalizadora e difere ligeiramente no que refere às fronteiras dos morfemas. Para Souza, S. (2010, p.92) os morfemas -tubo e $-n b o^{58}$ são alomorfes supletivos, sendo que o primeiro

\footnotetext{
${ }^{57}$ Este último tópico será tratado no último capítulo no que se refere aos apontamentos para futuros estudos sobre TAM.

58 Apenas no dialeto Arara há nasalização de obstruentes antecedidas por nasais. No dialeto Iriri, a forma deste morfema é -npo. Foram identificados os alomorfes \{-npo -tpo\} ocorrendo em distribuição livre: tapeda odo-npo e tapeda odo-tpo [professor-PSD.NOM] 'Era professor' (Lit.: '(Que) era dono do papel'). Ainda há a necessidade de mais estudos em relação a tal distribuição visto que a ocorrência de alomorfes semelhantes como -tpyn -npyn, por exemplo, é determinada pela natureza do último segmento do radical ao qual é sufixado. O alomorfe -npo não será tratado no presente estudo.
} 
apresenta os seguintes alomorfes -tubo, -dubo, -tpo, -tub-yry, -dub-yry, -tp-yn e o último apresenta as formas $-\boldsymbol{n} \boldsymbol{b} \boldsymbol{o}$ e $-\boldsymbol{n} \boldsymbol{b}-\boldsymbol{y n}$. As partes após os morfemas em negrito são analisadas como marcas de posse pela autora $(-y r y,-y n)$. No corpus analisado, considerando os grupos de morfemas que ocorrem em raízes possuídas e os que ocorrem em raízes não possuídas, não há contraste entre morfemas de mais de um grupo ocorrendo na mesma raiz, o que sugere que os morfemas estejam em distribuição complementar.

Deste modo, os alomorfes verificados no dialeto Iriri, de acordo com as regras fonológicas explicitadas no capítulo II, são: $\{-$ tubo $\sim$-tpo -tpyn npyn -tubry\}, os quais são presentados a seguir (seção 3.5.1). Optamos por não separar a última parte dos alomorfes tubry, tpyn e npyn já que as duas partes seriam determinadas lexicalmente e a divisão não contribui para a previsão de qual alomorfe deve ser anexado às raízes. Historicamente, no entanto, Gildea (1998) reconstrói o nominalisador absolutivo cognato **tupu-ru em que a última parte do morfema consiste em uma marca de posse.

Note que $\{$-tubo $\sim$-tpo -tpyn $\sim$ npyn $\sim$-tubry\} por modificar o significado do nome é glosado como um 'passado nominal'. Contudo, aparentemente, o morfema passa por um processo de gramaticalização haja vista que outros usos podem ser observados, como o da função nominalizadora, o que será demonstrado a seguir. O uso com uma função gramatical semelhante às flexões de TAM será apresentado no Capítulo 7.

Os demais morfemas nominalizadores são apresentados em seções individuais: $\{-n i\}$ em (3.5.2), $\{$-tobot $\sim$-tpot $\}$ em (3.5.3) e $\{t-\ldots-t(e)\}$ em (3.5.4).

\subsubsection{O morfema $\{$-tubo $\sim$-tpo $\sim$-tpyn npyn -tubry $\}$ PSD.NOM}

Os alomorfes -tpyn e -npyn ocorrem após radicais terminados em vogais. Neste contexto, a ocorrência de um ou outro é determinada lexicalmente. Quando anexados a nomes (ou nominalizações) acrescentam o significado de passado nominal, conforme ilustrado em (69), (70), (71), (72) e (73). O exemplo em (74) demonstra o uso do morfema como nominalisador. 
(69) imretpyn

te kumyk uro jeme muretpyn

i-mure-tpyn te kumyk uro jeme mure-tpyn

3-filho-PSD.NOM ? ASP 1 mãe filho-PSD.NOM

'Era filho dela, ex-filho da mãe' (Txt) (Contexto: Em uma narrativa pessoal, o consultor estava contando que sua mãe já havia falecido, assim ele era o 'ex-filho da mãe dele')

(70) erongmo lon jemiagrinpyn

ero-ngmo lon j-emiagri-npyn

DEIT.INA-COL FOC 1-trabalho-PSD.NOM

'Essas coisas mesmo eram meu trabalho' (Txt) (Lit.: "Essas coisas mesmo são meu trabalho passado")

(71) $\quad$ ibra... karei mydabri pongnotpyn ik potkun tximna ibra... karei mydabri pok-no-tpyn ik potkun tximna

Não, não.indígena comida sobre-NOM-PSD.NOM NEG INTENS $1+3$

'Nós não comia comida do branco de jeito nenhum' (Txt)

(72) tuminpyn juduny

t-umi-npyn j-udu-ny

3-comida-PSD.NOM REL-dar-PSD.IMD

'(Ele) deu aquilo que era comida' (Txt)

(73) karei wyna eganopko omorongmo lon yworuntutpyn karei wyna eganop-ko omoro-ngmo lon y-woruntu-tpyn não.indígena ADDR falar-IMP $\quad$ 2-COL $\quad$ FOC 1-palavra-PSD.NOM

' Vocês repassem o que eu falei para o não indígena' (Txt)

(Lit.: Fala para o não indígena! Vocês mesmo, aquilo que eu disse)

(74) odabytketpynkom

od-aby-tke-tpyn-kom

DTZR-brigar-ITR-PSD.NOM-COL

'Aquelas pessoas que discutiram' (Txt)

O alomorfe $\{$-tubry $\}$ ocorre após radicais cujo último segmento é uma consoante e pode ser traduzido como 'ex-', em algumas raízes. Exemplos são oferecidos em (75) e (76). Este sufixo também foi verificado com uma raiz verbal, (77). 
(75) Onat jodo edemtubry Iptximaum

Onat jodo edem-tubry Iptximaum

NOM.PROP marido-NOM.PSD NOM.PROP

'Iptximaum é ex-marido de Onat jodo.' (Elic.)

(76) ibytubry

i-by-t-tubry

3-fêmea-POSSD-PSD.NOM

'Era mulher dele' (Elic.)

(77) iptubry

iby-tubry

banhar.se-PSD.NOM

'O lugar onde ele banhou' (Elic.)

Os alomorfes $\{$-tubo $\sim$-tpo\}, diferentemente dos alomorfes anteriores, ocorre em nomes não possuídos. O exemplo em (78) demonstra a impossibilidade de afixação em um radical possuível. Quanto ao contexto de ocorrência, -tpo é verificado após vogais, como demonstram os exemplos (79), (80) e (81), e -tubo após consoantes, como em (82). O uso de $\{$-tubo -tpo\} como um nominalizador deverbal também foi atestada, como ilustrado em (83) e (84).

(78) *ikpitpo (Lugar onde era roça)

i-kpi-tpo

3-roça-PSD.NOM

(79) mobutpo

mobu-tubo

canoa-PSD.NOM

'Canoa velha, do falecido, deixada' (Elic)

(80) okpongotpo

okpo-ngo-tpo

chefe-NPOSSD- PSD.NOM

'Ex-liderança' (Elic.)

(81) umingotpo

umi-ngo-tpo

comida-NPOSSD- PSD.NOM

'Resto de comida (como galinha, castanha)' (Elic.) 
(82) ugondubo

ugon-tubo

homem-PSD.NOM

'O que era homem' (Elic)

(83) w-orik-tubo

CLASSE? ${ }^{59}$-dançar-NOM

'Lugar onde se dançava' (Elic)

(84) erengmy-tpo

matar-NOM

'Ferramenta que serve para matar' (Elic)

\subsubsection{O morfema $\{-$ ni $\}$ NOM.A}

O morfema -ni, conhecido na literatura Karib como nominalizador de agente, pode ocorrer em verbos transitivos e intransitivos, como mencionando anteriormente (seção 3.2.1, exemplos (5) e (6)). O rótulo escolhido indica que o resultado da nominalização é o agente do predicado verbal (oposto ao nominalizador de objeto cujo valor semântico resultante da nominalização é o objeto do predicado verbal). Outro exemplo deste morfema é apresentado em (85). Quando a raiz verbal recebe este sufixo, os prefixos pessoais encontrados são marcadores de objeto já que são estes os únicos licenciados a ocorrer em radicais nominais. Exemplos de radicais com flexão de pessoa são oferecidos em (86), (87) e (88).

$\begin{array}{lllll}\text { wongo } & \text { wo-tke-ni } & \text { inangry } & \text { Tema } & \text { iduako } \\ \text { wongo } & \text { wo-tke-ni } & \text { i-nangry } & \text { Tema } & \text { idua-ako } \\ \text { animais } & \text { matar-ITR-NOM.A } & \text { COP-IPFV } & \text { NOM.PROP } & \text { mata-dentro }\end{array}$

'Tema vai ser caçador no mato' (Elic) (Lit.: 'Tema será aquele que sempre mata animais')

(86) ideketkeni

i-deke-tke-ni

3-escrever-ITR-NOM.A

'Aquele que fica escrevendo' (Elic)

\footnotetext{
${ }^{59}$ Possivelmente consiste em um marcador de classe o qual ocorre apenas em raízes intransitivas.
} 
(87)

pumie ug-ene-ni-npyn angte-ny

mulher 1+2O-ver-NOM.A-PSD. NOM cair-PSD.IMD

'A mulher que nos viu caiu' (Elic) (Lit.: 'Mulher, aquela que nos viu, caiu')

(88) pumie ine-ni-npyn angte-ny

mulher 2over-NOM.A-PSD.NOM cair-PSD.IMD

'A mulher que viu você caiu' (Elic) (Lit.: 'Mulher, aquela que viu você, caiu')

\subsubsection{O morfema $\{$-tobot $\sim$-tpot $\}$ NOM}

Cognatos deste morfema são descritos como nominalizadores circunstanciais ou de evento (oposto às nominalizações de participantes) em Tiriyó (MEIRA, 1999) e Wayana (TAVARES, 2005). Foi verificado que este morfema ocorre tanto em radicais transitivos quanto intransitivos, nominalizando-os, como ilustram os exemplos (89) e (90), respectivamente. Veja nestes exemplos que as formas deverbais podem funcionar como argumento em (89) e como objeto de posposição em (90). Comparando (91) e (92), também é possível verificar que as formas com -tobot apresentam a mesma estrutura nominal $(\mathrm{N} \mathrm{N})$, além de ocorrem em construções subordinadas, como em (91).

$\begin{array}{ll}\text { eganoptobotkon } & \text { inidanangry } \\ \text { eganop-tobot-kon } & \text { ini-dang-nangry }\end{array}$

falar-NOM-somente? 1A-ouvir-IPFV

'Eu ouvia as histórias' (Txt) (Lit.: 'Eu ouvia a fala ou o falado')

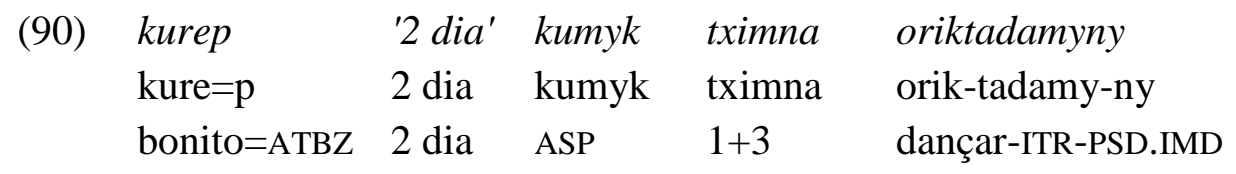

oreme-tpot pok

oreme-tpot pok

acabar-NOM sobre

'Nós dançamos dois dias antes de terminar' (Txt)

\begin{tabular}{|c|c|c|c|}
\hline \multirow{4}{*}{ (91) } & {$[[\mathrm{N}$} & ]$_{\mathrm{NP} . \mathrm{O}}$ & REL-V ] $]_{\mathrm{VP}}$ \\
\hline & [tybrinta & eguamtobot] & txenenangry \\
\hline & [ty-byrinta & eguam-tobot] & j-eneng-nangry \\
\hline & REFL-outro & sentar-NOM & REL-ver-IPFV \\
\hline
\end{tabular}


(92) [PSSR POSSD]

jei ektan

árvore galho

'Galho do pau'

Por outro lado, as formas sufixadas com -tobot podem carregar as mesmas marcas de pessoa encontradas em formas finitas. Compare os morfemas pessoas dos exemplos (93) e (94), nos quais há uma forma finita e uma nominalizada, respectivamente. Um exemplo com a segunda pessoa é fornecido em (95).

(93) komomyly

k-omomy-ly

$1 \mathrm{~S}_{\mathrm{A}}$-entrar-PSD.IMD

'Eu entrei' (Elic.)

(94) komomtobot

k-omomy-tobot

$1 \mathrm{~S}_{\mathrm{A}-\mathrm{entrar}-\mathrm{NOM}}$

'Minha entrada' (Elic.)

(95) momomtobot inmongoguly

m-omomy-tobot in-mongogu-ly

$\mathbf{2 S}_{\mathbf{A}}$-entrar-NOM 1A-esperar-PSD.IMD

'Eu esperei a tua entrada'

\subsubsection{O particípio $\{t-V-t e\}$}

A forma $\boldsymbol{t}$-V-te é considerada uma estrutura única, uma vez que sem uma das partes a expressão se torna agramatical. O morfema $t$ - apresenta as mesmas alomorfias do prefixo de terceira pessoa reflexiva $(t(y)-\text {, to- })^{60}$, entretanto, tal significado não se aplica a estas construções, pois elas podem ser usadas com qualquer pessoa. A segunda parte do circunfixo apresenta o alomorfe - $t$ após radicais terminados em vogal e -te após radicais terminados em consoantes.

\footnotetext{
${ }^{60} t$ - diante das vogais, ty- diante de consoantes, to- diante de raízes iniciadas por algumas vogais e por $w$ - (este alomorfe apresenta uma distribuição restrita, possivelmente se trata de uma exceção ocasionada por queda de segmentos ao longo do tempo).
} 
Souza, S. (1993) considera que a estrutura é formada por um prefixo reflexivo e um sufixo nominalizador (o morfema reflexivo e o morfema da primeira parte da estrutura seriam dois morfemas homófonos, embora ela use apenas a glosa 3REF para ambos). Em Souza, S. (2010, p.97), a autora reitera que há homofonia entre os dois morfemas citados anteriormente, assim como com o prefixo usado em alguns verbos transitivos para marcar o objeto. Contudo, ela afirma não estar tomando posição de que as formas sejam relacionadas ou apenas acidentalmente homófonas.

Em línguas Karib, estruturas cognatas à $t-\mathrm{V}-t(e)$ levaram à reconstrução na proto-língua da forma $* * t-V$-ce (GILDEA, 1998). Como será demonstrado, essa estrutura é verificada como um particípio estático e como um particípio passivo. Este último uso foi apontado em Souza, S. (1993). Os exemplos a seguir ilustram usos canônicos em que a palavra que contém o circunfixo está funcionando como predicado de um nome (da mesma forma que uma construção de predicação não verbal). A função de modificação atributiva também é possível. Quando o verbo com o circunfixo é transitivo, o participante mencionado na construção representa o $\mathrm{O}$ da construção ativa, como em (96) e (97). O participante A pode ocorrer como um argumento oblíquo, conforme ilustra o exemplo (98). Quando o verbo é intransitivo este participante corresponde ao argumento S, (99).

(96) wampiat ty-ge-t

açaí PRTC-tirar-PRTC

‘Açai (já está) tirado' (Elic)

$\left[\begin{array}{ll}\mathrm{O} & \mathrm{V}\end{array}\right]_{\mathrm{VP}}$

(97) wongo enemnangryngmo

wongo enep-nangry-ngmo ty-momy-t ty-amyt

animais trazer-IPFV-COL PRTC-amarrar-PRTC 3REFL-criação

'Eles estão trazendo carne de bicho amarrado' (Txt) (Lit.: 'Estão trazendo animais.

Criação deles mesmos (já estão) amarrados')

(98) (uro) jenengry karato tangmuket urangmo wyna

(uro) j-eneng-ry karato t-angmuke-t urangmo wyna

1 1A-ver-PSD.IMD cuia PRTC-quebrar-PRTC criança

'Eu vi a cuia quebrada pelo menino' (Elic.)

(99) t-odakpi-t uro

PRTC-embebedar.se- PRTC 1

'Eu estou bêbado' (Elic.) 
Além do uso participial, foi identificado o uso da estrutura com a função eventiva, o que será apresentado no Capítulo 7, entre os desdobramentos para futuros estudos.

\subsection{SÍNTESE}

Neste capítulo foi apresentado um panorama das características morfossintáticas que permitem a distinção da classe de verbos dentre as classes de nomes, advérbios e posposições. Os verbos são os que mais apresentam possibilidades de afixação de morfemas exclusivos como os prefixos argumentais e os morfemas de TAM. A partir do padrão de alinhamento dos argumentos pessoais presos, do alinhamento de pessoa no imperativo e da negação foi possível identificar uma classe de verbos transitivos e duas classes de verbos intransitivos. Certamente, outras características morfossintáticas serão descobertas em futuros estudos, corroborando a classificação aqui introduzida.

Além disso, foram explorados os processos que possibilitam a modificação de valência de um radical verbal como a causativização e, principalmente, a detransitivização que possibilita um amplo espectro de leituras as quais ainda não haviam sido verificadas nas línguas do ramo pekodiano. A formação de um radical verbal a partir de um nome também foi brevemente apresentada. Estes processos não se mostram tão robustos em Arara da forma como se apresentam em Kuikuro (SANTOS 2007) ou Tiriyó (MEIRA 1999), por exemplo. Os processos deverbais, por sua vez, são, basicamente, a nominalização realizada por meio de vários morfemas derivacionais de passado nominal que passam a assumir a nova função de nominalizar raízes verbais. Nesse caso, a conotação de passado é mantida. Foi apresentado ainda o processo de formação de particípio por meio do circunfixo $t$-...t(e), um mecanismo conhecido na família linguística.

A partir do conhecimento construído sobre o comportamento morfossintático da classe de verbos, passamos a explorar, especificamente, as flexões de pessoa e número e sua relação com os morfemas de TAM nos próximos capítulos. 


\section{PARTE II}

\section{CAPÍTULO 4 - MORFEMAS DE TAM E SUAS FUNÇÕES GRAMATICAIS: ALGUMAS CONSIDERAÇÕES}

Este capítulo investiga as funções gramaticais codificadas pelas flexões de TAM. A seção 4.1 explicita a literatura que fundamenta o estudo, a qual acaba se mostrando mais baseada em definições epistemológicas do que conceitos teóricos ${ }^{61}$. Tal seção não pretende fazer uma revisão exaustiva da robusta literatura sobre TAM. Por outro lado, busca apresentar conceitos chave que se mostrem suficientes para as análises. A seção, 4.2 apresenta a literatura prévia sobre TAM em Arara. Os morfemas são analisados nas seções subsequentes. Em 4.3, é tratada a categoria de Tempo: passados (imediato, médio e distante) e futuro. Em 4.4, é examinada a categoria de Aspecto com o iterativo, o imperfectivo, o imperfectivo passado e o resuntivo. Em 4.5, é investigado o Modo, categoria que mais se sobressai em termos de número de flexões, com: o imperativo (proximal e alativo), o vetativo, o permissivo, o hortativo, o admonitivo, o interrogativo, o intencional e o frustrativo. A seção 4.6 traz uma síntese do capítulo.

\subsection{INTRODUÇÃO TEÓRICA}

As línguas podem expressar a temporalidade de por diversos meios: morfemas de tempo, aspecto, aktionsart, advérbios temporais, partículas temporais e princípios do discurso (KLEIN, 2009). Dentre essas possibilidades, as categorias gramaticais Tempo e Aspecto estão tão intrinsecamente relacionadas que pode se tornar bastante complexo o exame de apenas uma categoria, se isto for possível na língua em análise. Como aponta Smith (1997), as noções de Tempo e Aspecto constituem sistemas individuais, mas diretamente relacionados: "Temporal location and aspect are complementary temporal systems. The former locates a situation in time, while the latter specifies the internal temporal structure of the situation (Ibid., p. 97)".

A temporalidade expressa pela categoria Tempo tem sido objeto de estudo de muitos autores. O conceito bastante citado na literatura é de Comrie $(1985)^{62}$, por exemplo. Para os

\footnotetext{
${ }^{61}$ A teoria da semântica formal, por exemplo, que apresenta grande rigorosidade metodológica.

62 "Tense is grammaticalized expression of location in time" (COMRIE 1985, p. 9)
} 
objetivos deste trabalho, porém, a versão conceitual mais específica, sugerida por Haspelmath (1997), se mostra mais adequada, já que este estudo abrange apenas as flexões verbais. Segundo esta, Tempo consiste na grammaticalized expression of location in time on verbs (Ibid., p.11, grifo nosso). Outras formas de expressar a temporalidade como por meio de advérbios, posposições, partículas e o aspecto lexical (aktionsart) são citadas, mas não constituem o foco desta investigação.

Quanto à definição operacional, este estudo segue a formalização de Smith (1997), inspirada em Hans Reichenbach, que está baseada na relação entre três momentos: o momento de fala (MF), o momento do evento (ME) e o momento de referência (MR) ${ }^{63}$. A relação entre tais momentos é utilizada para a identificação do tempo relativo e do tempo absoluto. $\mathrm{O}$ ME e o MR se posicionam em relação ao MF para darem as interpretações de passado, presente e futuro. Como para o tempo absoluto, o ME e o MR são sempre simultâneos, basta procurar o ME em relação ao MF. No presente simples, os três momentos são simultâneos. No passado simples, ME precede MF. No futuro simples, ME segue MF, lembrando que em ambos os casos, MR é simultâneo com ME. A notação temporal é resumida na tabela 4.1.

Tabela 4.1 - Notação na linha do tempo, baseada em (SMITH, 1997)

\begin{tabular}{|c|c|c|}
\hline Passado & Presente & Futuro \\
\hline ME $<$ MF & ME $=\mathbf{M F}$ & MF $>$ ME \\
\hline (ME é anterior ao MF) & (ME é simultâneo ao MF) & (ME é posterior ao MF) \\
\hline
\end{tabular}

No tempo relativo, por sua vez, não há qualquer simultaneidade entre os referidos momentos (ME, MF, MR), o que possibilita a criação de um tempo dentro de outro, como o pretérito-mais-que-perfeito do português brasileiro. Veja que em "Ele respondeu que já vendera o carro", o evento de "vender" ocorreu em um passado anterior ao evento de "responder" que também denota passado. Este estudo analisa apenas construções com o tempo absoluto.

Com base em 63 línguas de diferentes famílias linguísticas da América do Sul, Mueller (2014) indica que, em sua amostra, as línguas que apresentam marcas morfossintáticas de Tempo (absoluto) fazem três tipos de distinção, conforme a tabela 4.2.

Tabela 4.2 - Distinções de tempo gramatical, baseada em (MUELLER 2014, p.25)

\begin{tabular}{|l|l|}
\hline Tipo 1 & Futuro e Não futuro; Passado e Não passado \\
\hline Tipo 2 & Passado, Presente e Futuro \\
\hline Tipo 3 & Passado e Futuro \\
\hline
\end{tabular}

63 "Speech time, Reference time e Situation Time" 
A autora explica que estas distinções tratam o tempo Presente de maneira diferenciada. O primeiro tipo inclui a possibilidade de que o Presente seja marcado por uma forma ${ }^{64}$ de Futuro ou de Passado. O segundo tipo apresenta um conjunto de três marcas morfossintáticas diferentes de zero (overtly marked) e o terceiro tipo marca passado e futuro, mas nunca o presente (com morfema diferente de zero). A título de ilustração, vejamos os dados de Karitiana, de acordo com a análise de Storto (2002) para sentenças no modo declarativo:

(1) Karitiana (Tupi) (STORTO, 2002, p. 72, tradução nossa)

\begin{tabular}{|c|c|c|c|}
\hline $\begin{array}{l}A \quad \text { horot } \\
\text { aquele como }\end{array}$ & $\begin{array}{l}\text { tyym } \\
\text { também }\end{array}$ & $\begin{array}{l}\text { ajxa } \\
2 \mathrm{PL}\end{array}$ & $\begin{array}{l}\varnothing \text {-naka-'a-j } \\
\text { 3-DECL-fazer-FUT }\end{array}$ \\
\hline
\end{tabular}

aj-osi tykiri
2PL-fazer.osii PFV
'Vocês mesmos farão como quando vocês tiram Osiip'

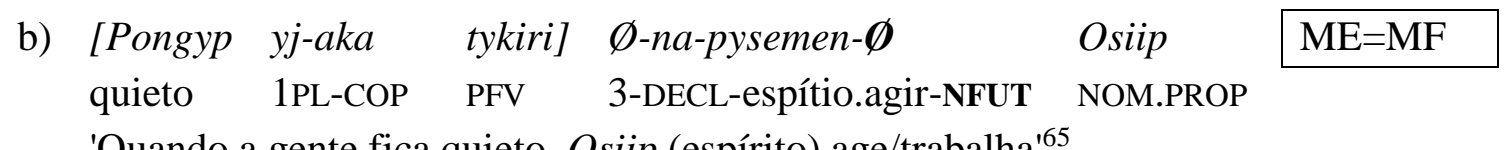

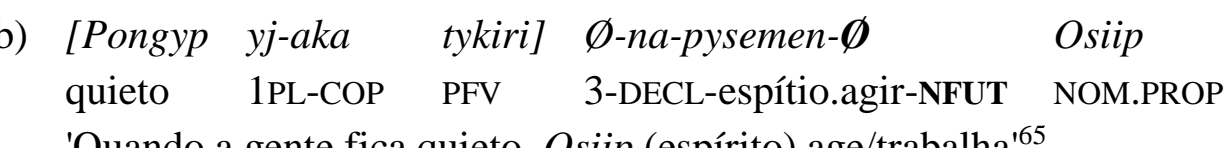

'Quando a gente fica quieto, Osiip (espírito) age/trabalha'65

$\mathrm{ME}>\mathrm{MF}$

$\begin{array}{lll}\text { c) Yjxa } & \emptyset \text {-na-oky-t } & \text { him } \\ \text { nós } & \text { 3-DECL-matar-NFUT } & \text { animais.selvagens }\end{array}$

$\mathrm{ME}<\mathrm{MF}$

'Nós matamos animais selvagens'

Segundo a autora, a distinção entre futuro e não futuro é marcada pelos alomorfes $\{-j$ / $-i\}$ e $\{-t /-\varnothing\}$, respectivamente. O exemplo (1a) ilustra o futuro e (1b) e (1c) ilustram o não futuro. Note que o não futuro pode ser interpretado como presente ou passado de acordo com o contexto. Deste modo, esta língua apresenta marcação morfossintática do tipo 1.

Também relevante para o presente estudo é a noção de graus de distância temporal (degrees of remoteness), ou seja, as "subdistâncias" entre o ME e o MF. Graus de distância temporal podem ser expressos morfossintaticamente para o passado e/ou para o futuro, com

\footnotetext{
64 Para a autora, essa forma seria portmanteau ou cumulativa, porém, como bem observado por um dos componentes da banca, diferente do que aponta a autora em suas conclusões tipológicas, uma forma que se refira ao Presente com uma marca morfossintática verbal de Não-Passado ou Não-Futuro não é realmente portmanteau. Trata-se, antes, de um caso em que a forma em questão não distingue Passado e Presente, ou Futuro e Presente. Isto é, não estão sendo marcadas duas categorias semânticas, simultaneamente, como é característico dos morfemas cumulativos. O que ocorre é que as categorias são indistintas, da mesma forma que Arara não distingue gênero em seus pronomes pessoais, por exemplo.

65 'when one is quiet, the Osiip's spirit works its way'
} 
variação quanto ao número de distinções. O Miranã, por exemplo, apresenta dois graus de distância temporal no passado: o passado remoto (PSD) e o passado recente (REC), como ilustrado em (2a) e (2b), respectivamente.

(2) Miraña (Witoto) (SEIFART, 2005, p.72, tradução nossa)

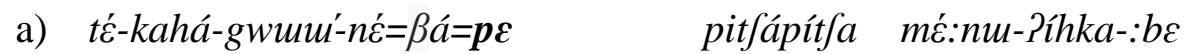

PN-SCM.lago-DIM-PL=RPT=PSD ONOM fazer-HAB-GCM.MASC.SG

'Nos laguinhos, ele sempre fazia "pitfápítfa" (som de ficção de uma sacola com veneno para peixe), eles dizem'66

b) $a:-b \dot{=}=n \varepsilon k u$

gwá?da-hké-?i- ri

ó $\quad u^{\prime} d z \varepsilon-h \varepsilon ́-? i$

CON-GCM.MASC.SG=REC guaya-SCM.vine-SCM.rio-LOC 1 ir-DIR3-PRD

'E eu fui para o rio da guaya-vine (recentemente)' ${ }^{67}$

É importante observar que, conforme explicitado pelo autor, no caso de Miraña o passado recente expressa uma sentença que ocorreu durante o mesmo dia ou no dia anterior, porém, de maneira geral, nem sempre há exatidão sobre onde termina um certo grau de distância e começa o próximo grau. Segundo Comrie (1985), as fronteiras dos tempos separados pelos graus de distância temporal são fluidas, de maneira que as escolha por um tempo atípico para uma dada distância é possível para dar a impressão subjetiva de proximidade ou afastamento/distância do momento presente.

Conforme indica Comrie (1985), uma diferença entre as categorias Tempo e Aspecto consiste no fato de que apenas o Tempo constitui um sistema deitico (relação de entidades a um ponto de referência), enquanto o Aspecto, isto é, a discussão da constituição temporal interna de uma situação é independente de sua relação com qualquer outro ponto.

Segundo Smith (1997), o Aspecto compreende dois tipos de informações. O primeiro tipo proporciona um ponto de vista, isto é, a situação é apresentada segundo uma perspectiva particular. O segundo tipo de informação corresponde à classificação indireta de um estado ou de um certo evento. Ambas as informações coexistem na sentença. O Aspecto de ponto de vista se refere ao perfectivo e imperfectivo, sendo, geralmente, codificado morfologicamente. Já o Aspecto situacional, referente a eventos e estados, é codificado mais abstratamente por meio do verbo e seus argumentos, os quais a autora chama de constelação verbal. Este último

66 'In the little creeks he always did "pitfápitfa" (sound of rubbing a bag with poison for fishing), they say'.

${ }^{67}$ 'And I went to the river of the guaya-vine (recently)' 
é conhecido na literatura como aktionsart ou estrutura interna do evento ou aspecto lexical. Os dois tipos de aspecto, frequentemente, têm algum tipo de efeito sobre o outro e esta relação implica que o estudo apenas de um deles fornece um conhecimento parcial. Contudo, a fim de estabelecer uma delimitação, este trabalho prioriza o aspecto de ponto de vista.

O aspecto situacional é dividido em cinco 'situações': States, Activities, Accomplishments, Achievements e Semelfactives. Estas situações aspectuais são identificadas por um conjunto de três propriedades binárias: i) Estaticidade/dinamicidade, ii) Duratividade/estantaneidade, iii) Telicidade/atelicidade. Resumidamente, a dinamicidade é o traço responsável pela divisão inicial entre Estados e Eventos, em que aqueles são todas as situações não dinâmicas, logo todo Evento é dinâmico. Além da dinamicidade, a interação entre as outras propriedades binárias são usadas para demonstrar o tipo de evento denotado pela sentença, isto é, Activities, Accomplishments, Achievements e Semelfactives. Desta forma, os eventos caracterizados como Activities apresentam como propriedade a durativide. Accomplishments são durativos e télicos. Achievements são télicos e Semelfactives são instantâneos e atélicos. Este tipo de Aspecto não será investigado neste estudo, o que torna desnecessário maiores elaborações sobre o tópico.

$\mathrm{O}$ aspecto de ponto de vista, por sua vez, fornece uma visão parcial ou total do evento. Em termos genéricos, o perfectivo denota a totalidade do evento, apresentando o início e o final da situação, também chamadas situações fechadas. Dahl (1985) assim o descreve: "[...] Mais frequentemente do que nunca, o evento será pontual, ou pelo menos, será visto como uma transição única de um estado para o seu oposto, cuja duração pode ser desconsiderada". (Ibid, p. 78, tradução nossa)

O imperfectivo expressa uma visão parcial da situação, sendo conhecido por expressar situações abertas. De acordo com Comrie (1976), o imperfectivo faz "[...] explícita referência à estrutura temporal interna da situação, vendo a situação a partir do lado de dentro." (Ibid., p.24, tradução nossa). Ademais, o imperfectivo e o perfectivo são descritos com subdivisões. Bybee, Perkins e Pagliucca (1994), por exemplo, mencionam os Aspectos Completivo e o Resultativo como instâncias do Perfectivo; e Habitual, Progressivo/Durativo/Contínuo, Iterativo, Frequentativo e Continuativo como instâncias do Imperfectivo. Há ainda o Aspecto Anterior, também conhecido como Perfeito. De maneira geral, a distinção entre as instâncias aspectuais não é facilmente identificada e mais de uma pode ser codificada pelo mesmo morfema. 
Além de Tempo e Aspecto, a categoria Modalidade faz parte desse conjunto de categorias muitas vezes referido como uma unidade, simplesmente, TAM. Conforme apresentado em Bybee, Perkins e Pagliuca (1994), há uma grande área de conexão entre estas categorias. Tempo e aspecto podem ser codificados pelo mesmo morfema, assim como modo e tempo etc. Além disso, questões morfofonológicas podem influenciar a favor de uma análise com morfemas cumulativos. De acordo com Palmer (2001, p. 1), a modalidade se diferencia de tempo e aspecto por não se referir diretamente a nenhuma característica do evento, mas simplesmente ao status da proposição que o descreve. No entanto, ainda não há consenso sobre como a definição deve ser elaborada. Nuyts (2006, p.1) aponta que este domínio é caracterizado por um conjunto mais específico de noções, cada uma das quais é definida separadamente, elas podem compartilhar certos traços, motivando o agrupamento sob o rótulo Modalidade, mas diferem em muitos outros aspectos ${ }^{68}$. Frequentemente, o termo Modalidade se refere à função ou domínio semântico enquanto Modo se refere apenas à flexão verbal. Este estudo investiga apenas a Modalidade expressa por meio de flexões verbais, isto é, Modo.

Quanto às combinações possíveis entre as categorias de Tempo, Aspecto e Modo, há uma assimetria no sentido de que nem todas as combinações teriam compatibilidade de significados. Segundo Haspelmath (2002, p. 65), por exemplo, o Aspecto Perfectivo, que implica que um evento é visto em sua totalidade, não combinaria bem com o tempo Presente, que implica que o falante ainda está no meio do evento. Ou ainda, o Imperativo, que expressa um comando, não combina com o Passado.

Este estudo não ambiciona uma separação estritamente delineada entre as categorias. Assim, estipulamos que o rótulo de uma categoria será dado de acordo com a principal função identificada. No caso de categorias multifuncionais, por exemplo, que expressam modo e aspecto, o rótulo deverá fazer referência à função que se sobressair. Demais observações sobre as definições de cada categoria são feitas no decorrer das (sub)seções específicas, quando pertinente.

A seção a seguir resume o que é dito na literatura anterior acerca dos morfemas de TAM em Arara.

\footnotetext{
${ }^{68}[. .$.$] the domain is usually characterized by referring to a set of more specific notions, each of which is defined$ separately, and which may be taken to share certain features motivating their grouping together under the label modality, but which differ in many other respects (ibib., p. 1, grifo do autor).
} 


\subsection{A LITERATURA PRÉVIA E TAM EM ARARA}

Alguns morfemas de Tempo, Aspecto e Modo são explicitamente tratados no apêndice II da dissertação de Souza, S. (1993). Este trabalho identifica os sufixos e seus alomorfes, ilustrando-os com alguns exemplos. As flexões abordadas são de: passado (recente e remoto), presente, futuro (imediato, remoto), imperativo, hortativo, advertência, permissivo, contínuo, repetição, deslocamento. O tema é novamente apresentado, de passagem, em Souza, I. (2010) que oferece morfemas que não haviam sido trazidos por Souza, S. (1993), como o tempo universal -tang -ang. Segundo Souza, I. (2010), o tempo universal indica sentenças que não apontam para um tempo específico, mas funcionam como suporte para marcadores aspectuais de perfectivo e de imperfectivo. Em sentenças interrogativas parece funcionar como tempo não passado (Ibid., p. 30, tradução nossa ${ }^{69}$ ). $\mathrm{O}$ mesmo autor traz ainda os aspectos perfectivo e imperfectivo e os modos afirmativo e indicativo.

Os morfemas flexionais verificados nestes trabalhos são resumidos na tabela 4.3. Demais glosas, embora não tratadas diretamente como flexões verbais nestes trabalhos, também foram incluídas.

Tabela 4.3 - Morfemas de tempo, aspecto e modo ${ }^{70}$

\begin{tabular}{|c|c|c|}
\hline \multirow{7}{*}{ 尽 } & $-y l y \sim-y r y,-l y \sim r y$ & PSD.REC \\
\hline & $-n e \sim-n$ & PSD.REM \\
\hline & -tome & FUT (sentenças afirmativas) \\
\hline & $-t x a$ & FUT.IMD \\
\hline & -tang $\sim-$ ang & FUT.INT, NPSD \\
\hline & -tang $\sim-$ ang & Tempo universal (incompletivo?) \\
\hline & $-t x i \sim-t$ & PRES \\
\hline \multirow{5}{*}{$\begin{array}{l}\frac{0}{0} \\
\frac{\pi}{2} \\
\frac{0}{2}\end{array}$} & -nangyry & PROG, CONT \\
\hline & $-k y \sim-g y$ & IPFV \\
\hline & -tadamy & ITR \\
\hline & -tke & ITR, repetição \\
\hline & $-d e$ & PFV \\
\hline \multirow{5}{*}{$\frac{0}{8}$} & $-k \partial \sim-k$ & IMP \\
\hline & $-n \varepsilon \sim-n$ & HORT \\
\hline & $-b a$ & AFIR \\
\hline & -tane $\sim$-ane $\sim$-jane & ADVERTÊNCIA, ADM \\
\hline & $-b a$ & IND \\
\hline
\end{tabular}

69 \%-(t)ay/ has been glossed as universal tense (Uni) because: (a) in indicative clauses it does not point to a specific time, but only functions as a support to the aspect markers for perfective and imperfective; (b) in interrogative clauses it seems to function as a non-past tense (SOUZA, I. 2010, p. 30)'

${ }^{70}$ A escrita foi adaptada de acordo com a ortografia utilizada neste trabalho. 


\begin{tabular}{|l|l|}
\hline $\boldsymbol{- b} \boldsymbol{a}$ & Enfase \\
\hline $\boldsymbol{- t} \boldsymbol{a}, \boldsymbol{- a},-$ tana $\sim$-ana & DESL, Distal \\
\hline $\boldsymbol{-} \boldsymbol{d} \boldsymbol{a}$ & Próximo (Near) \\
\hline $\boldsymbol{- a}$ & PERM \\
\hline $\boldsymbol{- n} \boldsymbol{b o m}$ & IMP.EUF ("depois") \\
\hline
\end{tabular}

Fonte: Adaptado de Souza, I. (2010) e Souza, S. (1993, 2010)

O presente estudo oferece a função gramatical e exemplos de todos estes morfemas, exceto -txi $\sim-t$ PRES, $-k y \sim-g y$ IPFV, $-b a$ IND, $-b a$ AFIR, $-b a$ Ênfase', pois os dados disponíveis não foram suficientes para se chegar a conclusões. Com relação aos morfemas aqui tratados, algumas vezes, os rótulos foram mantidos ou atualizados e, em outras situações, apresentamos uma análise para justificar um novo rótulo. Além disso, são apresentados os morfemas $\{-(t) a k p y\}$ RESUN, $\{-$ menpo $\}$ FRUST, $\{-(t) a\}$ IMP.ALA, e $\{-(t) a n g\}$ ADM que não haviam sido identificados anteriormente como morfemas flexionais. Todas as formas finitas apresentam uma flexão de tempo ou de aspecto ou ambas. Ou, ao invés disso, uma flexão de modo, modo e aspecto ou modo e tempo.

Os títulos das seções a seguir fazem referência apenas a uma categoria por vez, Tempo, Aspecto e Modo, refletindo a categoria que se sobressai naquela seção, porém categorias relacionadas são incluídas nas discussões. As flexões de TAM analisadas até o presente são apresentadas nas seções subsequentes.

\subsection{TEMPO}

A temporalidade relacional entre o ME e o MF é marcada por sufixos de passado e de futuro (o morfema de futuro não expressa o Presente, o qual é uma das nuances de significado do imperfectivo). Como é comum às línguas Karib, há mais de um grau de distância temporal para o passado enquanto o futuro apresenta apenas uma distância ( $C f$. DERBYSHIRE, 1999). Como será demonstrado na seção 4.3.1, o morfema de passado selecionado no predicado verbal depende de três graus de distância temporal. Sempre que disponível, são apresentados advérbios de tempo como uma forma de corroborar o significado da flexão, já que, mesmo que isto cause redundância, a flexão é obrigatória. Pela mesma lógica, se os significados não forem compatíveis (ex.: em português: amanhã é incompatível com a flexão de passado), o esperado é uma sentença considerada agramatical. 


\subsubsection{Os passados: $\{-l y \sim-$-ry $\}$ PSD.IMD, $\{-n e \sim-n\}$ PSD.DST, $\{-$ te $\sim-t\}$ PSD.MED}

Foram identificados três morfemas de passado que chamaremos de imediato, médio e distante. Enquanto a distinção entre o passado imediato e o passado distante é mais facilmente observada, a forma chamada de passado médio requer de estudos mais específicos. Vale obervar que tanto o passado imediato quanto a do passado distante possuem cognatos em várias línguas Karib, sendo reconstruível em proto Karib (Cf. GILDEA 1998, p. 98).

O passado imediato $\{-l y \sim-r y\}$ denota eventos que ocorreram antes do evento de fala, ME < MF. Exemplos são apresentados em (3), (4) e (5):

(3)

$\begin{array}{llll}\text { urangmo } & \text { korongkoro } & \text { engrukely } & \text { dan } \\ \text { urangmo } & \text { korongkoro } & \text { eng-ru-ke-ly } & \text { dan } \\ \text { menino } & \text { sapo.sp. } & \text { olho-POSSD-VBZ-PSD.IMD } & \text { aqui }\end{array}$

'Menino viu sapo aqui.' (Txt)

(4) papa irumpoly

papa i-rumpo-ly

papai 3-morrer-PSD.IMD

'Papai morreu' (Txt)

(Obs.: O pai do autor faleceu antes do aldeamento, há mais de 30 anos.)

$\begin{array}{llll}\text { (5) abiana } & \text { abadyly } & \text { ydelon } & \text { potkun } \\ \text { abiana } & \text { abady-ly } & \text { ydelon } & \text { potkun } \\ \text { queixada } & \text { passar-PSD.IMD } & \text { hoje } & \text { INTENS } \\ \text { 'Porcão passou agorinha' (Elic.) } & \end{array}$

Não foram identificadas fronteiras precisas entre os graus de passado. O passado imediato é utilizado tanto em textos que narram eventos que ocorreram há muito tempo, como em (4), quanto em textos que reportam eventos que acabaram de ocorrer, (5). Da mesma forma, o passado distante $\{-n e \sim-n\}$ pode ser usado para se referir a um evento muito anterior ao momento de fala (vários anos), como em (6) e (7) ou para um evento que ocorreu ontem, (8). Este tipo de imprecisão causada por fronteiras fluidas parece indicar que mais fatores podem estar envolvidos, além dos graus de distância temporal. Por exemplo, nos textos, enquanto o passado distante na forma do morfema portmanteu kun- 3PSD.DST ocorre, majoritariamente, no verbo ke 'dizer', o passado imediato é mais observado na fala reportada. Não se pode esquecer que o tipo de texto analisado também pode estar desempenhando algum papel na escolha das flexões. Uma sequência de passado imediato e passado distante é ilustrada em (9). 
(6)

$\begin{array}{llll}\text { entento } & \text { mygen } & \text { omro } & \text { potkun } \\ \text { entento } & \text { my-ke-n } & \text { omro } & \text { potkun } \\ \text { eu.estou.aqui(?) } & 2 \mathrm{~S}_{\mathrm{A}} \text {-dizer-PSD.DST } & 2 & \text { INTENS }\end{array}$

'Eu estou aqui, você mesmo falou' (Txt)

(Contexto: o evento ocorreu quando o interlocutor era criança. Atualmente ele é um adulto)

(7)

$\begin{array}{llllll}\text { tybongne } & \text { lon } & \text { tximna } & \text { omomne } & \text { txik } & \text { ento } \\ \text { ty-bogo-ne } & \text { lon } & \text { tximna } & \text { omomy-ne } & \text { txik } & \text { ento } \\ \text { ADV-choro-ADV } & \text { FOC } & 1+3 & \text { entrar-PSD.DST } & \text { IDEO.parado } & \text { aqui }\end{array}$

' Nós viemos chorando de saudades ficar aqui' (Txt)

(Contexto: Falando do período do aldeamento definitivo, cerca de 30 anos atrás)

(8) inkokun

in-koku-n

1A-chamar-PSD.DST

'Eu o chamei' (Explicação do falante: 'faz tempo, ontem') (Elic)

$\left[\begin{array}{ll}\mathrm{S} & \mathrm{V}\end{array}\right]_{\mathrm{VP}}$

(9) tximna anpydeny tximna wem egromodu $=p$

tximna anpyde-ny tximna wem egromodu $=p$

$1+3$ cansar-PSD.IMD $1+3$ bagagem pedado=ATBZ

$[3-\mathrm{V} \quad \mathrm{S}$ ] $\mathrm{VP}$

$\begin{array}{llll}\text { kunke } & \text { Txibingmo } & \text { bige } & \text { lon } \\ \text { kun-ke } & \text { Txibi-ngmo } & \text { biget } & \text { lon } \\ \text { 3PSD.DST.dizer } & \text { NOM.PROP-COL } & \text { mais.ou.menos } & \text { FOC }\end{array}$

'Nós cansamos, nossa bagagem está pesada, falou o pessoal do Txibi' (Txt)

Enquanto o passado distante, idealmente, expressa um passado mais anterior ao momento de fala do que o passado imediato, o passado médio $\{-t e \sim-t\}$ expressaria um passado intermediário entre estes dois. Exemplos são oferecidos em (10), (11) e (12).

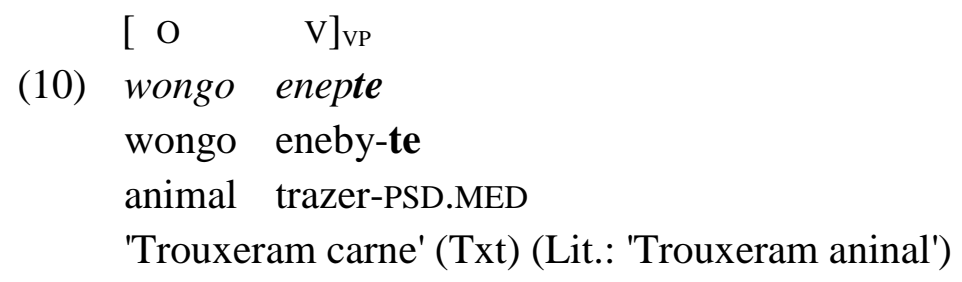




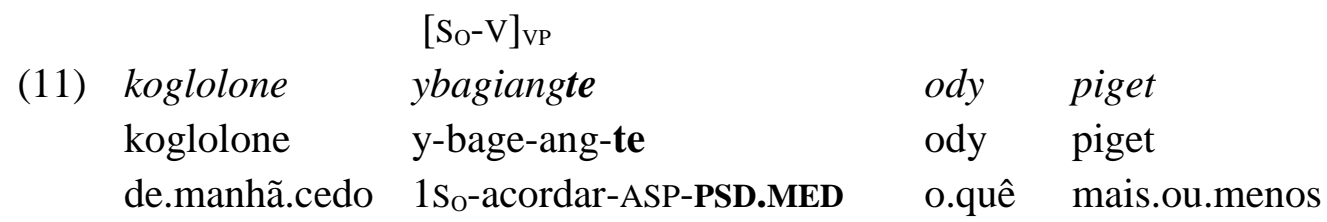

\begin{tabular}{|c|c|c|c|c|}
\hline jengaptang & $p a$ & ymren & $\begin{array}{l}{\left[\mathrm{S}_{\mathrm{A}}-\mathrm{V}\right]_{\mathrm{VP}}} \\
\text { wygeangte }\end{array}$ & jubaget \\
\hline j-engap-tang & pa & y-mure-n & wy-ke-ang-te & ju-bage-t \\
\hline REL-comer-INT & $?$ & 1-filho-POSSD & $1 \mathrm{~S}_{\mathrm{A}}$-dizer-ASP-PSD.MED & 3S $\mathrm{S}_{\mathrm{O}}$-acordar-PSD.MED \\
\hline
\end{tabular}

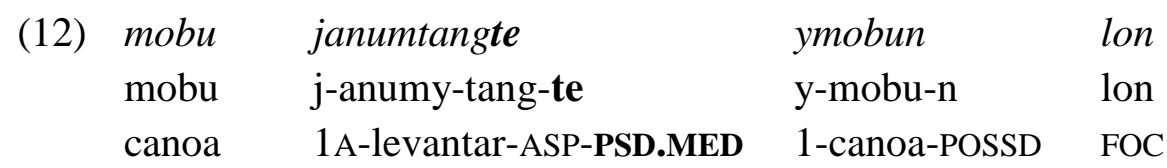

'Peguei minha canoa mesmo' (Txt) (Lit.: 'Eu peguei canoa, minha canoa mesmo')

Note-se que o morfema de passado médio é raramente encontrado sem a presença do morfema \{-tang ang\}. Este último morfema será tratado na seção 4.4.3 juntamente com o morfema \{-tak\} IPFV.PSD. Ainda sobre o passado médio, Souza, I. (2010) glosa o morfema -de como um marcador de perfectivo. Em nossos dados, algumas vezes, o sentido de perfectivo também foi observado, como em (13). No entanto, este morfema não ocorre com os outros passados, o que não exclui a possibilidade de se tratar de uma dimensão dessa mesma categoria temporal. E ainda, de acordo com nossa estipulação, o rótulo deve fazer referência à principal denotação funcional do morfema. Neste caso, o perfectivo deveria por default ser codificado por meio da flexão \{-te\}. O que se verifica, no entanto, é que a noção de situação completa ou fechada, que apresenta início e fim, também se faz presente com os passados imediato e distante, como ilustram os exemplos (14) e (15), respectivamente.

\section{(13) wiptangte}

w-iby-tang-te

$1 \mathrm{~S}_{\mathrm{A}}$-tomar.banho-ASP-PSD.MED

'Eu já banhei' (Elic.)

(14) kongpo tebyny

kongpo t-eby-ny

chuva 3-vir-PSD.IMD

'Já choveu' (Elic.) (Lit.: Chuva veio) 


\section{(15) kogokun}

ko-goku-n

1A2O-chamar-PSD.DST

'Eu já te chamei' (Comentário do falante: 'não vai chamar novamente') (Elic.)

Vale observar que morfemas cognatos a $\{-(t)$ ang $\}$ também são encontrados em Ikpeng. Pacheco (2001, p.80) descreve -ay+te como um passado remoto completivo. Chagas (2013), por sua vez, prefere chamar -tangte de passado não imediato o qual está em variação livre com o morfema $\{-m y\}$. Segundo a autora, "ambos os morfemas podem ser usados tanto para se referir a um evento que aconteceu há um ou dois dias antes do evento narrado, quanto a um evento que aconteceu há muitos anos antes (Ibid., p. 102). Ou seja, ainda há uma ausência de consenso sobre a relação entre o sentido de perfectividade e o morfema -tangte.

\subsubsection{O futuro $\{$-tome $\sim$-tpom $\sim$-npom $\}$}

As flexões \{-tome, -tpom e -npom\} indicam que o evento ocorrerá após o momento de fala, MF > ME, conforme exemplificado em (16). Observe que a flexão é compatível com o advérbio koglon 'amanhã' em (17). As variantes \{-tpom\} e \{-npom\} são ilustradas em (18) e (19), respectivamente. Geralmente, as situações são traduzidas pelos falantes como eventos que serão realizados depois.
ugubagedub
kudeptome
ugu-bage-dup
kud-eby-tome
$1+2 \mathrm{~S}_{\mathrm{O}}$-acordar-SUB $\quad 1+2 \mathrm{~S}_{\mathrm{A}}$-vir-FUT
'Quando a gente acordar, a gente vem.' (Elic.)

(17) jeneptome mobu koglon

j-eneby-tome mobu koglon

1A-trazer-FUT canoa amanhã

'Eu vou trazer a canoa amanhã' (Elic.)

(18) kogonnge tagie mukudytpom

kogonnge tagie m-uku-dy-tpom

final.de.tarde INTENS 2A-experimentar-COL-FUT

'De tarde vocês vão dançar (ao redor do Jei bari)' (Txt)

(Obs.: Enunciado antes do final da tarde) 
(19) jenenpom

j-eneng-npom

1A-ver-FUT

'Vou dar uma olhada depois' (Elic.)

Souza, I. (2010) aponta apenas a variante $\{$-tome $\}$ como um morfema de futuro em sentenças afirmativas e glosa $\{-n b o m\}$ como um imperativo eufêmico. Entretanto, duas pistas sugerem que o melhor rótulo para esta última flexão também seja futuro. Primeiro, a alomorfia das variantes é previsível (Capítulo II, seção 2.10.10) e, segundo, o verbo com estas flexões apresenta morfemas argumentais para todas as pessoas, o que não é comum para o imperativo. Por outro lado, considerando o caminho de gramaticalização apontado em Bybee, Perkins e Pagliuca (1994) para o futuro e a sua relação com a modalidade, talvez os morfemas tenham tido diferentes origens em que um dos morfemas possa ter tido uma função mais modal. Conforme estes autores apontam, possíveis fontes originárias do futuro têm sabores modais de obrigação e desejo, por exemplo.

\subsection{ASPECTO}

As distinções aspectuais expressas por flexão são o iterativo, o imperfectivo (passado e não passado) e o resuntivo

\subsubsection{O iterativo $\{$ tke $\}$, $\{$-tadamy $\}$}

Comrie (1979) define as situações iterativas como aquelas em que fatos pontuais ou semelfactivos se repetem por determinado período de tempo. Contudo, este período de tempo pode ser relativo o que, por sua vez, torna a diferença entre fatos iterativos e habituais bastante tênue. Este trabalho considera situações habituais aquelas em que os eventos se repetem entre intervalos de tempo maiores do que em situações iterativas, as quais apresentam repetições sucessivas de um mesmo evento que também pode ser semelfactivo (ex.: explodir várias vezes).

No corpus analisado, o sentido de habitualidade é marcado com o imperfectivo, apresentado na seção a seguir, 4.4.2. O aspecto iterativo, por sua vez, é codificado por dois 
alomorfes supletivos $-t k e^{71}$ e -tadamy que indicam que um evento ocorreu várias vezes. Compare os pares de exemplos (20a) e (20b), e (21a) e (21b) nos quais é possível perceber que tal sentido está sendo codificado pelos referidos morfemas. As traduções de construções com estes morfemas, geralmente, trazem expressões como 'tanto', 'demais' e 'bastante' de acordo com o radical verbal.

$\begin{array}{lll}\text { a) } & \text { kekeu } \quad \text { igokuny } & \text { Tuki } \\ \text { kekeu } \quad \text { i-goku-ny } & \text { Tuki } \\ \text { NOM.PROP } & \text { 3O-chamar-PSD.IMD } & \text { NOM.PROP } \\ \text { 'Kekeu chamou Tuki' (Elic) } & \end{array}$

$\begin{array}{ll}\text { b) igokutkeny } & \text { enmeptobotke } \\ \text { i-goku-tke-ny } & \text { enmep-tobot=ke } \\ \text { 3O-chamar-ITR-PSD.IMD } & \text { amanhecer-NOM=INS } \\ \text { '(Ela) chamou tanto antes de amanhecer' (Txt) }\end{array}$

arangmo anumyny
urangmo anumy-yny
criança levantar-PSD.IMD
'(Ele) levantou o menino' (Elic.)

b) anumtadamynangry

$\varnothing$-anumy-tadamy-nangry

(3A)3O-levantar-ITR-IPFV

'(Ele) levantou (o menino) várias vezes' (Elic)

Como pode ser observado nos exemplos acima, o morfema $\{$-tke\} denota múltiplos eventos. Além disso, como ficará claro a seguir, foi verificado que o morfema pode denotar a distribuição desses eventos entre os participantes. Estas características são compatíveis com a noção de pluracionalidade, isto é, o plural de eventos.

Hofherr e Laca (no prelo) definem plural de eventos como um mecanismo linguístico por meio do qual se expressa multiplicidade de eventos o que pode ser marcado por expressões adverbiais, adnominais ou afixos verbais. Segundo as autoras, o marcador verbal foi denominado de pluracional para que este morfema pudesse ser facilmente diferenciado do morfema de plural verbal que marca concordância. Tal definição se alinha com as análises de

\footnotetext{
71 Um morfema cognato é descrito em Ikpeng também como um marcador aspectual de iteratividade ( $C f$. PACHECO 1997, 2001; CHAGAS 2013).
} 
Lasersohn (1995) que caracteriza os marcadores pluracionais como aqueles que se ligam ao verbo para indicar a multiplicidade de ações que podem envolver distribuição por participantes, ocorrência em intervalos de tempo ou em diferentes locais. Estes marcadores se apresentam, principalmente, na forma de afixos, reduplicações (certamente um subcaso de afixação) ou supleção (possivelmente um subcaso de afixação na morfologia distribuída).

Exemplos em que o morfema $\{$-tke $\}$ também expressa pluracionalidade são apresentados em (22) e (23). Note que, em ambos os casos, houve mais de um evento de matar. Em (22), a denotação de multiplicidade de eventos conferida ao verbo implica mais de um paciente, embora não haja qualquer marca de plural no argumento objeto, abiana 'queixada'. Em (23), a distribuição dos eventos ocorre em um maior intervalo de tempo e em locais diferentes. Note que, segundo informação dos falantes, a história se passa antes do contato definitivo, período em que, esporadicamente, animais pertencentes aos não indígenas eram mortos dentro dos currais.

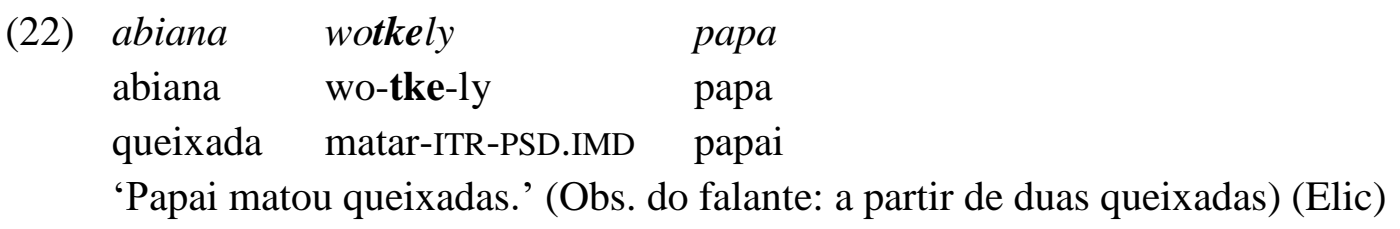

$\begin{array}{llllll}\text { (23) jei } & \text { amtem } & \text { podap } & \text { kunwotke } & \text { aturaum } & \text { Karajamkeni } \\ \text { jei } & \text { amtem } & \text { podap } & \text { kun-wo-tke } & \text { aturaum } & \text { Karaja-mkeni } \\ \text { árvore } & \text { casa } & \text { dentro } & \text { 3PSD.DST-matar-ITR } & \text { boi } & \text { NOM.PROP-finado } \\ \text { 'Finado karaja matou (muito) boi dentro da casa de madeira'. (Txt) }\end{array}$

É relevante observar que o aspecto iterativo/habitual e o campo da pluracionalidade sofrem intersecção principalmente no que se refere à distribuição de eventos no tempo. Hofherr e Laca (no prelo) apontam que é flagrante a imposição da pluralidade sobre a distribuição das ações não apenas no tempo, mas também entre os argumentos, o que é difícil de ser explicado apenas com o aspecto. Além disso, há restrições sobre eventos declarativos e pressupostos, e a existência de alguns eventos múltiplos que são incompatíveis com a marcação de exata cardinalidade. Assim, para estas autoras, esses dois campos apresentam áreas de confluência, mas são fenômenos diferentes. Isto é, o plural de eventos pode marcar iteratividade assim como o aspecto verbal e vice-versa, mas, possivelmente, outros indícios na língua analisada corroborarão a existência de pluracionalide como um fenômeno por si próprio.

Alguns trabalhos como os de Abdolhosseiniet (2002) e Yu (2003) oferecem uma análise da relação entre o aspecto lexical e a multiplicidade de eventos. Segundo tais discussões, o 
significado conferido ao verbo pelo marcador pluracional é mais derivacional, sendo previsível de acordo com a classe de aspecto lexical a qual pertence o verbo. Porém, em geral, esta relação ainda necessita de mais estudos, como observam Hofherr e Laca (no prelo). Como, até o presente, não se verificou fatos que justificassem uma divisão entre duas categorias, este trabalho, trata a pluraconalidade com um dos traços semânticos do aspecto. Isto é, a pluracionalidade consiste em um traço secundário.

\subsubsection{O imperfectivo $\{$-nangry}

Trabalhos anteriores glossam o morfema \{-nangry\} como um marcador aspectual progressivo ou continuativo ( $C f$. SOUZA, S. 1993; SOUZA, I. 2010), no entanto, segundo a presente análise, uma melhor definição seria a de um marcador aspectual geral de imperfectivo, como será exposto.

Conforme os exemplos (24), (25) e (26), construções com o \{-nangry\} são interpretadas como eventos contínuos. Este parece ser o sentido default.

$\begin{array}{llll}\text { tohk tohk tohk } & \text { ewe } & \text { itpyn } & \text { jangnangryngmo } \\ \text { tohk tohk tohk } & \text { ewe } & \text { itpyn } & \text { j-agu-nangry-ngmo } \\ \text { ONOM.bater? } & \text { mururu caroço } & \text { REL-comer.alimento.consistente-IPFV-COL } \\ \text { 'Eles todos estavam comendo caroço de murumu' (Txt) }\end{array}$

(25)

$\begin{array}{llll}\text { urangmo } & \text { igokunangry } & \text { en podap } & \text { ronam } \\ \text { urangmo } & \text { i-goku-nangry } & \text { en=podap } & \text { ronam } \\ \text { criança } & \text { 3O-chamar-IPFV } & \text { DEIT=dentro } & \text { buraco } \\ \text { 'Menino está gritando dentro do buraco' (Txt) }\end{array}$
pyndonongmo
erewepipo
dynangry
pyndono-ngmo erewepipo dy-nangry
esperador-COL tipo.de.flauta tocar-IPFV
'Os esperadores estão tocando flauta' (Txt)

Segundo Smith (1997), é típico do progressivo apresentar a conotação de dinamicidade, isto é, o progressivo é incompatível com verbos estativos. O imperfectivo, por outro lado, ocorre com todos os tipos de situações - dinâmicas ou estáticas (ibid., p.74). A mesma conclusão é encontrada em Comrie (1976, p. 35) que afirma que stative verbs do not have progressive forms, since this would involve an internal contradiction between stativity and the non stativity 
essential to the progressive. Ainda segundo este autor, o continuativo consiste em uma supercategoria, pois abrange o progressivo e pode ser usado com predicados estativos. Em Arara, a cópula pode ser sufixada por -nangry, acrescentando, principalmente, o sentido incoativo (mudança de estado) às construções, conforme ilustrado em (27), (28), (29) e (30). Considere que, nesta língua, a semantica relativa a propriedades é expressa, morfossintaticamente, por nomes e advérbios. A sufixação da cópula demonstra que o sentido de uma situação contínua é apenas uma das nuances deste morfema. Isto sugere que a caracterização 'progressivo', enquanto categoria gramatical, não cobre todas as referências aspectuais por ele codificadas.

$\begin{array}{llll}\text { iretput } & \text { pok } & \text { inangry } & \text { amy } \\ \text { i-retput } & \text { pok } & \varnothing \text {-iti-nangry } & \text { amy } \\ \text { 3-cabelo.da.cabeça } & \text { sobre } & \text { 3-COP-IPFV } & \text { piolho }\end{array}$

'Tem piolho na cabeça ou piolho existirá para a cabeça ou piolho está vindo para a cabeça.' (Elic.)

(28) emetju odo w-i-nangry

emetju odo w-iti-nangry

enfermeiro $\quad 1 \mathrm{~S}_{\mathrm{A}}$-COP-IPFV

'Eu vou ser enfermeira' ou 'Eu me tornarei enfermeira'

(29) toregrumte

inangry

t-oregrum-te

iti-nangry

PRTC-triste?-PRTC COP-IPFV

'Ele/a vai ficar triste.'

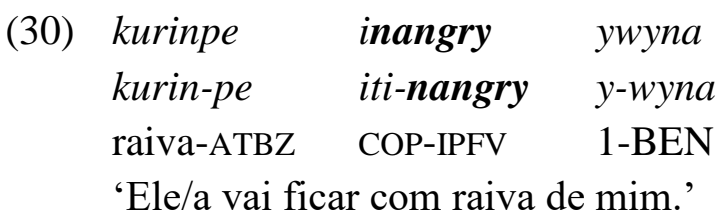

Quando advérbios e expressões temporais são acrescentadas às construções, eles funcionam como âncora para o tempo da situação (ME), tornando possível se verificar que \{-nangry\} é compatível com marcadores de futuro e de habitualidade. Os exemplos (31) e (32) ilustram eventos no presente habitual, sem expressões temporais, e os em (33) e (34) demonstram a compatilidade com expressões habituais, isto é, que indicam intervalos temporais regulares. 
(31) [kodotpotup] jerimtonangry wongo

k-odotpody-tup j-erimtong-nangry wongo

$1 \mathrm{~S}_{\mathrm{A}}$-Voltar-SUB $1 \mathrm{~A}$-cozinhar-IPFV animal

'Quando eu volto (da caçada), eu cozinho bicho' (Txt) (Contexto: o falante está contando como é sua rotina)

(32) kok tximna ibenangry

kok tximna i-beng-nangry

noite $\quad 1+3 \quad 3$ S-correr-IPFV

'Nós corremos de noite' (Txt) (Contexto: antes do contato, o deslocamento à noite se tornou um hábito, pois nesse horário eram menores as chances de encontrarem não indígenas pelo caminho)

(33) jemopkenangry iwap kyden

j-emopke-nangry i-wap kyden

$1 \mathrm{~A}$-arrancar-IPFV 3-frente mandioca

'Primeiro, eu arranco a mandioca.' (Txt) (Contexto: explicação de como o falante faz farinha)

(34) ydek potkun judunangry mипи

ydek potkun j-udu-nangry munu

todos.os.dias INTENS 1A-dar-IPFV carne

'Todo dia, eu dou carne de bicho' (Elic.) (Contexto: todos os dias a pessoa vai caçar, então ela dá/distribui carne todos os dias)

O exemplo (35) demonstra a possibilidade de ocorrência com um advérbio que expressa futuro.

\section{(35) koglon wydonangry \\ koglon $\quad w$-ydo-nangry \\ manhã $1 \mathrm{~S}_{\mathrm{A}}$-ir-IPFV}

'Eu vou embora amanhã.' (Elic)

Foi verificado também que o morfema é compatível com o termo temporal de passado idangron 'antigamente', conforme demonstra o exemplo (36). Entretanto, este caso demanda mais investigações visto que quando tentamos combinar o advérbio kogonnge que pode ser traduzido como 'ontem' ou 'ao entardecer do mesmo dia', a interpretação escolhida é sempre esta última, indicando que o evento ocorrerá após o evento de fala (MF > ME), como exemplificado em (37). 
(36)
jeme eganomnangry
idangron
jeme
$\varnothing$-eganop-nangry
idangron
mamãe 3-falar-IPFV
antigamente

'Antigamente mamãe falava.' (Txt) (Contexto: a mãe do autor falava que o queixada era criado pelo não indígena)

\section{kogonnge \\ anmenangry \\ kogonnge \\ $\emptyset$-anme-nangry}

ao.entardecer.do.mesmo.dia 3O-jogar-IPFV

'De tarde ele vai jogar O' (Elic) (Expl.: enunciado antes da tarde)

Conforme os exemplos apresentados, são várias as possibilidades de interpretação das construções com \{-nangry\}. Seguindo a lógica das supercategorias, autores têm chamado de imperfectivo apenas aqueles morfemas que expressam mais de uma subcategoria $(C f$. BYBEE; REVERE; PAGLIUCA, 1994; MUELLER, 2013). Adotando a mesma perspectiva, e considerando que as sentenças com -nangry codificam o presente/habitual e o continuativo, além do sentido incoativo/futuro, este sufixo é descrito como um marcador aspectual geral imperfectivo.

O imperfectivo passado, por sua vez, é codificado por outro morfema, apresentado a seguir.

\subsubsection{O imperfectivo passado $\{(-\mathrm{t}) \mathrm{ak}\}$}

O morfema aqui chamado de imperfectivo passado $\{-t a k \sim-a k\}$ ocorre apenas com o passado distante $\{-n e\}$, exceto na terceira pessoa quando o passado distante é expresso por um morfema portmanteau de pessoa e tempo (ver seção 5.3.1.3). O significado observado é compatível com uma situação que denota passado habitual, como pode ser verificado nos exemplos em (38), (39), (40) e (41).
(38) Txana jabotadamyninpyn,
Txana j-abotxi-tadamy-ni-npyn
NOM.PROP 1O-segurar-ITR-NOM.A-PSD.NOM 


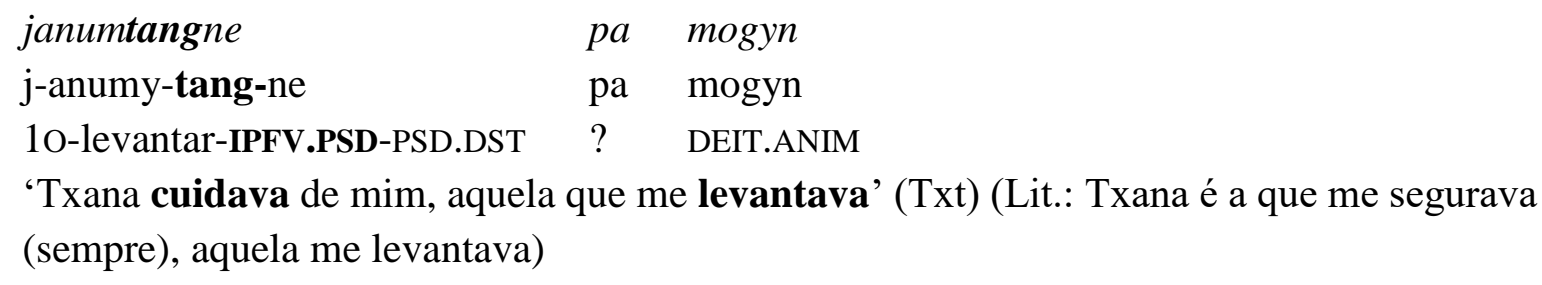

$\begin{array}{lllll}\text { kuremne } & \text { taje } & \text { wyduangne } & \text { tymrongne } & \text { taje } \\ \text { kure-mne } & \text { taje } & \text { w-ydo-ang-ne } & \text { tymrongne } & \text { taje } \\ \text { bom-PRIV? } & \text { INTENS } & 1 \mathrm{~S}_{\mathrm{A}} \text {-ir-IPFV.PSD-PSD.DST } & \text { sozinho } & \text { INTENS }\end{array}$

'Eu ía no silêncio (sem falar nada) sozinho' (Txt)

$\begin{array}{lll}\text { inwangne } & \text { wongo } & \text { jengrukedup } \\ \text { in-wo-ang-ne } & \text { wongo } & \text { j-engruke-dup } \\ \text { 1A-matar-IPFV.PSD-PSD.DST } & \text { animal } & \text { 1A-achar-SUB }\end{array}$

abiana tawe, wongoum, arun

abiana tawe, wongoum, arun

queixada macaco.prego macaco.sp guariba

'Eu matava bicho quando via, porcão, macacaco prego, macaco cara branca, guariba.' (Txt)

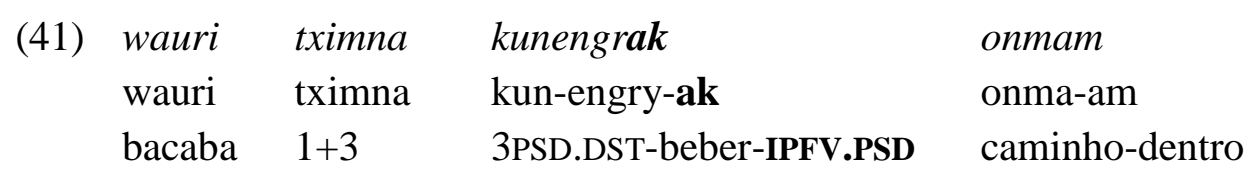

'Nós tomávamos bacaba no meio do caminho' (Txt)

Observe que o morfema é nasalizado após o passado distante -(t)ang-ne, tornando-se homófono ao morfema que ocorre com frequência com o passado médio -(t)ang-te, porém diferenças formais e semânticas sugerem que se tratam de dois morfemas distintos. Primeiro, estes morfemas se diferenciam no plural quando, no caso do imperfectivo passado, a forma verificada é -(t)adyng enquanto, para o passado médio, é -(t)ang-ty-t. Além disso, são observadas diferentes alomorfias com a terceira pessoa, quando ambas as flexões selecionam formas diferentes para marcar este argumento. Na terceira pessoa do passado distante, a forma identificada é $\{-t a k \sim-a k\}$, isto é, o morfema perde a nasalização após a queda do morfema de passado distante $\{-n e\}$. Além disso, a terceira pessoa empregada é kun-, um morfema cumulativo que codifica pessoa e tempo simultaneamente. Um esquema com a terceira pessoa é $k u n(i)-\mathrm{V}-(t) a k$ [3PSD.DST-V-IPFV.PSD]. No passado médio, por sua vez, é verificada a terceira pessoa mon(i)-. O forma esquemática consiste em mon(i)-V-(t)ang [3PSD.MED-V-ASP?]. Perceba que o alomorfe $\{-(t) a n g\}$ que ocorre com a terceira pessoa do passado médio continua 
nasal. Quanto à diferença de significado, é possível atribuir um significado imperfectivo ao morfema $\{-t a k \sim-a k\}$, o que, no entanto, não se sustenta para a o morfema $\{$-tang $\sim-a n g\}$. Veja nos exemplos (42a) e (42b) que a tentativa de combinar o morfema \{-tang\} com a terceira pessoa do passado distante e o sentido imperfectivo gerou um exemplo agramatical, (42b).

a) kunmomomtak

kun-momomy-tak

3PSD.DST-entrar-IPFV.PSD

'Ele entrava' (Elic)

b) *kunmomomtang ('Ele entrava')

kun-momomy-tang

3PSD.DST-entrar-ASP? (Elic)

\subsubsection{O resuntivo $\{-(t) a k p y\}$}

O resuntivo $\{-(t) a k p y\}$ expressa i) a repetição de um evento, como em (43) e (44), ou ii) a continuação de uma ação, conforme ilustrado em (45) e (46) . Em (46), a tradução do falante é quase uma explicação de que o evento terminou e começou novamente.

(43) papa mitakpy-ly

papa m-iti-takpy-ly

papai $2 \mathrm{~S}_{\mathrm{A}}$-COP-RESUN-PSD.IMD

'Você vai ser pai novamente' (Elic.)

(44) wiptakpyny

w-iby-takpy-ny

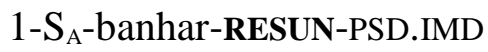

'Eu banhei de novo' (Elic.)

$(45)$
tybongne
mong, keny.
Ibraaa, kedakpyny
ty-bong-ne
mong, Ø-ke-ny.
Ibra,
$\varnothing$-ke-takpy-ny
ADV-choro-ADV
DEIT $3 \mathrm{~S}_{\mathrm{A}}$-dizer-PSD.IMD
NEG
$3 \mathrm{~S}_{\mathrm{A}}$-dizer-RESUN-PSD.IMD

'Está chorando, ela disse. Nããoo, continuou a falar' (Txt) 
(46) agrobudakpyly

agrobu-takpy-ly

pilar-RESUN-PSD.IMD

'Terminou. Continuou a pilar' (Elic.)

Em alguns radicais o morfema pode apresentar sentidos diferentes, como demonstram os exemplos a seguir.

(47) ibongnumtakpyny

i-bong-numy-takpy-ny

3S $\mathrm{S}_{\mathrm{O}}$-choro-VBZ-RESUN-PSD.IMD

'Aumentou o choro' (Elic.)

(48) tongongtakpyly

t-ongong-takpy-ly

3-morder-RESUN-PSD.IMD

'Terminou de mordê-lo' (Elic.)

(49) omomtakpyly

$\varnothing$-omomy-takpy-ly

$3 \mathrm{~S}_{\mathrm{A}}$-entrar-RESUN-PSD.IMD

'Entrou mais para lá' (Elic.)

Em (47) podemos perceber um aumento da intensidade do evento chorar enquanto em (48) há a indicação do término do evento moder. Já com o radical para entrar, em (49), o sentido conferido pelo morfema resuntivo é de avanço.

Um morfema com função semelhante é verificado em Wayana (TAVARES, 2005, p. 261). Assim como nesta língua, reconhecemos que o rótulo não dá conta da descrição de todas as funções do morfema ${ }^{72}$. Além disso, o elencamos dentre os morfemas aspectuais por que tais funções parecem estar relacionadas à maneira como o evento é realizado e aos processos envolvidos. Este tipo função está mais próxima da categoria aspecto do que da de modalidade, por exemplo. Isto porque, não há nada que remeta à condição do agente ou ao ato de fala com força ilocucionária ou ao comprometimento do falante com a verdade da proposição. Por outro lado, a diferença entre este aspecto, o habitual e o iterativo reside no fato

\footnotetext{
$72 \mathrm{O}$ termo resuntivo (resumptive) tem sido usado de forma diversa na literatura. Por exemplo, o resumptive pronoun remete a um item citado previamente, geralmente em sentenças relativas. Em Kwaza (VOORT, 2004, p. 581), por sua vez, resumptive é o rótulo usado para descrever uma partícula que poderia ser chamada de antecipativa porque remonta a um participante que será introduzido posteriormente na sentença principal
} 
que de apenas apenas o resuntivo apresenta outras funções além da repetição de um evento, o que possivelmente, está ligado à combinação com o aspecto lexical.

\subsection{MODALIDADE}

As modalidades aqui abordadas são orientadas pelo agente e pelo falante, na terminologia de Bybee e Fleischman $(1995)^{73}$. A função modal orientada pelo agente compreende os significados que predizem condições sobre um agente com relação a realização de uma ação, como obrigação, desejo, abilidade, permissão. A função orientada pelo falante, por sua vez, contém os chamados diretivos [...], ou seja, significados expressos por meio de atos de fala nos quais o falante pretende que o addressee realize uma ação (Ibib., p. 6, tradução nossa $\left.{ }^{74}\right)$. As seções a seguir apresentam as seguintes modalidades diretivas: imperativo (proximal e alativo), vetativo, permissivo, hortativo, admonitivo. Como parte da modalidade orientada pelo agente é apresentado o modo intencional. Outras modalidades apesentadas são o interrogativo e o frustrativo que estão dentre os significados da categoria irrealis. Esta categoria inclui um amplo conjunto de significados modais não-assertivos (Ibid., p. 9, tradução nossa).

Sobre os tipos de comando, seguimos a classificação de Mueller (2013), que se baseia em Searle (1975). Segundo tal classificação, comando é usado como um termo guarda chuva que se refere aos atos de fala cuja força ilocucionária impele o addressee (aquele que está sendo comandado) a ralizar um ação. Assim, também estão incluídos conselhos, pedidos, avisos, entre outros, gerados pela quantidade de força ilocucionária existente por trás do comando. $\mathrm{O}$ comando tradicional e prototípico é dado ao addressee de segunda pessoa com força ilocucionária forte enquanto outros tipos de comandos têm menos força (Ibid, p.167, 168).

\footnotetext{
${ }^{73}$ Essas duas supercategorias, somadas à modalidade epistêmica são os principais tipos de modalidade para Bybee e Fleischman (1995). A modalidade epistêmica se refere ao grau de comprometimento do falante com a verdade da proposição. Esta função é realizada por meio de itens lexicais e não será abordada. Fazendo uma equivalência entre as terminologias, podemos ver que Palmer (2001) faz uma divisão mais ampla: modalidades proposicional e de evento. Esta engloba a modalidade deôntica (relacionada à permissão e obrigação) e a dinâmica (relacionada a desejo, disposição). A modalidade proposicional, por sua vez, inclui a evidencialidade e a tradicional modalidade epistêmica.

${ }^{74}$ Agent-oriented modality encompasses all modal meanings that predicate conditions on an agent with regard to the completion of an action referred to by the main predicate, e.g. obligation, desire, ability, permission and root possibility.[...]. Markers of directives, such as imperatives, optatives or permissives, which represent speech acts through which a speaker attempts to move an addressee to action, are called speaker-oriented. (Ibid, p.6, grifos do autor)
} 
Dentre os comandos apresentados a seguir, apenas o imperativo apresenta força ilocucionária forte.

\subsubsection{O imperativo: proximal $\{-\mathrm{ko} \sim-\mathrm{k}\}$ e alativo $\{-\mathrm{ta} \sim-\mathrm{a}\}$}

O imperativo expressa um comando direto endereçado à segunda pessoa que pode ser singular ou plural. Este tipo de comando apresenta um ato ilocucionário forte que deixa clara a pretensão do falante. As pessoas atreladas ao verbo são apenas as que se referem ao objeto. No caso de Arara, estas podem ser a 3 ou a 2 pessoas, de acordo com a classe do radical verbal, como descrito no capítulo 5, seção 5.3.3. O sufixo $\{-k o \sim-k\}$ expressa o imperativo proximal o qual não implica movimento, como em (50). O morfema $\{-t a \sim-a\}$, por sua vez, codifica o imperativo alativo, pois, se contrapondo ao imperativo proximal, indica movimento/deslocamento em direção oposta à do falante, como demonstrado em (51). Veja que a versão venitiva é feita com o imperativo proximal acompanhado de um item lexical dinâmico, exemplificado em (52).

$\begin{array}{llll}\text { iduetkom } & \text { egrugedyk } & \text { wygiangne } & \text { awonnge } \\ \text { iduet-kom } & \varnothing \text {-egruge-ty-k } & \text { wy-ke-ang-ne } & \text { a-wo-nnge } \\ \text { 2.rede-COL } & \text { 3-lavar-COL-IMP } & \text { 1S }_{\mathrm{A}} \text {-dizer-IPFV.PSD-PSD.DST } & \text { 3-DAT-COL }\end{array}$

'Eu falava para eles lavarem a rede deles' (Txt)

(Lit.: 'Lavem a rede de vocês!', eu dizia para eles)

(51) moro eganopta

moro eganoby-ta

DEIT.INAN falar-IMP.ALA

'Vai lá falar isso' (Txt)

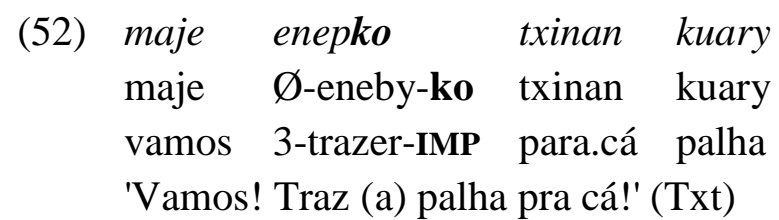

Segundo Souza, S. (1993) os morfemas -ta -a e -tana -ana '[...] marcam deslocamento, -ta $\sim$-a marcam a segunda pessoa; -tana -ana marcam a primeira pessoa.' (Ibid., p.71, grifos da autora). Segundo a presente análise, os alomorfes $-\mathbf{t a} \sim \boldsymbol{- a}$ são melhor descritos como morfemas de comando alativo já que I) apresentam um significado que 
compreende força ilocucionária, sendo o deslocamento apenas um dos traços semânticos dessa flexão, e II) predicados com essa flexão são afixados pelos mesmos morfemas de pessoa que o imperativo proximal, 2 e 3 pessoas (e não apenas 2 pessoa). Quando esta flexão ocorre com a primeira pessoa inclusiva, de acordo com a classificação determinada pela morfologia de pessoa, o chamamos de hortativo alativo (subseção 5.3.4). Quanto aos alomorfes -tana -ana, propomos uma divisão, em morfema alativo e morfema intencional (-tan+na $\rightarrow$ tana), o que será discutido na subseção correspondente (seção 4.5.7).

\subsubsection{O vetativo $\{$-tane $\sim$-ane $\}$}

$\mathrm{O}$ vetativo $\{$-tane $\sim$-ane $\}$ (chamado de proibitivo na literatura mais atual $(C f$. VAN DER AUWERA ET AL., 2013)) ${ }^{75}$ consiste em um imperativo negativo, isto é, o falante proíbe ou tenta impedir o addressee de realizar um evento. É possível observar uma interpretação mais atenuada, com uma força ilocucionaria não tão forte que atribui um sentido de aviso ou de prevenção (como admonitivos). Souza, S. (1993, p. 74) usa a expressão sufixo de advertência para se referir a este morfema. De acordo com os dados investigados esta é uma das nuances desta flexão. Como exposto na seção 4.5.5, há outro morfema cuja função principal é advertir ou aconselhar e que foi rotulado de admonitivo.

Tal cenário observado em Arara é compatível com a definição encontrada em Mueller (2013, p. 170), segundo a qual o proibitivo, geralmente, é a negação do imperativo, mas também pode incluir nuances de significado como ameaças ou advertências, também chamados de admonitivos, que significam "não faça X que não/por que/ para evitar...". Ainda segundo a mesma autora, um mesmo marcador pode ser usado como proibitivo, incluindo seus significados relacionados, ou cada significado pode ter seu próprio marcador.

Exemplos de comandos negativos são oferecidos em (53) e (54). Um exemplo mais atenuado pode ser visto em (55).

\section{mimuntxikotane}

mi-muntxi-kody-tane

2A-cabeça-quebrar-VET

'Não vai quebrar cabeça dele!' (Elic.)

\footnotetext{
${ }^{75}$ Sigo com o termo vetativo que vem sendo usado na literatura Karib para morfemas com a mesma função $(C f$. HOFF1968, p.188; CASER-FOX 2003, p.121-122).
} 
(54) mimoktepuane

jentxin,

keny

mi-mo-ktepu-ane

j-e-n-txin,

$\varnothing$-ke-ny

2A-cabeça-quebrar-VET 3-dente-POSSD-em.direção.a 3S $\mathrm{S}_{\mathrm{A}}$-dizer-PSD.IMD

'Não bate com a parte do dente do machado nas costas' (Txt)

55)

$\begin{array}{ll}\text { minuane } & \text { ibrinta ge } \\ \text { mi-no-ane } & \text { i-brinta }=\text { ge } \\ \text { 2A-deixar-VET } & \text { 3-outro=INS } \\ \text { 'Cuidado para você não o deixar por outro (marido)' (Elic.) }\end{array}$

\subsubsection{O hortativo: proximal $\{-n(e)\}$ e alativo $\{-$ ta $\sim-a\}$}

Neste estudo, consideramos que o chamando modo hortativo consiste em uma sugestão ou exortação que sempre inclui a primeira pessoa, plural "Vamos nadar!, Deixe-nos nadar!". Neste sentido, pode-se dizer que se trata de um diretivo, mas não necessariamente uma forma de comando. Em Arara, o hortativo envolve apenas a primeira pessoa inclusiva (1+2). Na versão proximal, além da pessoa, o radical é recebe o morfema - $n(e)$ HORT, como exemplificado em (56), (57) e (58). Vele mencioanar que, geralmente, o hortativo também inclui formas com a primeira pessoa singular "Deixe-me dançar!", porém, como em Arara há uma forte ambiguidade com o futuro quando se trata da primeira pessoa, consideramos que para este caso o rótulo itencional é descritivamente mais adequado.

\begin{tabular}{|c|c|c|c|}
\hline (56) idem & kutpitken & kuntxak & ugon tamru \\
\hline idem & kut-pitke-n & kun-te-ak & ugon tamru \\
\hline 2.marido & 1+2A-procurar-HORT & 3PSD.DST-dizer-IPFV.PSD & NOM.PROP \\
\hline
\end{tabular}

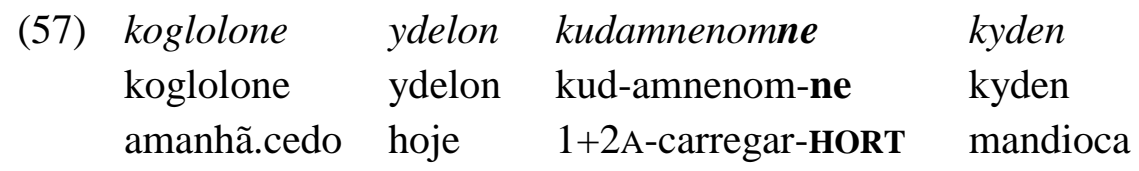

$\begin{array}{llll}\text { wygen } & \text { awo, } & \text { Tybrybi } & \text { wo } \\ \text { wy-ge-n } & \text { a-wo } & \text { Tybrybi } & \text { wo } \\ \text { 1S } \mathrm{S}_{\mathrm{A}} \text {-dizer-PSD.DST } & \text { 3-DAT } & \text { NOM.PROP } & \text { DAT }\end{array}$

'Hoje de manhã cedo, nós vamos carregar mandioca, eu disse para ele, para o Tybryri' (Txt) 
(58) ta lon kudodokpedyn

ta lon kud-odokpe-ty-n

aqui FOC 1+2A-fazer-COL-HORT

'Vamos ficar por aqui mesmo!' (Txt)

A versão alativa, por sua vez, é marcada pelo sufixo $\{-t a \sim-a\}$. Nesse caso, há a indicação da realização de um deslocamento com posterior consumação do evento (ex.: 'Vamos lá comer'), como ilustrado em (59) e (60).

$\begin{array}{lll}\text { kudeneta } & \text { kyden } & \text { wygen pa } \\ \text { kut-eneng-ta } & \text { kyden } & \text { wy-ke-n=pa } \\ \text { 1+2-ver-HORT.ALA } & \text { macaxeira } & 1 \mathrm{~S}_{\mathrm{A}} \text {-dizer-PSD.DST=? } \\ \text { 'Eu falei: nós vamos lá ver mandioca' (Txt) }\end{array}$

(60) kutxipta

kut-iby-ta

$1+2 \mathrm{~S}_{\mathrm{A}}$-banhar-HORT.ALA

'Vamos banhar lá nós dois' (Elic.)

Em algumas línguas, o imperativo e o hortativo são expressos pela mesma forma morfológica ou pela mesma estratégia sintática $(C f$. VAN DER AUWERA, DOBRUSHINA GOUSSEV, 2013). No caso de Arara, tais formas de comandos são expressas por morfemas distintos se observarmos as versões proximais. Por outro lado, quanto às versões alativas, apesar de poderem ser analizadas de maneira uniforme, sigo a análise que diferencia de acordo com a morfologia de pessoa, paralelamente, o imperativo proximal e o imperativo alativo, assim como o hortativo proximal e o hortativo alativo. Por consequência, as formas do imperativo alativo e do hortativo alativo são tomadas como homófonas.

\subsubsection{O permissivo $\{-\mathbf{a}\}$}

O modo permissivo também consiste em um diretivo, com pouca força ilocucionária. Neste caso, o addressee corresponde a uma terceira pessoa e não recebe instruções diretamente, como em "Deixe-o comer em paz!". Assim, o falante fornece/reporta condições para um agente realizar um evento. Exemplos são fornecidos a seguir. O radical é anexado pela terceira pessoa n- em textos. Em elicitação outras pessoas foram aceitas: 10, 2o, 1+2o (Capítulo 5, seção 5.3.6). 
Este fato nos levou a escolher o rótulo permissivo ao invés de jussivo, que ocorre apenas com a terceira pessoa.

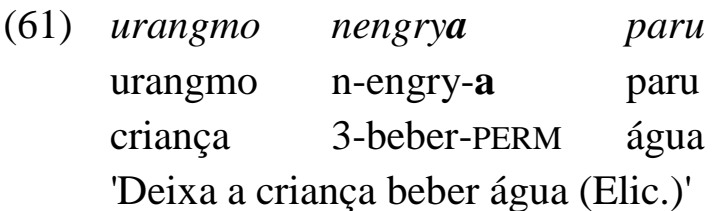

(62) nangtxa jenguaktxi

n-angte-a j-engu-aktxi

3-cair-PERM 1-rosto-em.direção.a

'Deixa eu lembrar' (Lit.: deixa-o cair no meu rosto, na minha frente) (Elic.)

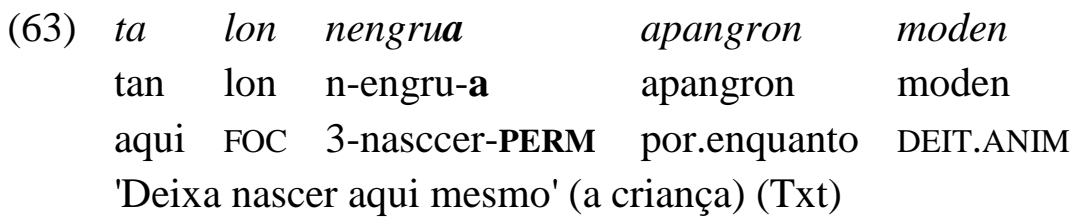

\subsubsection{O Admonitivo \{-tang -ang\}}

$\mathrm{O}$ admonitivo \{-tang -ang\} é utilizado para advertir, avisar ou fazer alguma recomendação sobre algum possível perigo. Exemplos são oferecidos em (64) e (65).
(64) kunkeak
jeme-ngmo papangmo kunkanoptak.
kun-ke-ak
jeme-ngmo papa-ngmo kun-kanoby-tak.
3PSD.DST-dizer-IPFV.PSD
mamãe-COL papai-COL 3PSD.DST-falar- IPFV.PSD

$\begin{array}{lll}\text { wabotang } & \text { kenangry } & \text { ywo } \\ \text { o-abotxi-tang } & \varnothing \text {-ke-nangry } & \text { y-wo } \\ \text { 2O-segurar-ADM } & \text { 3-dizer-IPFV } & \text { 1-DAT }\end{array}$

'Povo da minha mãe, do meu pai davam conselho. Eles falavam para mim: 'Vai te pegar!' (Txt) (Lit.: 'Povo da minha mãe dizia, povo do meu pai falava pra mim: vai te pegar!')

(65) omumpatpuang

o-mum-patpo-ang

2O-cabeça-acertar.um.alvo-ADM

'Cuidado, vai acertar tua cabeça' (Elic) 
O morfema admonitivo é homófono ao interrogativo (seção 4.5.6), porém além destes morfemas possuírem funções gramaticais diferentes, o número de afixos pessoais empregados com cada um também identifica a existência dois sufixos distintos. No modo admonitivo, como demonstrado na seção 5.3.5, apenas segundas pessoas ( $2 \mathrm{O}$ e $2 \mathrm{~S}_{\mathrm{A}}$ ) são verificadas em textos. Note que, no caso de verbos transitivos, apenas morfemas da classe $\mathrm{O}$ são aceitos. Como demonstrado no exemplo (64), a raiz abotxi 'segurar' é afixada com o morfema $o$ - 20. Em contrapartida, o exemplo agramatical em (66) demonstra a impossibilidade de anexação do morfema $m$ - 2A. Em elicitação, a primeira pessoa singular e plural também foram aceitas em verbos transitivos.

(66) *mabotang

m-abotxi-tang

2A-segurar-ADM (Elic.)

No modo interrogativo, por sua vez, embora mais estudos sejam demandados, já é possível verificar que há mais possibilidades de morfemas de pessoa, pois ambas as classes de argumentos ( de A e O) são aceitas, conforme exemplificado em (67), com kut-1+2A e ugu1+20. Assim, os dados sugerem que a distribuição de morfemas de pessoa no modo admonitivo é mais restrita do que a distribuição dos morfemas no modo interrogativo.

a) ody kudabangtom

ody kud-aby-ang-tom

o.que 1+2A-mexer-INT-COL

'O que nós estamos fazendo?' (Elic.)

b) ogro kak ugaktangtom pa kenangry Iaut toworunte

ogro kak ugu-agu-tang-tom pa Ø-ke-nangry Iaut to-woruntu-e

onça Q 1+20-comer ${ }^{76}$-INT-PL ? 3-dizer-IPFV NOM.PROP PRTC-palavra-?PRTC

'Iaut falava, será que a onça vai nos comer?, ele disse' (Txt)

\subsubsection{O interrogativo $\{$-tang -ang $\}$}

$\mathrm{O}$ morfema $\{$-tang -ang\} ocorre em perguntas do tipo $\mathrm{WH}$ ou QU, expressas pela partícula $k a$, como ilustrado em (68) e (69), respectivamente.

\footnotetext{
${ }^{76}$ Comer alimento consistente como carne, castanha, macaxeira, coco babaçu, ente outros.
} 
(68) ody abyang Pablo

ody $\varnothing$-aby-ang Pablo

o.quê 3O-mexer-INT Pablo

'O que o Pablo está fazendo?' (Elic.)

(69) mabuang $k a$

m-abu-ang ka

2A-cavar-INT QU

'Você está cavando?' (Elic.)

Esta flexão confere um significado que pode ser interpretado como continuativo, como nos exemplos acima, ou de futuro, como em (70).

$\begin{array}{llllll}\text { (70) ty } & \text { ibongnane } & \text { odybenam } & \text { ugumpyang } & \text { tompan } & \text { txik } \\ \text { ty } & \text { i-bok-nane } & \text { odybenam } & \text { ug-umpy-ang } & \text { tompan } & \text { txik } \\ \text { INTERJ } & 3 \text {-sobre-? } & \text { quando } & 1+2 \mathrm{~S}_{\mathrm{o}} \text {-transformar.se-INT } & \text { todos } & \text { ONOM }\end{array}$

'De repente, quando será que nós vamos nos transformar todos? (Txt)

Veja que o exemplo (71) demonstra que em perguntas polares, a ausência deste morfema implica uma leitura de perfectivo/passado.

(71) $m a b u \quad g a$

m-abu ka

2A-cavar QU

'Você cavou?' (Elic.)

Em poucos casos, aparentemente, a interpretação aspectual/temporal observada não parece estar presente:

(72) engpadyny, midangtang $k a$ edet engpadyny, mi-tang-tang ka edet engpadyny 2A-escutar-INT QU nome

'"Engpadyny', você entendeu o nome? (Txt)

(73) jedadyang $\mathrm{ka}$

j-edady-ang ka

1A-falar-INT QU

'Eu posso falar?' (Txt) 
Souza, S. (1993, p. 72) trata este morfema como um futuro que ocorre em sentenças interrogativas. Como vimos, além da interpretação de futuro o morfema é compatível com a noção de aspecto que descreve um evento contínuo, assim, por enquanto, preferimos usar o rótulo INT, neutro com relação aos demais significados gramaticais do morfema.

\subsubsection{O intencional $\{-$ da $\sim-$ txa $\sim-$ na $\}$}

No modo intencional, o falante expressa uma intenção a ser realizada em um futuro próximo. Apenas primeiras pessoas são marcadas no radical. Os alomorfes $\{-d a \sim-t x a \sim-n a\}$ indicam a realização de um evento que não requer deslocamento para a realização do evento, como em (74) e (75). Uma versão alativa é possível a partir da adição do morfema alativo $\{-(t) a n \sim(t) a\}$ que ocorre juntamente com o morfema intencional. Desta forma, o falante terá que se movimentar até um local diferente daquele onde a sentença foi enunciada (ex.: "Vou lá banhar”). Exemplos do intencional alativo são oferecidos em (76) e (77).

$\begin{array}{llll}\text { imu } & \text { jetxitxin } & \text { ogro } & \text { aguny } \\ \text { i-mu } & \text { j-etxi-txin } & \text { ogro } & \emptyset \text {-agu-ny } \\ \text { 3-ovo } & \text { REL-casa-em.direção.a } & \text { onça } & \text { 3O-comer.alimen.consist-PSD.IMD }\end{array}$

wygetkeda

wy-ke-tke-da

$1 \mathrm{~S}_{\mathrm{A}}$-dizer-ITR-INTC

'Ela ía no caminho pegar ovo e a onça a comeu, eu vou contar' (Txt)

$\begin{array}{lllll}\text { wauri } & \text { walatketpyn } & \text { Ugon tamru } & \text { jeganoptxa } & \text { moro } \\ \text { wauri } & \text { walatke-tpyn } & \text { Ugon tamru } & \text { j-eganoby-txa } & \text { moro } \\ \text { bacaba } & \text { virar-PSD.NOM } & \text { NOM.PROP } & \text { 1A-falar-INTC } & \text { DEIT.INAN }\end{array}$

' Eu vou falar isso que Ugon tamru jogou bacaba' (Txt)

(Lit.: 'Virada de bacaba, Ugon tamru. Eu vou falar isso/aquilo'.)

(76) warami ugop inmo[ngo $]^{77}$ ktana kunke

warami ugop in-mongogu-tan-na kun-ke

babaçu embaixo 1A-esperar-ALA-INTC 3PSD.DST-dizer

'Eu vou lá esperar embaixo do pé de coquinho brabo, ele disse' (Txt)

(Lit.: Eu vou lá esperar embaixo do babaçu, ele disse)

\footnotetext{
${ }^{77}$ Sílaba omitida na transcrição.
} 


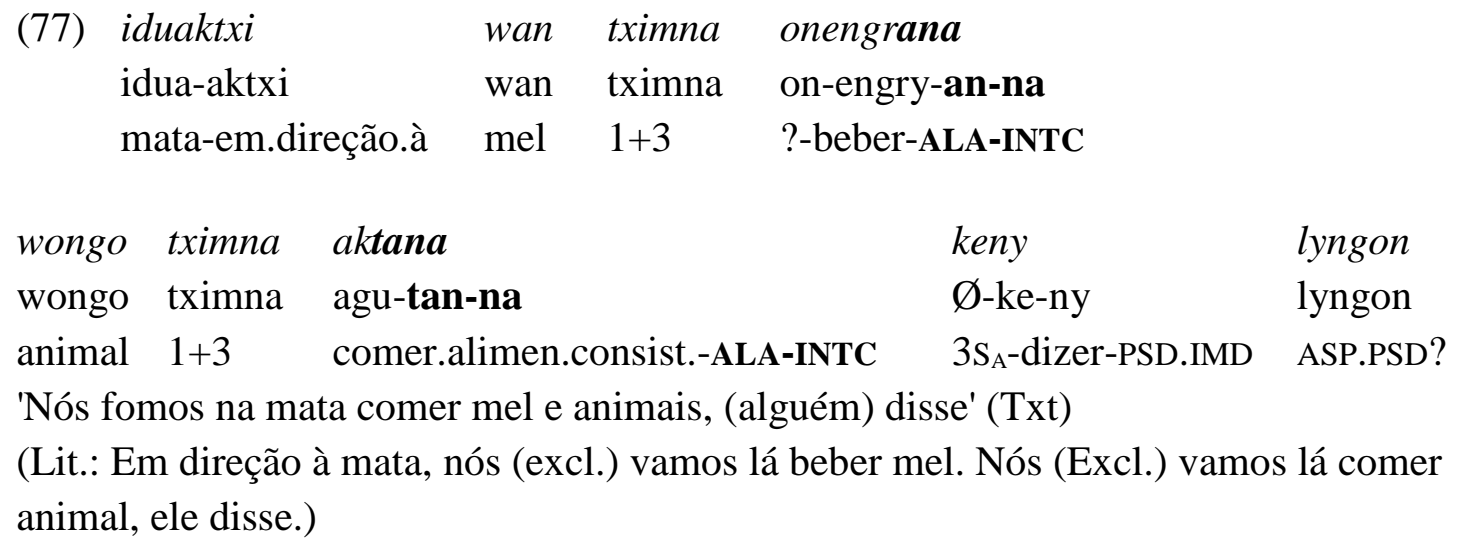

Ademais, em alguns casos, foi verificado um sentido diretivo que envolve apenas a primeira pessoa singular "Deixe-me...", como ilustrado em (78) e (79). Note que as fronteiras entre os significados são discutíveis, pois não há uma linha exata que mostre onde se termina uma intenção e se começa um comando ou um ato de fala diretivo, na terminologia de Searle (1975). Por outro lado, mantemos a terminologia intencional, já que é flagrante a ambiguidade deste com o futuro, o que não se dá da mesma forma com os morfemas chamados de hortativo.

(78) Carol jenena

Carol j-eneng-na

NOM.PROP 1A-ver-INTC

'Eu vou ver (a) Carol ou me deixa ver (a) Carol' (Elic)

(79) Komomtxa

k-omom-txa

$1 \mathrm{~S}_{\mathrm{A}}$-entrar-INTC

'Eu vou entrar ou deixa eu entrar' (Elic)

Algumas destas flexões são encontradas em trabalhos anteriores com glosas distintas. Souza, S. (1993, p.74) considera os alomorfes $\{$-tana $\sim$-ana $\}$ como marcadores de deslocamento para a primeira pessoa. A mesma autora glossa o morfema $\{$-txa\}, como um marcador de futuro imediato (Ibid., passim). Souza, I. (2010, p. 14) glossa o morfema $\{-d a\}$ como um 'proximal' (Near). Conforme exposto, consideramos que a principal função destes morfemas, bem como dos outros alomorfes apresentados nesta seção, consiste em expressar uma intenção do falante, o que é destacado pelo fato do radical ser conjugado apenas na primeira pessoa. Neste quesito, o tempo futuro, geralmente, pode ser conjugado com todas as pessoas. Obviamente, é flagrante que os significados apontados para tais morfemas estão relacionados, pois o evento que se tem a intenção de realizar só poderá ser efetivado após o momento de fala (MF>ME). Além disso, estas observações estão de acordo com o caminho de gramaticalização 
do futuro, o qual inclui significados como desejo, disposição e intenção, inicialmente da primeira pessoa e depois de outras pessoas (BYBEE; PERKINS; PAGLIUCA. 1994, p. 256)

\subsubsection{O frustrativo $\{$-menpo $\}$}

As definições do frustrativo encontradas na literatura são semelhantes. Em seu estudo tipológico, Mueller (2013) define o modo frustrativo como aquele que se refere a um evento que não teve o resultado desejado ou foi terminado sem sucesso. A ação pode ser deixada sem conclusão, ou pode ser concluída, mas não com resultado esperado ou pode ser realizada em vão. O sentimento de frustração do falante pode estar envolvido, mas não necessariamente (Ibid., p. 158, tradução nossa). Por outro lado, há ainda as especificidades das línguas individuais. Por exemplo, Galucio (2014) atesta que a partícula furstrativa da língua Sakurabiat (Tupi) adiciona a semântica de frustração ou não alcance do resultado esperado à proposição e, além disso, é usada para expressar a verdade ou a realidade do mundo com relação à proposição.

Mueller (2013) também aponta distinções entre o frustrativo e o incompletivo já que ambos podem se referir à eventos sem conclusão. Segundo a autora, no incompletivo a ação não é concluída, independentemente da expectativa ou desejo do falante. Poderia-se dizer que, semanticamente, o marcador de frustrativo pode ser um incompletivo adicionado de frustração, nos casos em que a ação não é terminada, mas esta característica faz parte somente do frustrativo. Além disso, no frustrativo as ações podem muito bem ser concluídas, o que exclui o sentido do incompletivo, embora não com o resultado desejado (Ibid., p. 158, tradução nossa).

Em Arara, o frustrativo \{-menpo\} indica um evento que não foi concluído, que não ocorreu completamente, como em (82), (83), (84) e (85). A maioria dos exemplos com o frustrativo são traduzidos com a palavra quase em português.

$\begin{array}{lll}\text { otxinomenpodup } & \text { janumne } & \begin{array}{l}\text { moden } \\ \text { moden }\end{array} \\ \text { otxi-no-menpo-dup } & \mathrm{j} \text {-anumy-ne } & \text { DEIT.ANIM } \\ \text { DTRZ-deixar-FRUST-SUB } & \text { 1A-levantar-PSD.DST } & \text { DETI }\end{array}$

inomenpodupennge

i-no-menpo-dup-ennge

3O-deixar-FRUST-SUB-COL

'Quase ía ficando, eu peguei esse, quando eles íam deixar (a criança)' (Txt) 
(83)

$\begin{array}{llll}\text { kun-otxi-no-menpo } & \text { moden } & \text { y-byra } & \text { aptam } \\ \text { kun-otxi-no-menpo } & \text { moden } & \text { y-byra } & \text { aptam } \\ \text { 3PSD.DST-DTZ-deixar-FRUST } & \text { DEIT.ANIM } & \text { 1-NEG } & \text { COP.PSD.DST }\end{array}$

'O Iaut ía ficar, se eu não estivesse lá' (Txt)

(Lit.: Aquele (o Iaut) ia ficar, se eu não estivesse lá)

$\begin{array}{lll}\text { toooo } & \text { erengmymenpoly } & \text { tagie } \\ \text { toooo } & \varnothing \text {-erengmy-menpo-ly } & \text { tagie } \\ \text { ONOM.árvore.caindo } & \text { 3O-bater-FRUST-PSD.IMD } & \text { INTENS }\end{array}$

waramium jebyngmo

warami-um j-eby-ngmo

babaçu-AUM REL-árvore-COL

'Barulho de árvore caindo, touceira de babaçu e outros paus quase machucam (uma pessoa)' (Txt)

$\begin{array}{llll}\text { koglon } & \text { wydomenpoly, } & \text { ontobra } & \text { witxa. } \\ \text { koglon } & \text { W-ydo-menpo-ly, } & \text { on-ydo-bra } & \text { w-iti-txa. } \\ \text { amanhã } & \text { 1S } \mathrm{S}_{\mathrm{A}} \text {-ir-FRUST-PSD.IMD } & \text { NEG-ir-NEG } & 1 \mathrm{~S}_{\mathrm{A}} \text {-COP-INTC }\end{array}$

$\begin{array}{ll}\text { Urangmo } & \text { abududely } \\ \text { urangmo } & \text { abudu-de-ly } \\ \text { criança } & \text { doente-VLZ-PSD.IMD }\end{array}$

'Eu ía embora amanhã, não vou mais. Criança adoeceu' (Elic)

Em (82) e (83) são apresentados exemplos sobre o mesmo episódio em que uma criança de colo que seria deixada na mata. Pode ser verificado que o evento de deixar uma criança chegou a certo estágio, porém foi interrompido quando o falante a carrega. Neste momento, foi evitado o resultado óbivo da ação, isto é, de que haveria alguém abandonado. Da mesma forma, em (84), o evento de machucar não fora concretizado, apesar de uma árvore ter caído, levando consigo outras árvores em direção a alguém. Em (85), o falante fornece a explicação pela qual o evento não ocorreu. $\mathrm{O}$ fato da criança (seu próprio filho) ter adoecido o impediu de ir embora da cidade, frustrando sua vontade de voltar para sua casa na aldeia. Tal frustração pode ser inferida a partir do contexto pragmático. 


\subsection{SÍNTESE}

Os morfemas de tempo, aspecto e modo aqui analisados são resumidos na tabela 4.4. De modo geral, enquanto algumas questões referentes ao tempo e ao aspecto ainda necessitam de maiores esclarecimentos, as flexões de modo mostraram que o sistema de modalidade parece desempenhar um papel mais relevante do que se tinha conhecimento.

Tabela 4.4 - Resumindo os morfemas de TAM

\begin{tabular}{|c|c|c|}
\hline \multirow{4}{*}{$\stackrel{\circ}{\stackrel{0}{0}}$} & $-l y(\sim n y) \sim-r y$ & PSD.IMD \\
\hline & $-t e \sim-t$ & PSD.MED \\
\hline & $-n e \sim-n$ & PSD.DST \\
\hline & -tome -tpom -npom & FUT \\
\hline \multirow{4}{*}{$\begin{array}{l}0 \\
\stackrel{0}{0} \\
\stackrel{0}{0} \\
\stackrel{0}{4}\end{array}$} & -nangry & IPFV \\
\hline & -tke -tadamy & ITR \\
\hline & $-t a k \sim-a k$ & IPFV.PSD \\
\hline & -takpy & RESUN \\
\hline \multirow{10}{*}{$\frac{0}{\frac{0}{8}}$} & $-k o \sim-k$ & IMP \\
\hline & $-t a \sim-a$ & IMP.ALA \\
\hline & $-n e \sim-n$ & HORT \\
\hline & $-t a \sim-a$ & HORT.ALA \\
\hline & -tane $\sim$-ane & VET \\
\hline & $-d a \sim-t x a \sim-n a$ & INTC \\
\hline & $-a$ & PERM \\
\hline & $-\operatorname{tang} \sim-$ ang & $\mathrm{ADM}$ \\
\hline & -tang - ang & INT \\
\hline & -тепро & FRUST \\
\hline
\end{tabular}

Quanto ao tempo, o passado apresenta três graus de distância temporal enquanto o futuro apresenta apenas um. No que se refere ao aspecto, o imperfectivo é utilizado para um amplo conjunto de significados (se comparado às demais categorias), expressando o presente, o futuro e o continuativo. Finalmente, o modo engloba o maior número de possibilidades. Dentre estas, são destacadas as formas de comandos. Há mais de uma forma morfossintática de comando com distinções semânticas, por exemplo, de movimento de afastamento em relação ao falante e a primeira pessoa inclusiva. Assim, o imperativo e o hortativo são codificados por flexões diferentes, $\{-k(o)\}$ e $\{-n(e)\}$. As versões alativas, por sua vez, são codificadas por morfemas homófonos de comando alativo. Ainda no bojo dos comandos estão o vetativo (comando negativo) e o permissivo, além do admonitivo. 


\section{CAPÍTULO 5 - INTERAÇÃO ENTRE AS CONSTRUÇÕES VERBAIS: ÍNDICES DE PESSOA E NÚMERO CONDICIONADOS POR TAM}

Este capítulo apresenta as formas presas de pessoa e de número anexadas aos verbos e demonstra o condicionamento causado pela categoria de TAM. Como é comum às línguas Karib, pessoa e número pertencem a categorias separadas, o que possibilita que certos prefixos de pessoa e certos sufixos de número ocorram apenas com certas flexões tempo-modoaspectual. Isto é, nem todas as marcas de pessoa, nem as de número são iguais em todos os tempos, aspectos e modos. Este capítulo está organizado como a seguir. A seção 5.1 explicita as definições terminológicas gerais necessárias para a descrição das categorias de pessoa e número. A seção 5.2 apresenta quais morfemas de TAM causam a afixação de morfemas pessoais e de número específicos. Em seguida, a seção 5.3 apresenta os prefixos de pessoa verificados na língua, assim como os padrões de alinhamento desses morfemas (hierarquia de pessoa e intransitividade cindida). A seção 5.4 traz os morfemas de número e a relação entre estes e os morfemas de TAM. Um resumo do capítulo é oferecido na seção 5.5

\subsection{INTRODUÇÃO}

O conceito básico de relação gramatical associa participantes ${ }^{78}$ (sintagmas nominais) de um evento/ação/estado a papéis gramaticais (Sujeito, Objeto, Objeto Indireto). A distinção entre os argumentos principais de uma sentença simples é feita por meio de propriedades ${ }^{79}$ morfológicas, como concordância verbal, marcação de caso (codificação morfológica da relação entre predicado e argumentos marcada no argumento por meio de afixação ou adposição) e propriedades sintáticas, como controle de referência entre sentenças, passivização, reflexivização etc. Isto é, um conjunto de propriedades semelhantes e internas à língua é utilizada como ferramenta descritiva para o agrupamento de sintagmas em categorias como $\mathrm{S}$, A ou O. Este capítulo explora duas das propriedades que caracterizam os argumentos principais em Arara: I) os prefixos pessoais, que indicam que participantes ocupam as posições de A, S e O e II) os sufixos de número ${ }^{80}$.

\footnotetext{
${ }^{78}$ Categoria semântica.

${ }^{79}$ Givón (2001) divide as propriedades morfossintáticas das relações gramaticais em overt coding properties e behavior-and-control-properties.

${ }^{80}$ As demais propriedades não discutidas neste estudo são as construções passivas, as construções relativas, as estratégias de extração como topicalização e perguntas, a correferência entre sentenças coordenadas, e o controle
} 
Argumentos principais são os participantes fundamentais da sentença, geralmente um sintagma nominal que pode estar sintaticamente explícito ou implícito. Eles são, obrigatoriamente, determinados pelos predicados para que a sentença tenha sentido. Argumentos periféricos ou oblíquos são sintagmas nominais, opcionalmente, associados aos predicados. Em Arara, os predicados verbais podem apresentar até dois argumentos principais, sendo caracterizados como predicados monovalentes e bivalentes (sobre a inexistência de predicados trivalentes, ver subseção 5.3.1.1, § 4).

Quanto à expressão de pessoa, formas pessoais presas expressam as relações entre o predicado e seus argumentos em sentenças principais. Essas formas presas são marcas morfológicas de argumentos que não podem ser usadas por si só, já que elas se opõem às formas de pessoa livres que ocorrem nos mesmos contextos sintáticos de um sintagma nominal. Em Arara, os mesmos prefixos de pessoa são verificadas em: verbos, expressando argumentos; nomes, expressando o possuidor; e posposições, expressando o seu complemento. Quando afixados aos predicados verbais, os morfemas pessoais codificam apenas argumentos principais, os quais podem ser no máximo dois. Isto é, todas as raízes transitivas recebem índices que codificam uma relação entre dois participantes de fala enquanto todas as raízes intransitivas são flexionas por penas um dos dois subconjuntos de prefixos que codificam apenas um argumento. Os demais participantes não afetam a prefixação verbal.

Neste estudo, as tradicionais letras capitalizadas S, A e O (COMRIE, 1981; DIXON, 1994) são utilizadas como ferramentas auxiliares na referência às categorias gramaticais de sujeito e objeto, conforme especificado a seguir:

$\mathbf{A}=$ argumento de sentenças transitivas; protipicamente, denota o controlador ou o iniciador de um evento.

$\mathbf{O}=$ o outro argumento de sentenças transitivas; prototipicamente, denota o participante afetado. $\mathbf{S}=$ argumento único de sentenças intransitivas.

$\mathbf{S}_{\mathbf{A}}=$ argumento único de sentenças intransitivas, morfologicamente semelhante a A.

$\mathbf{S}_{\mathbf{o}}=$ argumento único de sentenças intransitivas, morfologicamente semelhante a $\mathrm{O}$.

Como demonstrado no decorrer deste capítulo, os prefixos pessoais afixados aos predicados caracterizam dois tipos alinhamentos: um semântico-morfológico, que distingue duas classes de sentenças intransitivas e um hierárquico, o qual define que argumento será

de correferência da terceira pessoa reflexiva. Estas duas últimas propriedades, geralmente, indicam a posição de A e $\mathrm{O}$, respectivamente, em línguas Karib. 
indexado no predicado transitivo. Harris e Campbell (1995, p. 240) definem alinhamento de maneira abrangente como a distribution of morphological markers or of syntactic or morphological characteristics; it is intended as a neutral way of refererring to ergative, accusative, and other distributional patterns. Considerando escopo deste estudo, por alinhamento entenda-se o padrão de distribuição morfológica do argumentos pessoais encontrados nos predicados de diferentes valências.

Quanto ao número, de forma geral, a categoria pode ser nominal ou verbal, codificando a quantidade de participantes ou de eventos, respectivamente (CORBETT, 2000). Os morfemas aqui apresentados indicam apenas número de participantes. O plural de eventos, da maneira como este fenômeno é descrito por Lasersohn (1995) ou Hofherr e Laca (prelo), por exemplo, é codificado por outro morfema flexional, conforme demonstrado no Capítulo 4.

Esta categoria é morfologicamente expressa de forma distinta da categoria de pessoa. Há sufixos de número específicos de certas classes de palavras (Capítulo 3, Tabela 3.2), situação comparável, por exemplo, à dos prefixos de pessoa. No que concerne ao significado gramatical, quando o sufixo ocorre em nomes próprios, ele expressa um conjunto ao qual pertencem o indivíduo e seus associados, tal como em Iaut-kom [NOM.PROP-COL] 'Iaut e seu grupo $^{\prime 81}$. Em outros sintagmas nominais, o singular é a forma não marcada, isto é, não apresenta especificação morfológica. O plural expressa uma totalidade, um conjunto, um grupo, mais do que um plural, no sentido canônico que distingue "um" em oposição a "mais de um", como em abiana-ngmo [queixada-COL] 'Um bando de queixadas' e ugro-ngmo [1+2-COL] 'Nós todos'. Esta última palavra também pode significar 'gente, indígena ou ser humano', caso em que o sufixo pode ocorrer mais uma vez: ugrongmo-ngmo [indígena-COL] 'Indígenas, pessoas'. Estas características seguem o padrão, geralmente, verificado nas línguas da família ( $C f$. Hixkaryana (DERBYSHIRE, 1979, p. 84; 1985, p. 245), Waiwai (HAWKINS, 1998, p.129), Tiriyó (MEIRA, 1999, p.139)). Por outro lado, ainda não foram feitos estudos específicos que considerem, por exemplo, a investigação da distinção entre nomes contáveis e massivos.

Além disso, a morfologia de número não é obrigatoriamente marcada no sintagma nominal. Normalmente, ocorre ocorre apenas no predicado verbal, porém pode ser marcado no sintagma nominal e no verbal, apenas no nominal ou apenas no verbal.

\footnotetext{
${ }^{81}$ Este tipo de morfema é frequentemente chamado de associativo ou plural associativo.
} 
Neste capítulo nos concentramos, especialmente, nas formas das flexões, isto é, como as categorias de TAM, pessoa e número são expressas e como elas interagem entre si.

\subsection{MORFEMAS DE TAM}

Diversas configurações de pessoa e de número foram identificadas para os morfemas de TAM investigados: $\{$-nangry $\}$ IPFV, $\{$-ly $\sim-r y\}$ PSD.IMD, $\{-t(e)\}$ PSD.MED, $\{-n(e)\}$ PDS.DST, $\{-a\}$ PERM, $\{-n(e)\}$ HORT, $\{-(t) a\}$ HORT.ALA, $\{-k(o)\}$ IMP, $\{-(t) a\}$ IMP.ALA, $\{$-tome $\sim$-tpom $\sim-n p o m\}$ FUT, $\{-(t) a n e\}$ VET, $\{-d a$, -txa, -na $\}$ INTC, $\{-(t) a n g\}$ ADM. De acordo com as configurações de pessoa, encontramos conjuntos diferentes de morfemas para os seguintes agrupamentos:

- Os passados, o futuro e o imperfectivo;

- Imperativo proximal e alativo;

- Hortativo proximal e alativo;

- Os demais diretivos formam configurações únicas.

Como será demonstrado no decorrer deste capítulo, a afixação de pessoa ocorre não apenas de acordo com o tipo de flexão de TAM, mas também com a classe verbal, transitiva ou intransitiva no caso do imperativo. A forma do radical também influencia a forma dos morfemas, porém as alomorfias não serão ressaltadas nesta parte da descrição, visto que os padrões foram apresentados dentre os processos morfofonológicos no Capítulo II.

As configurações de morfemas de número, por sua vez, são distintas de acordo com seis grupos de TAM e pessoa. Cada um destes apresenta marcas morfossintáticas particulares:

- Hortativo, imperativo, futuro, vetativo e passados distante e médio (com exceção das terceiras pessoas desses passados);

- Perfectivo e passado imediato;

- Admonitivo e permissivo

- Morfemas portamteau correspondentes à terceira pessoa do passado distante e à terceira pessoa do passado médio;

- Vetativo

Nos passados médio e distante, o plural também interage com pessoa, além de aspecto, o que será explicado na seção correspondente. 
A seção a seguir apresenta a categoria de pessoa e seu alinhamento de acordo com a morfologia de TAM.

\subsection{PESSOA E TAM}

\subsubsection{A pessoa nos passados (imediato, distante e médio), no futuro e no imperfectivo}

As línguas Karib são relativamente conhecidas por apresentarem padrões de alinhamento complexos. Gildea (1998) aponta que a inerente complexidade da categoria de pessoa, combinada à grande variação com que ela é marcada entre as línguas Karib atuais, permite entender por que a classificação quanto ao sistema de pessoa dessas línguas provoca tanta discordância entre os pesquisadores de línguas individuais. Neste contexto, em análises anteriores, Souza, S. (1993, p. 12, 23; 2010, p. 55) e Souza, I. (2010, p. 27) apontam um alinhamento ergativo-absolutivo para os índices argumentais de Arara, conforme ilustra a tabela 5.1 .

Tabela 5.1- Alinhamento ergativo absolutivo

\begin{tabular}{c|cc}
\hline \multicolumn{1}{c}{ ABS } & ERG \\
\hline $\mathbf{1}$ & $\mathrm{y}-/ \mathrm{i}-/ \mathrm{w}-$ & $\mathrm{in}-/ \mathrm{k}-/ \mathrm{i}-$ \\
$\mathbf{1}$ & o-/ $\varnothing-$ & $\mathrm{mi}-/ \mathrm{my}-/ \mathrm{m}-$ \\
3REAL & uk- & kut- \\
3VIRTUAL & i-/ $\varnothing-/ \mathrm{t}(\mathrm{y})-$ & $\emptyset-$ \\
\hline
\end{tabular}

Fonte: Adaptado de Souza, S. (1993, p. 12)

Contudo, nas próximas seções é demonstrada a pertinência de uma análise baseada na ideia de intransitividade cindida, além de hierarquia de pessoa. Estes são os padrões encontrados nos tempos passados, expressos pelos sufixos $\{$-ly $\sim-r y\}$ PSD.IMD, $\{-n(e)\}$ PSD.DST, $\{-t(e)\}$ PSD.MED, no futuro, codificado por \{-tome $\sim$-tpom -npom\} FUT, e no imperfectivo, marcado por $\{$-nangry $\}$ IPFV. 
O presente estudo também demonstra que a aparente divergência entre os sistemas verbais de Arara e Ikpeng, observada pela comparação de descrições individuais dessas línguas, como as de Pachêco (2001) e Chagas (2013) para Ikpeng e de Souza S. (1993, 2010) e Souza, I. (2010) para Arara, não se sustenta.

A seção a seguir apresenta evidências de que o padrão dos prefixos argumentais verificados em raízes transitivas caracteriza o alinhamento conhecido como hierarquia de pessoa.

\subsubsection{Verbos bivalentes}

Verbos bivalentes exigem dois argumentos para formar uma sentença gramatical. A estrutura verbal de Arara apresenta diferentes classes de afixos para indicar estes argumentos. Dados de fala natural demonstram que é comum apenas um argumento ser expresso explicitamente na sentença, por meio de um sintagma nominal (geralmente o objeto na ordem $\mathrm{OV})$, enquanto o outro é marcado no verbo por meio de prefixos. Em línguas Karib, a primeira pessoa exclusiva $(1+3)$ é representada por um pronome sem um marcador específico de pessoa no verbo. Quando o pronome é usado, o verbo concorda com ele na terceira pessoa, situação comparável à concordância com a expressão "a gente" em português, como em "a gente faz = nós fazemos."

Seguindo o padrão da família, em Arara há formas presas obrigatórias para todas as pessoas gramaticais, exceto para a primeira pessoa exclusiva. Os participantes do ato de fala, isto é, 'eu' (1), 'você' (2) e também a primeira pessoa inclusiva 'nós' (1+2) são marcados no verbo por duas séries de morfemas. A série 'A' corresponde aos morfemas que codificam a categoria de pessoa do sujeito (A) e a série 'O' corresponde aos morfemas de objeto (O), conforme apresentado adiante. A realização de cada série de morfemas depende da configuração de traços de pessoa e da interação entre os participantes do discurso mais referenciais, como ficará claro nesta seção. Os morfemas pessoais não apresentam variação de número. As configurações de número para cada flexão de TAM são apresentadas em mais detalhes na seção 5.4. Uma lista com os verbos biargumentais analisados é fornecida no apêndice B.

Neste capítulo, setas são utilizadas para indicar as relações nas sentenças transitivas entre participantes dos atos de fala (PAF) e não participantes (NPAF), isto é, a terceira pessoa. Os termos configuração direta, inversa, local e não local, apresentados em Gildea (1994, 
1998), serão utilizadas para indicar a relações de referência entre PAF e os NPAF, conforme explicitado na tabela a seguir:

Tabela 5.2 - Termos utilizados para as relações de participantes

\begin{tabular}{|l|lll|l|}
\hline Configuração & \multicolumn{4}{|c|}{ Relação } \\
\hline Direta & PAF.A & $\rightarrow \quad 30$ & $\begin{array}{l}1,2 \text { e 1+2 afetam a terceira pessoa. } \\
\text { Ex.: 'Eu o vi, Você o viu' }\end{array}$ \\
\hline Inversa & 3A & $\rightarrow$ PAF.o & $\begin{array}{l}\text { Terceira pessoa afeta 1, 2, 1+2. } \\
\text { Ex.: 'Ele me viu, ele nos viu' }\end{array}$ \\
\hline Local & $1 \mathrm{~A}$ & $\rightarrow \quad 2 \mathrm{O}$ & $\begin{array}{l}\text { Primeira pessoa afeta a segunda pessoa. } \\
\text { Ex.: 'Eu vi você' }\end{array}$ \\
\hline Não-local & 20 & $\rightarrow 1 \mathrm{~A}$ & $\begin{array}{l}\text { Segunda pessoa afeta a primeira pessoa. } \\
\text { Ex.: 'Você me viu' } \\
\text { Terceira pessoa afeta terceira pessoa. } \\
\text { Ex.: 'Ele o viu' }\end{array}$ \\
\hline
\end{tabular}

Não há verbos bitransitivos como uma classe a parte, pois nenhuma característica morfossintática indica a distinção entre objeto indireto e qualquer argumento oblíquo. Observando os exemplos (1) e (2), constatamos que, embora a posposição esteja introduzindo um recipiente, não há nada que indique a distinção sintática entre o que seria o 'objeto indireto' nocional, em (1), ou o argumento oblíquo, em (2). Todos os adjuntos, exceto adverbiais, são introduzidos por posposições.

$\begin{array}{lllll}\text { Irma } & \text { wyna } & j \text {-udu-ang-te } & \text { ba } & \text { wot } \\ \text { irmã } & \text { DAT } & \text { 1A-dar-ASP-PSD.MED ? } & \text { Peixe }\end{array}$

'Eu dei peixe para minha irmã' (txt)
(2) kure-p potkun i-wyna
bonito-ATBZ INTENS 3-BEN
'É muito bonito para ele/a'. (Elic)

\subsection{Configurações direta e inversa}

A tabela 5.3 apresenta os prefixos de $\mathrm{A}$ empregados na relação direta e os de $\mathrm{O}$ empregados na relação inversa. Dentro de cada coluna de prefixos, a primeira série de morfemas ocorre diante de raízes iniciadas pelas vogais /a, e, o, u, y/ e a segunda série diante de raízes 
iniciadas por consoantes. Não foram atestados verbos bivalentes iniciados por /i/ e há apenas uma raiz iniciada por $/ j /:$ jadu 'queimar'.

Tabela 5.3 - Prefixos argumentais de verbos bivalentes

\begin{tabular}{|c|cc|cc|}
\hline Pess. & \multicolumn{2}{|c|}{$\begin{array}{c}\text { Série A } \\
\text { PAF } \rightarrow 3\end{array}$} & \multicolumn{2}{c|}{$\begin{array}{c}\text { Série O } \\
\text { 3 } \rightarrow \text { PAF }\end{array}$} \\
\hline & $+\mathrm{V}$ & $+\mathrm{C}$ & $+\mathrm{V}$ & $+\mathrm{C}$ \\
\hline $\mathbf{1}$ & $\{j-\}$ & $\{$ in $(i)-\}$ & $\{j-\}$ & $\{y-\}$ \\
\hline $\mathbf{2}$ & $\{m-\}$ & $\{m i-\}$ & $\{o-\}$ & $\{o-\}$ \\
\hline $\mathbf{1 + 2}$ & $\{k u d-\}$ & $\{k u t(i)-\}$ & $\{u g-\}$ & $\{u g u-\}$ \\
\hline
\end{tabular}

A seguir, os prefixos que ocorrem diante de vogais são ilustrados em (3) e (4) com uma raiz iniciada por /a/, agrobu 'pilar'. Os exemplos são apresentados no passado recente, marcado por $\{-l y \sim-n y \sim-r y\}$.

(3) Série A
a) $\quad j$ - agrobu-ly 'Eu o/a pilei'
b) $\quad \boldsymbol{m}$ - agrobu-ly 'Você o/a pilou'
c) kud- agrobu-ly 'Nós (dois) o/a pilamos'

(4) Série O
a) $\quad j$ - agrobu-ly 'Ele me pilou'
b) o- agrobu-ly 'Ele pilou você'
c) ug- agrobu-ly 'Ele nos (dois) pilou'

Observe-se que a relação entre a 1 e a 3 pessoas é marcada por morfemas homófonos, como demonstrado em (3a), (4a). A distinção é feita segundo critérios pragmáticos ou contextuais.

Nos próximos exemplos são apresentados os prefixos que ocorrem diante de raízes iniciadas por consoante. Em (5), é ilustrada a série A e, em (6), a série O, ambas com a raiz tang 'ouvir'.

(5) Série A
a) ini- dang-ry 'Eu o/a ouvi'
b) mi- dang-ry 'Você o/a ouviu'
c) kutxi- dang-ry 'Nós (dois) o/a ouvimos' 
(6) Série O
a) $y$ - dang-ry 'Ele me ouviu'
b) o- dang-ry 'Ele ouviu você'
c) $\quad \boldsymbol{k}$ - tang-ry 'Ele nos (dois) ouviu'

No que concerne aos alomorfes da configuração direta que ocorrem diante de consoantes (ini-1A3O, mi-2A3O, kutxi-1+2A3O), o corpus apresenta o seguinte cenário. Há 23 raízes iniciadas por consoantes. Ocorre a queda da vogal final do índice ini- em 14 raízes, com 11 raízes há queda da vogal final de kutxi- e a vogal de mi-2A3O nunca é apagada. Não há condicionamento morfofonológico da raiz que justifique os apagamentos, já que os ambientes são os mesmos quando há e quando não há elisão. Assim, ainda é desconhecido o motivo pelo qual ini- e kutxi- não são reduzidos a in- e kut- com as mesmas raízes.

Optou-se, por enquanto, por incluir a vogal como parte do prefixo, podendo ocorrer apagamento da vogal sempre que não houver impedimento fonotático. A deleção da última vogal em ini-1A3O e kutxi-1+2A3O resulta em sílabas bem formadas, e por isso pode haver deleção na maior parte das raízes. Por outro lado, a impossibilidade de uma sílaba formada apenas por consoante previne a deleção da vogal presente no prefixo mi-. Do ponto de vista histórico, Meira, Gildea e Hoff (2010, p. 594) reconstroem morfemas palatais os quais ocorreriam entre prefixos pessoais e raízes verbais na série direta. $\mathrm{O}$ cenário observado nesta língua é compatível com tal hipótese já que foi atestado um segmento palatal que aparece neste mesmo contexto, apenas na série direta.

\subsection{Configuração local}

Na tabela 5.4 são apresentados os morfemas portmanteau das relações que ocorrem apenas entre PAF.

Tabela 5.4 - Prefixos empregados na configuração local

\begin{tabular}{|l|c|}
\hline Pess. & Prefixos \\
\hline 1A2O & $\{k o-\}$ \\
\hline 2A10 & $\{u g u-\}$ \\
\hline
\end{tabular}


Exemplos dos morfemas são oferecidos em (7), com uma raiz iniciada por vogal, e, em (8), iniciada por consoante. Em (9) são apresentados os alomorfes da configuração local que ocorrem em raízes que sofrem ablaut (seção 2.7.6).

(7)
a) $\quad \boldsymbol{k} w$ - agrobu-ly 'Eu pilei você'
b) ug- agrobu-ly 'Você me pilou'

(8)
a) ko- dang -ry 'Eu ouvi você'
b) uk- tang-ry 'Você me ouviu'

(9)
a) $\quad \boldsymbol{k}$ - identu-ny 'Eu apertei você'
b) ug- edentu-ny 'Você me apertou'

\subsection{Configuração não-local}

Quanto à relação apenas entre terceiras pessoas, o morfema $i$ - (3A)3O ocorre em distribuição complementar com o argumento $\mathrm{O}$, anteposto ao verbo. Este morfema ocorre apenas em raízes iniciadas por consoantes. Diante de raízes iniciadas por vogais, o morfema é zero, conforme apresentado na tabela 5.5.

Tabela 5.5 - Prefixos empregados na relação não local

\begin{tabular}{c|cc}
\hline Pess. & \multicolumn{2}{|c}{ Prefixos } \\
& $+\mathrm{V}$ & $+\mathrm{C}$ \\
\hline $\mathbf{3 A}) 30$ & $\{\emptyset-\}$ & $\{\mathrm{i}-\}$ \\
\hline
\end{tabular}

Os exemplos (10) e (11) demonstram a ordem dos constituintes OV com predicados que iniciam por vogal e consoante, respectivamente. Em (12), é possível verificar o morfema $i$ (3A)3O que ocorre apenas quando o objeto é demovido de sua posição canônica (apresentada em (10) e (11)). O morfema zero, por sua vez, é glossado em raízes iniciadas por vogais quando a ordem for diferente de OV, como em (13). 
\begin{tabular}{lll}
{$[\mathrm{O}$} & \multicolumn{1}{c}{$\mathrm{V}]_{\mathrm{VP}}$} & \multicolumn{1}{c}{ adjunto } \\
tyde & erengmyly & paduap \\
ty-de & erengmy-ly & padua-p \\
3REFL-mãe & matar-PSD.IMD & tatu.sp-ATBZ
\end{tabular}

'Ele matou a mãe que virou bandeira.' (Txt) (Lit.: 'Ele matou a própria mãe transformada em tatu bandeira')

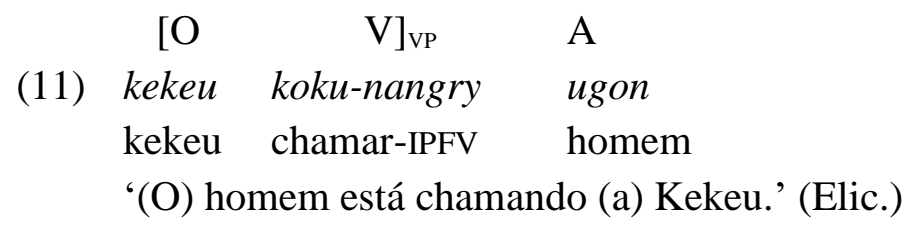

\begin{tabular}{ccl} 
A & \multicolumn{1}{c}{ 3-V } & O \\
Pilik & i-goku-nangry & ugon \\
Pilik & (3A)3O-chamar-IPFV & homem \\
'Pilik está chamando o homem.' (Elic)
\end{tabular}
$\begin{array}{lll}\mathrm{O} & \mathrm{A} & \mathrm{V}\end{array}$
(13) anane taje kuruatxi eniptongry mogyn anane taje kuruatxi $\varnothing$-eniptong-ry piget mogyn um INTENS urubu (3A)3O-descer-PSD.IMD mais.ou.menos DEIT.ANIM 'O urubu desceu para o chão com a pessoa (que não se transformou)'. (Txt)

Note também que no sintagma OV ocorre um morfema relacional diante de radicais iniciados em vogais, apenas quando o argumento $\mathrm{O}$ antecedente tem um elemento consonantal como último segmento. Exemplos são fornecidos em (14) e (15). Isto explica por que em (10), por exemplo, não há morfema relacional ${ }^{82}$.

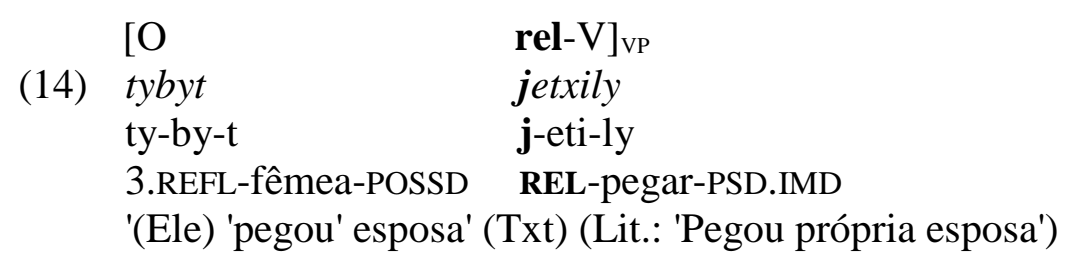

\begin{tabular}{lllll} 
& & & {$[[\mathrm{PSSR}$} & \multicolumn{1}{c}{ POSSD $]_{\mathrm{NP} . \mathrm{O}}$} \\
(15) & ugon & ugon pene & {$[[$ kyden } & jakytpot $]$ \\
ugon & ugon pene & kyden & j-aky-tpot \\
homem & homem & ? & mandioca & REL-peneirar-NOM
\end{tabular}

\footnotetext{
${ }^{82}$ Paralelo aos sintagmas verbais (OV), a mesma regra de inclusão do relacional é observada em sintagmas do tipo Possuidor-Possuído.
} 
rel-V]] $]_{\mathrm{VP}}$

jabonangryngmo

j-abotxi-nangry-ngmo

REL-segurar-IPFV-COL

'Dois homens jogando peneira' (Lit.: Dois homens estão jogando )

\subsection{Alinhamento hierárquico}

O sistema acima descrito é compatível com o padrão condicionado por hierarquia de pessoa. A ideia principal de um sistema hierárquico é a de que os PAFs $(1,2,1+2)$ são mais referenciais do que a terceira pessoa, sendo, portanto, adicionados ao verbo ao invés desta. Algumas línguas também estabelecem um ranking de indexabilidade para os PAFs entre si, em que $1>2$ ou $2<1$. Por outro lado, o conceito mais amplo de alinhamento hierárquico pode envolver, translinguisticamente, vários traços semânticos como animacidade, egoforicidade, +/humano, dentre outros, os quais se mostram relevantes para a marcação morfossintática dos participantes. A figura a seguir exemplifica uma combinação geral de hierarquia de marcação de pessoa, segundo (ZÚÑ̃NGA, 2006, pg.21):

Figura 5.1 - Hierarquia de indexabilidade

$\mathrm{SAP}>3 \mathrm{rd}$ person pronoun $>[+$ human $]>[+$ animate $]>$ [animate $]$

Em Arara, tanto na relação direta como na inversa os morfemas argumentais indexados no verbo são os de PAF, logo a hierarquia verificada é PAF > 3. No que concerne à relação local, os morfemas $\{k o-\} 1 \mathrm{~A} 2 \mathrm{O}$ e $\{u g u-\} 2 \mathrm{~A} 1 \mathrm{O}$ são analisados como morfemas portmanteau, não sendo possível determinar diferença hierárquica entre a primeira e a segunda pessoa. De acordo com o apresentado para as outras configurações de pessoa, desconsidera-se a possibilidade de analisar o morfema $\{k o-\}$ como sendo composto por dois índices: $k$ - ' 1 ' e $-o$ ' 2 '. Uma análise em que se consideram dois lugares para a indexação argumental implicaria a postulação de muitos zeros para a terceira pessoa na configuração direta, o que seria inviável por razão de economia. A figura 5.2 representa a hierarquia observada:

Figura 5.2 - Hierarquia de pessoa em Arara

$$
1=2>3
$$


A seção a seguir apresenta os índices encontrados em raízes intransitivas, demonstrando a cisão semântico-morfológica entre duas classes.

\subsubsection{Verbos monovalentes}

Os verbos intransitivos dividem-se em duas classes que apresentam séries distintas de prefixos de pessoa. Há uma classe prefixada por morfemas aqui chamados $\mathrm{S}_{\mathrm{A}}$ por sua semelhança morfológica como os prefixos de A em verbos biargumentais e outra classe caracterizada pelo uso de prefixos aqui chamados $S_{\circ}$, porque são semelhantes aos prefixos de O. Línguas com esta característica foram denominadas de diferentes maneiras por uma vasta literatura: inacusativas-inergativas (PERLMUTTER, 1978), ativas-inativas (KLIMOV, 1974), ativo-estativas (MITHUN, 1991), S-cindido (Split-S) (DIXON, 1994), Cisão intransitiva (Split-intransitivity) (MERLAN, 1985; VAN VALIN Jr; LAPOLLA, 1997). Neste estudo, é adotada a denominação Cisão intransitiva ou Intransitividade cindida.

\subsection{As classes $\mathrm{S}_{\mathrm{A}}$ e $\mathrm{S}_{\mathrm{O}}$}

Dentre a classe $\mathrm{S}_{\mathrm{A}}$, há duas subclasses de predicados. Há aqueles cujo prefixo argumental de primeira pessoa é $k$ - e aqueles que apresentam $w(y)$ - como primeira pessoa, conforme pode ser verificado na tabela 5.6. Esta cisão é considerada morfologicamente determinada na maioria dos casos. Novos membros são incorporados à classe cuja primeira pessoa é $k$-, como será demonstrado na subseção (5.3.1.2.2). As alomorfias da primeira pessoa inclusiva kut- são idênticas às que ocorrem em raízes biargumentais.

Tabela 5.6 - Prefixos Argumentais $\mathrm{S}_{\mathrm{A}}$

\begin{tabular}{|c|c|c|}
\hline Pess. & \multicolumn{2}{|c}{ Prefixos $\mathbf{S}_{\mathbf{A}}$} \\
\hline & $\mathbf{+ V}$ & $\mathbf{+} \mathbf{C}$ \\
\hline $\mathbf{1}$ & $\{k-\},\{w-$, & $w y-\}$ \\
\hline $\mathbf{2}$ & $\{m-$, & $m y-\}$ \\
\hline $\mathbf{3}$ & \multicolumn{2}{|c|}{$\emptyset-$} \\
\hline $\mathbf{1 + 2}$ & \multicolumn{2}{|c|}{$k u t-$} \\
\hline
\end{tabular}


Os paradigmas dos verbos da classe $\mathrm{S}_{\mathrm{A}}^{83}$ são ilustrados em (16) e (17). O paradigma (16) exemplifica os verbos cuja primeira pessoa é $k$ - e (17) representa aqueles cuja primeira pessoa é marcada por $w$-. Observe que a primeira e a segunda pessoas desta subclasse apresentam os alomorfes $w y-1 \mathrm{~S}_{\mathrm{A}} \mathrm{e} m y-2 \mathrm{~s}_{\mathrm{A}^{\prime}}$ diante de consoantes, como ilustrado em (18) com a única raiz desta classe verificada no corpus que inicia por um segmento consonantal. A lista de verbos analisados pode ser vista na tabela 2 do apêndice $\mathrm{A}$

(16) origu 'Dançar'
a) $\quad k$ - origu-ny 'Eu dancei'
b) $\quad \boldsymbol{m}$ - origu-ny 'Você dançou'
c) $\quad$ - origu-ny 'Ele dançou'
d) $\quad \boldsymbol{k}$ d- origu-ny 'Nós (dois) dançamos'

(17) iby 'tomar banho'
a) $\quad \boldsymbol{w}$ - iby-ny 'Eu tomei banho'
b) $\quad \boldsymbol{m}$ - iby-ny 'Você tomou banho'
c) $\varnothing$ - iby-ny 'Ele tomou banho'
d) kutx- iby-ny 'Nós (dois) tomamos banho'

(18) $k e$ 'dizer'
a) wy- ge-ny 'Eu disse'
b) my- ge-ny 'Você disse'
c) $\quad$ - $k e-n y \quad$ 'Ele disse'
d) kut- ke-ny 'Nós (dois) dissemos'

A classe $S_{o}$, por sua vez, é a mais numerosa e regular, isto é, sem cisão na primeira pessoa. Os prefixos argumentais desta classe são apresentados na tabela 5.7.

Tabela 5.7 - Prefixos Argumentais $\mathrm{S}_{\mathrm{O}}$

\begin{tabular}{c|c|}
\hline Pess & Prefixos So \\
\hline & $+\mathbf{V}+\mathbf{C}$ \\
$\mathbf{1}$ & $\{j-\},\{y-\}$ \\
\hline
\end{tabular}

\footnotetext{
${ }^{83}$ Uma das raízes desta classe, eby 'vir', apresenta paradigma irregular com morfologia extra apenas com algumas flexões. No passado imediato e passado distante é acrescentado o morfema ot- 'DTRZ' entre o índice de segunda pessoa e a raiz, como em m-od-eby-ny [2- DTRZ-vir-PSD.IMD] 'Você veio' e m-od-ep-tang-te [2- DTRZ-vir-ASPPSD.DST] 'Você veio (há bastante tempo)'. No imperativo é verificado o mesmo morfema, como em od-ep-ko [DTRZ-vir-IMP] 'Vem!'. Outra irregularidade do paradigma refere-se à terceira pessoa, pois ao invés de zero, a raiz recebe $t$ - ' 3 '.
} 


\begin{tabular}{|c|c|}
\hline Pess & \multicolumn{2}{|c|}{ Prefixos So } \\
\hline & $+\mathbf{V}+\mathbf{C}$ \\
\hline $\mathbf{2}$ & $\{o-\}$ \\
\hline 3 & $\{\varnothing-, i-\}$ \\
\hline $\mathbf{1 + 2}$ & $\{u g u-\}$ \\
\hline
\end{tabular}

Quanto às variações alomórficas, a primeira e a terceira pessoa são determinadas de acordo com a natureza do primeiro segmento da raiz. Os índices $j$ - $1 S_{\circ}$ e $\emptyset$ - 3 ocorrem diante de raízes iniciadas por vogal e $y$ - $1 \mathrm{~S}_{\circ}$ e $i$ - $3 \mathrm{~S}_{\circ}$ ocorrem diante de raízes iniciadas por consoantes. A primeira pessoa inclusiva e a segunda pessoa apresentam as mesmas alomorfias encontradas para os morfemas encontrados em verbos transitivos.

Paradigmas são oferecidos em (19) e (20) com as raízes erangy 'ficar assustado' e pongnumy 'chorar'.

(19) erangy 'ficar assustado, ter medo'

a) $j$ - erangy-ny 'Eu fiquei assustado'

b) irangy ${ }^{84}$-ny 'Você ficou assustado'

c) $\varnothing$ - erangy-ny 'Ele ficou assustado'

d) ug- erangy-ny 'Nós (dois) ficamos assustados'

(20) pongnumy 'chorar'
a) $y$ - bongnumy-ny
'Eu chorei'
b) o- bongnumy-ny
'Você chorou'
c) i- bongnumy-ny
'Ele chorou'
d) uk- pongnumy-ny
'Nós (dois) choramos'

A tabela abaixo oferece um resumo de todos os prefixos citados, tanto os que ocorrem em predicados biargumentais como os que ocorrem em predicados monoargumentais. São apresentadas apenas as formas fonêmicas a fim de proporcionar a melhor observação dos padrões descritos.

\footnotetext{
${ }^{84}$ Forma da segunda pessoa ocasionada por ablaut: irangy-ny [2ficar.assustado-PSD.IMD] 'Você ficou assustado'
} 
Tabela 5.8 - Padrão completo de morfemas argumentais
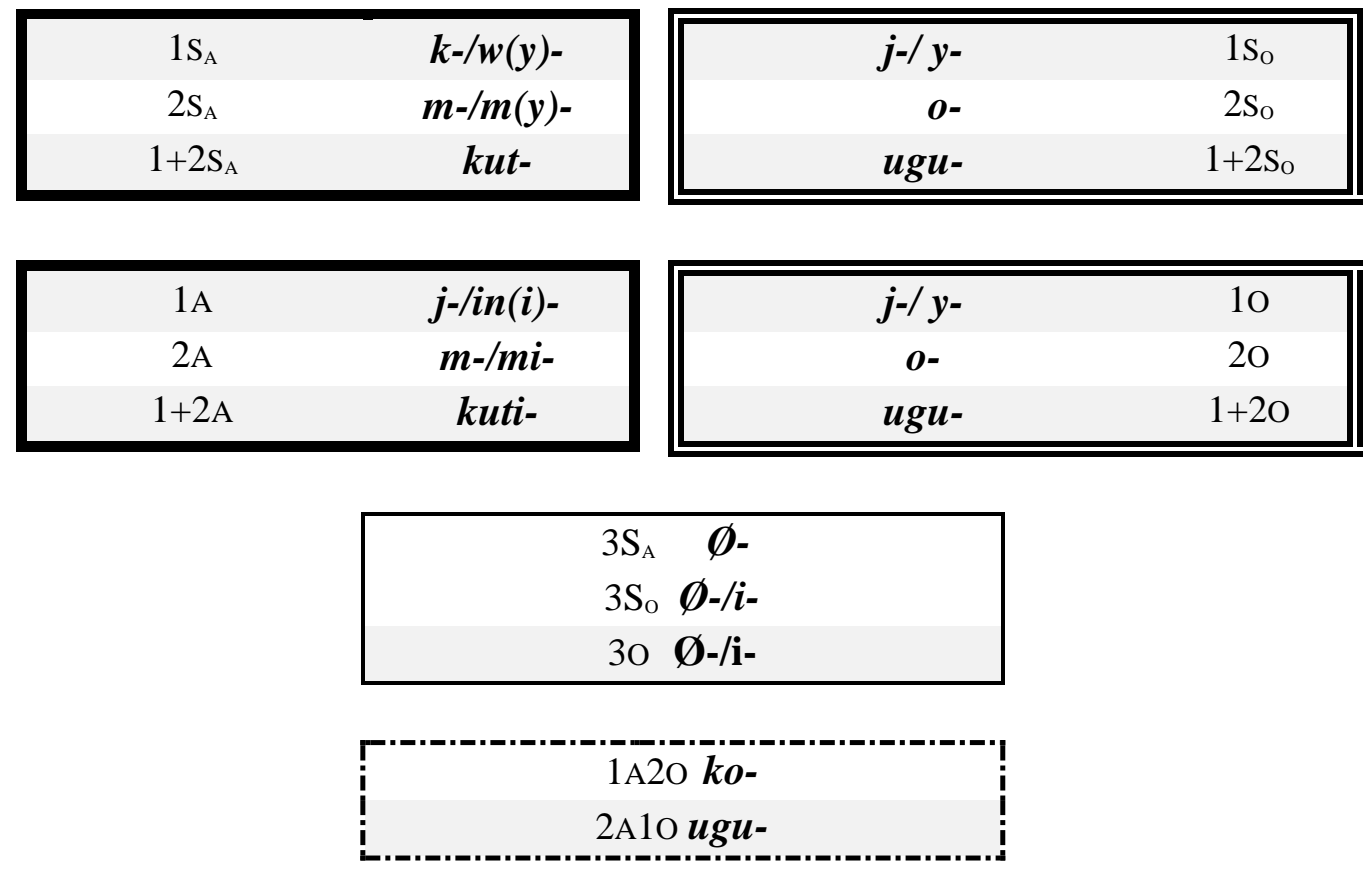

\subsection{Sobre a natureza semâtico-morfológica dos predicados monoargumentais}

Segundo a literatura que discute a motivação para a divisão das classes de predicados monoargumentais, tal divisão está condicionada a fatores como controle/agentividade, afetação e aspecto lexical (Cf. MITHUN, 1991; DIXON, 1994). Por outro lado, segundo Meira (2000), o padrão de indexação encontrado em línguas Karib do Norte, aqui chamado de intransitividade cindida, é epifenomenal. De acordo com este autor, trata-se de uma consequência casual do desenvolvimento histórico de morfologia detransitivizadora, que pode ser observado sincronicamente e/ou diacronicamente. Neste contexto, a existência dessas duas classes de predicados intransitivos não está correlacionada apenas com fatores encontrados na literatura, isto é, motivações semânticas ou sintáticas. Ainda segundo Meira (2000), a única correlação bastante clara nas línguas por ele analisadas é de natureza morfológica, visto que a maioria absoluta dos verbos da classe $S_{\mathrm{A}}$ são formas detransitivizadas de verbos transitivos, sincronicamente ou diacronicamente reconhecíveis. Os verbos detransitivizados foram lexicalizados como $\mathrm{S}_{\mathrm{A}}$, apresentando significado reflexivo, médio ou passivo. $\mathrm{O}$ cenário morfológico encontrado em Arara não difere do padrão descrito para as línguas Karib do Norte, reforçando a hipótese apresentada em Meira (2000), segundo a qual a maior parte dos predicados intransitivos $S_{\mathrm{A}}$ pode ser fruto de um acaso histórico. 
Foram analisados 57 verbos intransitivos, dos quais a maioria pertence à classe $S_{0}$, somando 38 predicados (Apêndice A). Os 19 verbos da classe $S_{A}$ estão divididos entre 7 membros que apresentam $w$ - como primeira pessoa e 12 que marcam esta pessoa com o morfema $k$-. A tabela 5.9 apresenta todos verbos $\mathrm{S}_{\mathrm{A}}$ analisados até o presente. Todas as raízes estão flexionadas na primeira pessoa e no tempo passado imediato.

Tabela 5.9 - Verbos intransitivos da classe $S_{a}$

\begin{tabular}{|l|l|l|l|}
\hline Verbo & Glosa da raiz & Verbo & Glosa da raiz \\
\hline $\boldsymbol{k}$-omomyly & 'entrar, mergulhar' & $\boldsymbol{w}$-geny & 'dizer' \\
\hline $\boldsymbol{k}$-onkuly & 'subir' & $\boldsymbol{w}$-itxiny & 'deitar' \\
\hline $\boldsymbol{k}$-origuly & 'dançar' & $\boldsymbol{w}$-itxiny & 'ser, estar' \\
\hline $\boldsymbol{k}$-otximtabringely & 'comer' & $\boldsymbol{w}$-ebyny & 'vir, chegar' \\
\hline $\boldsymbol{k}$-odakpily & 'ficar bêbado' & $\boldsymbol{w}$-ibyny & 'banhar' \\
\hline $\boldsymbol{k}$-odubuly & 'sobrar' & $\boldsymbol{w}$-iptongry & 'descer' \\
\hline $\boldsymbol{k}$-odotpodyly & 'voltar' & $\boldsymbol{w}$-ydoly 85 & 'ir' \\
\hline $\boldsymbol{k}$-odetxily & 'casar' & & \\
\hline $\boldsymbol{k}$-otpaimymtongry & 'casar' & & \\
\hline $\boldsymbol{k}$-oremely & 'errar' & & \\
\hline $\boldsymbol{k}$-odewyny & 'dar a volta' & & \\
\hline $\boldsymbol{k}$-odapoimely & 'atrasar' & & \\
\hline & & & \\
\hline
\end{tabular}

Observe que todos os 12 verbos indexados pelo morfema $k$ - $1 \mathrm{~S}_{\mathrm{o}}$ apresentam a raiz iniciada pela vogal /o/. Não por acaso, o prefixo detransitivizador encontrado em Arara é ot( $i$ ). Além disso, os novos itens detransitivisados são introduzidos à classe $\mathrm{S}_{\mathrm{o}}$ por meio do referido morfema, como ilustrado a seguir com os verbos para 'comer' e 'casar'. Os exemplos em (21) e (22) apresentam verbos derivados a partir de nomes que, após detransitivização via morfema ot $(i)$-, entraram na classe de verbos $\mathrm{S}_{\mathrm{A}}$.
(21) kotximtabringeny
imrenpe
k-oti-mydabri-nge-ny
i-mure-n-pe
1 $\mathrm{S}_{\mathrm{A}}$-DTRZ-3-comida-VBZ-PSD.IMD
3-filho-POSSD-ATBZ
'Eu comi um pouco' (Elic.)

\footnotetext{
${ }^{85}$ Veja que neste verbo o /y/ pertence à raiz (/w-ydoly/), e não ao prefixo, como /wy-geny/ 'dizer', pois uma análise que considera a mesma forma da primeira pessoa forçaria a criação de uma terceira pessoa $y$ - apenas para a raiz de ir. Deste modo, nossa análise optou por identificar alomorfes diferentes para a primeira pessoa e manter uma terceira pessoa unificada ( $\varnothing$-ydo-ly [3-ir-PSD.IMD] 'foi', $\varnothing$-ke-ly [3-dizer-PSD.IMD]] 'disse').
} 
(22) kodetxiny $^{86}$

k-oti-etxi- $\varnothing$-ny

1-DTRZ-casa-VBZ-PSD.IMD

'Eu me casei'

\subsubsection{Terceiras pessoas condicionadas pelos passados médio e distante}

Os paradigmas de pessoa do passado distante e do passado médio apresentam a mesma configuração de morfemas de pessoa apresentados anteriormente, exceto para a terceira pessoa. Apenas nos paradigmas destas duas categorias, os afixos pessoais são expressos por morfemas portmanteau $\{$ kuni- $\sim$ kun-\} e \{moni- $\sim$ mon-\}, respectivamente. O prefixo kun- expressa a terceira pessoa e o passado distante. Exemplos são apresentados em (23) e (24). Neste último, além do morfema kun- 3PSD.DST há a ocorrência do morfema aspectual - ak. Veja que -ak IPVF.PSD pode ocorrer com o passado -ne em outras pessoas que não a terceira, conforme apresentado na seção (4.4.3), onde são apresentados exemplos. Em (25) é oferecido um paradigma completo no qual pode-se verificar que apenas na terceira pessoa não há coocorrência do prefixo kun- e com a flexão temporal -ne.

$\begin{array}{llllll}\text { ybari } & \text { tximna } & \text { kunke } & \text { odengruket } & \text { Igraut } & \text { wyna } \\ \text { y-bari } & \text { tximna } & \text { kun-ke } & \text { od-engru-ke-t } & \text { Igraut } & \text { wyna } \\ \text { 1-amigo } & 1+3 & \text { 3PSD.DST -falar } & \text { DTZR-olho-VBZ-PROPS? NOM.PROP } & \text { ADRSS } \\ \text { 'Amigo', nós (excl.) falamos para aparecer para o Geraldo' (Txt) } & \end{array}$

$\begin{array}{llll}\text { tukto } & \text { tximna } & \text { kunagiang } & \text { mylo } \\ \text { tukto } & \text { tximna } & \text { kun-age-ak } & \text { mylo } \\ \text { roça } & 1+3 & \text { 3PSD.DST-derrubar-IPFV.PSD } & \text { lá } \\ \text { 'Nós derrubávamos roça lá (no mato)' (Txt) } & \end{array}$
a) $\quad k$ - omom-ne
'Eu entrei'
b) m- omom-ne
'Você entrou'
c) kun- omom
'Ele entrou'
d) kud- omom-ne
'Nós incl. entramos'

\footnotetext{
${ }^{86}$ Segundo informação do falante, o verbo para 'casar' é kotpaimymtongry 'Eu me casei', enquanto o verbo kodetxiny consiste em uma inovação criada após o aldeamento definitivo, há cerca de 30 anos.
} 
Não foram encontradas outras marcas de tempo quando este morfema é sufixado ao radical. Um caminho de mudanças históricas é apresentado em Gildea (1998, p. 97), segundo o qual haveria quatro estágios de mudança entre a perda do passado distante -ne e substituição pelo prefixo de terceira pessoa em Akuriyó, Wayana e Tiriyó. Até o presente, os indícios verificados em Arara estão de acordo com os estudos anteriores.

O morfema moni- mon-, por sua vez, expressa a terceira pessoa e o passado médio. A maioria dos exemplos deste prefixo foi verificado com o possível sufixo aspectual \{-tang -ang (txang $\left.\left.{ }^{87}\right)\right\}$ ASP, como em (26) e (27) ${ }^{88}$. Assim como no caso de kun(i)-, dentre os dados disponíveis, não foi encontrada nenhuma outra marca de tempo ocorrendo com o prefixo mon(i)-. O exemplo (28) apresenta um paradigma completo. Em (28c) é possível verificar que a ocorrência com o morfema de passado médio faz com que o verbo se torne agramatical.

$\begin{array}{ll}\text { jebyngmo } & \text { moneptang } \\ \text { j-eby-ngmo } & \text { mon-eby-tang } \\ \text { 1-parente-COL } & \text { 3PSD.MED-vir-ASP } \\ \text { 'Meus parceiros chegaram' (Elic) }\end{array}$

$\begin{array}{ll}\text { ae } & \text { monibruang } \\ \text { ae } & \text { moni-bru-ang } \\ \text { abelha.europa } & \text { 3PSD.MED-atacar-ASP } \\ \text { 'Europa atacou' (Txt) }\end{array}$

(28)
a) $\quad k$ - onku-txang-te 'Eu subi'
b) $\quad m$ - onku-txang-te 'Você subiu'
c) *mon- onku-txang-te (Ele subiu)
d) mon- onku-txang 'Ele subiu'
e) kud- onku-txang-te 'Nós incl. subimos'

\footnotetext{
${ }^{87}$ Variação idiossincrática.

88 Alguns casos atestados ocorrem com o morfema $\{k y\}$, que ainda necessita ser pesquisado. Em textos, frequentemente, encontrar-se a expressão mon-tx-ang ky [3-falar-ASP ?] 'Ele disse ou estava dizendo assim' (Segundo comentário do consultor indígena, as pessoas que falam assim, não falam bem). Além disso, há o morfema \{mon\}, possivelmente, um pronome de terceira pessoa anafórico que pode ter dado origem ao prefixo apresentado.
} 


\subsubsection{Idiossincrasias: $\{t(y)-\} 3$ e $\{w-\}$ consoante de ligação}

Além dos morfemas de terceira pessoa apresentados, há o morfema $t(y)$ - 3 que foi atestado em um limitado grupo de raízes, independentemente da flexão de TAM. Estas raízes são iniciadas principalmente por vogais altas ou médias e posteriores, conforme exemplos apresentados na tabela 5.10. Vale assinalar que Gildea e Payne (2007, pg. 27) apresentam um morfema idiossincrático $t$ - 3 , reconstruível em Proto-Karib. Todos os exemplos da tabela a seguir estão flexionados no passado imediato.

Tabela 5.10 - Lista de raízes que recebem $t(y)$ - '3'

\begin{tabular}{|l|l|l|l|}
\hline \multicolumn{4}{|c|}{ Verbos biargumentais } \\
\hline t-ygy-ny & 'ralar' & t-udu-ny & 'dar' \\
\hline t-yby-ny & 'dar banho' & t-ugetke-ny & 'abanar' \\
\hline t-ygaby-ny & 'tecer' & t-uktu-ny & 'começar' \\
\hline $\begin{array}{l}\text { t-okpetke-nangry } ~ \\
\text { w-okpetke-nangry }\end{array}$ & 'fazer' & t-ubitke-ny & 'procurar' \\
\hline $\begin{array}{l}\text { t-ongong-ry } ~ \\
\text { w-ongong-ry }\end{array}$ & 'morder' & ty-wo-ny & 'matar' \\
\hline
\end{tabular}

\begin{tabular}{|c|c|c|c|}
\hline \multicolumn{4}{|c|}{ Verbos monoargumentais } \\
\hline$t-e b y-n y$ & 'vir' & t-yngky-ny & 'dormir' \\
\hline
\end{tabular}

Souza, S. (1993, p. 24) e Souza, I. (2010, p. 26) consideram o prefixo ty- como um marcador de objeto direto, entretando, como apresentado na tabela 5.10, o morfema também ocorre em verbos intransitivos.

Ademais, uma consoante epentética $\langle w\rangle$ foi atestada nas relações inversa e local dos paradigmas dos verbos iniciados por /y/ (yby 'dar banho', ygaby 'tecer', ygy 'ralar') e /o/ (okpe 'fazer'). O morfema é ilustrado no paradigma em (29).
a) $\quad y-\quad \boldsymbol{w}$ yby-ny 'Ele me banhou'
b) $o-\quad w \quad y b y-n y \quad$ 'Ele banhou você'
c) ug- $\boldsymbol{w}$ yby-ny 'Ele nos (dois) banhou' 

d) ko- $\quad \boldsymbol{w} \quad y b y-n y \quad$ 'Eu banhei você'
e) ug- w yby-ny 'Você me banhou'

\subsubsection{Nota sobre a semelhança com Ikpeng}

A presente descrição demonstra que o complexo sistema de marcação de pessoa em Arara, na verdade, é mais semelhante ao sistema encontrado em Ikpeng do que as descrições de Souza, S. (1993, 2010), Souza, I. (1987, 2010), Pacheco (2001) e Chagas (2013) permitiam perceber. Isto porque, enquanto os dois primeiros autores descrevem um sistema ergativoabsolutivo para Arara, como apresentado na seção 5.3.1 (Tabela 5.1), os dois últimos descrevem um sistema complexo para Ikpeng, com hierarquia de pessoa e intransitividade cindida, sendo que o estudo mais recente sobre esta língua acrescenta uma série completa de prefixos pessoais que ainda não havia sido descrita. Comparando-se os resultados aqui descritos com o sistema oferecido por Chagas (2013), pode-se verificar uma grande proximidade entre os marcadores de pessoa em Arara e Ikpeng. Um resumo dos morfemas encontrados é apresentado nas tabelas 5.11 e 5.12. A ortografia de Ikpeng foi adaptada para facilitar a comparação dos prefixos.

Com relação à primeira pessoa in(i)- 1A, verificada em Arara (primeira linha das tabelas), Pacheco (2001) apresenta o prefixo in- como um marcador de 3o, em Ikpeng. Segundo o autor, este último prefixo ocorre diante de consoantes e $j$ - diante de vogais (i.e. $i n-\sim j$ - 30), contudo, em seu estudo, há exemplos apenas para o alomorfe $j$-. Além disso, o morfema de 3o estaria violanado a hierarquia de pessoa. Chagas (2013), por sua vez, demonstra que tal violação não ocorre e apresenta os alomorfes $j$ - $\sim j e$ - e $k$ - como prefixos de 1 A e $j$ - $\sim i$ - como alomorfes de 3o, como pode serverifiacado na tabela 5.12. Esta autora não inclui o morfema in- em seu estudo, mas afirma que o mesmo está presente em textos (CHAGAS, 2017, Comunicação pessoal). Futuros estudos sobre Ikpeng deverão esclarecer a qual pessoa o mofema ser refere. 
Tabela 5.11 - Prefixos argumentais em Arara

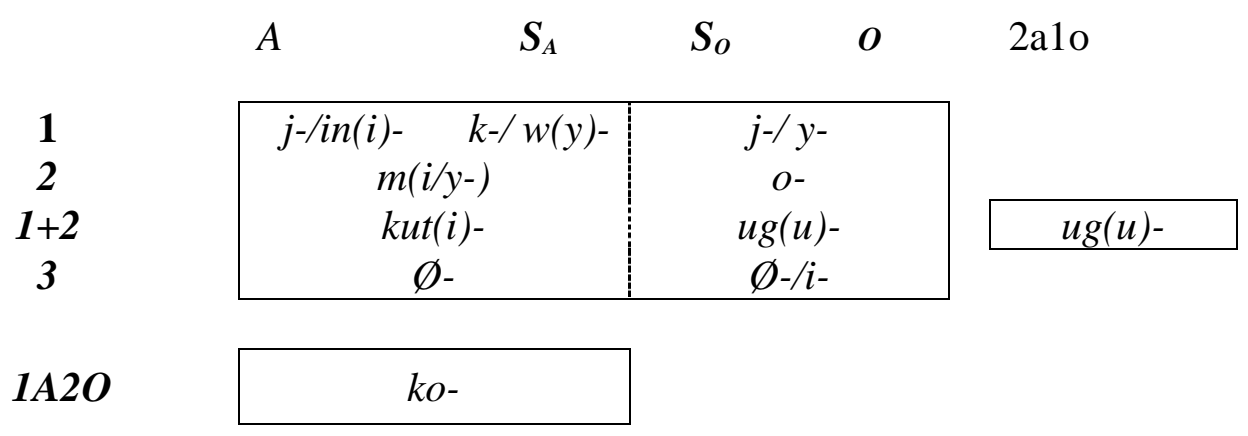

Tabela 5.12 - Prefixos argumentais em Ikpeng

\begin{tabular}{|c|c|c|c|}
\hline & $S_{A}$ & $S_{o}$ & $2 \mathrm{a} 1 \mathrm{o}$ \\
\hline $\begin{array}{l}1 \\
2\end{array}$ & $\begin{array}{c}j(e)-/ k- \\
m\left(e^{-}\right)\end{array}$ & $\begin{array}{c}g-/ y- \\
o-\end{array}$ & \\
\hline $\begin{array}{c}1+2 \\
3\end{array}$ & $\begin{array}{l}\text { kut- } \\
\emptyset-l e-\end{array}$ & $\begin{array}{c}u g(w)-/ w y- \\
j-/ i-\end{array}$ & $u g(w)-/ w y-$ \\
\hline $1 A 2 O$ & $k o-, k w-, k-$ & & \\
\hline
\end{tabular}

Fonte: Adaptado de Chagas (2013, p. 142-146).

Vale ressaltar que, com relação à genealogia interna da família Karib, esta similaridade entre os sistemas de pessoa corrobora a proximidade entre as duas línguas/dialetos, conforme apontam Meira e Franchetto (2005).

As seções a seguir apresentam as configurações de pessoa nos modos que denotam comando, com força ilocucionária forte e fraca, os quais são relativos à modalidade orientada pelo falante. Também é oferecido o paradigma do modo intencional, referente à modalidade orientada pelo agente.

\subsubsection{A pessoa no modo vetativo}

O paradigma de pessoas no modo vetativo apresenta os prefixos elencados na tabela abaixo. Os dados mais comumente encontrados são com a segunda pessoa $m$ - para raízes transitivas e intransitivas $S_{\mathrm{A}}$, como ilustram os exemplos em (30) e (31), respectivamente. A 
segunda pessoa $o$ - ocorre em raízes So, (32). A forma de $1+2$ também foi identificada nos três grupos de raízes, (33), (34) e (35). Os morfemas portmanteu 2A10 e 1A2O são verificados apenas em raízes transitivas. Exemplos são apresentados em (36) e (37).

Tabela 5.13 - Prefixos de pessoa no vetativo

\begin{tabular}{|c|c|c|}
\hline \multirow[t]{2}{*}{ Pessoa } & \multirow{2}{*}{$\begin{array}{c}\text { Raiz } \\
\text { Transitiva }\end{array}$} & Intransitivas \\
\hline & & Sa $\quad$ So \\
\hline 2A10 & $\{u g u-\}$ & \\
\hline $1 \mathrm{~A} 2 \mathrm{O}$ & $\{k o-\}$ & \\
\hline $1+2 \mathrm{~A} / \mathrm{S}_{\mathrm{A}}$ & $\{k u t-\}$ & $\{k u t-\}$ \\
\hline $1+2 S_{o}$ & & $\{u g u-\}$ \\
\hline $2 \mathrm{~A} / \mathrm{S}_{\mathrm{A}}$ & $\{m-\}$ & $\{m-\}$ \\
\hline $2 S_{o}$ & & $\{o-\}$ \\
\hline
\end{tabular}

(30) medentukiane

m-edentu-ke-ane

2A-amarrar-VLZ-VET

'Você não pode desamarrá-lo.' (Elic.)

(31) momomtane

m-omomy-tane

$2 \mathrm{~S}_{\mathrm{A}}$-afundar-VET

'Cuidado, você vai afundar-se.' (Elic.)

(32) oalumtane

o-alumy-tane

$2 \mathrm{~S}_{\mathrm{O}}$-pular-VET

'Não pula!' (Elic.)

(33) kutpympotxiane

kut-pympotxi-ane

$1+2 \mathrm{~A}$-cobrir-VET

'Nós não vamos cobrir ele.' (Elic.)

(34) kudomomtane

kud-omomy-tane

$2 \mathrm{~S}_{\mathrm{A}}$-afundar-VET

'Cuidado para nós não nos afundarmos.' (Elic.) 
(35) ugumpyanepty

wygiangne

ug-umpy-ane-pty

wy-Ke-ang-ne

1+2So-transformar.se-VET-COL $\quad 1 \mathrm{~S}_{\mathrm{A}}$-dizer-ASP-PSD.DST

'Eu falava: "cuidado para nós todos não nos transformarmos."' (Txt)

(36) ugangkotane

ug-angkody-tane

2A1O-cortar-VET

'Cuidado para você não me cortar.' (Elic.)

\section{(37) koangkotane}

ko-angko-tane

1A2O-cortar-VET

'Cuidado para eu não cortar você.' (Elic.)

Apesar do vetativo (ou proibitivo) ser considerado uma contraparte do imperativo, tanto a forma de sua expressão quanto as flexões de pessoas são distintas do imperativo, como pode ser observado na próxima seção.

\subsubsection{A pessoa no imperativo (proximal e alativo)}

Quando no modo imperativo, o verbo recebe flexões capazes de fazer a distinção entre verbos transitivos e intransitivos, assim como a distinção entre duas subclasses de intransitivos. Verbos transitivos são flexionados com terceira pessoa e com 2A1O, como ilustrado em (38), (39) e (40), enquanto intransitivos $S_{O}$ são flexionados pela segunda pessoa, como em (41) e intransitivos $S_{A}$ não são marcados para pessoa, (42). Todos os prefixos são resumidos na tabela 5.14 .

Tabela 5.14 - Prefixos de pessoa no imperativo

\begin{tabular}{|c|c|cc}
\hline Pessoa & \multicolumn{2}{|c|}{ Raiz } & \multicolumn{2}{|c}{ Intransitivas } \\
& Transitiva & So $_{\text {o }}$ & $\mathbf{S}_{\mathbf{A}}$ \\
\hline 30 & $\{i-, \phi-\}$ & & \\
\hline $\mathbf{2 A 1 0}$ & $\{u g u-\}$ & & \\
\hline $\mathbf{2 A S o}$ & & $\{o-\}$ & \\
\hline-- & & & -- \\
\hline
\end{tabular}


(38) inok

i-no-k

3-deixar-IMP

'Deixa-o!' (Elic)

(39) anmek

ø-anme-k

3-jogar-IMP

'Joga-o!' (Elic)

(40) ugedentukek

ug-edentu-ke-k

2A1O-amarrar-DER-IMP

'Desamarra-me!' (Elic)

(41) oalumko

o-alum-ko

$2 \mathrm{~S}_{\mathrm{O}}$-pular-IMP

'Pula!' (Elic)

(42) odotpotko

odotpot-ko

voltar-IMP

'Volta!'(Elic)

Observe que raízes intransitivas $S_{\circ}$, após mudança de valência (transitivisação), podem receber $\{u g u-\} 2 \mathrm{~A} 1 \mathrm{O}$, como demonstrado em (43a) e (43b). Os verbos $\mathrm{S}_{\mathrm{A}}$, por sua vez não apresentam esta forma no seu paradigma e não podem ser afixados por $\{u g u-\} 2 \mathrm{~A} 1 \mathrm{O},(44)$. Como esperado, este morfema também pode ocorrer na versão transitiva desses verbos, se esta existir, como em (45).

(43)
a) *uk-page
b) uk-page-nop-ko
2A1O-acordar
2A1O-acordar-TRZ-IMP
(Acorde-me!)
'Pode me acordar'
(44) *ugoriko
ug-origu-ko
2A10-dançar


(45) ugu-yp-ko

2A1O-banhar-IMP

'Banhe-me!'

O paradigma de pessoa observado no predicado flexionado com o imperativo alativo $\{-t a \sim-a\}$ apresenta o mesmo conjunto de prefixos encontrados para o imperativo proximal, compare as tabelas 5.14 e 5.15. Exemplos são oferecidos a seguir.

Tabela 5.15 - Prefixos de pessoa no imperativo alativo

\begin{tabular}{|c|c|cc|}
\hline Pessoa & \multicolumn{2}{|c|}{ Raiz } & \multicolumn{2}{|c|}{ Intransitivas } \\
& Transitiva & So & S $_{\mathbf{A}}$ \\
\hline 3 o & $\{i-, \phi-\}$ & & \\
\hline 2 A10 & $\{u g u-\}$ & & \\
\hline $2 S_{0}$ & & $\{o-\}$ & \\
\hline-- & & & -- \\
\hline
\end{tabular}

(46) angkota

Ø-angkody-ta

3O-cortar-IMP.ALA

'Vai lá cortar O.' (Elic.)

(47) ungmongokta

CASAI mapo

ung-mongogu-ta

CASAI mapo

2A10-esperar-IMP.ALA

CASAI perto

'Me espera lá na CASAI' (Elic.)

(48) otximtabringia $\left(\mathrm{S}_{\mathrm{A}}\right)$

oti-midabri-nge-a

DTZ-comida-VBZ-IMP.ALA

'Vai lá comer' (Elic)

(49) iguamta $\left(\mathrm{S}_{\mathrm{o}}\right)$

iguam-ta

2.sentar-IMP.ALA

'Vai lá sentar' 


\subsubsection{A pessoa no horativo (proximal e alativo)}

Em algumas línguas, a função hortativa é marcada pelo mesmo morfema de imperativo enquanto em outras tal função é codificada por um morfema distinto. Este último é o caso verificado em Arara em que a versão hortativa é cofificada por um morfema diferente do imperativo $\{-n e \sim-n\}$. Além disso, uma versão alativa é criada por meio do acréscimo do morfema de comando alativo, $\{-t a \sim-a\}$ HORT.ALA. As marcas de pessoa são as mesmas nas duas versões, exceto pelo fato de não foi encontrada no corpus a forma alativa em raízes So. A princípio, nada impediria sua ocorrência. Exemplos para cada classe de raiz verbal são oferecidos a seguir. O hotativo proximal é apresentado nos exemplos (50), (51) e (52) e os hortativo alativos podem ser visto em (53) e (54).

Tabela 5.16 - Prefixos de pessoa no hortativo

\begin{tabular}{|c|c|c|}
\hline \multirow[t]{2}{*}{ Pessoa } & Raiz & Intransitivas \\
\hline & Transitiva & $\mathbf{S a}$ \\
\hline $1+2 \mathrm{~A}$ & $\{k u t-\}$ & \\
\hline $1+2 S_{A}$ & & $\{k u t-\}$ \\
\hline $1+2 \mathrm{So}_{0}$ & & $\{u g u-\}$ \\
\hline
\end{tabular}

(50) ta lon kudodokpedyn

ta lon kud-odokpe-dy-n

aqui FOC 1+2A-acampar-COL-HORT

'Vamos ficar aqui!' (Txt)

(51) kudonkun

kud-onku-n

$\mathbf{1}+\mathbf{2} \mathbf{S}_{\mathrm{A}}$-subir-HORT

'Vamos subir!' (Elic.)

(52) ugeguamne

ug-eguamy-ne

1+2So-subir-HORT

'Vamos sentar!' (Elic.)

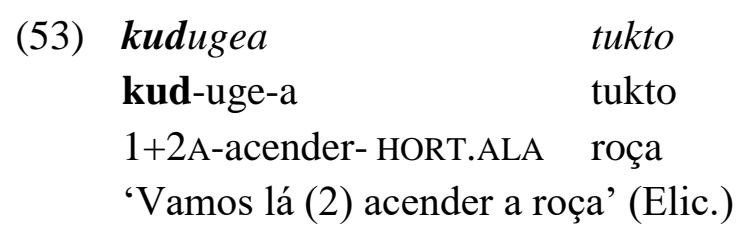


(54) kudomomta

kut-omomy-ta

$1+2 \mathrm{~S}_{\mathrm{A}}$-entrar- HORT.ALA

'Vamos (incl.) lá entrar'(Elic.)

A forma do hortativo é homófona ao passado distante, $\{-n(e)\}$, o que não causa problemas aos falantes já que a ambiguidade é desfeita no contexto. Além disso, a forma do hortativo alativo também é homófona à do imperativo alativo $\{(-t) a\}$. Apesar de primarmos pela não proliferação de terminologia desnecessária, optamos por seguir o padrão morfológico baseado nos prefixos de pessoa e manter o paralelismo das versões proximal e alativa.

\subsubsection{A pessoa no admonitivo}

As pessoas argumentais verificadas no admonitivo são elencadas na tabela 5.17. Em textos foi verificada apenas a segunda pessoa, que é, geralmente, encontrada com este modo. No entanto, em elicitação também foram aceitas mais duas pessoas que indicam a pessoa do objeto, a 10 e a 1+20. Exemplos para cada morfema são oferecidos em (55), (56), (57) para raízes transitivas e (58) para raízes intransitivas Sa. Para raízes intransitivas So, ainda é necessário verificar quais morfemas podem ser afixados, como, provavelmente, a segunda pessoa $o-$.

Tabela 5.17 - Prefixos de pessoa no admonitivo

\begin{tabular}{|c|c|c|}
\hline Pessoa & $\begin{array}{c}\text { Raiz } \\
\text { Transitiva }\end{array}$ & $\begin{array}{c}\text { Intransitivas } \\
\text { Sa }\end{array}$ \\
\hline $\mathbf{1 0}$ & $\{j-\}$ & \\
\hline $\mathbf{2 0}$ & $\{o-\}$ & \\
\hline $\mathbf{1 + 2 0}$ & $\{u g u-\}$ & \\
\hline $\mathbf{2} \mathbf{s}_{\mathbf{A}}$ & & $\{m-\}$ \\
\hline
\end{tabular}

(55) jabotang

j-abotxi-tang

10-segurar-ADM

'Cuidado para ele não me segurar' (Elic) 
(56) wangkotang

o-angkody-tang

2O-cortar-ADM

'Cuidado, pode cortar você.' (Elic)

\section{(57) ugabotang}

ug-abotxi-tang

1+2O-segurar-ADM

'Não vamos para lá, não. Ele vai nos segurar' (Elic)

(58) modakpiang

m-odakpi-ang

$2 \mathrm{~S}_{\mathrm{A}}$-embebedar.se-ADM

'Você pode ficar bêbado' (Elic)

\subsubsection{A pessoa no permissivo}

O permissivo apresenta apenas a terceira pessoa como sujeito, inclusive quando outras formas expressam a função de objeto. A terceira pessoa $n$ - é o morfema mais comumente encontrado em textos. Em elicitação, também foi verificada a possibilidade de ocorrência das seguintes pessoas em radicais transitivos: $j-10, o-1+20$ e $u g u-20$. A tabela 5.18 apresenta os morfemas verificados até o momento. Exemplos são fornecidos em seguida.

Tabela 5.18 - Prefixos de pessoa no permissivo

\begin{tabular}{|c|c|c|c|}
\hline \multirow[t]{2}{*}{ Pessoa } & Raiz & \multicolumn{2}{|c|}{ Intransitivas } \\
\hline & Transitiva & $\mathbf{S a}$ & So \\
\hline 3 & \multicolumn{3}{|c|}{$n(i)-$} \\
\hline 10 & $\{j-\}$ & & \\
\hline 20 & $\{o-\}$ & & \\
\hline $1+20$ & $\{u g u-\}$ & & \\
\hline
\end{tabular}

(59) nugia porido ge

n-uge-a porido $=\mathrm{ge}$

3-acender abano INS

'Deixa acender com abanador' (elic.) 
(60) naluma

n-alumy-a

3So-Voar-PERM

'Deixa-o voar' (Elic)

(61) nomoma

n-omomy-a

3S $\mathbf{S}_{\mathbf{A}}$-entrar-PERM

'Deixa-o entrar' (Elic)

(62) inenga

ineng-a

2Over-PERM

'Deixa-o te ver' (Elic)

(63) jenenga

j-eneng-a

10-ver-PERM

'Deixa-o me ver' (Elic)

(64) ugenentoma

ug-eneng-tom-a

1+20-ver-COL-PERM

'Deixa-o ver nós todos' (Elic)

\subsubsection{A pessoa no modo intencional}

Apenas primeiras pessoas ocorrem com o intencional $\{-d a \sim-t x a \sim-n a\}$, inclusive a primeira pessoa inclusiva $(1+2)$ verificada em raízes intransitivas $\mathrm{S}_{\mathrm{O}}{ }^{89}$, como demonstrado em (65). Além disso, foi constatada a ocorrência do morfema portmanteau 1A2O, exemplificado em (66).

Todos os prefixos são apresentados na tabela 5.19. Exemplos são fornecidos lado a lado, primeiro para o modo intencional e, na segunda coluna, para o intencional com alação. Nos exemplos de (67) a (70) são apresentados os morfemas das raízes transitivas, de (71) a (74), os das raízes intransitivas $S_{\mathrm{A}}$ e em (75) a (77), os prefixos das raízes intransitivas $S_{\mathrm{O}}$.

\footnotetext{
${ }^{89} \mathrm{~A}$ princípio, nada impediria a ocorrência desta pessoa para raízes transitivas e intransitivas $\mathrm{S}_{\mathrm{A}}$. Da mesma forma, possivelmente, o intencional ocorre com a primeira pessoa exclusiva $(1+3)$ que concorda com o morfema de terceira pessoa.
} 
Tabela 5.19 - Prefixos de pessoa no modo intencional

\begin{tabular}{|c|c|c|c|}
\hline Pessoa & Transitivo & \multicolumn{2}{|c|}{ Intransitivo } \\
\hline & & $\mathrm{S}_{\mathrm{A}}$ & $\mathrm{S}_{\mathrm{o}}$ \\
\hline $\mathbf{1 A}$ & $\{i n i-\},\{j-\}$ & $\{k-\},\{w-\}$ & $\{j-\},\{y-\}$ \\
\hline $\mathbf{1 + 2 S o}$ & $?$ & $?$ & $\{u g u-\}$ \\
\hline $\mathbf{1 A 2 0}$ & $\{k o-\}$ & & \\
\hline
\end{tabular}

(65) uktamkodeda

uk-tamko-de-da

$1+2 \mathrm{~S}_{\mathrm{o}}$-velho-VBZ-INTC

'Nós vamos envelhecer' (Elic)
(66) kimida

k-imi-da

1 A2O-2comer.comida.macia ${ }^{90}$-INT

'Eu vou te beijar' ${ }^{91}$ (Elic)
(67) inikotxa

ini-kody-txa

1A-quebrar ${ }^{92}$-INTC

'Eu vou quebrar ele' (Elic.)

(69) jeganoptxa

j-eganoby-txa

1A-falar-INTC

'Eu vou falar' ${ }^{93 \prime}$ (Elic.)

(71) konkuda

k-onku-da

$1 \mathrm{~S}_{\mathrm{A}}$-subir-INTC

'Eu vou subir.' (Elic.)

(73) wiptxa

w-ip-txa

$\mathrm{S}_{\mathrm{A}}$-banhar-INTC

'Eu vou banhar.' (Elic.)

(75) jalumtxa

j-alum-txa

1S $\mathrm{S}_{\mathrm{O}}$-pular-INTC

'Eu vou pular.' (Elic.)
(68) inikotana

ini-kody-tan-na

1A-quebrar-ALA-INTC

'Eu vou lá quebrar' (Elic.)

(70)

jeganoptana mook wyna

j-eganoby-tan-na mook wyna

1A-falar- ALA-INTC 3DEIT.ANIM ADDRSS

'Eu vou lá falar pra ele' (Elic.)

(72) konkuana

k-onku-an-na

$1 \mathrm{~S}_{\mathrm{A}}$-subir-ALA-INTC

'Eu vou lá subir.' (Elic)

(74) wiptana

w-ip-tan-na

$1 \mathrm{~S}_{\mathrm{A}}$-banhar-ALA-INTC

'Eu vou banhar.' (Elic.)

(76)

$\begin{array}{lll}\text { jalumtana } & \text { jei } & \text { bok } \\ \text { j-alum-tan-na } & \text { jei } & \text { bok } \\ \text { 1So-pular-ALA-INTC } & \text { árvore } & \text { sobre } \\ \text { 'Eu vou pular.' (Elic.) } & & \end{array}$

\footnotetext{
${ }^{90}$ Comer alimentos como banana, cacau e mingau. Também traduzido como 'lamber'.

${ }^{91}$ Desenvolvimento semântico plausível mais ou menos recente.

${ }^{92}$ Quebrar objetos como flecha, pau, palito.

${ }^{93}$ Observação do falante: "É dito quando alguém está fazendo algo de errado."
} 
(77) $\boldsymbol{y}$ damkodeda

y-damko-de-da

1 $\mathrm{S}_{\mathrm{O}}$-velho-VBZ-INTC

'Eu vou envelhecer.' (Elic.)

A tabela a seguir resume as pessoas atestadas nos modos supracitados. Na última coluna são apresentados os morfemas de TAM correspondentes.

Tabela 5.20 - Resumo dos prefixos de pessoa das modalidades orientadas pelo falante e pelo agente

\begin{tabular}{|c|c|c|c|c|c|c|c|c|c|c|c|c|}
\hline & 10 & $\begin{array}{c}\mathbf{1 A} \\
\mathrm{S}_{\mathrm{A}} / \mathrm{S}_{\mathrm{O}}\end{array}$ & $1 \mathrm{~A} 20$ & 20 & $\begin{array}{c}\mathbf{2 A} \\
\mathrm{S}_{\mathrm{A}} / \mathrm{S}_{\mathrm{O}}\end{array}$ & $2 S_{A}$ & $2 A 10$ & 30 & 3 & $1+20$ & $\begin{array}{l}1+2 O \\
S_{O} / S_{A}\end{array}$ & TAM \\
\hline IMP & & & $\mathrm{X}$ & $\mathrm{X}$ & & & & $\mathrm{X}$ & & & & $-k(o)$ \\
\hline IMP.ALA & & & $\mathrm{x}$ & $\mathrm{x}$ & & & & $\mathrm{X}$ & & & & $-(t) a$ \\
\hline HORT & & & & & & & & & & & $\mathrm{X}$ & $-n(e)$ \\
\hline HORT.ALA & & & & & & & & & & & $\mathrm{X}$ & $-(t) a$ \\
\hline VET & $\mathrm{X}$ & & $\mathrm{X}$ & & $\mathrm{X}$ & & $X$ & & & & $\mathrm{X}$ & $-(t) a n e$ \\
\hline ADM & $\mathrm{X}$ & & & $\mathrm{X}$ & & $\mathrm{X}$ & & & & $\mathrm{X}$ & & $-(t) a n g$ \\
\hline PERM & $\mathrm{X}$ & & & $\mathrm{x}$ & & & & & $\mathrm{X}$ & $\mathrm{X}$ & & $-a$ \\
\hline INTC & & $\mathrm{X}$ & $\mathrm{x}$ & & & & & & & & $\mathrm{X}$ & $\begin{array}{l}-d a,-t x a, \\
-n a\end{array}$ \\
\hline
\end{tabular}

\subsection{NÚMERO E TAM}

Esta seção apresenta os seguintes morfemas de número adicionados ao verbo \{-ngmo\}, $\{-t y \sim-d y\},\{-$ tom $\sim-d o m\},\{-p t y\}$ e $\{-(t) a d y k\}$. Tais sufixos, assim como sua posição na palavra verbal, são escolhidos de acordo com as flexões de TAM. A categoria de pessoa também apresenta interação no paradigma de passado distante e passado médio, quando o morfema de coletivo é diferente apenas para as terceiras pessoas. Quanto à distribuição, há morfemas verificados antes ou após a flexão de TAM. Além disso, há um morfema que assume a forma portmanteau, codificando aspecto e número $\{-(t) a d y k\}$. O sufixo \{-ngmo\} ocorre tanto em nomes quanto em verbos, mas $\{$-ty $\}$ e $\{$-tom $\}$ ocorrem exclusivamente em verbos ${ }^{94}$. Como um todo, esta subseção demonstra como os morfemas de TAM e número se relacionam, de maneira a aproximar categorias que, tipologicamente, são descritas em sistemas diferentes.

94 Conforme apresentado no capítulo 3, há uma exceção, pois -tom também foi atestado com a partícula interrogativa: kang-tom [2QU-COL]. 
Dentre a literatura prévia sobre Arara, a categoria de número é mencionada em Souza, S. (1993, 2010) e Souza, I. (2010). Em dois desses trabalhos, os morfemas e o ambiente em que são encontrados são brevemente apresentados. Comparando-se as tabelas 5.21 e 5.22 é possível perceber algumas diferenças entre as análises dos autores. Por exemplo, com relação ao número de morfemas, eles são 5 para Souza, I. (2010) e 6 para Souza, S. (1993). Quanto às informações sobre os contextos de ocorrência, o futuro, o imperativo eufêmico e o sufixo que o autor traduz como "sempre", por exemplo, foram citados apenas em Souza, I. (2010). Ainda segundo este último autor, em verbos, os morfemas se referem, principalmente, ao sujeito e não há concordância (Ibid, p. 32, 33). Exemplos sobre o tópico são oferecidos apenas em Souza, S. (1993). Em 2010, a autora cita a ocorrência do morfema $\{-n g m o\}$ em verbos flexionados no passado recente e no modo contínuo (terminologia da autora). Para ela, que trata sobretudo do plural nominal nesta referência, o morfema indica a forma canônica de plural em que o singular equivale a 'um' e o plural a 'mais de um' (SOUZA, S. 2010, p.63-73).

Tabela 5.21 - Morfemas de número I

\begin{tabular}{l|ll}
\hline \multicolumn{2}{c}{ MORFEMAS } & CONTEXTO \\
\hline I & {$[-\eta g m s]^{95} \sim$} & Nomes, nomes próprios, adjetivos, sujeitos em verbos no modo \\
& {$[-k \supset m \sim-g \supset m]$} & indicativo, sufixo de verbos de propósito 96 \\
II & {$[-t \supset m \sim-d \supset m]$} & Sujeito em verbos no modo interrogativo e no futuro \\
III & {$[-t u \sim-d m]$} & Sujeito em verbos no imperativo e no modo hortativo, sujeito \\
& & em verbos com sufixo para 'depois' (imperativo eufêmico) \\
& sujeito em verbos com sufixo para 'sempre' \\
IV & {$[-p t w]$} & Sujeito em verbos com sufixo para 'admonição' \\
V & {$[-n d m]$} & Sujeito em verbos com sufixo para 'distal' \\
\hline
\end{tabular}

Fonte: adaptado de Souza, I. (2010, p. 32, tradução nossa)

\footnotetext{
${ }^{95}$ A forma fonética vem do trabalho original. No dialeto Iriri não há o alomorfe [-gəm].

${ }^{96}$ I) 'nouns, proper nouns, adjectives, subject in verbs in the indicative mood, verb suffix of purpose'.

II) 'subject in verbs in the interrogative mood and in verbs in future tense'

III) subjects in verbs in imperative and hortatory mood, subjects in verbs with the suffix or 'later (euphemic imperative)', subject in verbs with the suffix for 'always'

IV) 'subject in verbs with the suffix for 'admonition"'

V) "subject in verbs with the suffix for "distal",
} 
Tabela 5.22 - Morfemas de número II

\begin{tabular}{|c|c|c|}
\hline \multicolumn{2}{|r|}{ MORFEMAS } & CONTEXTO \\
\hline $\mathrm{I}$ & $-n g m o$ & $\begin{array}{l}\text { Manifesta-se em frases declarativas e com substantivos } \\
\text { terminados em [-consonantal] }\end{array}$ \\
\hline II & -kom -gom & $\begin{array}{l}\text { Ocorre com substantivos terminados em [+ consonantal }] \text {, o } \\
\text { primeiro depois de }[+ \text { consonantal, }- \text { voz, -estridente }] \text { e o } \\
\text { segundo depois de }[+ \text { nasal }]\end{array}$ \\
\hline III & -tom $\sim$-dom & Manifesta-se com interrogativas \\
\hline IV & $-t y \sim-d y$ & Manifesta-se com o imperativo e o hortativo \\
\hline $\mathrm{V}$ & $-p t y$ & Ocorre depois do marcador de advertência \\
\hline VI & $-n d y$ & Ocorre depois do sufixo marcador de deslocamento \\
\hline
\end{tabular}

Fonte: Adaptado de Souza, S. (1993, p. 62-66)

Especificamente sobre a terminologia de número que se refere aos participantes da oração, a literatura Karib apresenta o termo coletivo ao invés de plural. Como aponta Meira (1999, p. 139), isto se deve ao fato de que a categoria de número não denota uma entidade vs. mais de uma entidade, mas todos vs. menos de todos, sendo que este último significado é o não marcado. Considerando a pertinência deste significado em Arara, como ilustrado em (77), este estudo também adota o termo coletivo97.
(77) tarikompe
kumydyk irumpolyngmo
tarik-kom-pe
kumydyk i-rumpo-ly-ngmo
grande-COL-ATBZ ASP.COL 3-morrer-PSD.IMD-COL
'(Eles eram) grandes, (todos) morreram.' (Txt)

É conhecido que tanto a hierarquia de pessoa (ex.: Tiriyó, Wayana) quanto o traço animacidade (GILDEA, 1998, p.117) podem interagir com a marcação de número em línguas Karib. Quanto à animacidade, não há indícios de que este traço esteja interferindo em tal marcação, pois nomes animados e inanimados recebem morfologia coletivizadora \{-kom -ngmo ${ }^{98}$ \}, como ilustrado em (78), (79), (80) e (81). Contudo, ainda resta a verificação de restrições como a possibilidade de não se coletivizar alguns elementos da natureza, quando, provavelmente, um outro item lexical (uma palavra que indique 'um', 'dois', 'muitos') poderá indicar a quantidade, por exemplo. Não se descarta a possibilidade de existência de uma classe

\footnotetext{
${ }^{97}$ Meira, S (1999) comenta a infelicidade de uso da terminologia coletivo que, tradicionalmente, é usada com outras finalidades. Como contrapartida, o autor sugeria que o termo totalitativo talvez fosse descritivamente mais adequado, embora este também já tenha outro uso. Atualmente, o mesmo autor cogita a pertinência do termo plural definido como uma opção mais precisa (MEIRA, 2017, Comunicação pessoal).

${ }_{98}$ Esta mesma morfologia quando atrelada a nomes próprios se comporta com a função associativa.
} 
de nomes com propriedades especiais (vegetais, nomes de animais, astros). De acordo com Souza, S. (2010 p.8, 9,10), estes elementos não podem ser possuídos morfologicamente no dialeto Arara. No dialeto Iriri, por sua vez, alguns falantes aceitam que unidades dos itens descritos sejam possuídos morfologicamente como $u k$-typy- $n$ [1+2-cará-POSSD] 'Nosso (incl.) cará', y-wa-ry [1-mel-POSSD] 'Meu mel', o-garampi-n [2-pato-POSSD] 'Teu pato'. Da mesma forma, foram encontrados exemplos de nome de animais flexionados, como demonstrado em (79) e (80). Note que neste último exemplo, o significado indica um conjunto, um coletivo genérico.

$\begin{array}{lll}\text { ugonkom } & \text { pumiengmo } & \text { urangmytxingmo } \\ \text { ugon-kom } & \text { pumie-ngmo } & \text { urangmytxingmo } \\ \text { homem-COL } & \text { mulher-COL } & \text { criança.COL }\end{array}$

$\begin{array}{lll}\text { tomban } & \text { oringnangryngmo } & \text { imamko } \\ \text { tompan } & \text { origu-nangry-ngmo } & \text { i-mamko } \\ \text { todos } & \text { dançar-IPFV-COL } & \text { 3-ao.redor }\end{array}$

'Homens, mulheres, crianças, todos estão dançando ao redor (do Iei pari ${ }^{100}$ )

(Txt)

(79)

$\begin{array}{llllll}\text { wongop } & \text { itxily } & \text { tompan } & \text { potkun } & \text { eroge } & \text { aguringmop } \\ \text { wongo }=\mathrm{p} & \text { iti-ly } & \text { tompan } & \text { potkun } & \text { eroge } & \text { aguri-ngmo=p } \\ \text { animal=ATBZ } & \text { COP-PSD.IMD } & \text { todos } & \text { INTENS } & \text { agora } & \text { cotia- } \mathrm{COL}=\mathrm{ATBZ}\end{array}$

'Todos se transformaram em bicho, cotia' (Txt) (Lit.: 'Todos mesmo se transformaram em animais agora, em cotias')

(80)
torik potkun lon odubunyngmo
torik potkun lon $\quad$-odubu-ny-ngmo
INTENS INTENS FOC 3-sobrar-PSD.IMD-COL

$\begin{array}{ll}\text { tywotempe } & \text { abianangmo } \\ \text { ty-wo-te-m-pe } & \text { abiana-ngmo } \\ \text { PRTC-matar-PRTC-NOM-ATBZ } & \text { queixada-COL }\end{array}$

'Tinham muitos que sobraram para serem flechados, bando de porcão' (Txt)

\footnotetext{
${ }^{99}$ Variante dialetal verificada no que chamamos de dialeto Arara.

${ }^{100}$ Poste cerimonial utilizado em um evento homônimo. Para maiores detalhes ver a etnografia de Teixeira-Pinto (1997).
} 

(81) otxingongmo jenetangne ibode
otxi-ngo-ngmo j-eneng-tang-ne i-bode
casa-NPOSSD-COL 1A-ver-ASP-PSD.DST 3-dentro
'Eu olhava dentro das casas' (Txt) (Contexto: como agente de saúde indígena, a
falante visistava todas as casas da aldeia.)

Veja também que uma consequência da semântica coletiva mencionada é que a forma não marcada pode ser usada para mais de uma entidade. Perceba, no exemplo (82), que não há nenhuma marca de coletivo no participante joru 'Jaboti', embora a referência, claramente, não seja apenas a um jaboti neste contexto. Da mesma forma, em (83) não há qualquer marcação morfológica de número em abiana 'Queixada'. Desta forma, podemos constatar que a concordância de número não é obrigatória no sintagma verbal, porém veja-se a seguir a relação com hierarquia de pessoa. Além disso, verificamos que o singular consiste na forma não marcada. Ou seja, expressa o singular por default e em determinados contextos, pode expressar um conjunto de entidades.

$\begin{array}{lll}\text { adak adak } & \text { menebyny } & \text { joru } \\ \text { adak adak } & \text { m-eneby-ny } & \text { joru } \\ \text { dois dois } & \text { 2A-trazer-PSD.IMD jaboti } \\ \text { 'Você trouxe quatro jabutis' (Elic.) }\end{array}$

(83) mogy lone taje abiana pumuly mogyn lone taje abiana pumu-ly DEIT.ANIM FOC INTENS queixada matar.todos/acabar-PSD.IMD 'Essa pessoa (que apanhou) matou muito porcão' (Txt) (Lit.: 'Essa pessoa matou muitos porcos. A informação "que apanhou" é proveniente do contexto)

A hierarquia de pessoa, por sua vez, se mostra relevante para a marcação de número, uma vez que interfere na concordância. De forma geral, número consiste em uma categoria flexional nominal, que ocorre no verbo como concordância. Isto é, consiste em uma exigência do nome que é codificada no predicado verbal. Segundo a definição de Mithun (1988), a concordância é assinalada por regras de cópia as quais devem duplicar os traços de número dos NPs nos demais elementos da sentença. Esta relação foi checada apenas para eventos que ocorreram no passado imediato $\{$-ngmo\}. Como será demonstrado na seção correspondente, a configuração não local apresenta um tipo de concordância independente enquanto as configurações local, direta e inversa seguem a hierarquia. 
Vale mencionar que, além dos morfemas coletivizadores, outras possibilidades disponíveis para indicar o número são o morfema iterativo/pluracional, que em seu bojo funcional também pode implicar plural de participantes; e os itens lexicais, que podem indicar quantidades, como torik torek INTENS, potkun INTENS, taje INTENS, tompan 'todos, tudo'. Estes itens podem dispensar o uso da flexão de número nos argumentos verbais sintaticamente expressos.

A próximas seções apresentam e ilustram os morfemas de coletivo verificados até o presente, assim como as relações com os morfemas de TAM e a interação com a terceira pessoa (apenas nos passados distante e médio).

\subsubsection{O sufixo \{-ngmo $\}$, o PSD.IMD e o IPFV}

O sufixo -ngmo ocorre apenas com o passado imediato e com o imperfectivo, conforme os exemplos oferecidos em (84) e (85), respectivamente. Note que, em verbos intransitivos, o coletivo só pode se referir ao sujeito.

$\begin{array}{lll}\text { tompan } & \text { ydolyngmo } & \text { ywap } \\ \text { tompan } & \varnothing \text {-ydo-ly-ngmo } & \text { y-wap } \\ \text { todos } & 3 \mathrm{~S}_{\mathrm{A}} \text {-ir-PSD.IMD } & 1 \text {-frente } \\ \text { 'Todos foram embora da minha frente' }\end{array}$
temnangryngmo tagie, kenyngmo
t-eby-nangry-ngmo tagie, Ø-ke-ny-ngmo
3-vir-IPFV-COL INTENS 3-dizer-PSD.IMD-COL
'Estão vindo (os caçadores), disseram.'

Em verbos transitivos, na configuração local (apenas entre 1 e 2 pessoas), o coletivo se refere apenas à segunda, como ilustrado em (86). Para coletivizar a primeira pessoa, o prefixo de 1+2A (incl.) é utilizado, como em (87).

\section{(86) komongogunyngmo \\ ko-mongogu-ny-ngmo \\ 1A2O-esperar-PSD.IMD-COL \\ 'Eu esperei vocês'}


(87) kunmongogunyngmo

kut-mongogu-ny-ngmo

1+2A-esperar-PSD.IMD-COL

'Nós (todos) o esperamos'

$\mathrm{Na}$ configuração direta (envolvendo PAFs e a terceira pessoa), o coletivo se refere apenas aos participantes do discurso, seja o prefixo de sujeito, como em (88), ou de objeto, (89). Isto demonstra que a categoria de número também está sujeita à hierarquia de pessoa.

$\begin{array}{lll}\text { txitamne } & \text { umingo } & \text { kudagunyngmo } \\ \text { txi-t-tam-ne } & \text { umingo } & \text { kud-agu-ny-ngmo } \\ \text { casa-POSSD-dentro-? } & \text { macaxeira } & \mathbf{1 + 2} \text {-comer-PSD.IMD-COL } \\ \text { 'Nós comemos dentro de casa' (Txt) } & \\ \text { (Lit.: 'Nós (todos) comemos macaxeira dentro de casa') }\end{array}$

(89) imobun

$$
\begin{array}{llll}
\text { imobun } & \text { podap } & \text { ugenebynyngmo } & \text { ugrongmo } \\
\text { i-mobu-n } & \text { podap } & \text { ug-eneb-yny-ngmo } & \text { ugrongmo } \\
\text { 3-canoa-POSSD } & \text { dentro } & \mathbf{1 + 2 0} \text {-trazer-PSD.IMD-COL } & \text { indígenas } \\
\text { '(Ele) nos trouxe no barco (dele)' (Elic.) } &
\end{array}
$$$$
\text { 3-canoa-POSSD dentro 1+20-trazer-PSD.IMD-COL indígenas }
$$

Quanto à configuração não local ( que envolve apenas $3^{\text {as }}$ pessoas), o coletivo aparenta ser usado, preferencialmente, para se referir ao sujeito. Este é o uso verificado em textos, por exemplo. No verbo, a marcação só é obrigatória quando o sintagma nominal ou pronome livre não estão presentes na sentença. Neste caso, o número está diretamente relacionado ao prefixo pessoal verbal. Os exemplos em (90a), (90b) e (90c) demonstram a opcionalidade de marcação no verbo se o número já estiver no NP.

(90)

a)

$$
\begin{array}{ll}
\text { imro } & \text { abunangry } \\
\text { imro } & \emptyset \text {-abu-nangry } \\
3 & \text { 3O-cavar-IPFV } \\
\text { 'Ele está cavando O.'(Elic.) }
\end{array}
$$

c) abunangryngmo imrongmo

$\emptyset$-abu-nangry-ngmo imro-ngmo

3O-cavar-IPFV-COL 3-COL

'Eles estão cavando O.' (Elic.) b) imrongmo abunangry imro-ngmo $\varnothing$-abu-nangry

3-COL 3O-cavar-IPFV 'Eles estão cavando O.' (Elic.)

Por outro lado, quando o objeto é marcado para número, não há cópia no verbo, conforme ilustrado em (91). O exemplo em (92) demonstra a marcação tanto do sujeito feita no 
verbo quanto do objeto, no NP. Por outro lado, dados de elicitação demonstram que o sufixo pode ser usado também para se referir ao objeto, como demonstram os exemplos em (93) e (94) cuja referência é ao objeto e ao sujeito, respectivamente. Assim, embora a referência do verbo em isolamento corresponda ao sujeito, a marcação parece ser ambígua em determinados contextos.

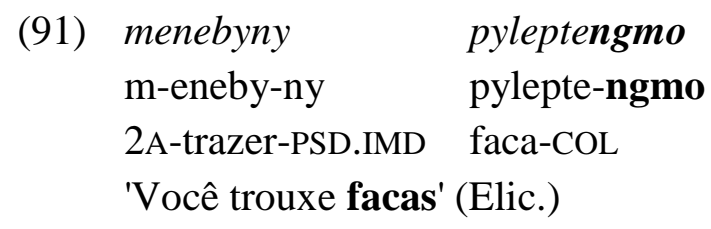
(92) menebynyngmo pylepte-ngmo
m-eneby-ny-ngmo pylepte-ngmo
2A-trazer-PSD.IMD-COL faca- COL
'Vocês trouxeram facas (todas)' (Elic.)
(93) Pablo imongongnangryngmo Arapukangmo
Pablo i-mongogu-nangry-ngmo Arapuka-ngmo
NOM.PROP 3-esperar-IPFV-COL NOM.PROP-COL
'Pablo está esperando Arapuka e os outros (Pyjaka e Tybrybi)' (Elic.)
(94) Arapukangmo imongongnangryngmo Pablo
Arapuka-ngmo i-mongogu-nangry-ngmo Pablo
NOM.PROP-COL 3-esperar-IPFV-COL NOM.PROP

‘Arapuka e os outros estão esperando Pablo' (Elic.)

Em resumo, o coletivo parece seguir a hierarquia de pessoa, exceto na configuração não local. Nesta situação, o coletivo se refere de preferência à pessoa do sujeito, embora possa também, ocasionalmente e segundo o contexto, referir-se à pessoa do objeto.

\subsubsection{O sufixo \{-tom $\}$ e o PERM, o ADM, a 3PSD.DST a a 3PSD.MED}

A ocorrência do coletivo - tom é condicionada pela flexão dos modos permissivo, (95), e admonitivo, (96), e pela terceira pessoa do passado distante kun(i)- 3PSD.DST e médio mon(i)3PSD.MED, conforme exemplificado em (97) e (98), respectivamente. 
(95) ugenentoma

ug-eneng-tom-a

1+2O-ver-COL-PERM

'Deixa ele ver todos nós' (Elic)

(96) wabotangtom okokemy kuntxadyk

w-abotxi-tang-tom okokemy kun-te-adyk

2O-segurar-ADM-COL Jibóia 3PSD.DST-falar-ASP.COL

'Cuidado que a cobra pega vocês, diziam' (Txt)

(97) ta lon tximna kunkedom $\mathrm{ka} \quad \mathrm{ba}$ biget

ta lon tximna kun-ke-dom ka ba biget

aqui FOC 1+3 3PSD.DST-falar-COL PERG ? mais.ou.menos

'Será que eles (o grupo que foi na frente) disseram: "nós estamos aqui"? (Txt)

(98) moniptangtom

mon-iby-tang-tom

3PSD.MED-banhar-ASP-COL

'Eles banharam' (Elic.)

A tabela a seguir resume as formas do singular e do plural:

Tabela 5.23 - Sufixos do ADM, PERM, 3PSD.DST e 3PSD.MED

\begin{tabular}{l|ll}
\hline TAM & SINGULAR & PLURAL \\
\hline ADM & $-(t)$ ang & -tang-tom \\
PERM & $-a$ & - tom- $a$ \\
3PSD.DST & kun $(i)-V$ & kun- $V$-tom \\
3PSD.MED & mon $(i)$ - $V$-tang & mon $(i)$ - $V$-tang-tom \\
\hline
\end{tabular}

\subsubsection{O sufixo $\{$-ty $\}$, o IMP, o HORT, o FUT, o PSD.DST e o PSD.MED}

A distribuição do sufixo -ty é a mais abrangente. Este sufixo é verificado com o hortativo proximal, (99), com o hortativo acrescido do morfema de alação, (100), com o imperativo proximal, (101) e o imperativo crescido do morfema de alação, (102), com o futuro (103), e com todos os participantes do discurso do passado distante, (104), e do passado médio, (105). Estes dois últimos tempos quando conjugados na terceira pessoa recebem o morfema -tom, como exposto em na seção anterior. 

(99) kunmongoktyn temnangry materero
kut-mongogu-ty-n t-ep-nangry materero
1+2-esperar-COL-HORT 3-vir-IPFV madeireiro

kuntxak idangron

kun-te-ak idangron

3PSD.DST-falar-PSD.IPFV antigamente

'Vamos esperar! Lá vem madeireiro, nós falávamos.' (Lit.: 'Vamos esperar! Madeireiro está vindo, falava antigamente')

(100) nabiot kutkeantyn kunkedom

nabiot kut-ke-an-ty-n kun-ke-dom

batata 1+2-tirar-ALA-COL-HORT 3PSD.DST-dizer-COL

Eles falaram: vamos lá arrancar batata! (Txt)

(101) obagedyk, obagedyk ketkeny

o-page-ty-k, o-page-ty-k ke-tke-ny

$2 \mathrm{~S}_{\mathrm{o}}$-acordar-COL-IMP $2 \mathrm{~S}_{\mathrm{O}}$-acordar-COL-IMP dizer-ITR-PSD.NOM

'Acordem! acordem! Ela pediu tanto'

(102) idantantyk

i-dang-tan-ty-k

3-ouvir- ALA-COL-IMP

'Vão lá ouvi-lo!' (Elic)

(103) ogomno menentytpom

ogomno m-eneng-ty-tpom

depois 2A-ver-COL-FUT

'Depois vocês vão olhar ele' (Elic.)

(104) momomtyn

m-omomy-ty-n

$2 \mathrm{~S}_{\mathrm{A}}$-entrar-COL-PSD.DST

'Vocês entraram' (Elic.)

(105) memiangtyt

m-emi-ang-ty-t

$2 \mathrm{~S}_{\mathrm{A}}$-comer.alimento.macio-ASP-COL-PSD.MED

'Vocês comeram' (banana) (Elic.) 
O resumo das formas é fornecido na tabela 5.24. Como mencionado anteriormente, as formas dos passados ocorrem apenas com PAFs.

Tabela 5.24 - sufixos do IMP, HORT, FUT, PSD.MED e PSD.DST

\begin{tabular}{l|ll}
\hline TAM & SINGULAR & PLURAL \\
\hline IMP & $-k(o)$ & $-t y-k$ \\
HORT & $-n(e)$ & $-t y-n$ \\
FUT & - tome, -tpom, -npom & - ty-tpom \\
PSD.MED & - tang-te & - tang-ty- $t$ \\
PSD.DST & $-n(e)$ & $-t y-n$ \\
\hline
\end{tabular}

\subsubsection{O sufixo $\{-(t) a d y k\}$ e o PSD.DST}

O sufixo -(t)adyk ASP.COL ocorre com o passado distante $-n(e)$ e com os participantes dos atos de fala, como em (106) e (107). Apenas na terceira pessoa que consiste em um morfema portmanteu e expressa também o passado distante (conforme demonstrado na subseção 5.3.1.3), o morfema coletivo apresenta uma versão com a consoante final surda e não-nasal -tadyk -adyk ASP.COL, exemplificado em (108)

(106) wiptona mygiadyngne

w-iptong-na my-ke-adyk-ne

$1 \mathrm{~s}_{\mathrm{A}}$-descer-INTC $2 \mathrm{~s}_{\mathrm{A}}$-dizer-ASP.COL-PSD.DST

'Vou descer, vocês diziam' (Txt)

(107) koangkuiadyngne

ko-angkui-adyk-ne

1A2O-espremer-ASP.COL-PSD.DST

'Eu apertei vocês' (Elic)

(108)

$\begin{array}{lll}\text { moro } & \text { kunkanoptadyk } & \text { nonpa } \\ \text { moro } & \text { kun-eganoby-tadyk } & \text { nonpa } \\ \text { 3DETT } & \text { 3PSDAN }\end{array}$

'Assim que eles falavam.' (Txt) (Lit.: Falavam aquilo também)

A tabela a seguir ilustra os sufixos de aspecto no singular e portmanteau, de plural e aspecto, no paradigma do passado distante. $(\mathrm{PAF}=1,2,1+2)$ 
Tabela 5.25 - Sufixos do passado distante nas versões singular e plural

\begin{tabular}{l|ll}
\hline \multicolumn{1}{c}{ TAM } & \multicolumn{1}{c}{ SINGULAR } & \multicolumn{1}{c}{ PLURAL } \\
\hline PAF-V-IPFV.PSD.DST-PSD.DST & PAF-V-(t)ang-ne & PAF-V-(t)adyng-ne \\
3PSD.DST-V- IPFV.PSD.DST & $k u n-\mathrm{V}-(\boldsymbol{t})$ ak & $k u n-\mathrm{V}-(\boldsymbol{t})$ adyk \\
\hline
\end{tabular}

\subsubsection{O morfema $\{-$ pty $\}$}

A ocorrência deste morfema foi verificada apenas com o modo vetativo. A referência corresponde sempre ao sujeito, o que é ilustrado nos exemplos a seguir. Veja que em (109) o número do objeto é indeterminado. Em (110), apenas o sujeito é coletivizado por \{-pty\} e para se coletivizar o argumento paciente, a marcação usada é afixada no próprio nome sintaticamente expresso, como ilustrado em (111). Um exemplo de coletivização da configuração local é oferecido em (112). Neste caso, a referência remete apenas à 2 pessoa.

(109) mongontane

m-ongon-tane

2A-morder-VET

'Você não morde ele ou eles' (Elic.)

(110) mongontanepty

m-ongon-tane-pty

2A-morder-VET-COL

'Vocês não podem morder ' (Elic.)

(111) mongontane imrongmo

m-ongon-tane imro-ngmo

2A-morder-VET pro.3-COL

' Você não pode mordê-los ' (Elic.)

$\begin{array}{lllll}\text { ugerengmanepty } & \text { potkun } & \text { yma } & \text { aumte } & \text { mogyn } \\ \text { ug-erengm-ane-pty } & \text { potkun } & \text { yma } & \text { aum-te } & \text { mogyn } \\ \text { 2A1O-matar-VET-COL } & \text { INTENS } \quad ? \quad \text { levantar-PSD.MED } & \text { 3DEIT.ANI } \\ \text { 'Vocês não vão me matar! Ele levantou com raiva.' (Txt) } & \end{array}$

A tabela 5.26 apresenta o resumo das interações entre as flexões de TAM e de número até o momento abordadas, incluindo a forma portmanteau de aspecto e plural (-(t)adyk), e suas respectivas flexões de TAM. 
Tabela 5.26 - Síntese dos morfemas de plural

\begin{tabular}{|c|c|c|c|c|c|}
\hline & -ngmo & -tom & $-t y$ & $-(t) a d y k$ & -pty \\
\hline IPFV & $\mathrm{X}$ & & & & \\
\hline PSD.IMD & $\mathrm{X}$ & & & & \\
\hline PSD.DST & & & $\mathrm{X}$ & $\mathrm{X}$ & \\
\hline 3PSD.DST & & $\mathrm{x}$ & & $\mathrm{X}$ & \\
\hline PSD.MED & & & $\mathrm{X}$ & & \\
\hline 3PSD.MED & & $\mathrm{X}$ & & & \\
\hline PERM & & $\mathrm{X}$ & & & \\
\hline ADM & & $\mathrm{X}$ & & & \\
\hline HORT & & & $\mathrm{X}$ & & \\
\hline IMP & & & $\mathrm{X}$ & & \\
\hline FUT & & & $\mathrm{x}$ & & \\
\hline VET & & & & & $\mathrm{X}$ \\
\hline
\end{tabular}

\subsection{SÍNTESE}

Este capítulo abordou o sistema de marcação de morfemas argumentais nos predicados em Arara. O complexo padrão de marcação desta língua é condicionado por dois fatores: classes de predicados e propriedades referenciais dos argumentos. A série de índices argumentais das sentenças transitivas é organizada de acordo com a hierarquia de pessoa enquanto a série de marcas argumentais das sentenças intransitivas é organizada segundo duas classes morfológicas de predicados monovalentes. Diferentes morfemas argumentais ocorrem de acordo com diferentes flexões TAM.

Também foram apresentados os morfemas de número que se referem aos participantes do discurso, mas ocorrem no predicado verbal. A particularidade desta categoria consiste no fato de diferentes formas morfológicas também serem condicionadas pelas flexões de TAM. Ademais, nos paradigmas dos passados distante e médio, o plural apresenta uma forma diferente apenas na terceira pessoa, mostrando também interação com a categoria de pessoa. No passado distante, há ainda uma forma portmanteu de aspecto e plural. 


\section{CAPÍTULO 6- TAM NA PREDICAÇÃO NÃO VERBAL}

Foi identificada uma cópula verbal, a cópula $\{i t x i\}$ que pode se combinar a vários predicados não verbais, isto é, pode ter complementos nominais, adverbiais e posposicionais. Cada tipo de predicado não verbal expressa funções predicativas específicas. As funções expressas pela relação dos predicados e seus argumentos são as mesmas em construções com e sem a cópula. Quando a cópula $\{$ itxi $\}$ está presente, ela carrega os morfemas de TAM, apresentando algumas nuances de significado no passado imediato que é interpretado como mudança de estado. Este capítulo apresenta as construções não verbais em geral, mostrando a relação com as categorias de TAM que podem ser expressas em construções sem a cópula por meio do tempo nominal, por exemplo, ou, em construções com a cópula, por meio das flexões verbais anteriormente exploradas. A seção 6.1 apresenta os conceitos e a terminologia da predicação não verbal utilizados. Na seção 6.2 são apresentadas as construções sem cópula que expressam o presente e o passado. A seção 6.3 trata da partícula existencial ipe. A seção 6.4 traz a distribuição das categorias de TAM na predicação não verbal com a cópula \{itxi\}. Em 6.5 é introduzida a forma \{aptam\} que apresenta características verbais, mas comportamento sintático não condizente com esta categoria. Uma síntese é fornecida na seção 6.6.

\subsection{INTRODUÇÃO}

Construções predicativas não verbais são aquelas em que um sintagma nominal é ligado a um predicado nominal, adjetival, adverbial ente outros. Isto é, o elemento responsável pela predicação não é um verbo. Por outro lado, Dryer (2007, p. 225) ressalta que este tipo de construção predicativa pode tornar-se gramaticalmente verbal por meio da adição de uma cópula verbal que, no entanto, apresenta-se mais como um item gramatical/funcional do que um verbo plenamente predicativo.

Payne (1997) apresenta a terminologia utilizada neste capítulo referente às relações semânticas expressas em construções predicativas. Segundo este autor são seis os tipos básicos noções/funções: equativa ('Ele é meu pai'), inclusiva ('Ele é um professor'), atributiva ('Ele é bonito'), locativa ('Ele está aqui'), existencial ('Existem bactérias no solo') e possessiva ('Ele tem um livro'). É importante enfatizar que a "relação atributiva" no presente contexto é diferente do conceito de "modificação atributiva". 
Em Arara, estas funções podem ser expressas por meio de predicados nominais, adverbiais e posposicionais. Há construções em que o predicado é justaposto ao argumento nominal e uma cópula verbal pode ser inserida sempre que houver necessidade de expressar determinado Tempo, Aspecto ou Modo. Foi identificada a cópula verbal: itxi /iti/a qual carrega flexões de pessoa, TAM e N. Não foram identificados pronomes copulares, como apontado em outras línguas Karib como Ikpeng (PACHECO, 2001) e Ye'kwana (CACERES, 2014, informação verbal ${ }^{101}$ ), por exemplo.

No decorrer da próxima seção, que apresenta as construções sem cópula, são feitas algumas discussões sobre os tipos de predicados e as classes de palavras, o que se mostra relevante também para o entendimento das construções com cópula, na seção 6.4.

\subsection{O PASSADO E O PRESENTE: CONSTRUÇÕES SEM CÓPULA}

Predicados nominais, adverbiais e posposicionais são justapostos aos seus sujeitos codificando as funções de predicação equativa, inclusiva, atributiva, locativa e possessiva. De acordo com os dados disponíveis, a predicação por justaposição é interpretada no tempo presente. A expressão do tempo passado neste tipo de construção, por sua vez, é realizada por meio de, pelo menos, duas estratégias não verbais que a língua possui a sua disposição: o acréscimo da partícula aspectual kumyk ou dos morfemas nominais de passado ('ex-N'). Quando outras categorias de TAMN necessitam ser codificadas, a cópula itxi é implementada.

A seguir são apresentados os tipos de predicados e suas correspondentes funções predicativas interpretadas no presente ou no passado. Neste último caso, a construção contém uma das estratégias indicadas. Os predicados nominais expressam a função equativa. Os predicados posposicionais expressam a função locativa e os adverbiais, as funções locativa, atributiva e possessiva.

\subsubsection{Predicados Nominais}

Um nome, uma forma nominalizada ou um pronome é justaposto a um sujeito expressando a função equativa. Estes predicados ocupam a primeira posição quando o sujeito é

\footnotetext{
${ }^{101}$ Comunicação apresentada no Simpósio Internacional Amazônicas V em Belém, 2014.
} 
um pronome, como ilustrado em (1). Se ambos o sujeito e o predicado são sintágmas nominais, a ordem pode ser revertida, como pode ser observado em (2) e (3). Os predicados nominais foram postos em negrito. O Exemplo (4) oferece uma nominalização como predicado. Não há diferença estrutural entre a relação de predicação equativa, na qual "o sujeito é idêntico à entidade especificada no predicado nominal (Payne 2007, p.114, tradução nossa) ${ }^{102 "}$ e de inclusão, quando uma entidade específica é incluída entre uma classe especificada no predicado nominal $^{103}$. Nos exemplos a seguir, a leitura da predicação equativa é de tempo presente.

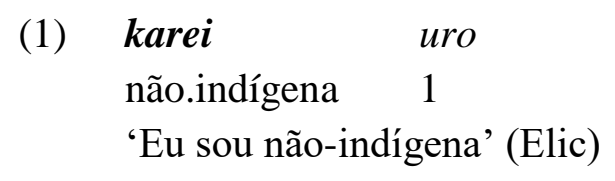

(2) Riten wongoum $\mathbf{j}^{104}$-odo

NOM.PROP macaco.cara.branca REL-dono

'O dono do macaco cara branca é Riten' (Text)

(3) wongo odo Riten

bichos dono NOM.PROP

'O dono dos bichos é Riten' (txt)

(4) $\quad$-bapa-n aum-tadamy-ni

1-pai-PSSD caçar-ITR-NOM

'Meu pai é caçador' (Elic)

O tempo passado pode ser expresso por meio da anexação dos alomorfes de passado nominal -npyn -tpyn, como em (5). Este morfema não é paradigmático, mas derivacional, conforme apresentado no Capítulo III. Eles modificam o significado de um nome adicionando o traço semântico de passado, como em y-woruntu-tpyn [1-palavra-PSD.NOM] 'O que eu falei' (Lit.: 'minha ex-palavra/fala'). O passado imperfectivo, por sua vez, pode ser expresso pela partícula kumyk, como demonstrado nos exemplos (6) e (7).

\footnotetext{
102 "Equative clauses are those which that a particular entity (the subject of the clause) is identical to the entity specified in the predicate nominal" (PAYNE 2007, p. 114)

103 "Proper inclusion is when a specific entity is asserted to be among the class of items specified in the nominal predicate" (Payne 2007, p. 114)

${ }^{104}$ Veja que, em sintagmas do tipo possuidor-possuído, o relacional ocorre no elemento possuído apenas quando este inicia por vogal e o possuídor termina em consoante. Compare, por exemplo, os sintagmas de posse presentes em (2) e (3). Como mencionado anteriormente, este ambiente também determina a ocorrência do relacional em sintagmas OV.
} 
(5) ero-ngmo lon j-emiagri-npyn

DEM.INAM-COL FOC 1-trabalho-PSD.NOM

'Esses eram meus trabalhos' (Lit.: Esses são meus ex-trabalhos) (Txt)

(6) j-emiagri-n ero te kumyk

1-trabalho-POSSD DEM.INAN ? ASP

'Meu trabalho era isso (agente de saúde)' (Txt)

(7) Marilene tapeda odo kumyk

NOM. PROP professor ASP

'Marilene era professora' (Elic)

A seção a seguir demonstra as funções expressas pelos predicados posposicionais e adverbiais. Como o predicado adverbial é formado por uma classe de palavras aberta, suas possibilidades predicativas são maiores.

\subsubsection{Predicados Posposicionais}

Conforme ilustrado nos exemplos (8) e (9), pedicados posposicionais expressam a função locativa.

(8)

$\begin{array}{lllll}\text { tatah po } & \text { ko } & \text { tximna } & \text { etxit } & \text { iduam } \\ \text { tatah po } & \text { ko } & \text { tximna } & \text { etxi-t } & \text { idua=am } \\ \text { IDEO.2deitar } & \text { ONOM.longe } & 1+3 & \text { casa-POSSD } & \text { mata=POSP }\end{array}$

'(Som duas coisas deitadas) nossa casa é dentro da mata' (Txt)

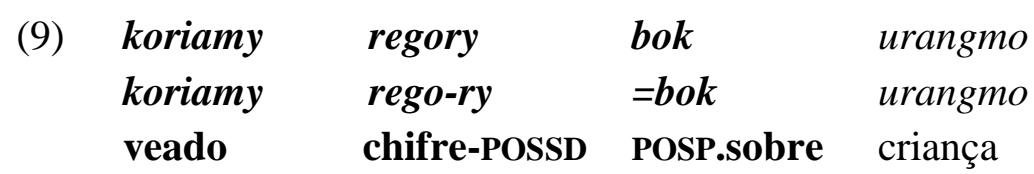

'A criança está sobre o chifre do veado' (txt)

\subsubsection{Predicados Adverbiais}

Os predicados adverbiais constituem uma classe mista da qual fazem parte um grupo de advérbios canônicos e um grupo de advérbios derivados por morfologia altamente produtiva. 
De acordo com as propostas de DeLancey (2001, p.41) e Croft (2015, p. 7), podemos fazer uma distinção entre uma categoria sintática (classes de palavras) e uma categoria semântica (classe semântica de palavras). Por exemplo, para a categoria sintática "adjetivo" há uma terminologia distinta para a categoria semântica que diz que são "palavras que expressam propriedades". Assim, a classe sintática que chamamos advérbios apresenta ao menos duas categorias semânticas, uma que se refere a palavras que denotam propriedades e outra que remete aos significados canônicos dos advérbios. Estes dois grupos podem expressar a predicação locativa, a atributiva, a equativa e a possessiva. Advérbios não derivados são responsáveis pela predicação locativa enquanto advérbios derivados por -pe ATBZ podem expressar a função equativa e atributiva, e, finalmente, a expressão adverbializadora $T$-N-ke codifica uma relação possessiva de caráter permanente. Quanto à predicação não verbal, uma característica inovadora desta língua em relação às demais línguas Karib consiste na possibilidade de predicados adverbiais derivados ocorrerem sem a cópula.

\subsubsection{Predicados adverbiais não derivados}

A predicação locativa é codificada por meio de advérbios de lugar, itens canônicos/não derivados, como exemplificado em (10) e (11).

$$
\begin{aligned}
& \text { (10) j-etxi-t ento } \\
& \text { 1-casa-POSSD aqui } \\
& \text { 'Minha casa é aqui' (Elic) }
\end{aligned}
$$

$\begin{array}{lll}\text { (11) } \text { otxi-ngo } & \text { monto } & \text { kumyk } \\ \text { casa-NPOSSD } & \text { lá } & \text { ASP } \\ \text { 'A casa era/ficava lá ( na floresta)' (Txt) }\end{array}$

\subsubsection{Predicados adverbiais derivados}

Devido às suas características específicas, os predicados adverbais derivados são apresentados em duas subseções. 
A predicação atributiva é codificada por advérbios derivados por meio do morfema -pe - $p$ ATBZ. Este morfema apresenta cognatos descritos em várias línguas Karib como Wayana: -pe/-me (TAVARES, 2009, p. 382), Tiríyo: -me (MEIRA, 1999, 3p. 54, 55), Ye'kwana: =me (CACERES, 2011, p. 136) e Makuxi: -pe (ABBOTT, 1991, p. 130). Variadas também foram as glossas utilizadas para identificar tal morfema. Atualmente, a forma mais utilizada é 'atributivisador' (Cf. GILDEA, 1998, p. 138) ou 'essivo' (Cf. MEIRA; GILDEA, 2009).

A distribuição dos alomorfes - $p e \sim-p$ em Arara é condicionada pela natureza do último segmento da raiz ao qual o morfema é anexado: -pe ocorre após consoantes, como em i-gat-pe [3-gordura-ATBZ] 'gordo', e - $p$ ocorre após vogais, o que pode ser verificado em kure- $p$ [bonitoATBZ] 'bonito'.

Souza, S. (2010, p. 104, 105) glosa o morfema -pe como um 'predicador' o qual seria adicionado a adjetivos para que estes pudessem ser usados predicativamente. Segundo a mesma autora, há apenas sete adjetivos básicos: kure 'bom, bonito', wyryp 'ruim, feio', tarik 'grande', muren 'pequeno', pyrymon 'enorme', paemnyn 'não maduro', amgun 'raso'105 (Ibid., p. 103, 104). De acordo com a presente análise, o morfema -pe não consiste em um predicador devido a três características:

(i) Seu escopo é limitado à classe de nomes;

(ii) Sua ocorrência é verificada em ambientes não predicativos e

(iii) Em tempos diferentes do presente e do passado, ocorre no mesmo enunciado com a cópula $\{$ itxi\}.

A seguir são exploradas essas três características do comportamento do morfema atributuvizador $-p e$ :

\section{- Coocorrência apenas com a classe de nomes}

Um grupo de palavras que semanticamente expressa propriedades ${ }^{106}$ é formada por membros que apresentam características gramaticais típicas da classe de advérbio bem como

\footnotetext{
105 No presente estudo, não foram encontradas características morfossintáticas que justificassem uma classe que incluísse estes itens e que fosse distinta da classe de nomes. Assim, a palavra muren 'pequeno', por exemplo, consiste em uma derivação semântica plausível advinda da raiz nominal mure 'filho'.

106 Esta classe semântica, geralmente, é classificada como uma classe morfossintática chamada de adjetivos em línguas como o inglês ou o português. Porém, também pode ser classificada como uma subclasse de verbos (ex.: Apinajé (Macro-Jê) (OLIVEIRA, 2003)) ou como uma subclasse nomes. Em Arara, até o presente não foram
} 
membros com características gramaticais nominais. Por ser de maior relevância para o tópico, apresentaremos apenas as propriedades da classe nominal. Dentre esta classe, há itens prototípicos, que indicam indivíduos/objetos em construções referenciais como jei 'árvore', yby 'pedra', ogoi 'cobra', e há itens que codificam propriedades como kure 'bom, bonito', tarik 'grande', wyryp 'feio'. Note que os nomes que indicam propriedade e os nomes prototípicos apresentam comportamentos morfossintáticos semelhantes. Por exemplo, recebem as mesmas marcas de plural (-kom -ngmo), como tarik-kom $\rightarrow$ tarikom [grande-COL] 'grandes' e kareingmo [não-indígena-COL] 'não indígenas'. E, podem ser objeto de posposição, conforme ilutrado em (12) e (13). Para este último exemplo, seria possível pensar em modificação de núcleo zero, porém tal postulação não seria condizente com os fatos da língua nos quais esta posição não é normalmente ocupada.

$\begin{array}{lllll}\text { ugon } & \text { tuduly } & \text { txitxi } & \text { pumie } & \text { wyna } \\ \text { ugon } & \text { t-udu-ly } & \text { txitxi } & \text { pumie } & \text { wyna } \\ \text { homem } & \text { 3-dar-PSD.IMD } & \text { relógio }^{107} & \text { mulher } & \text { BEN } \\ \text { 'Homem deu relógio para mulher.' (Elic.) } & \end{array}$

$\begin{array}{llll}\text { juduangte } & \text { kure } & \text { wyna } & \text { itakono } \\ \text { j-udu-ang-te } & \text { kure } & \text { wyna } & \text { itakono } \\ \text { 1A-dar-ASP-PSD.MED } & \text { bonito } & \text { BEN } & \text { coisas } \\ \text { 'Eu dei coisas para o (que é) bonito/para o bonito' (Elic.) }\end{array}$

$\mathrm{O}$ afixo -pe pode ser adicionado tanto aos nomes semanticamente prototípicos quanto aos que expressam propriedade, como será apresentado a seguir. Antes, porém, vejamos que os demais itens das maiores classes de palavras da língua, tais como advérbios, posposições e verbos, não podem ser afixados por - $p e$. Se anexados por este sufixo, posposições e advérbios se tornam agramaticais, conforme demonstram os exemplos: *ydelon-pe [hoje-ATBZ] ('É hoje') e *i-wyna-p [1-POSP-ATBZ] ('É para mim'), respectivamente. Verbos, por sua vez, apenas quando nominalizados são licenciados para a derivação por - $p e$. Neste caso, se o atributivizador for afixado a uma forma nominalizada por -tobot, o conjunto de morfemas expressará o modo indicador de propósito (purposive mood) que pode ser traduzido, genericamente, como 'para +

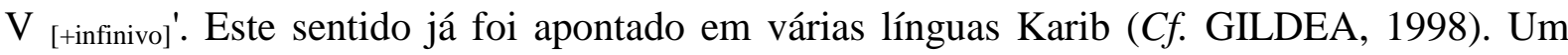
exemplo é oferecido em (14).

encontradas características morfossintáticas que sejam diferentes das propriedades apresentadas pelas classes chamadas de advérbios e de nomes.

${ }^{107}$ Derivação semântica moderna: txitxi 'sol' $\rightarrow$ 'relógio' . 
(14)

$$
\begin{array}{ll}
\text { tywotpotpe } & \text { onmarapkely, } \\
\text { ty-wo-tobot-pe } & \text { on-maraby-ke-ly, } \\
\text { 3-matar-NOM-ATBZ } & \text { ?-cerca-VBR-PSD.IMD }
\end{array}
$$

onmarapkeny, kely.

on-maraby-ke-ly, $\quad$-ke-ly.

?-cercar-VBR-PSD.IMD 3-dizer-PSD.IMD

'(Ele) abriu o cercado para poder matar, abriu o cercado, ele disse (Txt)

\section{- Ambientes não predicativos}

Tanto os nomes prototípicos quanto os não prototípicos podem receber o atributivizador -pe. Quando isto ocorre, se semanticamente compatíveis, os itens derivados podem modificar predicados verbais. Exemplos de modificação verbal são fornecidos em (15), (16) e (17). Algumas palavras aparentemente podem ter se lexicalizado, passando a existir apenas com -p(e), como no exemplo (16). Em casos semelhantes, não faremos a divisão morfêmica.
(15)
Kurep tebyly
kure-pe t-eby-ly
bonito-ATBZ 3-arrive-PSD.IMD
'Ele/a chegou bem' (*O bonito chegou) (Elic)
(16) Pih erup enepko, wygiang tan pene
pih erupe $\varnothing$-eneby-ko wy-ke-ang tan pene
ONOM rápido 3O-trazer-IMP $1 \mathrm{~s}_{\mathrm{A}}$-falar-ASP? aqui DISC
'Traz depressa, eu falei aqui.' (Txt)
(17) imrenpe angtely oringko
i-mure-n-pe angte-ly oringko
3-filho-POSSD-ATBZ cair-PSD.IMD panela

'A panela caiu 'um pouco' (não de muito alto)' (Elic.)

Além disso, nomes prototípicos ou nominalizações podem adquirir significados específicos os quais são traduzidos pela expressão 'como N', conforme ilustrado em (18).
(18) t-omiagri-n-te
uro tapeda
teke-tke-ni-p
PRTC-trabalho-POSSD-PRTC 1 papel
escrever-ITR-NOM.A-ATBZ
'Eu trabalho como professor' (Lit: 'Eu trabalho como escritor de papel') (Elic) 
- Ambientes predicativos (Predicação atributiva e equativa)

Nomes que codificam propriedades quando recebem o sufixo -pe expressam a predicação atributiva, conforme os exemplos (19), (20) e (21).

(19) ty enkaramanpe taje Onat Jodo

DISC forte INTENS NOM.PROP

'Onat jodo é muito forte' (Txt)

(20) tymren

ty-mure-n

wyna kurinpe

3REFL-filho-POSS ADDR raiva-POSSD-ATBZ

'(Ela está) com raiva do próprio filho' (Txt)

\section{(21) txiiiik}

\section{uraymetxingmo egromodup}

IDEO.parar crianças pesado

'Pararam. As crianças estavam pesadas' (Txt)

Por outro lado, nomes prototípicos sufixados por - pe predicam relações equativas, como demonstrado em (22) e (23). Note que o sentido 'como N' nestas construções pode estar presente, vide exemplo (22) ou ausente, como em (23).

(22) kareip

omro

karei-p

omro

não.indígena-ATBZ

\section{2}

'Você é (como) não indígena' (Elic)

$(23)$

$\begin{array}{lll}\text { wongoum } & \text { jodop } & \text { Riten } \\ \text { wongoum } & \text { j-odo- } \boldsymbol{p} & \text { Riten } \\ \text { macaco.sp. } & \text { REL-dono-ATBZ } & \text { NOM.PROP }\end{array}$

'Riten é o dono do macaco de cara branca' (Txt)

Ademais, o predicado adverbializado pode ocorrer sem o sujeito, como apresentado em (24).
(24) mydabringo kak en. Mydabringop
mydabri-ngo kak en. Mydabri-ngo-p
comida-NPSSD QU DEM comida-NPSSD-ATBZ
'Isto é comida? (Isto é) comida'
(Explicação do falante: "é comida, serve para comer") (Elic) 
A seguir é apresentada a predicação possessiva a qual pode ser expressa por meio do predicado formado pela expressão $t-\mathrm{N}-k(e)$ 'tendo $\mathrm{N}$, com N'.

\subsection{A expressão $\mathrm{t}-\mathrm{N}-\mathrm{k}(\mathrm{e})$}

A forma $t-\mathrm{N}-k e \sim t-\mathrm{N}-k$ deriva estruturas comumente descritas como adverbais em línguas Karib. Meira e Gildea (2009, p. 10) apontam o morfema reflexivo ( $t$-) e os sufixos (-ke, $-n e,-r e,-j e,-e)$ como as possíveis origens dessa expressão. Em Arara a estrutura é formada ao redor de um nome e seu significado pode ser traduzido como 'com $\mathrm{N}$ ' ou 'tendo N', conforme o padrão já observado em outras línguas da família. Souza, S. (2010, 99-100) usa a terminologia "adjetivos predicativos denominais" para se referir a esta bem como a estrutura $* * t$-...-ce em Arara. Esta última estrutura, reconstruída em Gildea (1998), é adicionada a raízes verbais para originar uma forma deverbal. Atualmente, tal estrutura é reconstruída como **t-..-tjô ou **t...-tjë, em que a última vogal corresponde a um shwa. Vale ressaltar que $t$-...-ke e $t$-...-ce (ou $t$ ...-tjë) são estruturas distintas.

Os circunfixos da expressão apresentam os seguintes alomorfes: $t$-, aqui glossado como $\mathrm{ADV}$, ocorre diante de raízes iniciadas por $/ \mathrm{a} / \mathrm{e} / \mathrm{o}^{108} /$, e $t y$ - ocorre diante de consoantes e demais vogais. O sufixo - $k e$ ocorre após raízes que terminam em consoante e $-k$ após raízes que terminam em vogais.

Observe que a língua também apresenta os morfemas individuais $t-\sim t y$ - $\mathrm{e}=k e \sim=g e$ os quais são a terceira pessoa reflexiva e a posposição instrumental, respectivamente, como ilustrado em (25). Já nos exemplos (26) e (27) os morfemas parecem estar lexicalizados como uma estrutura única, pois, quando ocorrem em separado (/t-/ 'posse reflexiva' e /=ke/ 'instrumental'), os seus significados divergem acentuadamente do significado observado quando ocorrem em conjunto (/t-N-ke/ 'tendo', 'possuindo').

\begin{tabular}{|c|c|c|c|}
\hline \multirow{3}{*}{\multicolumn{2}{|c|}{ (25) jei }} & amneny & typun ke \\
\hline & & amne-ny & $t y-p u-n=k e$ \\
\hline & & jogar-PSD.IMD & 3REFL-pé-POSSD=INS \\
\hline
\end{tabular}

\footnotetext{
${ }^{108}$ Raízes nas quais ocorre o processo de ablaut. Assim, os alomorfes do reflexivo não serão encontrados diante de /e/, salvo poucas exceções.
} 
(26) pylepte tyek

pylepte ty-e-k

faca ADV-dente-ADV

'A faca está amolada' (Lit.: 'A faca tem dente') (Elic)
(27) tymek kak i-mnu
ty-me-k kak i-mnu
ADV-roupa-ADV QU 3-carne
'Essa pessoa tinha roupa?' (Txt)

Além disso, no caso de nomes obrigatoriamente possuídos, o sufixo de posse é omitido na adverbialização por $t$ - $\mathrm{N}-k e$, mas não entre os morfemas $t y$ - REFL e $=k e$ INST. Esta diferença é ilustrada nos exemplos (25) e (26). Veja que em (26), o nome obrigatoriamente possuído (j)e- $n$ [dente-POSSD] 'dente' ocorre como uma raiz nua, sem a morfologia de posse (ty-e-k 'tem dente'), enquanto quando o nome obrigatoriamente possuído $i$-pu- $n$ [3-pé-POSSD] 'pé' carrega o prefixo reflexivo e a posposição =ke , como em (25), ele apresenta o sufixo de posse (ty-pu$n=k e$ 'com o próprio pé').

Os morfemas homófonos ke também apresentam uma diferença morfofonológica clara. A expressão $t$ - $\mathrm{N}-k(e)$ possui alomorfes fonologicamente condicionados: $-k$, ocorre após vogais, como em (26) e (27), e -ke, após consoantes, como em (28), enquanto a posposição instrumental $\{k e\}$ apresenta o alomorfe =ke após consoantes, (25), e =ge após vogais, como em (29).

(28) tumkebra

$\boldsymbol{t}-u m-\boldsymbol{k} \boldsymbol{e}=b r a$

ADV-pai-ADV=NEG

'Sem pai' (Contexto: "pai já falecido") (Txt)

(29) wapi jokpetkenangry pytxiga ge

wapi j-okpe-tke-nangry pytxiga $=$ ge

fleche 1-fazer-ITR-IPFV facão=INS

'Eu faço flecha com facão' (Txt)

Com relação à predicação possessiva, a estrutura $t$-N-ke expressa posse permanente, como no exemplo (30), o que contrasta com a posse temporária expressa por ipe EXIST, em (31). Esta partícula é apresentada na próxima subseção. 
(30)

$\begin{array}{ll}\text { tybyleptek } & \text { uro } \\ \text { ty-bylepte-k } & \text { uro } \\ \text { ADV-faca-ADV } & 1\end{array}$

'Eu tenho faca' (Explicação do falante: "A faca me pertence") (Elic.)

(31) pylepte ipe uro

pylepte ipe uro

faca $\quad$ EXIST PRO.1

'Eu tenho faca' (Explicação do falante: 'Eu a tenho por agora, mas ela não me pertence') (Elic.)

\subsection{A PARTÍCULA EXISTENCIAL $\{I P E\}$}

O cognato de ipe, em Ikpeng, é descrito como uma partícula existencial (PACHECO, 2001, p. 136). Em Arara, Souza, I. (2010, p. 23) se refere às formas /-ype -pe/ como um sufixo existencial. No dialeto analisado foi verificada a variação entre as formas ype $\sim$ ipe. Falantes mais velhos usam a primeira forma enquanto a última é utilizada por falantes mais novos. Veja que para estes, o morfema pode ser flexionado pela primeira pessoa singular: $y$-pe 'tem a mim', o que sugere a possibilidade de se tratar de uma posposição. Por outro lado, a forma ype ocorre nos exemplos coletados com colaboradores mais velhos (para os quais a forma não está flexionada com a primeira pessoa). Neste estudo, faremos referência a forma ipe por ser dela o maior número de itens no corpus. A forma ipe varia livremente com pe, após vogais. Veja nos exemplos (32) e (33) que os dois alomorfes ocorrem no mesmo ambiente. Após consoantes a redução ipe pe aparenta ser possível, conforme o exemplo em (39), porém testes devem confirmar esta hipótese já que, por enquanto, este é o único exemplo observado seguindo uma consoante.

$\begin{array}{lll}\text { otxingo } & \text { ipe } & \text { uro } \\ \text { otxi-ngo } & \text { ipe } & \text { uro } \\ \text { casa-NPOSSD } & \text { EXIST } & \text { PRO:1 }\end{array}$

'Eu tenho casa' (Elic)

$\begin{array}{lll}\text { otxi-ngo } & \boldsymbol{p e} & \text { uro } \\ \text { otxi-ngo } & =p \boldsymbol{e} & \text { uro } \\ \text { casa-NPOSSD } & \text { EXIST } & \text { PRO:1 }\end{array}$

'Eu tenho casa' (Elic) 
Faz-se necessário averiguar a distinção entre os morfemas homófonos: pe de ipe e o sufixo atributivizador -pe ATBZ (subseção 6.2.3.2.1). A existência individual destes dois morfemas é clara de acordo com características morfofonologicas, morfossintáticas e sintáticas. Quanto à morfofonologia, apenas -pe ATBZ reduz para - $p$, em contextos previsíveis, os quais se referem à natureza vocálica ou consonantal do último segmento da raiz ( subseção 6.2.3.2.1 $\S 2)$, enquanto ipe reduz para $[p e]$, mas não para $[p]$. O exemplo (34) demonstra que a redução de ipe para $[p]$ não é possível. Como mencionado na seção anterior, o significado de posse temporária ${ }^{109}$ também é realizado por meio da partícula existencial, o que ainda não havia sido descrito na literatura anterior.

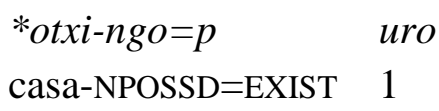

Quanto ao critério morfossintático, a negação é codificada de maneira diferente para cada um dos morfemas homófonos. Enquanto - $p e$ 'ATBZ' é negado pela forma =bra $\mathrm{NEG}$, como em (35), o alomorfe pe EXIST ocorre em distribuição complementar com a negação pyra NEG, como demonstrado em (36) e (37).

$\begin{array}{ll}\text { ugrongmobebra } & \text { Alessandra } \\ \text { ugrongmo-be }=\text { bra } & \text { Alessandra } \\ \text { indígena-ATBZ=NEG } & \text { NOM.PROP } \\ \text { 'Alessandra não é indígena' (Elic) }\end{array}$

(36) pylepte pyra uro

faca NEG 1

'Eu não tenho faca' (Elic)
(37) *pylepte pe=bra uro (Eu não tenho faca)
faca $\quad$ EXIST $=$ NEG 1

No que se refere à distribuição sintática, o morfema -pe ATBZ ocorre apenas após sintagmas nominais enquanto ipe foi verificado após PPs e a partícula kumyk, ilustrado em (38) e (39), respectivamente. Observe ainda que estes exemplos apresentam o sentido de existencialidade que em português também pode ser traduzido pelo verbo 'ter'.

\footnotetext{
109 Tal sentido foi elicitado apenas no dialeto Arara. Possivelmente, o mesmo vale para o dialeto Iriri, o que poderá ser corroborado em futuras investigações.
} 


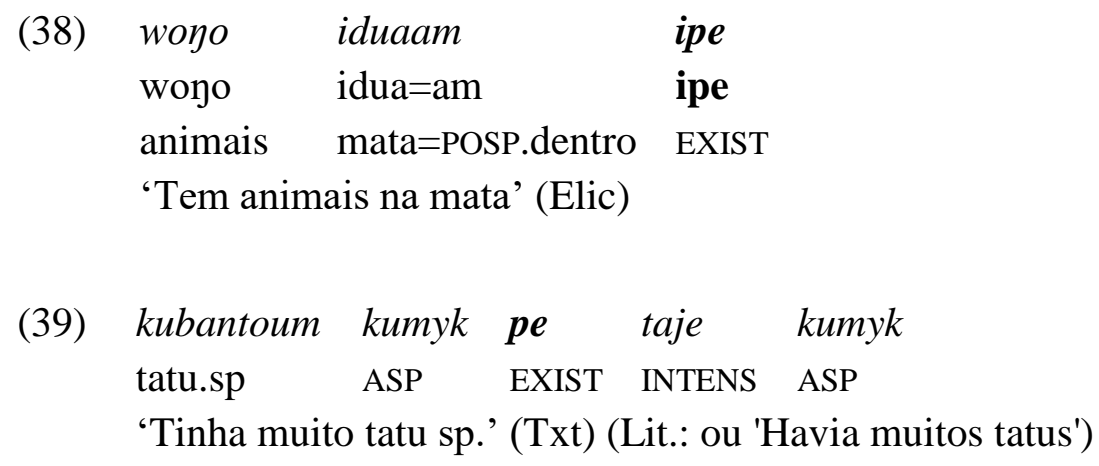

Ademais, em outros tempos, que não o presente, ipe é verificado com a cópula itxi, como em (40), comprovando não se tratar de um morfema copular.
(40) modo ipe kunitak
modo ipe kun-itxi-tak
verme EXIST 3PSD.DST-COP-IPFV.PSD
'Tinha verme' (Txt)

As próximas seções apresentam a distribuição das categorias de TAM e a cópula \{itxi\}.

\subsection{DEMAIS EXPRESSÕES DE TAM: CONSTRUÇÕES COM A CÓPULA \{ITXI\}/ITI/}

\subsubsection{Morfofonologia}

A cópula itxi apresenta os alomorfes [itxi it $\sim i]$ os quais são o resultado do processo de redução silábica (Capítulo II, seção 2.7.5).

A forma longa itxi é observada apenas quando esta é flexionada por sufixos que não desencadeiam a elisão da última vogal da raiz, isto é, os sufixos -ly PSD.IMD e - $a$ PERM. Note que, diferente do que ocorre com as oclusivas, em ambiente intervocálico não há assimilação da sonoridade da consoante africada ${ }^{110}$.

O alomorfe [it] é resultado da elisão da última vogal da raiz quando esta é afixada por um sufixo -CV ou um sufixo que contém esta sequência, como em /kure-p it-ko/ [bom-ATBZ COP-IMP] 'Fique bem!'.

\footnotetext{
${ }^{110}$ Apenas no dialeto Arara, há a versão vozeada [d3] a qual é verificada somente seguindo consoantes nasais.
} 
O alormorfe [i], por sua vez, resulta da elisão da última vogal seguida da elisão de consoantes anteriores. Estes processos poder ser verificados em /iti-taytel $\rightarrow$ /it-taytel $\rightarrow / i$ tayte/ [COP-PSD.DST] e /iti-nayri/ $\rightarrow$ /it-nayri/ $\rightarrow$ /i-nayri/ [COP-IPFV].

Como ilustra a tabela 6.1, a cópula é flexionada por morfemas de TAM e N, assim como pelo mesmo conjunto de morfemas de pessoa verificado em verbos intransitivos descritos como $\mathrm{S}_{\mathrm{A}}$. Observe na última linha da tabela que no imperativo não há marcação de pessoa. Exemplos com algumas destas flexões são oferecidos a seguir.

Tabela 6.1 - Conjugações da cópula itxi no singular e no plural

\begin{tabular}{|c|c|c|c|}
\hline & PSD.IMD & PSD.MED & IPFV \\
\hline 1 & $w$-itxi-ly & $w$-i-tangte & $w$-i-nangry \\
\hline $1+2$ & kutx-itxi-ly & kutx-i-tangte & kutx-i-nangry \\
\hline 2 & $m$-itxi-ly & $m$-i-tangte & $m$-i-nangry \\
\hline 3 & $\varnothing$-itxi-ly & mon-i-tang & $\varnothing$-i-nangry \\
\hline 2 PL & m-itxi-ly-ngmo & $m-i-\tan g-t y-t$ & $m$-i-nangry-ngmo \\
\hline $1+2 \mathrm{PL}$ & kutx-itxi-ly-ngmo & $k u t x-i$-tang-ty- $t$ & kutx-i-nangry-ngmo \\
\hline 3 PL & $\emptyset$-itxi-ly-ngmo & mon-i-tang-tom & $\emptyset$-i-nangry-ngmo \\
\hline 3 & \multicolumn{3}{|c|}{ PERMISSIVO: $n$-it $x$ - $a$} \\
\hline 3 PL & \multicolumn{3}{|c|}{ PERMISSIVO PLURAL: $n$ - $i$ - $t o m-a$} \\
\hline $1+2 \mathrm{PL}$ & \multicolumn{3}{|c|}{ HORTATIVO PLURAL: $k u t x-i-t y-n$} \\
\hline 1 & \multicolumn{3}{|c|}{ INTENCIONAL: $w$-i- $t x a$} \\
\hline 3PSD.DST & \multicolumn{3}{|c|}{ IPFV.PSD: $k u n-i-t a k$} \\
\hline-- & \multicolumn{3}{|c|}{ IMPERATIVO: $i t-k o$} \\
\hline
\end{tabular}

(48) amuru pok kutxityn, kelyngmo amuru pok kut-iti-ty-n, Ø-ke-ly-ngmo bebida.fermentada POSP 1+2A-COP-COL-HORT 3-falar-PSD.IMD-COL 'Vamos beber! ele disse.' (Txt) (Lit.: Vamos ficar na/ocupados com a bebida tradicional, disseram) 
(49) malon witangne

obyra jemiagrin pok

malon w-iti-tang-ne o-byra j-emiagri-n pok

assim 1S $1 \mathrm{~S}_{\mathrm{A}}$-COP-IPFV.PSD-PSD.DST 2-NEG 1-trabalho-POSSD POSP.sobre

'Meu trabalho é assim sem você ' (Txt) (Lit.: 'Eu fico assim ocupado com meu trabalho, sem você (quando você não está aqui)')

(50) kuremne itko, geny

kure-mne iti-ko, $\quad$-ke-ny

bom-NEG COP-IMP 3-dizer-PSD.IMD

'Calado! Ele disse.' (Txt)

(51) kurep witxa

kure-p w-iti-txa

bom-ATBZ $1 \mathrm{~S}_{\mathrm{A}}$-COP-INTC

'Eu vou ficar bom' (Expl. do falante: A pessoa fala assim quando está doente) (Elic.)

(52) igatpe ga mitang

i-gat-pe ka m-iti-tang

3-gordura-ATBZ QU 2 $\mathrm{S}_{\mathrm{A}}$-COP-INT

' Você está ficando gordo?' (Elic.)

\subsubsection{Origens}

A cópula itxi, possivelmente, foi originada a partir do verbo posicional itxi 'deitar'. Atualmente, este significado ainda é usado na língua, como ilustrado em (53) e (54).

(53) itko

$\varnothing$-iti-ko

3-deitar-IMP

'Deita! (Elic.)

(54) onit pyra uro ydelon

on-iti=pyra uro ydelon

NEG-deitar $=$ NEG $\quad$ PRO.1 hoje

'Eu não deitei hoje' (Elic.) 


\subsubsection{A posição da cópula}

A cópula sempre ocupa a segunda posição da construção em que ocorre. Em construções com predicados adverbiais, a mais comum entre as línguas Karib, a cópula pode apresentar ou não um sujeito sintático, como em (55) e (56), respectivamente. A ordem gramatical da construção de argumento único deve ser AdvP Cop, caso contrário a construção se torna agramatical, como exemplificado em (57). De maneira não muito comum entre as línguas desta família linguística, construções com predicados nominais aparentemente podem ocorrer com a cópula, como em (58). Com este tipo de predicado, os dois NPs devem estar presentes na construção, caso contrário ela também se torna agramatical, (59). Considere os exemplos abaixo segundo o contexto pragmático: "Ele vai ser como um padrasto, um segundo pai".

$\begin{array}{lll}\text { odongop } & \text { inangry } & \text { ybapan } \\ \text { odo-ngo-pe } & \emptyset \text {-iti-nangry } & \text { y-papa-n } \\ \text { dono-NPOSSD-ATBZ } & 3 \mathrm{~S}_{\mathrm{A}} \text {-COP-IPFV } & \text { 1-pai-POSSD } \\ \text { 'Meu pai será chefe' (Elic) } & \end{array}$

$(56)$

$\begin{array}{ll}\text { ybapanpe } & \text { inangry } \\ \text { y-bapa-n-pe } & \text { Ø-iti-nangry } \\ \text { 1-pai-POSSD-ATBZ } & 3 \mathrm{~S}_{\mathrm{A}}-\mathrm{COP}-\mathrm{IPFV} \\ \text { '(Ele) será meu pai' (Elic) }\end{array}$

(57) $*$ i-nangry $y$-bapa-n-pe

COP-IPFV 1-pai-POSSD-ATBZ (Elic)

((Ele) será meu pai)

\begin{tabular}{|c|c|c|c|c|c|}
\hline (58) & $\begin{array}{l}\text { wongo } \\
\text { bichos }\end{array}$ & $\begin{array}{l}\text { wo-tke-ni } \\
\text { matar-ITR-NOM }\end{array}$ & $\begin{array}{l}\text { i-nangry } \\
\text { COP-IPFV }\end{array}$ & $\begin{array}{l}\text { Tema } \\
\text { NOM.PROP }\end{array}$ & $\begin{array}{l}i d u a=a k o \\
\text { mata }=\text { POSP.dentro }\end{array}$ \\
\hline & 'Tema será c & caçador no mato' & Elic) & & \\
\hline (59) & *ybapan & inangry & & & \\
\hline & $\begin{array}{l}\text { 1-pai-POSSD } \\
\text { ((Ele) será n }\end{array}$ & $\begin{array}{l}\text { D } 3 \text {-COP-IPFV } \\
\text { meu pai) (Elic) }\end{array}$ & & & \\
\hline
\end{tabular}




\subsubsection{Outro uso de itxi: verbo auxiliar}

A cópula pode ser usada como verbo auxiliar, carregando flexões de pessoa, TAM e N em sentenças complexas. Este é o caso de construções negativas, como ilustrado em (60). Este tipo de construção não será investigada neste estudo.

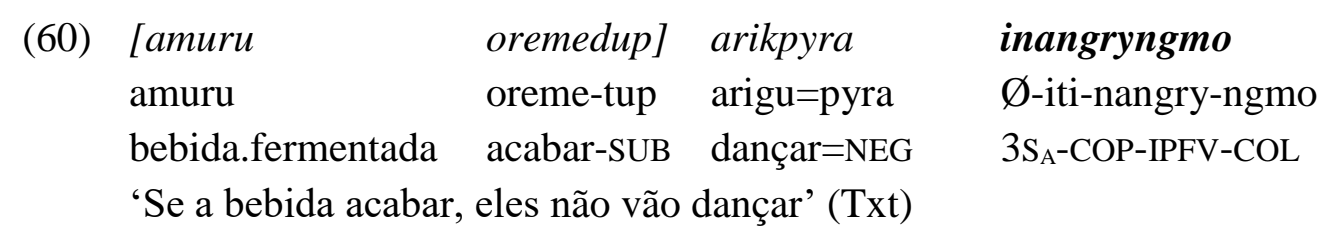

\subsubsection{O passado imediato e a cópula itxi}

Quando a cópula é sufixada com o morfema $\{-l y \sim-n y\}$ PSD.IMD, instâncias sutis de significado são acrescentados à predicação, dependendo do tipo de predicado que complementa a cópula, como veremos na próxima seção.

\subsubsection{Predicados nominais}

Quando a cópula é flexionada com -ly PSD.IMD, o sentido incoativo é acrescentado à predicação equativa. Este novo sentido de mudança de estado pode ser traduzido pelo verbo 'tornar-se', como ilustram os exemplos em (61) e (62).

\begin{tabular}{|c|c|c|c|}
\hline (61) & Fabio & itxily & odongo \\
\hline & Fabio & $\emptyset$-iti-ly & odo-ngo \\
\hline & NOM.PROP & $3 \mathrm{~S}_{\mathrm{A}}-\mathrm{COP}-\mathrm{PSD} . \mathrm{IMD}$ & dono-NPOSSD \\
\hline
\end{tabular}
(62) kareip uro apangron, ugrongmo witxily karei-p uro apangron, ugrongmo w-iti-ly não.indígena-ATBZ 1 anteriormente indígena $1 \mathrm{~S}_{\mathrm{A}}$-COP-PSD.IMD 'Antes, eu era (como) branco, (agora) eu me tornei indígena' (Elic)




\subsubsection{Predicados posposicionais}

Quando a cópula é flexioanada por -ly 'PSD.IMD' em construções com predicados posposicionais, o significado da cópula é compatível com o verbo 'ficar', como em (63).

$\begin{array}{llll}\text { topkalongmo } & \text { waramium } & \text { pok } & \text { itxily } \\ \text { topkalo-ngmo } & \text { warami-um } & =\text { pok } & \emptyset \text {-iti-ly } \\ \text { outro-COL } & \text { coco.babaçu-AUM } & \text { POSP } & \text { 3-COP-PSD.IMD } \\ \text { 'Os outros (animais) ficaram sobre a palmeira de babaçu (Orbignya phalerata)' (Txt) }\end{array}$

\subsubsection{Predicados adverbiais}

Predicados formados por advérbios não derivados e advérbios derivados por meio da adição do sufixo -pe, ambos acompanhados pela cópula, ilustram a predicação locativa e a atributiva em (64) e (65), respectivamente.

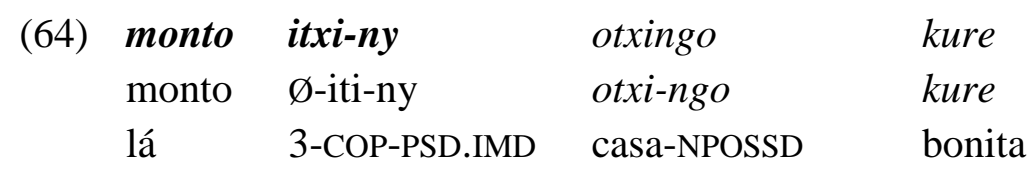

'A casa bonita estava lá' (Elic)

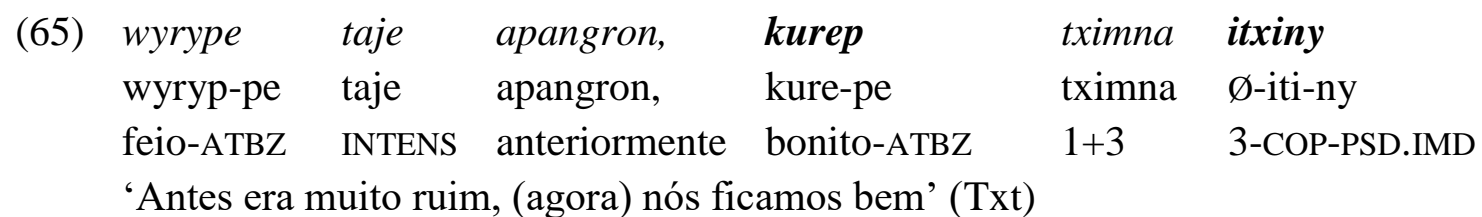

\subsection{A FORMA $\{$ APTAM $\}$}

A forma laptam/ apresenta tanto características verbais quanto posposicionais. Adicionada a esta forma, foi verificada a corrência de uma parte da morfologia verbal as quais correspondem aos morfemas de pessoa e número. Os prefixos de pessoa encontrados seguem o paradigma que caracteriza verbos intransitivos da classe Sa. Quanto ao sufixo de número, foi atestado o morfema $\{t y\}$, o qual é semelhante aos sufixos que correm em combinação com determinadas flexões verbais. A tabela 6.2 apresenta a referida forma acompanhada de suas 
flexões de pessoa e de plural. Veja ainda que quando flexionada na segunda pessoa, ela apresenta o prefixo od- que é semelhante a um alomorfe do morfema detransitivisador ot $(i)$-.

Tabela 6.2 - Singular e plural da forma aptam

\begin{tabular}{|c|c|c|}
\hline PESS & POSP & POSP.PL \\
\hline $\mathbf{1}$ & $\boldsymbol{w}$-aptam & -- \\
\hline $\mathbf{2}$ & m-od-aptam & m-od-aptydam \\
\hline $\mathbf{3}$ & $\emptyset$-aptam & $\emptyset$-aptydam \\
\hline $\mathbf{1 + 2}$ & kud-aptam & kud-aptydam \\
\hline
\end{tabular}

Por outro lado, sintaticamente, esta forma apresenta características de posposição já que introduz uma oração subordinada adverbial temporal, conforme os exemplos a seguir. Note que o significado desta forma se funde a um sentido adverbial que pode ser traduzido como 'se, quando'. O entendimento completo acerca desta forma hibrida demanda mais estudos.

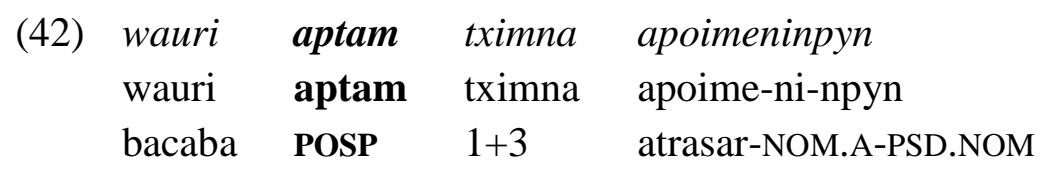

$\begin{array}{lll}\text { wauri } & \text { tximna } & \text { engrynangry } \\ \text { wauri } & \text { tximna } & \text { engry-nangry } \\ \text { bacaba } & 1+3 & \text { beber-IPFV }\end{array}$

'Se fosse bacaba que atrasava a viagem, parava para beber' (Txt) (Lit.: Se bacaba fosse o nosso (excl.) atrasador, nós (excl.) bebíamos bacaba.)
(43) 'saude' pok w-aptam [...]
saúde POSP.sobre 1-POSP

'Quando eu era da "saúde"' [...]

(Contexto: Trabalhava como agente de saúde) (Txt)

$\begin{array}{llllll}\text { (44) } & \text { uro } & \text { lon } & \text { apangron, } & \text { paebra } & \text { waptam } \\ \text { j-uku-nangry } & \text { uro } & \text { lon } & \text { apangron, } & \text { paebra } & \text { w-aptam } \\ \text { 1A-experimentar-IMPF } & 1 & \text { FOC } & \text { antigamente } & \text { não.maduro } & \text { 1-POSP }\end{array}$

'Eu também ía procurar, quando eu era nova' (Txt)

Um exemplo da versão plural da forma aptam é oferecido em (45). Neste caso, um predicado participial está sendo modificado. 
(45)

$\begin{array}{ll}\text { todokpene } & \text { kutxityn } \\ \text { t-od-okpe-ne } & \text { kut-iti-ty- } n \\ \text { ADV-DTRZ-acampar-ADV } & 1+2 \mathrm{~S}_{\mathrm{A}} \text {-COP-COL-HORT }\end{array}$

tynot

ty-no-t kudaptydam

PRTC-deixar-PRTC

1+2-POSP.COL

'Vamos ficar acampados aqui, se estamos deixados' (o pessoal foi na frente) (Txt)

\subsection{SÍNTESE}

Construções não verbais realizadas pela justaposição de um predicado (nome, posposição, advérbio) a um sujeito (nome, pronome, nominalização) expressam o presente ou o passado. Para o passado, a construção é acrescida de morfologia nominal ou da partícula aspectual kumyk. Para expressar outras categorias de TAM, ocorre o acréscimo de uma cópula verbal flexionada também para as categorias de pessoa e N. Predicados nominais e adverbiais do tipo - $p e$, derivados a partir de nomes prototípicos, expressam a relação equativa. Predicados do tipo - pe derivados a partir de nomes que denotam propriedade expressam a função atributiva. Predicados adverbiais não derivados e predicados posposicionais expressam a função locativa. Advérbios derivados do tipo $t$-N-ke expressam a relação possessiva de caráter permanente. Construções com ipe, cuja classificação ainda é incerta, expressam a função possessiva de caráter temporário e a relação existencial. A tabela a seguir resume as principais estruturas e o tipo de predicação identificadas. Não foi encontrado nenhum exemplo de construção na qual ocorrem ipe e a cópula expressando a relação possessiva temporária, o que foi representado na tabela com um ponto de interrogação.

Tabela 6.3 - Estruturas das construções e suas funções predicativas

Equ. Atribt. Loc. Possess. Exist.

$[N P]_{S U J}[N P]_{P R E D}$

$[N P]_{S U J} S-i t i-T A M-N[N P]_{P R E D}$

$[P P]_{\text {PRED }}\left([N P]_{S U J}\right)$

$[P P]_{\text {PRED }}$ S.iti-TAM-N ([NP] $\left.]_{\text {SUI }}\right)$

$[A D V]_{P R E D}[N P]_{S U J}$ 
Equ. Atribt. Loc. Possess. Exist.

\begin{tabular}{l|l}
\hline$[A D V]_{\text {PRED }}$ S.iti-TAM-N $[N P]_{S U J}$ & \\
\hline$[A D V]_{\text {PRED }}$ ipe $[N P]_{S U J}$ & \\
{$[P P]_{\text {PRED }}$ ipe S.iti-TAM-N $[N P]_{S U J}$} & \\
\hline
\end{tabular}




\section{CAPÍTULO 7 - CONCLUSÃO}

O objetivo deste estudo consistiu em descrever detalhadamente o sistema de marcação das categorias de TAM, Pessoa e Número e suas inter-relações. A fim de se compreender tal sistema em sua completude foi oferecido um tratamento morfofonológico e morfossintático dessas flexões. A seção 7.1 apresenta um resumo dos principais achados descritos nos capítulos anteriores. A seção 7.2 apresenta possíveis desdobramentos deste estudo também no que se refere a TAM como uma categoria funcional. Considerações finais são feitas na seção 7.3.

\subsection{TAM COMO CATEGORIA FORMAL/GRAMATICAL: SÍNTESE}

Comparativamente, no que se refere ao sistema verbal conjugado, Arara consiste em uma língua típica da família Karib. Foi demonstrado que a língua apresenta um rico conjunto de afixos verbais, especialmente de morfemas de pessoa, número e TAM. Não obstante, a relação entre estas categorias é notável. O sistema apresenta prefixos de pessoa com alomorfias previsíveis e mais de uma configuração de acordo com as flexões de TAM. Estes morfemas, por sua vez também apresentam alomorfias, algumas formas supletivas além de formas pormanteau.

Foi evidenciado que as flexões de TAM, pessoa e número estão sujeitas aos processos morfofonológicos gerais da língua. Os processos envolvidos nas formas dos prefixos de pessoa são a sonorização em ambiente intervocálico (processo abundante na língua), a palatalização diante de vogal alta anterior, a nasalização de oclusivas diante de consoantes nasais e o ablaut, cuja mudança consiste, principalmente, na alternância: $o \rightarrow e$. Este processo é pervasivo na gramática da língua, sendo observado pela comparação entre as formas não possuídas, paradigmas, a terceira pessoa reflexiva e a forma do circunfixo que deriva o particípio $\{t$ - $V$ $-t(e)\}$. As flexões de TAM e número apresentam alomorfes condicionados, basicamente, pelo processo de sonorização intervocálico, que resulta em um alomorfe surdo e uma contraparte sonora, além disso há alomorfes que perdem a última vogal. Como exemplo destes últimos, as formas do imperativo são condicionadas pela possibilidade de formar uma sílaba aberta ou fechada, que leva à escolha das variante $-k$ ou $-k o$. Um morfema zero também é verificado após radicais terminados em nasal velar. Destacam-se os radicais intransitivos $S_{\circ}$ os quais são os 
únicos que recebem a segunda pessoa e, ao contrário do que se espera quando o radical termina em vogal, essas formas não recebem marcas sufixais de imperativo.

Foi realizada uma análise das classes de palavras com a finalidade de se conhecer as propriedades morfossitáticas definidoras da classe verbal, bem como as que diferencia esta das demais principais classes de palavras da língua, a saber: nomes, posposições e advérbios. De fato, a classe verbal é a mais facilmente identificada, pois verbos finitos apresentam uma gama de morfemas exclusivos como prefixos pessoais, flexões de TAM e morfemas de alteração de valência. Sobretudo, a partir de padrões de marcas de pessoa, do imperativo e da negação foi possível definir a classe de verbos transitivos e as duas classes de verbos intransitivos que foram chamadas de $S_{\mathrm{A}}$ e $S_{\mathrm{O}}$. Além disso, radicais verbais podem ser derivados de outros verbos ou de nomes. O processo inverso também ocorre, isto é, verbos podem ser nominalizados. Processo abundante na língua.

Quanto aos rótulos de TAM utilizados neste estudo, foram apresentados os morfemas de tempo os quais se dividem em passado e futuro, sendo que o passado apresenta três possibilidades de expressão de acordo com o grau de distância temporal. $\mathrm{O}$ aspecto foi dividido em imperfectivo, imperfectivo passado, iterativo e resuntivo. O imperfectivo apresenta mais contextos de uso podendo denotar sentidos que remetem ao processo do evento (continuativo), ao início do evento (remete ao futuro) e a habitualidade do evento (remete ao presente). $\mathrm{O}$ imperfectivo passado ocorre apenas no passado distante, o iterativo também pode denotar pluracionalidade e o resuntivo apresenta o sentido de repetição, além de outros sentidos, possivelmente, a partir da interação com o aspecto lexical. O modo consiste na categoria que mais se destaca na língua em termos de número de flexões. Foram identificados 8 modos: imperativo, vetativo, hortativo, permissivo, intencional, admonitivo, interrogativo, frustrativo. A maioria cai sob o escopo dos atos de fala diretivos. O imperativo compreende as formas de comando com grande força ilocucionária, o hortativo abrange comandos que incluem apenas a primeira pessoa plural, com força ilocucionária moderada. O vetativo, o permissivo e o admonitivo apresentam força ilocucionária fraca. É importante ressaltar que a escolha dos rótulos tem fins descritivos e algumas das categorias analisadas apresentam áreas de interação, por exemplo, o intencional apresenta nuances da categorias de modo e tempo.

Além do sentido dos morfemas de TAM, a distribuição dos prefixos de pessoa em paradigmas contribuiu para o entendimento de cada categoria e para a escolha da terminologia adequada. A relação entre os morfemas de TAM e os prefixos pessoais mostraram padrões típicos, com paradigmas com todas as pessoas em verbos com categorias de tempo e aspectos e com paradigmas menores em verbos flexionados com as categorias de modo. Em especial 
para a categoria de tempo, o alinhamento dos morfemas de pessoa demonstrou um padrão aqui chamado de intransitividade cindida, mas que ficou conhecido de várias maneiras na literatura. De acordo com este padrão, verbos transitivos recebem duas séries de prefixos de pessoas, uma que se refere ao objeto $(\mathrm{O})$ e uma que se refere ao sujeito $(\mathrm{A})$, sendo que a relação com a terceira pessoa é sempre pressuposta de acordo com uma interação de hierarquia de pessoa. Os verbos intransitivos, por sua vez, apresentam morfemas morfologicamente semelhantes aos morfemas dos verbos transitivos. Isto é, a classe chamada $S_{\circ}$ recebe morfemas semelhantes aos verificados na série $O$ em transitivos e a classe chamada $S_{A}$ recebe prefixos que se assemelham aos morfemas da série A em transitivos.

A distribuição dos morfemas de número mostrou alinhamentos independentes dos alinhamentos da categoria de pessoa. Por exemplo, um mesmo morfema de plural pode ocorrer no paradigma de tempo e modo, como \{-tom\} que ocorre no paradigma do permissivo, do admonitivo e também nos de passado médio e distante. Especialmente nestes dois últimos paradigmas, se observa uma interação com o morfema de pessoa, pois, apenas nas terceiras pessoas, o número é expresso por \{-tom\}, enquanto que para as demais é marcado por $\{$-ty\}. Além disso, a posição das marcas de número também é variada em relação ao radical.

Por fim, investigamos o comportamento das flexões de TAM na construção não verbal. Foi verificada uma cópula verbal que, quando presente na predicação, carrega as flexões de TAM, a cópula $\{$ itxi $\}$. Esta cópula é afixada por morfemas de pessoa e flexões de TAMN que sofrem os processos morfofonológicos comuns à língua. Quando a cópula \{itxi\} é flexionada no passado imediato acompanhada de predicados nominais tem-se o sentido incoativo, uma nuance de significado não encontrada em predicados verbais.

Obviamente, o estudo das formas verbais presas não foi exaustivo, de modo que, principalmente, no que concerne às flexões ainda há morfemas que não foram abordados. Este estudo focou apenas nas marcas de maior ocorrência presentes no corpus. Dentre estas, naturalmente, restaram lacunas que por sorte poderão ser sanadas em novas e futuras incursões acadêmicas no tópico.

Na seção a seguir, sobre futuros estudos, optamos por oferecer uma breve caracterização de TAM como uma categoria funcional. Mais especificamente, será discutido que, além das formas flexionais canônicas, outras possibilidades de expressão de TAM são inovações a partir de morfemas nominais e participiais. 


\subsection{TAM COMO CATEGORIA FUNCIONAL/NOCIONAL: FUTURAS INVESTIGAÇÕES}

Esta seção apenas indica potenciais formas inovadoras de codificação de TAM para que possam ser futuramente investigadas em detalhes. As estruturas apresentadas a seguir, basicamente, consistem em formas não finitas (nominalizações) ou menos finitas (participiais $(t-\mathrm{V}-t(e))$ presentes em sentenças principais, nas quais predicados eventivos seriam esperados. A ferramenta de análise utilizada faz parte das mudanças observadas no processo de gramaticalização: a reanálise. Segundo Lehmann (2005, p. 8-9, grifo do autor):

The reanalysis of a construction is the assignment of a different grammatical structure to it. Expressions instantiating the construction are thereby not changed. The reanalysis is therefore itself not observable. Its accomplishment can only be diagnosed ex post when the construction behaves in ways that presuppose its new structure.

Apontamos a mudança de significado como um indício de que o processo pode estar em andamento. O processo em si estará completo somente após a verificação de mudanças dos padrões morfossintáticos que sejam capazes de mostrar um paralelo com construções eventivas. Como encerra Meira (2006), a questão consiste em saber qual a consequência da reanálise para a descrição de construções morfossintáticas.

\subsubsection{A estrutura $t-V-t(e)$}

Dentre os sete tipos de sentenças verbais da família Karib descritas em Gildea (1998), está o sistema não conjugado do qual faz parte a estrutura **t-V-ce (t-...tjô ou $t$-...-tjë, na literatura mais atual). Segundo o autor, o sistema, que se caracteriza por apresentar morfossintaxe ergativa, foi originado a partir do particípio que se transformou em passiva para depois se desenrolar em um sistema ergativo.

No ramo pekodiano, estruturas cognatas são encontradas em Bakairi (SOUZA, T., 1994 apud GILDEA, 1998), Ikpeng (CHAGAS, 2013) e Arara (SOUZA, S. 1993). Em Ikpeng e Arara, as formas são descritas como particípio. Esta construção que modifica um nome como um particípio estativo/passivo foi ilustrada no Capítulo III, subseção 3.5.4, dentre os processos 
deverbais. A presente subseção, por sua vez, demonstra que a estrutura está sendo utilizada como uma construção ativa semelhante a um predicado eventivo. Futuros estudos dirão se esta hipótese se sustenta, o que não seria de se estranhar visto que estruturas cognatas já foram interpretadas ativamente. Este é o caso de Bakairi, como ilustra o exemplo (1), retirado de Gildea (1998).

Bakairi (Karib) (SOUZA, T. 1994 apud GILDEA 1998, p. 232, tradução nossa)

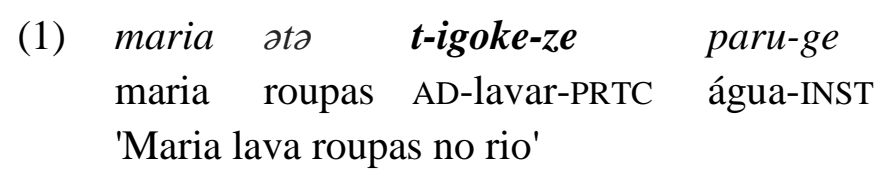

Ademais, Meira (1995 apud GILDEA, 1998) argumenta que em Tiriyó a estrutura cognata deu origem a uma nova flexão de passado. Como demonstram os dados a seguir, semelhante ao que ocorreu em Tiriyó, a forma $t-\mathrm{V}-t(e)$, em Arara, está sendo interpretada ativamente no passado. Esta interpretação ocorre tanto em radicais intransitivos, como em (2), quanto transitivos, porém, somente quando há dois argumentos sintáticos expressos, como em (3) e (4). Se um dos argumentos é retirado, o participante único representa o $\mathrm{O}$ da versão transitiva, conforme os exemplos (5), (6) e (7). Isto é, a construção volta a ser interpretada como um particípio.

$\begin{array}{lll}\text { (2) } & \begin{array}{ll}\text { Kubenete } \\ \text { Kubenete }\end{array} & \begin{array}{l}\text { toepte } \\ \text { to-ep-te }\end{array} \\ \text { NOM.PROP } & \text { PRTC-vir-PRTC } & \text { nok } \\ & \text { noite }\end{array}$

'Kubenete chegou à noite' (Elic)

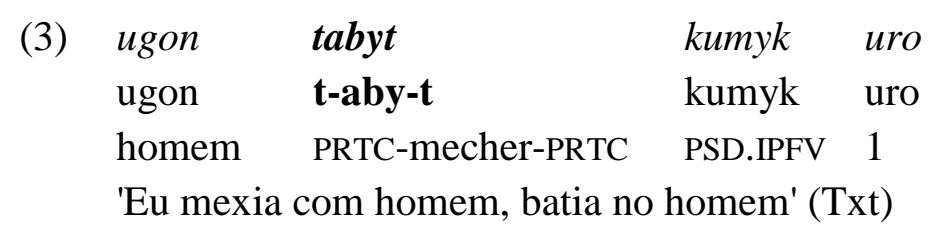

(4) wot t-abo-te uro

wot t-abotxi-te uro

peixe PRTC-segurar-PRTC 1

'Eu peguei peixe' (Txt) 
(5) t-abo-te uro

t-abotxi-te uro

PRTC-segurar-PRTC 1

'Eu estou segurado' (por alguém) (Elic.)

(6) wot t-abo-te

wot t-abotxi-te

peixe PRTC-segurar-PRTC

'(Pessoa) pegou peixe, peixe tá segurado' (Elic.)

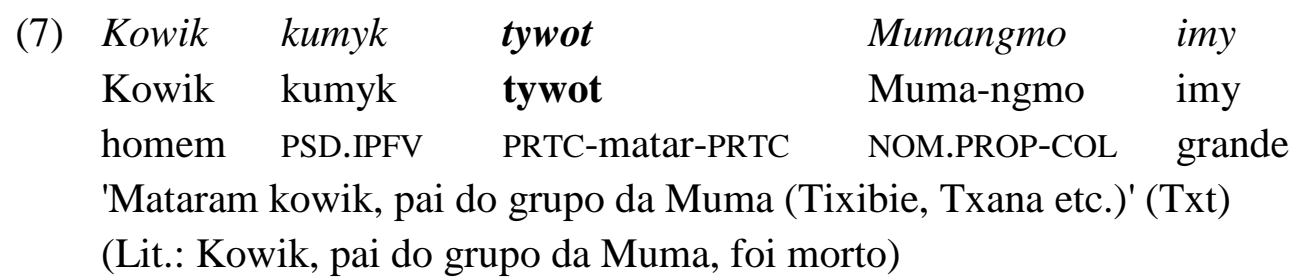

Este cenário sugere o início de uma inovação. Se esta conjectura puder ser confirmada, então a estrutura derivada $t$-V-te está se tornando mais flexional e, assim, ela pode ocupar o lugar de um predicado eventivo em sentenças principais. Vale observar também que esta mudança, assim como no caso de Bakairi, não se encaixa nos estágios apresentados em Gildea (1998), pois o particípio ${ }^{111}$ está passando diretamente para um predicado verbal ativo, sem a presença de um marcador ergativo.

As subseções a seguir apresentam os demais potenciais morfemas flexionais.

\subsubsection{O passado nominal $\{-$ tpyn $\sim$-npyn $\sim$-tubry $\}$}

Como apresentado no Capítulo 3, seção 3.5.1, os alomorfes \{-tpyn -npyn -tubry\} expressam a temporalidade da relação de posse ou a temporalidade do referente (objeto), ou seja, existe certa uma ambiguidade a qual é resolvida no contexto. Por outro lado, estes morfemas também foram verificados em radicais verbais, os quais são interpretados de maneira eventiva. Veja em (8) e (9) exemplos de radicais anexados por $\{$-tpyn -npyn\} em construções eventivas.

\footnotetext{
${ }^{111}$ Provavelmente, as construções de particípio com argumento oblíquo possam ser analisadas como passivas, porém este tópico ainda não foi estudado em profundidade.
} 
(8) kowik wotpyn

kowik wo-tpyn

NOM.PROP matar-PSD.NOM

Mataram kowik (Txt)

(9) [ugengguanoptontadamynyngmo

ype itub],

ug-engguam-no-ptong-tadamy-ny-ngmo ype iti-tub],

1+2O-saber-NOM-VBZ-ITR-PSD.IMD-COL EXIST COP-SUB

$\begin{array}{lll}\text { kureb } & \text { itpyn } & \text { owynannge } \\ \text { kure-b } & \text { iti-tpyn } & \text { o-wyna-nnge } \\ \text { bom-ATBZ } & \text { COP-PSD.NOM } & \text { 2-BEN-PL }\end{array}$

'Se tivesse um "ensinador", seria bom pra vocês' (Txt)

(10) otunan ingrutpynkom

otunan ingru-tpyn-kom

mesmo.período 2nascer-PSD.NOM-COL

'Vocês nasceram no mesmo período (no mesmo dia ou na mesma hora).' (Txt)

Exemplos do \{-tubry\} em construções eventivas podem ser vistos em (11) e (12):

(11) pumie kok-tu inidangdubry angdely

pumie kok-tu ini-tang-dubry angde-ly

mulher grito-? 1A-ouvir-PSD.NOM cair-PSD.IMD

'A mulher que eu ouvi gritar caiu' (Elic.)

(12) ko urangmo ik te kumyk pa uro txinan teptubryp

ko urangmo ik te kumyk pa uro txinan t-eby-tubry-p

INTERJ criança NEG ? ASP ? 1 para.cá 3-vir- PSD.NOM-ATBZ

'Eu não era mais criança quando eu vim pra cá' (Txt)

Estes dados possibilitam formular a hipótese de que o acréscimo de morfemas nominais em raízes verbais também pressupõe uma expansão de escopo da localização temporal de um referente nominal ou da relação de posse para a localização temporal da proposição. Assim, os morfemas temporais nominais seriam comparáveis aos morfemas flexionais verbais. A natureza das evidências que podem ser investigas em futuros estudos são encontradas na literatura Karib. Além da reanálise do particípio, a reanálise de morfemas nominais e posposicionais em flexões temporais (como aspecto ou tempo) foram amplamente descritas em Gildea (1989, 1998). Segundo ele, a junção de fatores como inovação do significado e frequência de uso da construção em corpus textual robusto evidenciam a reanálise. Meira (2006), por outro lado, 
argumenta a favor também da evidência sintática. Possivelmente, tais evidências podem jogar alguma luz sobre a hipótese levantada.

\subsection{CONSIDERAÇÕES FINAIS}

Este estudo representa um primeiro passo para avanço do conhecimento sobre o sistema de flexões verbais da língua Arara e também do ramo Pekodiano. A complexidade dos sistemas verbais da família Karib em particular já havia sido apontada, porém pouco se sabia sobre Arara e ainda menos é conhecido para Ikpeng e Bakairi. Uma série de hipóteses foram lançadas, muitas das quais, à luz de novos achados não estão imunes ao risco de serem modificadas.

Ademais, gostaríamos de ressaltar a constituição de um corpus de textos robusto como uma premente necessidade para os estudos descritivos como este. Apesar dos esforços que, felizmente, tornaram possível iniciar um corpus Arara, a presente pesquisa verificou que para tornar o corpus plenamente útil, no sentido de permitir que hipóteses sejam testasdas, ainda há muito a ser feito. 


\section{REFERÊNCIAS BIBLIOGRÁFICAS ${ }^{112}$}

ABDOLHOSSEINIT, M. Haji, MASSAM, D; ODA, K. Number and events: Verbal reduplication in Niuean. Oceanic Linguistics 41:475-492, 2002.

ADGER, D. Core Syntax: A Minimalist Approuch. 2002. Disponível em http://www.pnu.ac.ir/portal/File/ShowFile.aspx?ID=c3f3731d-8509-45df-afc9-35b5fbcddd8e

ALVARES, J. Syllable reduction and mora preservation in Kari'na. In: Amerindia , n28. 2000, p 55-82.

BELEZINE, E. H. C. Os Arara do Laranjal: Uma Visão a partir do Iriri, do Outro Lado da Barragem. In: OLIVEIRA, J. P. de; COHN, C. (Orgs.). Belo Monte e a Questão Indígena. Brasília: DF, ABA, 2014.

BOWERN, C. Linguistic Fieldwork: A Practical Guide. New York: Palgrave Macmillan, 2008.

BYBEE, J.; FLEISCHMAN, S. Modality in Grammar and Discourse: An Introductory Essay. In: BYBEE, J.; FLEISCHMAN, S.(Eds.). Modality in Grammar and Discourse, pp. 1-14. Amsterdam: John Benjamins Publishing Company. 1995.

BYBEE, J.; PERKINS, R.D.; PAGLIUCCA, W. The Evolution of Grammar: Tense, Aspect, and Modality in the Languages of the World. Chicago: University of Chicago Press, 1994.

BYBEE, J. The description of the Native languages of North America: Boas and After. GODDARD, I. (ed.) Handbook of North American Indians. Volume 17: Languages. Washington D.C.: Smithsonian Institution. 43-63, 1996.

CACERES, N. Grammaire Fonctionnelle-Typologique du Ye'kwana: Langue caribe du Venezuela. 2011. Tese (Doutorado em Linguística) - Université Lumière Lyon 2, Lyon, 2011.

CAESAR-FOX. D. C. ZAURO'NÖDOK AGAWAYO YAU: Variants of Akawaio spoken at Waramagong. 2003. Rice University, Houton, 2003.

CHAGAS, A. F. A. O Verbo Ikpeng: Estudo Morfossintático e Semântico-Lexical. 2013. Tese (Doutorado em Linguística) - Universidade de Campinas, Campinas, 2013.

COMRIE, B. Aspect: An Introduction to the Study of Verbal Aspect and Related Problems. Cambridge: Cambridge University Press, 1976.

COMRIE, B. Tense. Cambridge: Cambridge University Press, 1985.

Language Universals and Linguistic Typology: Syntax and Morphology. Oxford: Blackwell, 1981.

\footnotetext{
${ }^{112}$ De acordo com a Associação Brasileira de Normas Técnicas (ABNT NBR 6023).
} 
COMRIE, B.; HASPELMATH, M.; BICKEL, B. (Eds). (2008). The Leipzig Glossing Rules: Conventions for interlinear morpheme-by-morpheme glosses. Leipzig: Department of Linguistics of the Max Planck Institute for Evolutionary Anthropology and of the University of Leipzig. Disponível em: http://www.eva.mpg.de/lingua/resources/glossing-rules.php. Acessado em 20 Jan 2017.

CORBETT, G. G. Number. Cambridge: Cambridge University Press, 2000.

CROFT, W . Typology and Universals. Cambrigde: Cambrigde University Press, 2003. Morphosyntax: constructions of the world's languages. Chapter 1: Grammatical categories, semantic classes and information packaging (Revised draft, August 2015).

DAHL, Ö. Tense and Aspect Systems. New York: Blackwell, 1985.

DeLANCEY, S. Lexical categories. Ms., University of Oregon, Eugene, 2001.

DERBYSHIRE, D. C. Carib. In: DIXON, R. M. W.; AIKHENVALD, A. Y. (Eds) The Amazonian Languages. p. 26-61, 1999.

Hixkaryana and Linguistic Typology. Dallas: The Summer Institute of Linguistics and the University of Texas at Arlington. Volume 76, 1985.

Hixkaryana. Amsterdam: North-Holland, 1979.

DIXON, R. W. Ergativity. Cambridge, England: Cambridge University Press, 1994.

FAUSTO, C.; FRANCHETTO, B.; HECKENBERGER, M. J. Language, ritual and historical reconstruction: towards a linguistic, ethnographical and archaeological account of Upper Xingu Society. In: HARRISON, K. D.; ROOD, D.S.; DWYER, A. (Eds.). Lessons from Documented Endangered Languages. Amsterdam: John Benjamins Publishing Company, p. 129-158, 2008.

FERREIRA ALVES, A. C. Aspectos do Sistema Fonológico de Arara (Karib). In: Bol. Mus. Para. Emílio Goeldi. Cienc. Hum., Belém, v. 8, n. 2, p. 265-277, maio-ago, 2013.

Estudo e Documentação da Língua Arara (Karib). 2011. Projeto realizado no MPEG processo 300851/2011-1.

Estudo e documentação da língua Arara (Karib): etapas iniciais. 2010a. Projeto realizado no MPEG processo 680-024/2018-5.

Phonological Aspects of Arara (Carib, Brazil). 2010b. Dissertação (Mestrado em Linguística) - Radboud University Nijmegen, Njimegen, $2010 \mathrm{~b}$.

FLECK, D. W. A grammar of Matses. 2003. Tese (Doutorado em Linguística) - Rice University, Houton, 2003. 
FRANCHETTO, B. Are Kuikuro Roots Lexical Categories? In: Ximena Lois and Valentina Vapnarski (eds). Lexical Categories and Root Classes in Amerindian Languages. Bern: Peter Lang, p. 33-68. 2006.

GILDEA, S. Simple and Relative Clauses in Panare. 1989. Dissertação (mestrado em linguística) - University of Oregon, Oregon, 1989.

Semantic and Pragmatic Inverse: 'Inverse alignment' and 'Inverse Voice' in Carib of Surinam. In: GIVON, T. (Ed.), Voice and Inversion. Amsterdam: John Benjamins Publishing Company, p. 187-230, 1994.

Comparative Cariban Syllable Reduction. International Journal of American Linguistics $61 \mathrm{n}^{\circ} 1$, p. 62-102, 1995.

On Reconstructing Grammar: Comparative Cariban Morphosyntax. Oxford: Oxford University Press, 1998. 7-32, 2003.

Proposing a new branch for the Cariban language family. Amerindia (28):

Linguistic Studies in the Cariban Family. In: CAMPBELL, L; GRONDONA, V. (Eds.). Handbook of South American Languages. Berlin: Mouton de Gruyter, p. 441-494, 2012.

GILDEA, S.; PAYNE, D. Is Greenberg's 'Macro-Carib' viable? Boletim do Museu Paraense Emílio Goeldi: Ciências Humanas 2 (2), 19-72, 2007.

HARRIS, A.; CAMPBELL, L. Historical Syntax in Cross-Linguistic Perspective. Cambridge: Cambridge University Press, 1995.

HASPELMATH, M. Arguments and Adjuncts as Language-Particular Syntactic Categories and as Comparative Concepts. Linguistic Discovery 12(2), 2014.

Understanding morphology. London: Arnold, 290 p, 2002.

Word Classes and Parts of Speech. In: BALTES, P.; SMELSER, N. (eds.). International Encyclopedia of the Social and Behavioral Sciences. Amsterdam: Pergamon, 16538-16545, 2001.

From Space to Time: Temporal Adverbials in the World's Languages. (Lincom Studies in Theoretical Linguistics, 3.) Munich: Lincon Europa, 181p, 1997.

HASPELMATH, M.; BARDEY, T. M. Valence Change. In: BOOIJ, G.; LEHMANN, C.; MUGDAN, J. (Eds). A Handbook on Inflection and Word Formation, p. 1130-1145, 2005.

HECKENBERGER, M. J., J. C. RUSSELL, C. FAUSTO, J. R. TONEY, M. J. SCHMIDT, E. PEREIRA, B. FRANCHETTO, and A. KAuikuro (2008). Pre-Columbian urbanism, anthropogenic landscapes, and the future of the Amazon. Science 321 (5893), 1214-1217. 
HIMMELMANN, N. Documentary and Descriptive Linguistics. Linguistics 36(1):161-196, 1998.

HOFF, B. J. The Carib Language. The Hague: Martinus Nijhoff, 1968.

HOFHERR, P.; LACA, B. Introduction: event plurality, verbal plurality. No prelo.

IBGE. Mapa etno-histórico do brasil e regiões adjacentes: adaptado do mapa de Curt Nimuendajú 1944. 1980. 1 mapa. Escala: 1:5.000.000. Disponível em: http://biblio.wdfiles.com/local--files/nimuendaju-1981- mapa/nimuendaju_1981_mapa.jpg. Acesso em 19 Jan. 2017.

KLEIN, W. How Time is Enconded. In: KLEIN, W.; Li, P. The Expression of Time. Berlin: Mouton de Gruyter, p.93-82, 2009.

KLIMOV, G. A. On the character of languages of active typology. Linguistics 131, p. 11-25, 1974.

KOEHN, E.; KOEHN, S. S. Apalai. In D. C. Derbyshire and G. K. Pullum (Eds.), Handbook of Amazonian Languages, Volume I. Berlin: Mouton de Gruyter, p. 33-127 1986.

KRAUSS, M. The world's languages in crisis. Language, Volume 68, nº 1, 1992.

LASERSOHN, P. Plurality, conjunction, and events. Dordrecht: Kluwer Academic Publishers, 1995.

MATTÉI-MULLER, M. C. La reducción silábica en Panare. Amerindia 6, p. 59-84, 1980.

MAYER, M. Frog, where are you? New York, Dial Books for Young Readers, 1969.

MEIRA, S. A Grammar of Tiriyo. 1999. Tese (Doutorado em Linguística) - Rice University, Houston, 1999. $174,2006$.

A família lingüística Caribe (Karíb). Revista de Estudos e Pesquisas v.3, n.1/2, p.157-

Cariban Languages. In: BROWN, Keith (ed.). Encyclopedia of Language and Linguistics. 2. ed. Boston: Elsevier, p. 199-204, 2005.

- Mental state postpositions in Tiriyó and other Cariban languages. Linguistic Typology, 8(2), p. 213-241, 2004

The accidental intransitive split in the Cariban family. In: GILDEA, S. (ed.) Typological studies in languages 43. Reconstructing grammar: Comparative linguistics and gramaticalization. John Benjamins publishing company: Amsterdam, 2000.

Syntactic reanalysis in Yukpa (Cariban). International Journal of American Linguistics 72: 135-150, 2006. 
MEIRA, S.; FRANCHETTO, B. The Southern Cariban Languages and the Cariban Family. International Journal of American Linguistics, v. 71, n. 2, p.127-192, 2005.

MEIRA, S.; GILDEA, S.; HOFF, B. On the Origin of Ablaut in the Cariban family. In: GILDEA, S.; GALUCIO, V. (eds). Historical Linguistics in South America. Special issue of the International Journal of American Linguistics, n 76, p. 477-515, 2010.

MERLAN, F. Split intransitivity: functional oppositions in intransitive inflection. In: NICHOLS, J.; WOODBURY, A. (Eds.). Grammar Inside and Outside the Clause. Cambridge: Cambridge University Press. p. 324-362, 1985.

MINISTÉRIO DA JUSTIÇA; FUNDAÇÃO NACIONAL DO ÍNDIO. Mapa das coordenções regionais e jurisdição das terras indígenas. 2013. Base cartográfica: malha municipal digital do Brasil Escala, IBGE, 2001. Escala 1:5.000.000.

MITHUN, M. The description of the Native languages of North America: Boas and after. In: GODDARD, I. (Ed.) Handbook of North American Indians. V. 17: Languages. Washington D.C: Smithsonian Institution. 2016, p, 43-63.

MITHUN, M. Active/agentive case marking and its Motivations. Language 67 (3), p. 510-546, 1991.

MITHUN, M. Lexical categories and the evolution of number marking. Theoretical Morphology. HAMMOND, M.; NOONAN, M. (eds.). New York: Academic Press. p.221-234, 1988.

MOORE, D.; STORTO, L. As Línguas Indígenas e a Pré-História. In: PENA, S. D. J. Homo Brasilis, São Paulo: FUNPEC, 2002.

MUELLER, N. Tense, aspect, modality and evidentiality marking in South American indigenous languages. Tese (Doutorado em Linguística). 2013. Radboud Universiteit, Nijmegen, 2013.

NIDA, E. A. The Descriptive Analysis of Words. Ann Arbor: University of Michigan Press, 1949.

NIMUENDAJÚ, C. Textos Indigenistas. São Paulo: Loyola, 1982.

OLIVEIRA, C. C. de. Lexical Categories and The Status of Descriptives in Apinajé. In: International Journal of American Linguistics, Vol. 69, No. 3 . 2003, pp. 243-274. The University of Chicago Press.

PACHÊCO, F. B. Morfossintaxe do Verbo Ikpeng (Karíb). 2001. Tese (Doutorado em Linguística) - Universiade de Campinas, Campinas, 2001.

PALMER, F. R. Mood and Modality. Cambridge: Cambridge University Press, 2001.

PERLMUTTER, D. Impersonal passives and the unaccusative hypothesis. Proceedings of the 6th Annual Meeting of the Berkeley Linguistics Society, Berkeley. University of California, p. 157- 189, 1978. 
SANTOS, M. G. Morfologia Kuikuro: Gerando Nomes e Verbos. 2007. Tese (Doutorado em Linguística) - Universidade Federal do Rio de Janeiro, Rio de Janeiro, 2007.

SCHARCHTER, P.; SHOPEN, T. Parts-of-Speech Systems. In: SHOPEN, T (ed.). Language Typology and Syntactic Description. New York: Cambridge University Press, v. 1, p. 1-60, 2007.

SEIFART, F. Orthography development. In: GIPPERT, J, HIMMELMAN, N. P., MOSEL, U. Essentials of Language Documentation. Berlin: Mouton de Gruyter, p. 275-300, 2006.

SEIFART, F. The structure and use of shape-based noun classes in Miraña (North West Amazon). 2005. Tese (Doutorado em Linguística) - Radboud Universiteit, Nijmegen, 2005.

SHEPARDJr, G.; RAMIREZ, H. "Made in Brazil": Human Dispersal of the Brazil Nut (Bertholletia excelsa, Lecythidaceae) in Ancient Amazonia. Economic Botany, Volume 65, No 1, p. 44-65, 2011.

SMITH, C. S. The parameter of Aspect. Boston: Kluwer Academic Publishers, 1997.

SORACE, A. The Use of Acceptability Judgements in Second Language Acquisition research. In: RITCHIE, W. C.; BHATIA, T. K. Handbook of second Language acquisition. San Diego: Academic Press, p. 375-409, 1996.

SOUZA, I. C. de. Contribuição para a fonologia da língua Arara. 1988. Dissertação (Mestrado em Linguística). - UNICAMP, Campinas, 1988.

A Phonological Description of the 'Pet talk' in Arara. 2010. Dissertação (Mestrado em Linguística) - Universityof North Dakota, Dakota, 2010.

SOUZA, R. M. Redes de monitoramento socioambiental e tramas da sustentabilidade. São Paulo: Annablume; Geoplan, 2007

SOUZA, S. D. C. de. Alguns Aspectos Morfológicos da Língua Arara (karib). 1993. Dissertação (Mestrado em Linguística) - Universidade de Brasília, Brasília-DF, 1993.

The morphology of nouns in the Ugoroymo language (Arara of Pará). 2010. Dissertação (Mestrado em Linguística) - University of North Dakota, North Dakota, 2010.

TAVARES, P. da S. A Grammar of Wayana. 2005. Tese (Doutorado em Linguística) - Rice University, Houton, 2005.

TEIXEIRA-PINTO, M. Ieipari: Sacrifício e Vida Social entre os Índios Arara (Caribe). São Paulo: Hucitec, ANPOCS- UFPR, 1997.

VAN DER AUWERA, J.; LEJEUNE, L. (with Valentin Goussev). 2013. The Prohibitive. In: DRYER, M. S.; HASPELMATH, M. (eds.) The World Atlas of Language Structures Online. Leipzig: Max Planck Institute for Evolutionary Anthropology. Disponível em http://wals.info/chapter/71, acesso em 2017-01-12. 
VAN VAlin Jr., R. D.; LaPOLLA, R. J. Syntax: Structure, Meaning, and Function. Cambridge: Cambridge University Press, 1997.

VOORT, H. van der. A grammar of Kwaza. Berlin: Mouton de Gruyter, v. 29. 2004. 


\section{APÊNDICE A - Lista de verbos monoargumentais}

Lista de verbos monoargumentais analisados. Todos os itens estão conjugados com a terceira e com passado imediato, exceto onde há indicação de outras flexões.

Tabela 1 Apêndice A - Verbos intransitivos da classe So

\begin{tabular}{|c|c|c|c|}
\hline Verbo & Glosa & Verbo & Glosa \\
\hline alumyly & 'voou, pulou' & $j^{113}$ ebrumyly & '(?)sorriu' \\
\hline angtely & 'caiu' & jumpyly & 'transformou' \\
\hline autkely & 'inchou' & abuntely & 'afofou' \\
\hline egaktumyly & 'correu, saiu' & augely & 'ficou embaixo' \\
\hline ilagaktely & 'cuspiu' & akuly & 'sujou' \\
\hline jubagely & 'acordou' & itymamyly & 'escureceu' \\
\hline ibongnumyly & 'chorou' & anpydekely & 'descansou' \\
\hline ipintely & 'peidou' & igridaktely & 'empalideceu' \\
\hline irumpoly & 'morreu' & ebroktely & 'floresceu' \\
\hline iwatkely & 'defecou' & eremtely & 'cantou' \\
\hline tyngkyly & 'dormiu' & eremnely & 'descansou' \\
\hline engruly & 'pariu, nasceu' & abadyly & 'passou' \\
\hline enguly & 'boiou' & idamkodely & 'envelheceu' \\
\hline igunely & 'suou' & ereudely & 'curou-se' \\
\hline itxiktely & 'urinou' & igarakpygebyly & 'emagreceu' \\
\hline edaginumyly & 'assobiou' & eguamyly & 'sentou' \\
\hline imuledenangry & 'tossiu' & abodetkely & 'alegrou-se' \\
\hline eregrumyly & 'entristeceu' & jeriktumyly & 'sorriu' \\
\hline imunodely & 'engravidou' & erangly & 'assustou-se' \\
\hline
\end{tabular}

Tabela 2 Apêndice A - Verbos intransitivos da classe $\mathrm{S}_{\mathrm{A}}$

\begin{tabular}{ll|ll}
\hline Verbo & Glosa da raiz & Verbo & Glosa da raiz \\
omomyly & 'entrou, mergulhou' & kely & 'disse' \\
onkuly & 'subiu' & itxily & 'deitou'
\end{tabular}

\footnotetext{
${ }^{113}$ Três exceções de terceira pessoa em raízes iniciadas por vogal: jebrumuly, jumpyly e jeriktumyly .
} 


\begin{tabular}{ll|ll}
\hline Verbo & Glosa da raiz & Verbo & Glosa da raiz \\
origuly & 'dançou' & itxily & 'é, está' \\
otximtabringely & 'comeu' & tebyy & 'veio, chegou' \\
odakpily & 'ficou bêbado' & ibyny & 'banhou' \\
odubuly & 'sobrou' & iptongry & 'desceu' \\
odotpodyly & 'voltou' & ydoly & 'foi' \\
odetxily & 'casou' & \\
otpaimymtongry & 'casou' & \\
oremely & 'errou' & \\
odewyly & 'deu a volta' & & \\
odapoimely & 'atrasou' & \\
\hline
\end{tabular}




\section{APÊNDICE B - Lista de verbos biargumentais}

Lista de verbos biargumentais analisados. Todos os itens estão conjugados com a terceira e com passado imediato.

Tabela 1 Apêndice B - Verbos transitivos

\begin{tabular}{|c|c|c|c|}
\hline Verbo & Glosa & Verbo & Glosa \\
\hline engkakpoly & 'seguiu' & idekely & 'escreveu' \\
\hline engedyly & 'sonhou' & ekumily & 'balançou' \\
\hline engrumily & 'cegou' & iwily & 'namorou' \\
\hline imongoguly & 'esperou' & ebiangtely & 'acalmou, esfriou' \\
\hline enebyly & 'trouxe' & erengmyly & 'matou, bateu' \\
\hline enengry & 'viu' & imokuly & 'cheirou' \\
\hline erimtongry & 'cozinhou' & enebyly & 'trouxe' \\
\hline engabyly & 'comeu' & tuduly & 'deu' \\
\hline agrobuly & 'pilou' & agely & 'cortou' \\
\hline eptpeny & 'pisou' & egrugely & 'lavou' \\
\hline emnangry & 'puxou' & aguly & 'comeu' \\
\hline emkodyny & 'cortou' & akily & 'peneirou' \\
\hline tokpeny & 'fez, acampou' & agrobuly & 'pilou' \\
\hline idangry & 'ouviu' & iwabuly & 'mastigou' \\
\hline epkely & 'pediu' & eganmely & 'misturou' \\
\hline akyly & 'pilou' & ikpily & 'molhou' \\
\hline agrobuly & 'pilou' & $i k o d y l y$ & 'quebrou' \\
\hline abuly & 'cavou' & tywoly & 'matou' \\
\hline igokuly & 'chamou, gritou' & ipitkyly & 'arrastou' \\
\hline eniptongry & 'desceu' & edankuly & 'coçou' \\
\hline abotxily & 'segurou, abraçou' & enibengry & 'carregou, roubou' \\
\hline eremebyly & 'acabou' & imyngry & 'sangrou' \\
\hline amokely & 'bateu, apanhou' & tubitkely & 'procurou' \\
\hline walatkely & $\begin{array}{l}\text { 'rolou, girou no próprio } \\
\text { eixo' }\end{array}$ & ibongry & 'encontrar' \\
\hline ibatpoly & 'acertou um alvo' & tongongry & 'mordeu' \\
\hline
\end{tabular}




\begin{tabular}{ll|ll}
\hline Verbo & Glosa & Verbo & Glosa \\
\hline etxily & 'tirou' & aworuntamely & 'conversou' \\
anmely & 'jogou, derrubou' & idetxily & 'respondeu' \\
idekely & 'escreveu' & ibumily & 'acabou, matou' \\
ingpomely & 'apagou' & ibumpotxily & 'cobriu' \\
jaduly & 'queimou' & ipkely & 'raspou' \\
edentuly & 'apertou' & edentuly & 'apertou' \\
tygabyly & 'teceu' & edentukely & 'afrouxou' \\
amteptongry & 'estender' & ekpityly & 'costurou' \\
angmunokely & 'desenrolar' & tygyly & 'ralou' \\
tuktuly & 'começou' & angkuily & 'espremeu, apertou' \\
edabrukely & 'abriu' & amungry & 'chorou' \\
imomyny & 'amarrou' & eganobyly & 'falou' \\
inongry & 'moqueou' & anumyly & 'levantou, ajuntou' \\
tybyly & 'deu banho' & inoly & 'deixou' \\
angkodyly & 'cortou' & & \\
\hline
\end{tabular}




\section{ANEXO - Mapa das Terras Indígenas Arara e Cachoeira Seca}

Mapa 1 - Terras indígenas Arara e Cachoeira Seca, região sudoeste do Estado do Pará-Brasil.

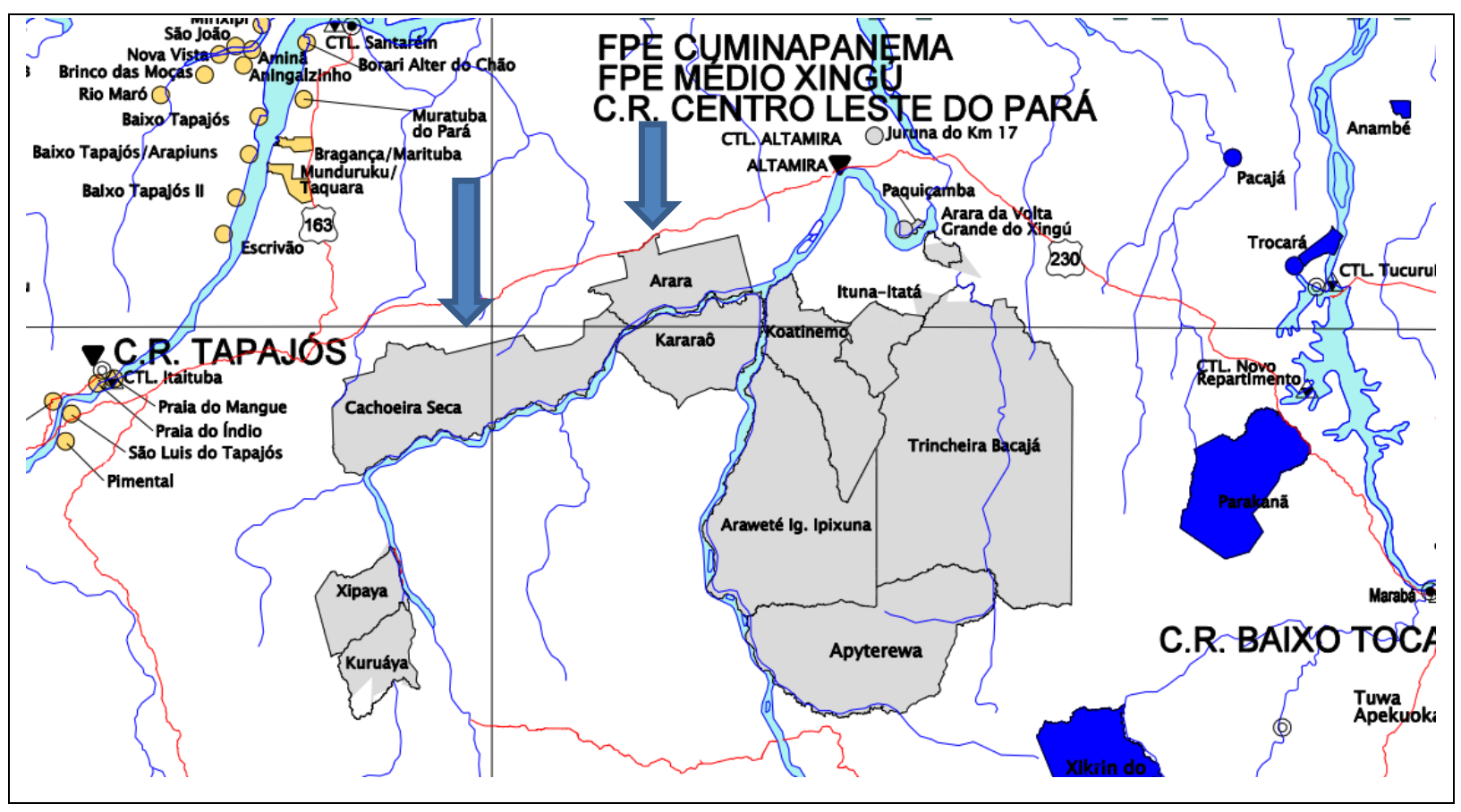

Fonte: Adaptado do mapa Coordenações Regionais e Jurisdição das Terras Indígenas (MINISTÉRIO DA JUSTIÇA; FUNDAÇÃO NACIONAL DO ÍNDIO 2013). 